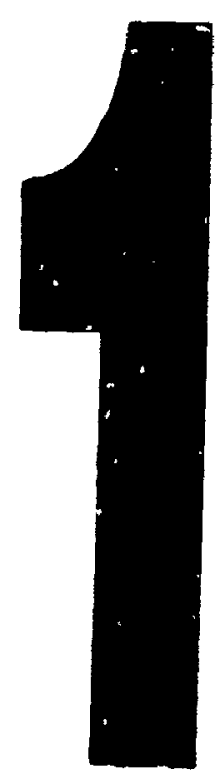

PM-1 31/2" $K$ A $^{\prime \prime}$ PHOTOGRAPHIC MICROCOPV TARGET NBS $1010 a$ ANSI/ISO \#2 EQUIVALEIYT

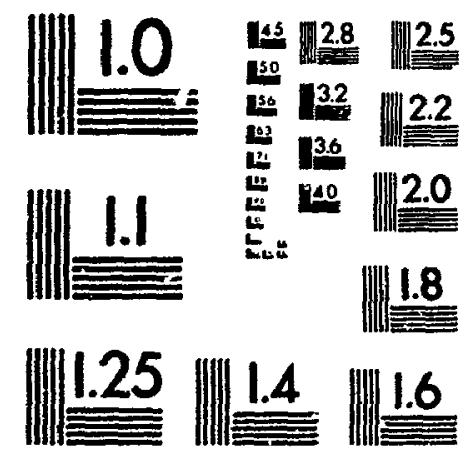

PRECISION\$N RESOLUTION TARGETS 
National Library

of Canada

Acquisitions and

Bibliographic Services Branch

395 Wellington Street

Ottawa, Ontario

KIA ON4
Bibliothèque nationale

du Canada

Direction des acquisitions et

des services bibliographiques

395, ne Wellington

Ottawa (Ontario)
Your shl votre celerence

Our hie Nolie relerence

NOTICE

AVIS

The quality of this microform is heavily dependent upon the quality of the original thesis submitted for microfilming. Every effort has been made to ensure the highest quality of reproduction possible.

If pages are missing, contact the university which granted the degree.

Some pages may have indistinct print especially if the original pages were typed with a poor typewriter ribbon or if the university sent us an inferior photocopy.
La qualité de cette microforme dépend grandement de la qualité de la these soumise au microfilmage. Nous avons tout fait pour assurer une qualité supérieure de reproduction.

S'il manque des pages, veuillez communiquer avec l'université qui a conféré le grade.

La qualité d'impression de certaines pages peut laisser à désirer, surtout si les pages originales ont été dactylographiées à l'aide d'un ruban usé ou si l'université nous a fait parvenir une photocopie de qualité inférieure.

La reproduction, même partielle, de cette microforme est soumise à la Loi canadienne sur le droit d'auteur, SRC 1970, c. C-30, et ses amendements subséquents.
Reproduction in full or in part of this microform is governed by the Canadian Copyright Act, R.S.C. 1970, c. C-30, and subsequent amendments. 
Personal Projects, Well-Being, and the

Social Ecology of Early Adolescence

Kevin P. Wilmut

Thesis submitted to the Faculty of Graduate Studies and Research in partial fulfillment of the requirements for the degree of Master of Arts

\author{
Department of Psychology \\ Carleton University \\ Ottawa, ontario \\ November, 1993
}


National Library

of Canada

Acquisitions and

Bibliographic Services Branch

395 Wetlington Street

Ottawa, Ontario

K1A ON4
Bibliotheque nationale

du Canada

Direction des acquisitions ef

des services bibliographiques

395. ne Wellington

Ottawa (Ontario)

K1A ONA
Your tio Votrenturence

Ourne Notre retsence
THE AUTHOR HAS GRANTED AN IRREVOCABLE NON-EXCLUSIVE LICENCE ALLOWING THE NATIONAL LIBRARY OF CANADA TO REPRODUCE, LOAN, DISTRIBUTE OR SELL COPIES OF HIS/HER THESIS BY ANY MEANS AND IN ANY FORM OR FORMAT, MAKING THIS THESIS AVAILABLE TO INTERESTED PERSONS.
L'AUTEUR A ACCORDE UNE LICENCE IRREVOCABLE ET NON EXCLUSIVE PERMETTANT A LA BIBLIOTHEQUE NATIONALE DU CANADA DE REPRODUIRE, PRETER, DISTRIBUER OU VENDRE DES COPIES DE SA THESE DE QUELQUE MANIERE ET SOUS QUELQUE FORME QUE CE SOIT POUR METTRE I YES EXEMPLAIRES DE CETTE THESE A LA DISPOSITION DES PERSONNE INTERESSEES.
THE AUTHOR RETAINS OWNERSHIP OF THE COPYRIGHT IN HIS/HER THESIS. NEITHER THE THESIS NOR SUBSTANTIAL EXTRACTS FROM IT MAY BE PRINTED OR OTHERWISE REPRODUCED WITHOUT HIS/HER PERMISSION.
L'AUTEUR CONSERVE LA PROPRIETE DU DROIT D'AUTEUR QUI PROTEGE SA THESE. NI LA THESE NI DES EXTRAITS SUBSTANTIELS DE CELLECI NE DOIVENT ETRE IMPRIMES OU AUTREMENT REPRODUITS SANS SON AUTORISATION.

ISBN $\quad 0-315-98539-9$ 
Name

Dissertation Abstracts International is arranged by broad, general subject categories. Please select the one subject which most neurly describes the content of your dissertation. Enter the corresponding four-digit code in the spaces provided.

\section{Subjact Calogories}

\section{The numanime and soctal scinNeIS}

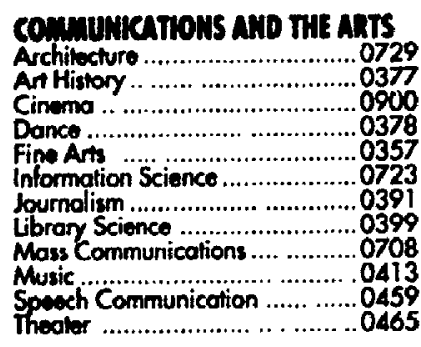

\section{EouchinoN}

General .................................0515

Administrotion .........................0514

Adult and Continuing ….............0516

Agriculturol .........................0517

Antingual and Muliculinural ...........0282

Communiy College ..................

Curriculum and Instruction .......072.

Early Childhood .....................0524

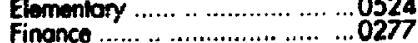

Fuidance and Counseling ............ 5519

Hoglth ............................. 0680

History of .............................0520

Home Eeonomics ....................0278

industrial ....................................0521

Languoge and titeroturo ............ 0279

Malhemotics ...........................028

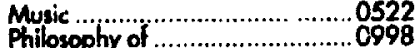

Physical .....................................0523
Business ............................. 98

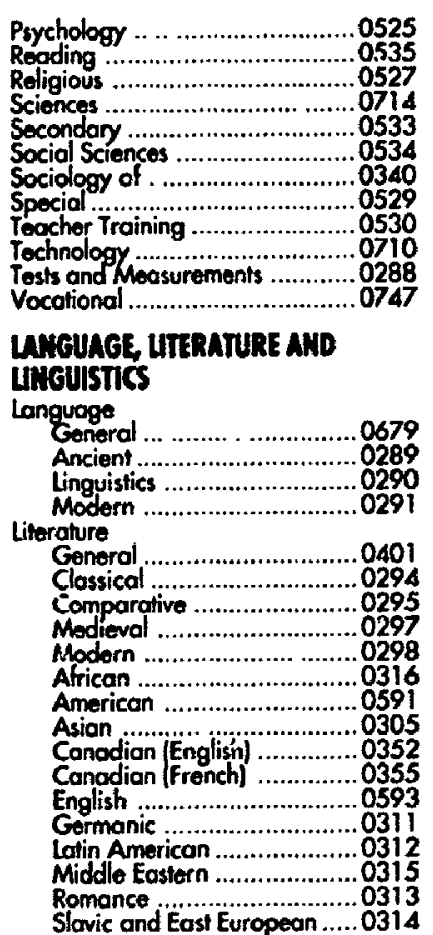

\section{THE SCIINCES AND ENOINEERING}

\section{Dewogtca sciknct}

Agriculture

General ..............................0473

Agronomy …………...........0285

Anutrion cure and

Animal Pathology ................0476

Foot Science and

Technology

Technology W...........0359

Forestry and Wildlite .........0478

Plant Pothetogy .................. .0480

Plant Physiology ...................0817

Range Manogernent ............0746

Biology

General ........................0306

Anctomy …..................0287

Bolany ............................0309

Ecology . ............. 032

Entomiology .................... 0353

Gemetics .....................0369

timnology ..............................0793

Microbiology .................0410

Molocular ......................0307

Oceonography .........................15

Physiotogy ........................... 0433

Rodiation ……..........................

Veterinary Science .................0778

Zoulogy . ............................0472

siophysics

Generol ..........................0786

sumin sotruas

Biogeochemistry

Geschemistry

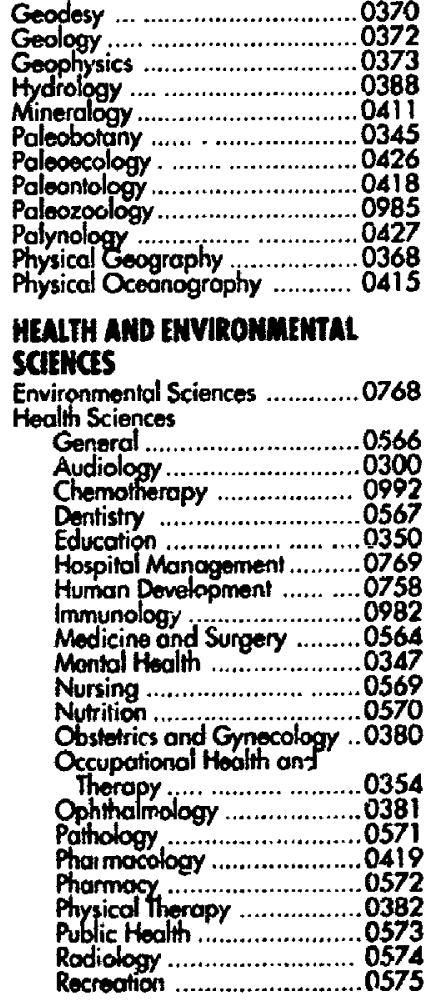

\section{PHILOSOPHY, REUEION AND}

THEOLOGY

Religion

Biblical st............

dies ....................032

Clergy ...............................

History of .............................0320

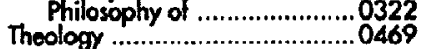

\section{SOCAL SCIENCES}

American Studies

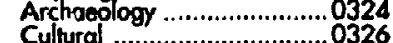

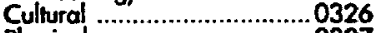

Physical Administration

Business Administration
General ..............................0310

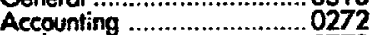

Bonking ….........................0770

Manogement .......................0454

Conadian Studies ...........................0385

Econadian

General

Agricultural ........................0503

Fir.ance …........................ 0508

History .................................0509

Lobor ................................... 0510

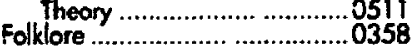

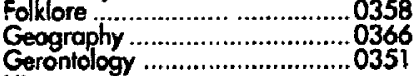

History

0578
Commerce-Business .................0505 Toxicology ........................0383

Mathemalics .............................0405

Astrophysics ...................0606
Philosophy .................................0422

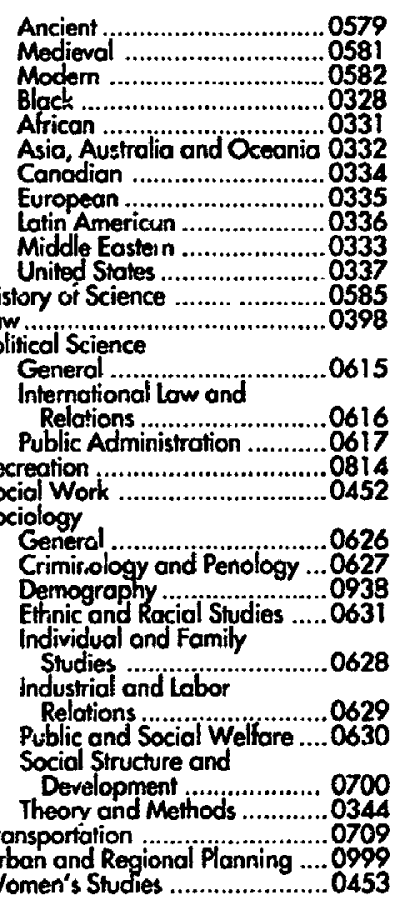

Speech Pathology .................0460 Home Economics .........................0386

\section{PHYSICAL SCIEHCES}

\section{Pure Sciences}

Chemistry

General ...........................0485

Analutical ............0486

Biochemistry ....................0487

Inorganic .............................0488

Nuclear ............................0738

Organic ..............................0490

Pharmaceutical ......................0491

Polymer .............................045

Mhysics

Generol .................................

Acoustics ............................0986

Astronomy and

Almospheric Science .............0608

Atomic ...............0607

Elementary Particless and

Elementary Particlas and
High Eneergy ....................0798
Fl L.d and Plosma ................0759

Molocular ..............................0609

Nuclear ................................1610

Optes ..............................0752

Solid State ................................0611

Solid Stare .............................0611
Statistics ...............................0463

Appliad Sciences

Applied Mochanics ..................0346

Compuler Scicince

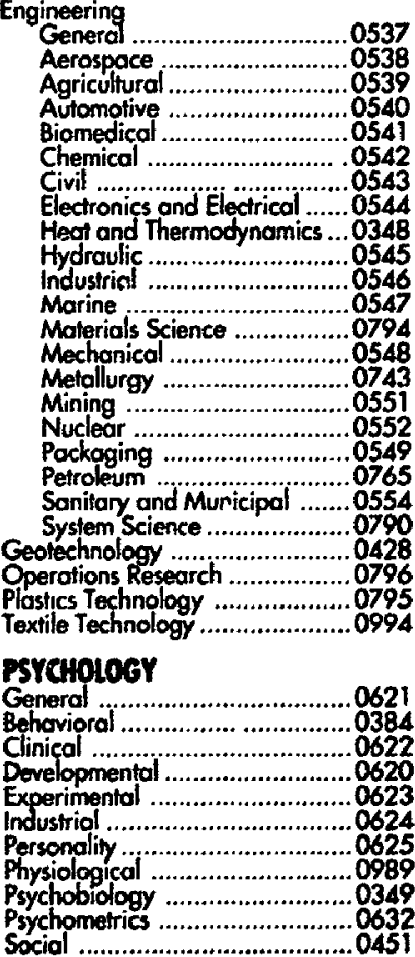


The undersigned recommend to the Faculty of Graduate studies and Research acceptance of the thesis

\author{
Personal Projects, Well-Being, \\ and the \\ Social Ecology of Early Adolescence
}

submitted by Kevin wilmut

in partial fulfillment of the requirements for

the degree of Master of Arts

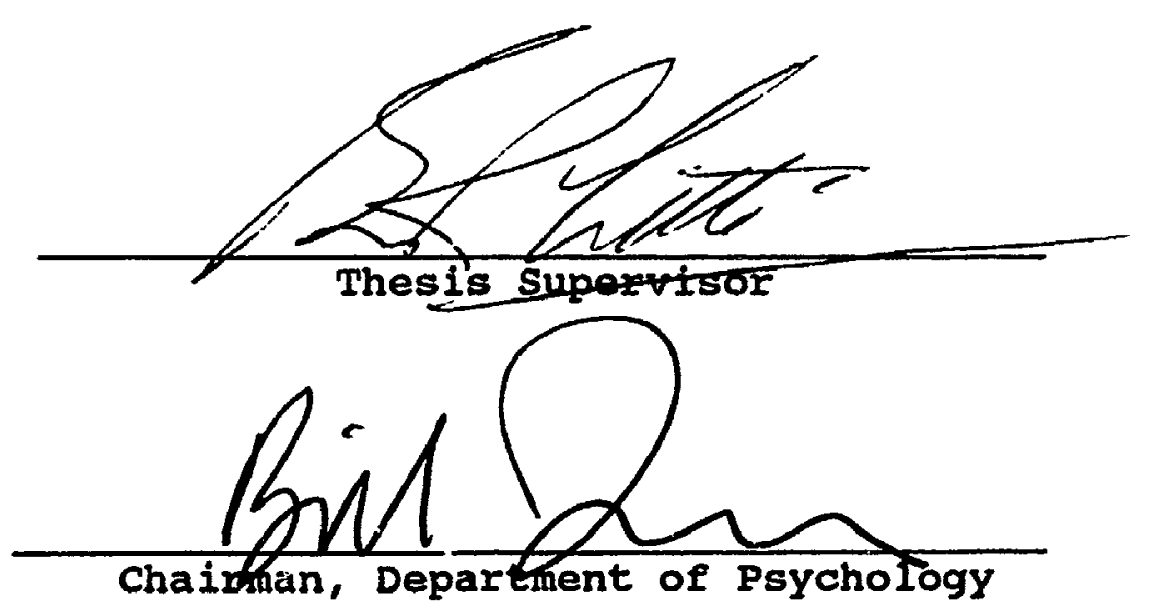

Carleton University

November, 1993 


\section{Abstract}

This study investigated the manner in which the everyday projects of early adolescents, and their personal evaluations of these activities, are related to their overall sense of well-being. Ninety-four grade seven and eight students in an Intermediate-level school responded to a battery of assessment instruments that included a Personal Projects Analysis (PPA, Little, 1983) pacikaỵe, the Centre for Epidimiologic Depression Scale for Children (Welseman, Orvaschell, \& Padian, 1980), the Perceived stress Scale (Cohen, Kamarck, \&ermelstein, 1983), as well as domain specific and general Life Satisfaction scales (Palys and Iitte, 1983).

Analyses revealed that Academic, Interpersonal, and Leisure projects were listed by the majority of males and females alike. Dimension ratings reflecting the sense of Efficacy, Meaning, stress, and Peer and Adult Community assoclated with these projects were similar for males and females. Academic projects were described as the most important and stressful types of activities, while leisure projects were rated as highest in initiation and enjoyment and lowest in stress. Pearson product-moment correlations showed that Efficacy and Meaning dimension ratings were the best overall predictors of early adolescent we1l-being, although ratings related to stress and Adult community were 
frequently the best predictors within specific activity domains.

Gender differences were found in the types of activities engaged in by early adolescents, as well as in the manner in which project evaluations were related to well-being. Girls were found to be more restrained than boys in interpersonal and leisure pursuits. Academic project evaluations were more related to female than male wellbeing, Leisure project evaluations were related to male, but virtually unrelated to female well-being, and Interpersonal project evaluations were relatively unrelated to both male and female well-being. The results of this study are compared to those found in other PPA studies involving older age groups, and are discussed with reference to the literature related to early adolescent development and well-being. 


\section{ACKNOWLEDGEMENTS}

The inspiration, guidance, and support of many persons made the completion of this thesis possible. I would particularly like to thank Tina for getting me started, Tim for getting me moving, Brian for seeing me through, and most of all susan - to whom this work is dedicated - for all of the above and more. 
Table of contents

Page

Introduction . . . . . . . . . . . . . . . . . . 1

Early Adolescence . . . . . . . . . . . 3

A Question of Definition . . . . . . . . . 3

The Changing Social Ecology of Early Adolescence . . . . . . . . . . . 4

Personal Projects Analysis . . . . . . . . . . 6

Personal Projects Elicitation Listing . . . . 7

Personal projects Rating Matrix . . . . . . B

Personal Projects and Well-Being . . . . . . . . . 11

Method . . . . . . . . . . . . . . . . . . 14

Sample . . . . . . . . . . . . . . . . 14

Procedure . . . . . . . . . . . . . . . 15

Description of Measures . . . . . . . . . 16

CES-Depression Scale for Children . . . 16

Perceived Stress Scale . . . . . . . 17

General Life Satisfaction Scale . . . 18

Domain Specific Satisfaction Scales . . 19

Personal Frojects Analysis . . . . . 19

Demographic Data . . . . . . . . 21

Results . . . . . . . . . . . . . . . . . . 22

Well-Being Scores . . . . . . . . . . . . 23

Personal Projects . . . . . . . . . . . . . 30 
Project Categorization . . . . . . . . 30

Group Differences in Project Content . . 31

Project-System Dimension Ratings . . . . . 33

Personal Project Factors . . . . . . . . 36

Project Cat.egory Dimension Ratings . . . . 38

Personal Projects and Well-Being . . . . . . . 43

The Relationship between project Dimension Ratings and Well-Being at the ProjectSystem Level . . . . . . . . . . 43

The Relationship between Project Dimension Ratings and Well-Being within Categories ............ . 48

Summary of the Results . . . . . . . . . . . 54

Discussion . . . . . . . . . . . . . . .

The Personal Projects of Early Adolescents . . . . 57

Project content . . . . . . . . . . 57

Project Content and Gender . . . . . 59

Dimensionality and Domains of Personal Project

systems . . . . . . . . . . . . 62

Project Factors . . . . . . . . . . . 62

Project Factor Dimension Evaluations . . . . 63

Project Meaning: Personal and Social . . 63

Project Stress . . . . . . . . 65

Project Efficacy . . . . . . . . 67

Project Community: Peers and Adults . . 69

vi 
Factor Dimension Profiles of Leisure, Academic and Interpersonal project Evaluations . . . . . . . 73 Personal Projects and Well-Being . . . . . . . . . . 74 Project-system Dimension Evaluations and WellBeing . . . . . . . . . . . . . . . . 75

Project-System Meaning and Well-Being . 76 Project-System Stress and Well-Being . . 78 Project-system Efficacy and Well-Being . 79 Project-system Community ind Well-Being 88 Category-specific Project Dimension Evaluations and Well-Being . . . . . . 94 Academic Projects and Well-Being . . . . 94 Leisure Projects and Fell-Being . . . . 96 Interpersonal Projects and Well-Being . 103

Conclusion and Recommendations . . . . . . . . . . . . 110

Footnotes . . . . . . . . . . . . . . . . . 115

References . . . . . . . . . . . . . . . . . 125

Appendix A Personal Projects Analysis Package:

Elicitation Listing and Rating Matrix . . . . . . . . . . 144

Appendix B Study Information Letter and Parental Consent Form . . . . . . . . . 150 vii 
Appendix c

Appendix D

Appendix $\mathrm{E}$

Appendix F

Appendix $G$

Appendix $\mathrm{H}$

Appendix I

Appendix $J$

Appendix $\mathrm{K}$

Appendix $L$

Appendix $\mathrm{H}$

Appendix $N$

Appendix 0

Appendix $P$

Appendix $Q$
Solicitation Poster . . . . . . . .

Student Information and Consent Forms - 155

Centre for Epidemiologic studies

Depression scale for Children . . 158

Perceived Stress scale . . . . . . . 160

General and Domain Specific Satisfaction

Scales . . . . . . . . .

study Booklet . . . . . . . . . . 165

Personal Project Dimension Questions with

Definitions and Question Regarding

Rationale for Project Engagement • 196

Data on Deleted Cases . . . . . . . 203

Gender Differences in Well-Being scores 205

Early Adolescent Personal Project

Categorization System . . . . . . 207

Personal Project Categorization system:

Lecci 1991 . . . . . . . .

Percentages of the Total Number of

Projects Iisted Within the nroad

Project Categories . . . . . . . 221

McQuitty Linkage Analyses . . . . . . 223

Project-system and Category Dimension

Rating Intercorrelations . . . . 229

Regression Analyses . . . . . . . 242 


\section{List of Tables}

Table Descxiption

1 Means and standard Deviations of Well-Being Scores . . . . . . . . . . . . .

Pearson Product Moment Correlations Between

Well-Being Variables . . . . . . . . 26

Means and Standard Deviations of Life

Satisfaction and Distress . . . . . . 29

Number and Percentages of Males and Females

Who isted Projects in the Major Project Categories . . . . . . . . . . .

5 Gender Differences in the Proportion of

Subcategory Listings within Broad Categories

6 Means and Standard Deviations on the Seventeen PPA Projert-"ystem Dimension Ratings . . .

7 Principle Components Analysis of Project Dimension Ratings . . . . . . . . . . . . . . .

8 Project Category Differences in Mean Dimension Rating scores .. . . . . . . . . . . 40

9 Pearson Product Moment Correlations Between Male and Female Project-system Dimension Ratings and Life satisfaction . . . . . . . . .

10 Pearson Product Moment Correlations Between Male and Female Project-system Dimension Ratings and Distress . . . . . . . . . . . . . 
11 Significant Pearson Product Moment Correlations Between Dimension Ratings and Life Satisfaction by Project Category . . . .

12 Significant Pearson Product Moment Correlations Between Dimension Ratings and Distress by Project Category . . . . . . . . . 
List of Figures

Figure Description

1

McQuitty Linkage Analysis of Well-Being Variables

xi 
Introduction

The sarly adolescent years are a time of great change: biological, social, and cognitive. They have been described as a time of particular vulnerability (Hamburg \& Takanishi, 1989). While most children are able to cope with the changes entailed in this period, a substantial proportion experience emotional distress (Offer, 1985; Petersen, 1988). Feelings of stress and depression may lead to an attitude of hopelessness and despair. On the other hand, a successful resolution of these feelings can lead to increased resillence and an ability to deal with subsequent life challenges. Early adolescents' perceptions of well-being, their feelings of stress or depression and evaluations of life satisfaction, have immediate meaning as well as implications for the long term.

This study examines the relationship between the everyday activities of early adolescents and their overall sense of well-being. A clearer picture of the early adolescent years, taken from the adolescent perspective, may allow us to better understand and help children negotiate this difficult transitional period. The study is set within a social ecological framewyrk (Little Ryan, 1979) centered in focus of early adolescent activity, and the manner in which adolescent appraisals of their activities is related to 
well-being is investigated using Personal projects Analysis (PPA) (Little, 1983, 1987a, 1987b, 1987c, 1989, 1992). PPA is one of a number of emerging assessment procedures that highlight the goal direcied nature of human behaviour. In what has been described as a conative revolution (Little, 1987a), emphasis in contemporary psychology has shifted from the "having" side of personality to the "doing" side of personality (Cantor, 1990). Increasingly, Personal Action Constructs (Little, 1989) such as life tasks (Cantor \& Kihlstrom, 1987), current concerns (KIInger, 1977), and personal projects (Iittle, 1983) have been used in personality research. These middle level units of analysis, set between more molar traits and overarching values and more molecular behavioural acts, highlight the intentional and ecological context of human action. Individuale are portrayed as embedded in, and in large part defined by. their environments. At the same time they are seen as actively and selectively interpreting, responding to, and transforming their worlds.

The next section presents a brief and selective overview of the literature on early adolescence focusing on definitional issues and the types of changes and chalienges experienced during this perlod that are thought to influence well-being. This is followed by a more detailed description of PPA, including protocols, scoring procedures, and anelytic approaches that are typically used in Personal 
Project research. The section closes with a presentation of findings relating Personal Projects to the well-being of older adolescents and adults.

\section{Early Adolescence}

\section{Q exestion of Definition}

Various criteria have been used to distinguish childhood from adolescence. While for some purposes age may prove a convenient and useful marker, it does not necessarily encompass or accurately reflect changes in disparate developmental domains. For example, physical and social changes such as the onset of menarche and the initiation of dating do not vary directly with age. For each developmental domain therefore, researchers have typically addressed definitional issues from their own chosen perspective. The result has been an accumulation of diverse, and at times seemingly contradictory, findings.

In an effort to account for and integrate a growing body of such findings, recent research has increasingly recognized the importance of considering the effect of context on early adolescent development (e.g., simmons and Blyth, 1987). The contributions of ecological and life span perspectives (e.g., Baltes, Reese: Lipsitt, 1980; Brofenbrenner, 1977; Little \& Ryan, 1979) have highlighted 
the significance of age-graded sociocultural influences. The move from elementary school (Kindergarten through Grade 6) to intermediate school (Grades 7 and 8) is a salient and consensually defined demarcation point between childhood and adolescence. It signals the beginning of a change in roles and expectations for the young adolescent and those in his or her environment. A different set of environmental opportunities and demands calls for a reorganisation of behaviour both within and outside of the immediate school setting.

The Changing Social Ecology of Early Adolescence

While some of the changes that take place during early adolescence are gradual, the change in the school environment is particularly abrupt. In many cases, students move directly from the intimate neighbourhood school with self-contained classrooms and familiar faces, to an intermediate school system with multiple classrooms, different teachers, and a peer group that increases in size and complexity (Crockett, Losoff Peterson, 1984). In other cases students remain in the same school. Here too there are major changes in routine and expectations. Teachers and/or students move from classroom to classroom and opportunities for extended contact with particular teachers decreases. An increased emphasin on academics is accompanied by more rigourous and normative grading 
standards and the use of competitive motivational strategies (Eccles and Midgley, 1989, 1990).

The home environment changes as well. A growing amount of time is spent in solitary activities such as grooming, reading, and listening to music (Duckett, Raffaelli, \& Richards, 1989; Richards \& Larson, 1989). Time spent watching television with family drops off and independent viewing preferences switch from cartoons and sitcoms to music programs and soaps (Larson, Kubey, Colletti, 1989). While young adolescents continue to discuss daily issues and ongoing interests with family members, they increasingly turn to friends to discuss emerging age-related concerns (Youniss and Smollar, 1985). Intimate self-disclosure to adults decreases while disclosures to peers increase (Buhrmester Furman, 1987). Time spest talking to friends, both on the telephone and in person becomes a major activity during this leriod (Ruffaelli \& Duckett, 1989).

A larger proportion of time is spent outside the structured settings of home and school in early adolescence than in earlier developmental periods (Coldins, 1988). Interestingly, perhaps tellingly, there are relatively few accounts of where or how teenagers spend these hours. Anecdotal evidence suggests that a substantial amount of this time is spent sociailzing with friends in arcades and shopping malls. Participation in both informal and organized sports activities drops off (Kirshnit, Ham, \& 
Richards, 1989) while experimentation with alcohol and drugs increases (Mccord, 1990).

Taken together these findings point to dramatic changes in the context of early adolescent development. New interests are explored with different companions in increasingly disparate settings. Changes in the diversify of context and influences to which young adolescents are exposed provide for new experiences and highlight additional domains of interest and concern.

While it is clear that there are documented shifts in the type of activities engaged in by young adolescents, little is known about how they are appraised by adolescents in terms of such factors as their enjoyment, stressfuliness, and challenge. Nor is there substantial evidence on how these experiences and such evaluations of adolescent activities or projects relate to well-being in adolescence. The present study will use Personal Projects Analysis (PPA), an assessment device explicitly designed to measure such phenomena to address these shortcomings in the Iitarature on early adolescence.

\section{Personal Projects Analyoin}

PPA consists of a number of interrelated asesesment modules that center around an individuals personal projects. Little (1989) has defined personal projects as "extended 
sets of personally relevant action" (p.15). PPA is not a fixed test, but rather is a flexible and generalized assessment methodology that may be used to investigate a wide range of human activity. Investigators are free to selectively use and modify chosen modules in order to address their specific research or clinical interests.

The following sections will present two PPA modules that are relevant to the study at hand. The standard PPA protocol and scoring procedures will be outlined along with a number of analytic approaches. This will be followed by a presentation of selected PPA resarch findings related to well-being.

\section{Personal Projects Elicitation Iisting}

The opening module, the Personal projects Elicitatation Listing, begins by introducing and outlining the concept of a personal project (see Appendix A). Respondents are invited to participate in a study of the kinds of activity and concerns that people have at different stages of their lives. A list of examples is provided in order to illustrate the wide range and level of activities and interests that may be construed as projects. This list normally includes examples of both short term and long term projects, projects done alone and those that involve others, and projects from a variety of activity domains. Respondents are then asked to make a list of the projects in which they are currently 
engaged or thinking about starting in the near future. The projects elicited through this procedure are the prime assessment units of PPA. As weIl as providing an element for further enquiry into an individuals project system, these idiosyncracically phrased units are a rich source of data in and of themselves. Projects such as "try to do better in school this year" carry information about the strength and direction of an individuals activity as well as their social and physical environments.

A detailed examination of an individuals project list may prove useful in a clinical setting. For research purposes however, it is frequently more fruitful to consider the data from a broader perspective. For example, it is often useful to sort projects into generic categories. A schema that orders projects into activity types may point to distinct areas of interest for particular age groups. A similar assay might reveal gender differences within a specific group. Such a breakdown of project systems also provides for finer grained analysis of data accumulated in other PPA modules.

\section{Personal Projects Rating katrix}

The core module of PPA is the Personal Project Rating Matrix (PPRY) (see Appendix A). Here respondents are asked to select the 10 projects that they are most 11 kuly to be engaged in over the following month, aris to list them on the 
PPRY. These 10 projects are referred to as an individual's "project- system". The 10 projects are not seen as an exhaustive list of all of the projects that an individual will be involved in. Rather the projects listed in the matrix provide a methodologically manageable, systematic approach to assessment and therefore are referred to as a gystem.

The respondents are then asked to rate each of their 10 selected projects on a number of dimensions. For example respondents are asked to indicate how important each project is to them and how difficult they find it to carry out each project. An 11 point Likert-type scale with anchor points is provided for each dimension. Typically a set of 17 dimensions, chosen on the basis of their theoretical and applied importance, is used. A list of the standard 17 dimensions, along with their definitions znd the Personal Projects Rating Matrix, are provided in Appendix A. The PPRM protocol may be contrasted with other assessment approaches. The 10 selected projects perform a similar function as the items on a traditional "objective" inventory. Unlike auch items however, these self-generated items are personally salient and have greater ecological validity than is typically the case. As such they provide an evocative and meaningful unit of analysis for investigation into the cognitive, affective, and conative aspects of peoples lives. Further, unlike more 
traditional approaches whith focus on an individuals cognitive, affective or conative functioning, or those that use different elicitation units to investigate these domains, PPA allows for a direct investigation into their interdependence.

Two types of indices, normative and ipsative, can be derived from the project dimension ratings. Normative scores such as mean-rated project stress provide a description of an individuals or groups project-system(s) that may be compared to that of a relevant comparison group. It is often enlightening to compute these mean dimension ratings within categories as well in order to ldentify the distinctive characteristics of different types of projects. Relationships among project dimension variables, both at the project system and category levels, provide further insight. For example, intercorrelations may reveal that projec's rated as most enjoyable are those that are felt to be self-initiated. Similar analysis within the various categories may show contrasting relationships. Individual differences in mean dimension ratings may also be correlated with other PPA variables and/or way be uead to investigate linkages with selected dependent or independent variables of interest.

The use of a common item across dimensions allowe ipsative indices to be calculated from the dimension ratings. The relationship between an individual's ratings 
of impor'ance and enjoyment across his or her project system may be expressed as a correlation. These ipsative scores may be used in a similar fashion as the normative scores in nomethetic analysis. For example, it is possible to regress a dependent variable of interest on this importanc" "unjoyment index.

\section{Personal Projects and Well-Being}

since the mid-1970s, there has been an increasing int:erest in the nature and measurement of subjective well-being (SWB). SWB is thought to be made up of cognitive and affective components (Chamberlain, 1988). The cognitive complonent consists of considered judgements of satisfaction with life made in relation to various comparison standards such as past personal experiences, the perceived situation of others, expectations, and aspirations (George, 1981; Michalos, 1985). It is likely that the relative salience of these standarde is influenced by such variables as age, gender, and environmental context. For example, social comparisons that are made by adolescents are affected by the emergence of formal operational thought and the egocentrism of this stage of development (Elkind, 1967). The increasing salience of social comparison which emerges during adolescence represents an important cognitive factor in the individual's perception of life satisfaction. 
The affective component embodies more recent and immediate everyday feelings such as happiness and enjoyment, or depression and stress (Watson and Tellegen, 1985). These feelings are related to the availability and quality of social support and to the quantity of accumulated worries and complaints (Harding, 1982; Headey, Holmstom, Wearing, 1985). Whether considered from a cognitive or afrective perspective, the assessment of subjective well-being must address both the positive and negative aspects of this construct. In its simplest form, SWB represents a blending of the overall distress in one's life and perceptions of life satisfaction.

PPA has been used in a widn variety of studies investigating the relationship between everyday activities and SWB. Significant correlations between project dimension ratings and various well-being measures have been consistently reported. For example, depressive affect (one measure of distress) has been shown to be negatively related to project outcome and control (Howe, 1980; Oke, 1985). Project stress and lack of control have also been whown to be negatively related to independently measured perceived stress levels (Collette, 1985; Mikelson, 1984). Finally iffe satisfaction has been shown to correlate positively with project control, outcome, and self-identity (Chatterjee, 1981; Little, 1988; Yard, 1980). While these studies have all reported signiflcant 
correlations between SWB measures and one or more project dimension ratings, the strength of these relationships varies from study to study. There is some evidence to suggest that age plays a major role in these differences. (IIttle, 1989) It would seem that age accounts for a substantial amount of the variance found in the relationship between everyday activities and SWB (Wilson, 1990).

As a consequence, findings from studies involving older adolescents or adults cannot be presumed to generalize to early adolescence. This study examines the relationship between the Personal Project Dimension ratings of 12-13 year olds and their overall sense of distress and life satisfaction in order to construct a more detailed account of the effects of this early life transition on the adolescent's subjective well-being. 
Method

Sample

The individuals involved in this study were drawn from an Intermediate school of the Ottawa Board of Education. This school is located in a middle class surburban neighbourhood and receives grade seven and eight students primarily from two feeder schools in the surrounding area. one hundred and eighty five students were registered in the school at the time of the study.

Participation in the study was voluntary and regulred the active consent of the participants as well as that of their parents. In order to inform the community about the study, and to obtain as extensive partioipation as possible a sample as possible, parental consent forms and information describing the nature and purpose of the study were attached to the weekly school newsletter sent home with students (see Appendix B). The students were also informed, both in the newsletter and via posters in the school, that the names of those who returned signed consent forms (with or without consent granted) would be entered in a draw for gift certificates that could be used at the local shopping centre (see Appendix C). Finally, active concent was obtained from respondents who wished to participate after they had been informed both verbally, and in writing, about the nature of 
the study and immediately prior to their participation (see Appendix D) .

A total of 115 students took part in the study.

School personnel reported that the students who participated were representative of the school population with respect to such variables as academic achievement, social skills, and extracurricular participation. Data from 21 respondents were not used in the analyses: 14 respondents had missing data and a further seven were identified as univariate or multivariate outliers. The final sample consisted of 51 grade seven students and 43 grade eight students. As grade level was not used is an independent variable in the study, the sample is better described by gender. The mean age of the males $(N=48)$ was 13 years $(S D=.77)$ and the mean age of the females $(N=46)$ was 12.8 years $(S D=.73)$. These figures closely resembled the age, grade; and gender profiles of the school student population.

\section{Procedure}

Subjects were asked to complete a package of tour guestionnaires. Included were the Perceived stress scale (Cohen, Kamarck, Mermelstein, 1983), The Center for Epidemiologic Studies Depression Scale for Children (Weissman, Orvaschell, \&adian, 1980), the Personal Projects Analysis package (Littie, 1983), and General Life 
and domain specific Satisfaction scales modified from Lecci (1991). Subjects were also asked to provide their age, grade, and gender.

The data were collected within the school in small group sessions of approximately 20 students per sitting. Administration was supervised by a trained investigator who answered any questions that arose. The average time required for completion of the package was approximately 50 minutes with a range of from 45 minutes to 70 minutes. Anecdotal evidence, including comments and questions from participants, indicated that the subjects found the procedure engaging and thought provoking.

\section{Description of Yeagures}

Several considerations simultaneously guided the choice of measures included in this study. The exploratory nature of the investigation called for the use of a broad band of assessment instruments of known reliability. selected measures were also chosen with a view to addressing the specific concerns of early adolescence, while at the aame time allowing for comparisons with extant data gathered erom other age groups. A brief description of these measures along with a rationale for their selection follows.

CES-Depression Scale for children. The center for Epidemiologic Studies Depression scale for Children (CES-DC 
Scale; Weissman, Orvaschell, (Padian, 1980) was chosen to provide a measure of the subjects' current level of depressive symptomalogy (see Appendix a). This 20-item inventory asks respondents to indicate the frequency with which they have felt or behaved in specified ways over the previous week. The response format includes a four-point rating system ranging from rarely or none of the time. through to most or all of the time.

The CES-DC is a particularly appropriate measure for this study. It is a child's version of the centre for Epidemiologic studies Depression Scale (CES-D, Radloff, 1977) which was originally developed to investigate the relationship between depressive symptomalogy and other variables across population sub-groups. The CES-D was designed to measure current levels of depressive symptomalogy with emphasis on the affective component.

The CES-D was modified where necessary to facilitate understanding and appropriateness for children. For example, the idult CES-D item "I felt like everything I did was an effort" was revised to "I felt like I was too tired to do anything this week" for the CES-DC. similarily, the adult item "I felt depressed" was revised to "I felt down and unhappy this week". The same scoring is used in the CES-DC as in the CES-D. A comparison of the results of a number of studies involving early adolescents (Allgood-Merten, Lewinson, Hops, 1990; Doerfler, Felner, Rowlinson, Raley, 
\&vans, 1988; Garrison, Addy, Jackson, McKeown, Waller, 2991; Roberts, Andrews, Lewinson, \& Hops, 1990; Tolar \& Murphy, 1985) indicates that scores on the CES-D and the CES-DC are comparable for this population.

Perceived Stress Scale. The Perceived stress Scale (PSS), developed by Cohen, Kamarck, and Mermelstein (1983), was selected to provide a global measure of the subjects' perceived stress (see Appendix F). This 14 item inventory asks respondents to indicate how often they have felt or behaved in specified ways over the previous month. A five-point frequency rating system ranging from never tinrough to very often accompanies these instructions. The PSS was chosen in order to tap directly into the subjects' perceived stress level. Unlike specific-event checklists (e.g. Holmes and Rahe Life-Event Scale, 1987), which assume that perceived stress levels are highly correlated with the number of reported life events, the PSS was designed to take the individuals perceptions of unspecified daily hassles and major events into account. In doing so it is more sensitive to the chronic stress of everyday life, stress engendered by anticipated events, and a wide variety of matters that may not be perceived by others as stressful.

General Life Satisfaction scale. A measure cr sisting of a 
single question inquiring about satisfaction with "life as a whole ", accompanied by an eleven-point Likert-type scale ranging from completely dissatisfied to completely satisfied, was included in the assessment package (see Appendix G). This General Life Satisfaction Scale adapted from Palys (1979), was chosen in order to provide a measure of the subjects' cognitive evaluation of SWB.

Domain Specific Satisfaction Scales. Six domain specific satisfaction measures, each consisting of a single question and an eleven point likert-type scale, were included in order to assess satisfaction within specific life domains (see Appendix $G$ ). Respondents were asked to rate their level of satisfaction with their Academis, Home, Social, and Recreational lives. As well, they were asked to indicate how satisfied they were with their Bmotional state and Physical Health. These particular domains were chosen to provide global indicators that would correspond to areas of early adolescent concern and to dimensions of SWB measured by other study instruments.

Personal proficts Analyets. The unit of analysis used to investigate the content and appraisals of young adolescents activities and interests was the personal project (Little, 1983). Subjects were asked to complete the Personal Project Analysis package found in Appendix $H$. The instructions asked 
subjects to generate a list of as many personal projects as they could in a ten minute period. They were then required to select the ten projects that they would most likely be involved in over the next month, and to rate each of these projects on 17 dimensions. A list of the study dimensions, along with their full definitions, axe provided in Appendix I. These dimensions were chosen in order to obtain information thought to be relevant to swB in early adolescence.

Changes were made to both the content and the format of the standard PPA package in order to address the goals of the research. Two dimensions frequently included in PRA research, Positive Impact and Negative Impact, were not included in the package used in this study. Pliot studies revealed that many early adolescents had difficuity responding to these questions, and those who did manage to respond took a disproportionate amount of time to do 80 . While project conflict, cohesion, and facilitation are likely relevant to early adolescent well-being, they are perhaps better addressed with other PRA components (see Ittle, 1989).

Two other dimensions typically included in PPA research - Visibility and others View of Importance - wore broken down into what are thought to be their principal components. Respondents were asked separately to indicate how visible and how important each of their projects was to their 
parents, teachers, and other significant adults, and to their Iriends and classmates. These questions were meant to measure what are thought to be discrete influences on early adolescent well-being.

The last question in the PPA matrix asked subjects to indicate why they were involved in each of their projects. This question was designed to aid in an anticipated categorization of the projects into generic activity domains. Project categories include: Academic, Interpersonal, Intrapersonal, Maintenance, Leisure, Appearance, Health/Body, and Vocational. Details of the development of the categorization schema used in this study; along with descriptions of the various categories, will be presented in the Results section.

Format changes included modifications to the dimension-rating question presentation and to the physical structure of the package. The rating questions were expanded and rewritten and an 11 point scale with clear anchor points was presented with each question. These changes were made to ensure that the intent of the questions was clearly understood and to facilitate responding. Finally, all of the messures included in the study were ordered and bound into a booklet, allowing respondents to proceed through the procedures entailed without turning back to previous pages for clarification. Appendix $\mathrm{H}$ is a page by page photo-reduced copy of this eight and one half by 
fourteen inch booklet as it would be seen by an individual proceeding through it.

Demographis Data. Subjects were asked to provide their age, grade, and gender in order to allow for comparison across these demographic variables. 
Results

The results are presented in four main sections. The first section reports results related to the well-being measures. The means and standard deviations of the nine well-being measures included in the study are presented. Well-being measure intercorrelations, and the results of a linkage analysis (McQuitty, 1967) identifying Life Satisfaction and Distress clusters within these intercorrelations are then presented.' This is followed by a presentation of the means and standard deviations of the Life Satisfaction and vistress composite measures selected as the criterion variables in this study.

The secoril section describes the development and reliability of the project-categorization system. This is followed by a presentation of the categorization system along with the results of between gender analyses of the projert listings content.

The third section presents results related to the project dimension ratings. Means and standard deviations of the project-system dimension ratings are presented. Five factors derived from the dimension ratings are then presented followed by a comparison of the dimension ratings associated with these factors across three of the project categories.

The final section opens up with a presentation of 
correlation matrices examining the relationship between the project-system dimension ratings and the Life satisfaction and Distress variables broken down by gender. This is followed by a presentation of a series of similar analyses conducted within selected activity domains. The results indicate that the relationship between early-adolescent well-being and the project dimension ratings varies across both project category and gender. ${ }^{2}$

\section{Well-Being scores}

Scores on the seven satisfaction measures, and on the CES-DC and PSS variables, were examined to determine if there were gender or grade level differences in these scores. MANOVAs revealed that gender and grade level differences were not sigjificantly different, $E(9,84)=$ $1.80, \mathrm{~g}=.08$ and $E(9,84)=0.80, \mathrm{~g}=.62$ respectively. Means and standard deviations of the nine well-being measures included in the study are presented in Table 1 . The Life Satisfaction and PSS figures displayed in Table 1 are comparable to those reported in studies involving older adolescents (Cohen et al., i333; MacDiarmid, 1990). The CEsDC mean is considerably higher than CES-D means reported in studies involving older populations (see Devin \& Orme, 1985) although both the mean and standard deviation are eimilar to figures reported in other early adolescent studies 
Table 1

Yeans and standard Deviations of Well-Being Scores

Variable

General satisfaction

Academic Satisfaction

social satisfaction

Home Satisfaction

Emotional Satisfaction

Recreational satisfaction

Physical Health Satisfaction

CES-DC*

Perceived stress Scale
Mean Standard Deviation

$\begin{array}{rl}7.30 & 1.94 \\ 7.07 & 1.90 \\ 6.65 & 2.45 \\ 7.39 & 2.21 \\ 6.94 & 2.35 \\ 7.80 & 2.06 \\ 7.81 & 2.15 \\ 15.82 & 9.47 \\ 23.17 & 7.47\end{array}$

Note. $N=94$

- Centre for Epidemiologic Studies Depression Scale for Children 
(Doerflex, Rowlinson, Raley, Evans, 1988; Faulstich, Carey, Ruggerio, Enyart, \& Gresham, 1986).3

Table 2 displays the intercorrelations amongst these well-being measures derived from scores collapsed across grade level and gender. A Mcquitty linkage analysis applied to these data identified two separate clusters (see Figure 1). The first cluster, hereafter referred to as Life Satisfaction, amalgamates the seven satisfaction measures. The second cluster, labelled $\mathrm{Di}$. -ress, is composed of the CES-DC and PSS variables.

A Life Satisfaction composite score was then calculated for each individual by averaging across the seven Satisfaction scores. Distress composite scr jes were calculated by averaging the CESD-C and PSS scores." Gender and grade level differences in these two composite measures taken together were not significant, $E(2,91)=$ $2.61, \mathfrak{k}=.08$ and $E(2,91)=1.00, p=.88$ respectively . Means and standard deviations of the life satisfaction and Distress scores are presented in Table 3.

A Pearson product moment correlation was then calculated from the individual Life satisfaction and Distress scores. The results of this analysis $(x=-.59$, $\mathrm{p}<.05)$ indicates that these two composites are measuring related though somewhat independent aspects of well-being. For both practical and theoretical reasons the relationshi, between personal projects and well-being were therefore 
Table 2

Pearson Product Moment Correlations Between Well-Being Variables

\begin{tabular}{|c|c|c|c|c|c|}
\hline Variable & Gensat & Acadsat & socsat & Homesat & EmotSat \\
\hline Gensat & - & .2337 & $.4164 * *$ & $.4198 * *$ & $.6508 * *$ \\
\hline Acadsat & .2337 & - & .0636 & .0752 & .2086 \\
\hline Homesat & $.4 . \cdots *$ & .0752 & .2230 & - & $.4530 * *$ \\
\hline Emotsat & $.6508 * *$ & .2086 & $.4596 * *$ & $.4530 * *$ & - \\
\hline Recsat & $.3542 * \star$ & .0699 & $.3203 * *$ & $.3062 *$ & $.399 I * *$ \\
\hline Physsat & $.2535 *$ & .0404 & $.3443 * *$ & .2336 & $.3102 *$ \\
\hline CES-DC & $-.3976 * *$ & -.0897 & $-.2412 *$ & $-.3446 * *$ & $-.5620 \% *$ \\
\hline PSS & $-.4328 * *$ & -.2234 & -.1908 & $-.3181 * *$ & $-.4853 * *$ \\
\hline
\end{tabular}

Variable RecSat Rhysat CESDC PSS

\begin{tabular}{|c|c|c|c|c|}
\hline Gensat & $.3542 * *$ & $.2535 *$ & $-.3976 * *$ & $-.4328 * t$ \\
\hline Acadsat & .0699 & .0404 & -.0897 & -.2234 \\
\hline socsat & . . . 3203** & $.3443 * *$ & $-.2412 *$ & -.1908 \\
\hline Homesat & $.3062 *$ & .2336 & $-.3446 * *$ & $-.3181 * *$ \\
\hline Emotsat & $.3991 * *$ & $.3102 *$ & $-.5620 * *$ & $-.4853 * *$ \\
\hline Recsat & - & $.3354 * *$ & $-.2823 *$ & $-.3778 * *$ \\
\hline Physat & $.3354 * *$ & - & $-.3390 * *$ & $-.3078 *$ \\
\hline CES-DC & $-.2823 *$ & $-.3390 * *$ & - & $.5811 * *$ \\
\hline $\begin{array}{l}\text { PSS } \\
k p<.01\end{array}$ & $\begin{array}{l}-.3778 * * \\
<.001\end{array}$ & $-.3078 *$ & $.5811 * *$ & - \\
\hline
\end{tabular}


- see below for explanation of variable names.

Table \& Continued

(Table continues)

Pearson Product Moment Correlations Between Wel1-Being Variables

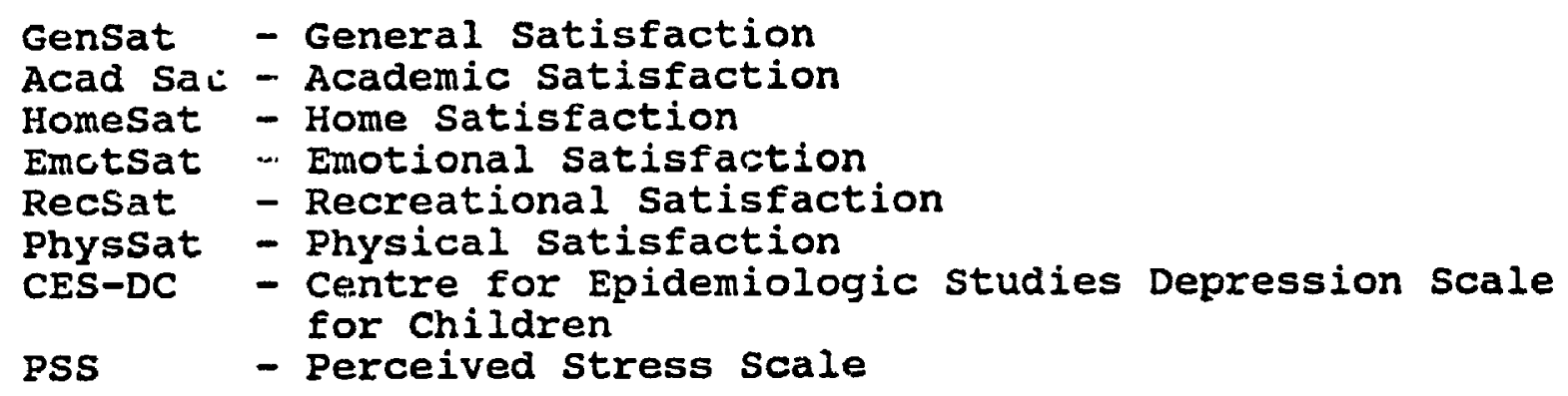


Figure 1

Mcouitty Linkage Analysis of Well-Being Variables

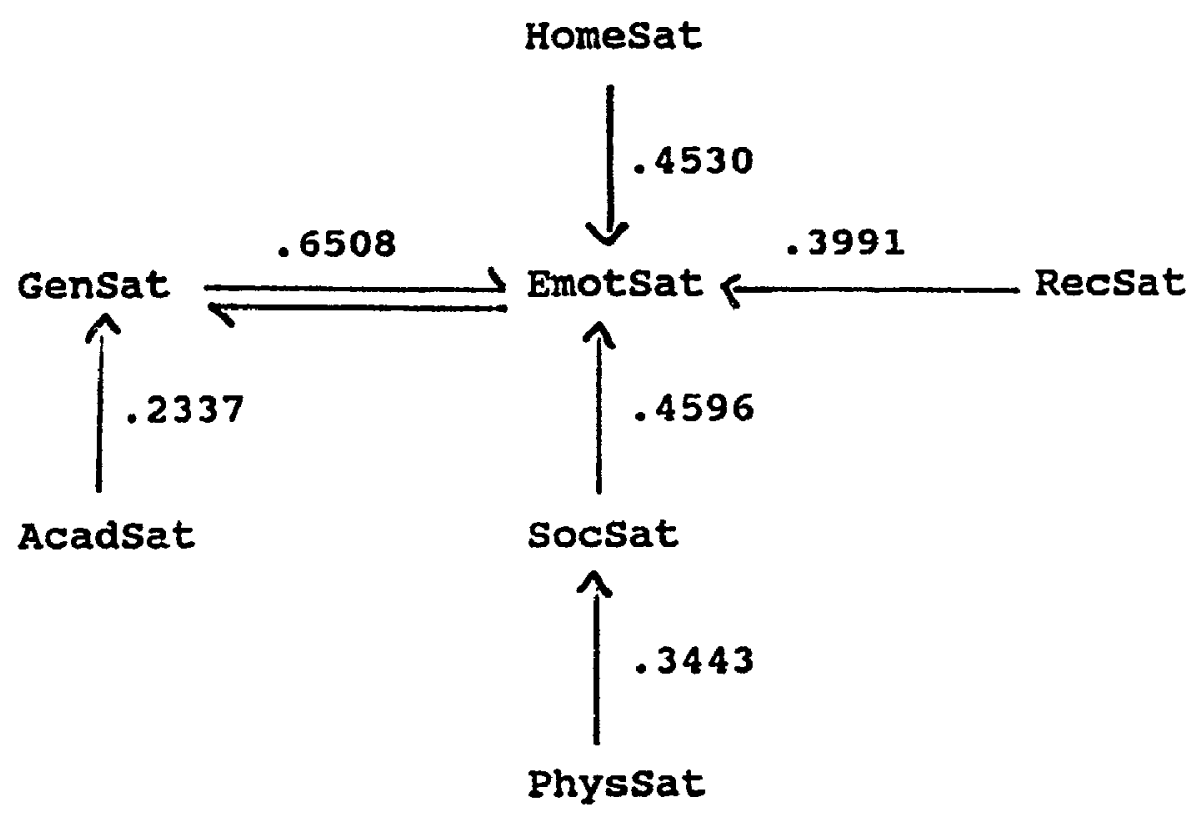

\section{Life Satisfaction}

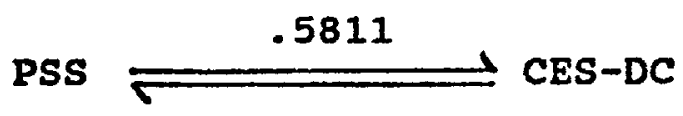

Distress

Note. $N=94$

- Refer to Table 2 for explanation of wellbeing variable names. 
Table 3

Means and Standard Deviations of Life Satisfaction and Distress

Variable

Life satisfaction

Distress
Mean

$-$

7.28

20.32
Standard Deviation

1.36

7.77 
analyzed using both Life Satisfaction and Distress as criterion variables. 5

\section{Personal Projects}

\section{Project Categorization}

In order to provide a framework for an investigation into the content of early adolescent activity, each selected project was classified according to the categorization system presented in Appendix $I$. This schema was derived from a set of categories (Lecci, 1991; see Appendix M) evolved from previous Personal Project research (Little, 1983, 1987C, 1988; Mavis, 1981). A random sample of 25 percent of the total projects listed by the sample was used to develop the categorization schema used in this study. This process was guided by an exasination of simmon and Blyth's (1987) Tasks of Adolescence and the domains and items contained in Harter's (1988) Self-Perception Profile for Adolescents. 6

The total 912 projects listed by the sample were then classified according to this system by the principle investigator. An independent judge was subsequently asked to categorize a random sanple of 200 projects. The overall concordance rate between the independent. judge and the principle investigator, based on the principle finvestigator's categorization, was 88 percent. The mean suhsategory concordance rate, similarily calculated within 
each of the major subcategories, was 85 percent. The range was 68 percent (i.e. Intrapersonal; $N=9$ ) to 100 percent (i.e. Vocational; $\mathbf{N}=9$ ).

Cohen's Kappa (1960) was used to further examine the interrater reliability. The value of the kappa statistic was .866 when categorization by uajor category was assessed and .867 when categorization by subcategory was assessed. Fleiss (1981) recomsends the following guidelines for the evaluation of the Kappa statistic: $k<.40$ representa poor agreement: $.40<=k<=.75$ represents fair to good agreement; and $1:>.75$ represents excellent agreement. Subsequent analyses were based on the principle investigators categorization of the projects.

Group Differences in project content. Gender and grade level differences in the proportion of Individuals who listed one or more projects in the major categories and in the subcategories were evaluated by Chi-square analyses. No gender, $\mathrm{X} 2(7, \mathrm{~N}=94)=11.48, \mathrm{2}=.12$ or grade level, $\mathrm{X} 2$ (7, $\mathrm{N}=94)=3.59, \mathrm{P}=.83$ alfferences were significant when only the major categories were considered. Gender differences were significant however when analysis was performed at the subcategory level, X2 (31, $N=94)=57.36,2=.003$. Grade level differences in subcategory proportions did not :each significance, $X 2(31, N-94)=25.64,2=.74 .^{7}$ In light of these findings, subsequent analysis examined gender 
differences collapsed across grade level where appropriate. rable 4 displays the number and percentage of males and females who listed projects in the major categories. Previous PPA research has highlighted differences in the manner in which Academic and Interpersonal projects are related to well-being (Benton, 1987; Little, 1992 ). An examination of Table 4 reveals that these two types of projects were listed by the majority of males and females alike. It may also be noted that Leisure projects were listed by the greatest number of respondents. Subsequent categorical analysis will therefore focus on these highly represented domains. ${ }^{8}$

Table 5 displays the percentages of males and temales who Iisted projects within ach of the Academic, Interpersonal, and Leisure subcategories. Gender differences are seen to be significant within two of these rategories. These differences are most striking in the Leisure domain where a subetantialiy larger percentage of males are seen to have listed Media Entertainment projects while a greater porcentage of fomales listed Hobby/Interest projects. With reapect to the Interpersonal domain, it is worth noting the relative dearth of projects involving significant adults other than parents as well as the predominance of male lietinge in the Intimate Friend/Peer aubcategory. 
Table 4

Number and Percentage of Males and Females Who Listed Projects in the Major project Categories

Project Category

Academic

Vocational

Interpersonal

Intrapersonal

Leisure

Aaministrative

Appearance

Health/Fitness

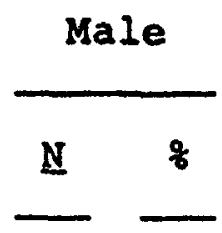

4185.4

$28 \quad 58.3$

2858.3

$12 \quad 25.0$

$48 \quad 100$

$35 \quad 72.9$

$11 \quad 22.9$

$17 \quad 35.4$
Female

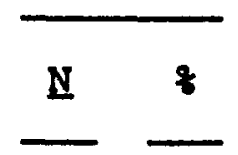

$38 \quad 82.6$

$18 \quad 39.1$

$30 \quad 65.2$

$20 \quad 43.5$

$43 \quad 93.5$

3576.1

$27 \quad 58.7$

$21 \quad 45.7$

Note. Male $N=48$, Female $N=46$ 
Table 5

Gender Differences in the Proportion of Subcategory Listings Within Broad Categories

Project Category

Academic

Acad. - Short Term

Acad. - Long Term

Interpersonal

Parent

Sibling

Friends

Intimate Peer

Significant Adults

Community Supportive

Meta
Maje

Percentage

95.1

14.6

35.7

35.7

25.0

57.1

0.0

0.0

17.9
Eemale Percentage

X2value

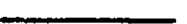

Leisure

Media Entertainment

Pleasure Reading

Window-Shopping

Sport

Hobby/Interest

Food

Pet

Drinking/Drugs

Parties/Dances

Getting out/Away

Phone/Letter Writing

$$
\begin{array}{r}
60.4 \\
14.6 \\
2.1 \\
66.7 \\
39.6 \\
10.4 \\
8.3 \\
2.1 \\
10.4 \\
25.0 \\
4.2
\end{array}
$$

89.5

15.8

$$
.27
$$$$
0.00
$$

$$
\begin{array}{r}
46.7 \\
40.0 \\
23.3 \\
20.0 \\
3.3 \\
6.7 \\
23.3
\end{array}
$$

.34
.00
.00
$6.98 * *$
.00
.45
.04

* p<.05 ** p<.01 *** p<.005

Note. Male $N=48$, Female $N=46$ 
Project-System Dimension Ratings

project ratings across the 17 dimensions were initially analyzed at the project system level. Average ratings were calculated across all of each individuals projects for each dimension. MANOVA revealed that gender differences in the mean project-system dimension ratings were not significant, $E(17,76)=1.3,2=.195$. Table 6 presents the means and standard deviations of the 17 project-system dimension ratings. These figures are comparable to data collected previously with a group of similarily aged adolescents (Franke, 1992).

A breakdown of the standard Personal Project dimensions of "others view of importance" and "visibility to others" into separate peer and adult components was amonget the modifications made to the PRA package used in this study. ANOVAs were performed to determine if there wera differences in these two sets of ratings. The results of these analyses indicate that adult visibility was rated higher than peer visibility, $F(1,93)=7.79,2<.000$, and that adult importance was rated higher than peer importance, $F(1,93)=$ $3.24,2<.002$.

\section{Personal Project Factorg}

In order to provide a framework for a more detailed presentation of data and analysis across gender and project category, a principal components analysis with varimax 
Table 6

Means and Standard Deviations on the Seventeen PPA ProjectSystem Dimension Ratings

PPA Dimension

Mean

standard Deviation

\begin{tabular}{|c|c|c|}
\hline Absorption & 6.57 & 1.14 \\
\hline Progress & 6.20 & 1.89 \\
\hline Outcome & 7.45 & 1.37 \\
\hline Time Adequacy & 5.99 & 1.67 \\
\hline Control & 7.63 & 1.52 \\
\hline Initiation & 8.51 & 1.07 \\
\hline Importance & 7.35 & 1.14 \\
\hline Value Congruency & 8.06 & 1.47 \\
\hline SeIf Identity & 6.79 & 1.73 \\
\hline Enjoyment & 6.81 & 1.51 \\
\hline stress & 4.05 & 1.93 \\
\hline Difficulty & 4.88 & 1.70 \\
\hline Challenge & 6.42 & 1.89 \\
\hline Peer Visibility & 4.61 & 1.97 \\
\hline Peer Importance & 5.46 & 2.07 \\
\hline Adult Visibility & 6.35 & 1.89 \\
\hline Adult Importance & 6.28 & 1.72 \\
\hline
\end{tabular}

Note. $N=94$ 
rotation was performed on the project-system dimension ratings. This procedure was guided by an examination of McQuitty linkage analyses performed on the male and female project-system dimension intercorrelations and by a similar assay of the Academic, Interpersonal, and Leisure project category intercorrelations (see Appendix 0$)^{\circ}$. The tive factor solution shown in Table 7 provided the best fit to these data. The first factor to emerge was an Efficacy factor witin the dimensions of absorption, progress, outcome, time adequacy, and control having the highest loadings. Initiation, importance, value congruency, self-identity and enjoyment have the highest loadings on the second factor hereafter referred to as Meaning. The third factor, titled Stress is most strongly associated with the project dimensions of stress, difficulty, and challenge. The tinal two factors, tentatively labeled Peer Community and Adult Community, are loaded by the visibility and importance project dimensions - peer visibility, peer importance and adult visibility, adult importance respectively.

\section{Profect Category Dimension Ratings}

Project ratings across the 17 dimensions wore then analyzed at the category level. Average ratings of each individuals projects within the Academic, Interpersonal, and Leisure project categories were calculated for each dimension. Gender differences in the dimension ratings 
Table 7

Principle Components Analysis of Project Dimension Ratings

Loadings

FAC 1 FAC 2 FAC 3 FAC $4 \quad$ FAC 5

Dimensions

\begin{tabular}{|c|c|c|c|c|c|}
\hline $\begin{array}{l}\text { Absorption } \\
\text { Progress } \\
\text { Outcome } \\
\text { Time Adequacy } \\
\text { Control }\end{array}$ & $\begin{array}{l}.86 \\
.76 \\
.71 \\
.59 \\
.43\end{array}$ & $\begin{array}{l}.20 \\
.16 \\
.36 \\
.32 \\
.40\end{array}$ & $\begin{array}{r}.19 \\
-.25 \\
-.25 \\
-.13 \\
-.34\end{array}$ & $\begin{array}{r}.07 \\
.17 \\
.01 \\
.26 \\
-.03\end{array}$ & $\begin{array}{r}-.03 \\
.29 \\
.10 \\
.41 \\
.34\end{array}$ \\
\hline $\begin{array}{l}\text { Initiation } \\
\text { Importance } \\
\text { Value Congruency } \\
\text { Self-Identity } \\
\text { Enjoyment }\end{array}$ & $\begin{array}{r}.25 \\
-.03 \\
.30 \\
.30 \\
.38\end{array}$ & $\begin{array}{l}.80 \\
.73 \\
.73 \\
.56 \\
.54\end{array}$ & $\begin{array}{r}.06 \\
-.05 \\
.11 \\
-.04 \\
-.23\end{array}$ & $\begin{array}{r}.09 \\
.27 \\
-.10 \\
.23 \\
.41\end{array}$ & $\begin{array}{r}-.20 \\
.37 \\
.15 \\
.26 \\
.05\end{array}$ \\
\hline $\begin{array}{l}\text { Stress } \\
\text { Difficulty } \\
\text { Challenge }\end{array}$ & $\begin{array}{r}-.07 \\
-.38 \\
.07\end{array}$ & $\begin{array}{r}-.20 \\
.05 \\
.15\end{array}$ & $\begin{array}{r}.79 \\
.75 \\
.74\end{array}$ & $\begin{array}{r}-.21 \\
-.23 \\
.21\end{array}$ & $\begin{array}{r}.17 \\
-.16 \\
.09\end{array}$ \\
\hline $\begin{array}{l}\text { Peer Visibility } \\
\text { Peer Importance }\end{array}$ & $\begin{array}{r}-.06 \\
.22\end{array}$ & $\begin{array}{l}.07 \\
.12\end{array}$ & $\begin{array}{l}-.03 \\
-.03\end{array}$ & $\begin{array}{l}.86 \\
.70\end{array}$ & $\begin{array}{l}.08 \\
.01\end{array}$ \\
\hline $\begin{array}{l}\text { Adult Importance } \\
\text { Adult visibility }\end{array}$ & $\begin{array}{l}.13 \\
.21\end{array}$ & $\begin{array}{l}.07 \\
.17\end{array}$ & $\begin{array}{r}.26 \\
-.11\end{array}$ & $\begin{array}{r}-.08 \\
.42\end{array}$ & $\begin{array}{l}.79 \\
.61\end{array}$ \\
\hline EIGENVALUES & 5.853 & 2.105 & 1.487 & 1.263 & .9413 \\
\hline PCT. OF VARIANCE & 358 & $12 \%$ & $9 \%$ & 78 & $6 \%$ \\
\hline
\end{tabular}

Note. $N=94$; varimax rotation. 
associated with each of these domains were evaluated by a series of MANOVAs. None of these tests reached significance $(p>05)$. Given the low $N$ to variable ratio used in these tests, it seemed appropriate to look at the univariate $F$ tests associated with the dimensions in each of the categories. A total of 51 ANOVAs yielded only one difference that was significant ( $p<.05) .{ }^{10}$ Given these findings, project dimension ratings were collapsed across gender in testing for category differences in these evaluations. MANOVA was then used to test for category differences in the project dimension ratings. The difference in the 17 dimension ratings taken together across the three categories was highly significant, $E(34,418)=9.90$, p<.000. ANOVAs revealed that differences in all but three of the individual dimensions were significant $(p<.05)$. These analyses were followed up by a series of paired sample t-tests identifying the location of these differences.

Table 8 presents the means of the dimension ratings in the Academic, Interpersonal, and Leisure project categories, along with the results of the t-tests identifying the location of differences in the dimension ratings. These data have been organized according to the factor structure outlined above. An overview of Table 8 reveals however that the data are better described on a dimension than factor level. For example, looking across the Academic, Interpersonal, and LEisure project categories, the dimension 
Table 8

Project Category Differences in Mean Dimension Rating Scores

\begin{tabular}{|c|c|c|c|}
\hline Dimension & Academic & Interpersonal & Leisure \\
\hline $\begin{array}{l}\text { Efficacy } \\
\text { Absorb }\end{array}$ & 7.6 & 6.4 & 6.9 \\
\hline Prog" & 7.3 & 5.9 & 6.8 \\
\hline out & 8.1 & 6.9 & 7.9 \\
\hline Time Ad & 7.1 & 6.4 & 6.3 \\
\hline Cont $^{8, c}$ & 8.4 & 6.5 & 8.1 \\
\hline
\end{tabular}

Meaning

$\begin{array}{llll}\text { Init } & & & \\ \text { Imp,c } & 7.3 & 8.4 & 9.1 \\ \text { Val cong } & 8.6 & 7.5 & 6.7 \\ \text { Self Idc } & 8.7 & 8.1 & 7.9 \\ \text { Enja,b,c } & 7.1 & 6.3 & 7.4 \\ \end{array}$

stres:

\begin{tabular}{|c|c|c|c|}
\hline Stress ${ }^{a, b, c}$ & 6.9 & 5.0 & 2.8 \\
\hline $\operatorname{Diff} u, t, c$ & 5.3 & 5.1 & 3.7 \\
\hline $\operatorname{Chal} 11^{b, c}$ & 7.4 & 6.8 & 5.5 \\
\hline
\end{tabular}

Peer Community

Peer Vis ${ }^{i, c}$

$\begin{array}{lll}6.0 & 3.4 & 5.3\end{array}$

Feer Imp

5.8

$5 \cdot 3$

5.6

Adult community

$\begin{array}{llll}\text { Adult Vis,b,c } & 7.9 & 5.1 & 6.5\end{array}$

\begin{tabular}{lccc} 
Adult Imp ${ }^{a, b, c}$ & 9.5 & 6.2 & 4.8 \\
\hline Note. $\quad N_{a, b, c, d}^{N}=$ & 87 & 58 & 91 \\
& & & (table continues)
\end{tabular} 
Table 8 (continued)

Project Category Differences in Mean Dimension Rating scores

a Paired sample t-tests* : Academic vs. Interpersonal.

- Paired sample t-tests* : Academic vs. Leisure.

c Paired sample t-tests* : Interpersonal vs. Leisure

* p<.025; modified Bonferroni 2 tailed significance.

$\begin{array}{llll}\text { A Absorb } & \text { - Absorption } & \text { Enj } & \text { - Enjoyment } \\ \text { Prog } & \text { - Progress } & \text { Stress } & \text { - Stress } \\ \text { Out } & \text { - Outcome } & \text { Diff } & \text { - Difficulty } \\ \text { Time Ad } & \text { - Time Adequacy } & \text { Chall } & \text { - Challenge } \\ \text { Cont } & \text { - Control } & \text { Peer Vis - Peer Visibility } \\ \text { Init } & \text { - Initiation } & \text { Peer Imp - Peer Importance } \\ \text { Imp } & \text { - Importance } & \text { Adult Vis - Adult Visibility }\end{array}$


ratings associated with the Adult Community factor - adult visibility and adult importance - are all significantly different from one another. The direction of these differences varies according to the dimension considered however. Adult visibility ratings, for example, are lowest for Interperscral projects wheras Leisure projects are lowest in ratings of adult importance. On the other hand, the rank orders of the Academic, Interpersonal, and Leisure dimension ratings associated with the stress factur are identical. Differences in these ratings are not all statistically significant however. For example, ratings of challenge in the Academic and Interpersona $i$ project categories are not significantly different whereas differences in the stress and difficulty dimension ratings of these same two categories are significantly different. While it is not feasible to present a detailed examination of all of the similarities and differences in dimension ratings across the three project categories contained in Table 8 , several findings are worthy of special note. First, with respect to the Efficacy dimensions, it can be seen that there is no significant difference between the Academic and Leisuie ratings on any of these dimensions. Second, with respect to the Meaning dimension evaluations, it can be seen that the initiation and enjoyment ratings are different for each of the three categories considered and that Leisure projects are rated highest on these two 
dimensions. In contrast, Academic projects are rated highest in importance while Leisure projects are rated similarily to Interpersonal projects on this dimension. Finally, with respect to the Peer Community dimension ratings, it is worth noting that there is no significant difference in the Acadenic, Interpersonal, and Leisure ratings of peer importance. This finding stands in sharp contrast to the ratings of adult importance. As noted above, each of these latier dimension ratings is significantly different from one another.

One further set of analyses were performed on the project category dimension ratings associated with the factors of Peer and Adult Community. A series of t-tests examined the differences in the peer visibility and adult visibility dimension ratings and in the peer importance and adult importance ratings in each of the Academic, Interpersonal, and Leisure project categories. With the exception of the peer importance versus adult importance comparison within the Interpersonal category, all of these differences were significant, $\mathrm{p}<.04 ;$ modified Bonferront, two tailed significance.

\section{Personal Projects and Well-Being}

The relationship between Personal Projects and Well-Being was analyzed at the project-system level as well 
as at the category level. Each set of analyses will be discussed in turn.

The Relationship between Project Dimension Ratings and Well-Being at the Proiect-System Level

Table 9 presents the correlations between Life Satisfaction and the male and female project-system dimension ratings. An examination of this table reveals a consistent pattern of significant correlations between the Efficacy and Meaning dimension ratings and Life Satisfaction. The relationship between the Efficacy dimensions and Life Satisfaction is somewhat stronger for males than for females for three of the five project dimensions that load on this factor. It can also be seen that the dimension of adult importance is significantly related to both female and male life satisfaction although the relationship between peer importance and Life Satisfaction is significant for females but not for males. Overall, although a few gender differences have been noted, the results indicate that the project-system dimensions which zake up the Efficacy and Meaning factors are most strongly related to both male and female Life satisfaction. The correlations relating Distress to the projectsystem dimension ratings are presented in Tables 10. The patterns of significant correlatio.rs in the male and female results are somewhat more disparate than those related to 
Table 9

Pearson Product Moment Correlations Between Male and Female Project-system Dimension Ratings and Life Satisfaction

PPA Dimension

Male

Female

Efficacy

Absorption

Progress

outcome

Time Adequacy

Control

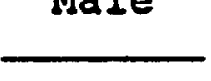

Female

Meaning

Initiation

Importance

Value Congruency

Self Identity

Enjoyment

$$
\begin{aligned}
& .28 \star \\
& .39 \star \star \\
& .34 \star \star \\
& .36 \star * \\
& .30 \star
\end{aligned}
$$

$.31 *$

$.39 * *$

.14

.26 औ

.24

$$
\begin{aligned}
& .32 \star \\
& .30 \star \\
& .30 \star \\
& .25 \star \\
& .34 \star *
\end{aligned}
$$

$.29 \star$

$.28 \star$

$.37 * *$

$.37 * *$

$.26 *$

\section{stress}

Stress

Difficulty

Challenge

Peer community

Peer Visibility

Peer Importance
$-.24$

$-.07$

.19

$-.10$

$-.01$

.09

\section{Adult Community}

Adult Visibility

Adult Importance
.20

.18

.16

$.32 *$

* p<.05 ** p<.01

Note. 
Table 10

Pearson Product Moment Correlations Between Male and Female Project-system Dimension Ratings and Distress

PPA Dimension

EEEicacY

Absorption

Progress

Outcome

Time Adequacy

Control
Male

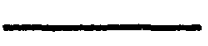

$-.11$

$-.21$

$-.38 * *$

$-.23$

$-.34 \star$
Female

$$
\begin{aligned}
& -.30 * \\
& -.38 * * \\
& -.13 \\
& -.23 \\
& -.16
\end{aligned}
$$

Maaning

$$
\begin{aligned}
& \text { Initiation } \\
& \text { Importance } \\
& \text { Value congruency } \\
& \text { Self Identity } \\
& \text { Enjoyment }
\end{aligned}
$$

$$
\begin{aligned}
& -.30 \star \\
& -.23 \\
& -.23 \\
& -.23 \\
& -.29 *
\end{aligned}
$$

$$
\begin{array}{r}
-.21 \\
-.10
\end{array}
$$$$
-.21
$$$$
-.11
$$$$
-.12
$$

\section{stress}

stress

Difficulty

Challenge
$.35 * *$

$-.11$

$-.10$
$.30 *$

.16

.01

Peer Community
Peer Visibility
$-.02$
$-.11$
Peer Importance
$-.03$
$-.17$

Adult Community

Adult Visibility

.05

.01

$-.21$

$-.17$

* p<.05 ** p<.01

Note.

Male $N=48$

Female $N=46$ 
Life Satisfaction. Within the Efficacy factor for example, the relationships (negative) between absorption and progress and the criterion variable Distress are significant for females but not for males. Conversely, outcome and control have a significant, negative correlation with Distress for males but not for females. Gender differences are also evident in the relationship between Distress and the dimensions associated with the Meaning factor. Specifically. the dimensions of initiation and enjoyment are significantly correlated (negatively) with Distress for males wheras none of the Meaning dimensions are significantly related to Distress for females. The results relating Distress to the dimensions associated with the factors of stress, Peer Community, and Adult Community are similar for males and females however. For both of these groups the relationship between project-system stress and Distress is significant while none of the correlations relating Distrese to the Peer and Adult Community dimensions reach significance.

A comparison of the findings displayed in Tables 9 and 10 reveals that Iife Satisfaction is more consistently and often more substantially related to the project-system dimension ratings than is Distress. However, despite this difference, the results relating these two well-being measures to the project dimensions are in overall accord. Taken together the findings indicate that the project dimensions which make up the Efflcacy and Meaning lactors 
are most strongly related to both Life Satisfaction and Distress for males and females alike. Gender differences in the patterning of results are evidert as well. The Efficacy dimensions of outcome and control for example are significantly related to both Life Satisfaction and Distress for males, but are not related to either of these well-being measures for females. Conversely, the correlation between the Peer Community dimension of peer importance and Life satisfaction is significant for females but not for males.

The Relationship between project Dimension Ratings and Well-Being within Categories

Table 11 displays sumaries of the correlations relating Life Satisfaction to dimension ratings within the Academic, Interpersonal, and Leisure project categories. An overview of this table reveals that there are differences in the number, magnitude, and pattern of significant correlations in the various categories. The Academic category for example is notable with respect to the large number of significant correlations found within the dimensione encompassed by Meaning and Efficacy. Overall, the number and magnitude of these correlations are greater for females than majes.

Relatively few correlations reach significance within the Interpersonal domain. This is true for males and females alike. There are gender differences however in the male and 
Table 11

Significant Pearson Product Moment Correlations Between

Dimension Ratings and Life Satisfaction by Project Category

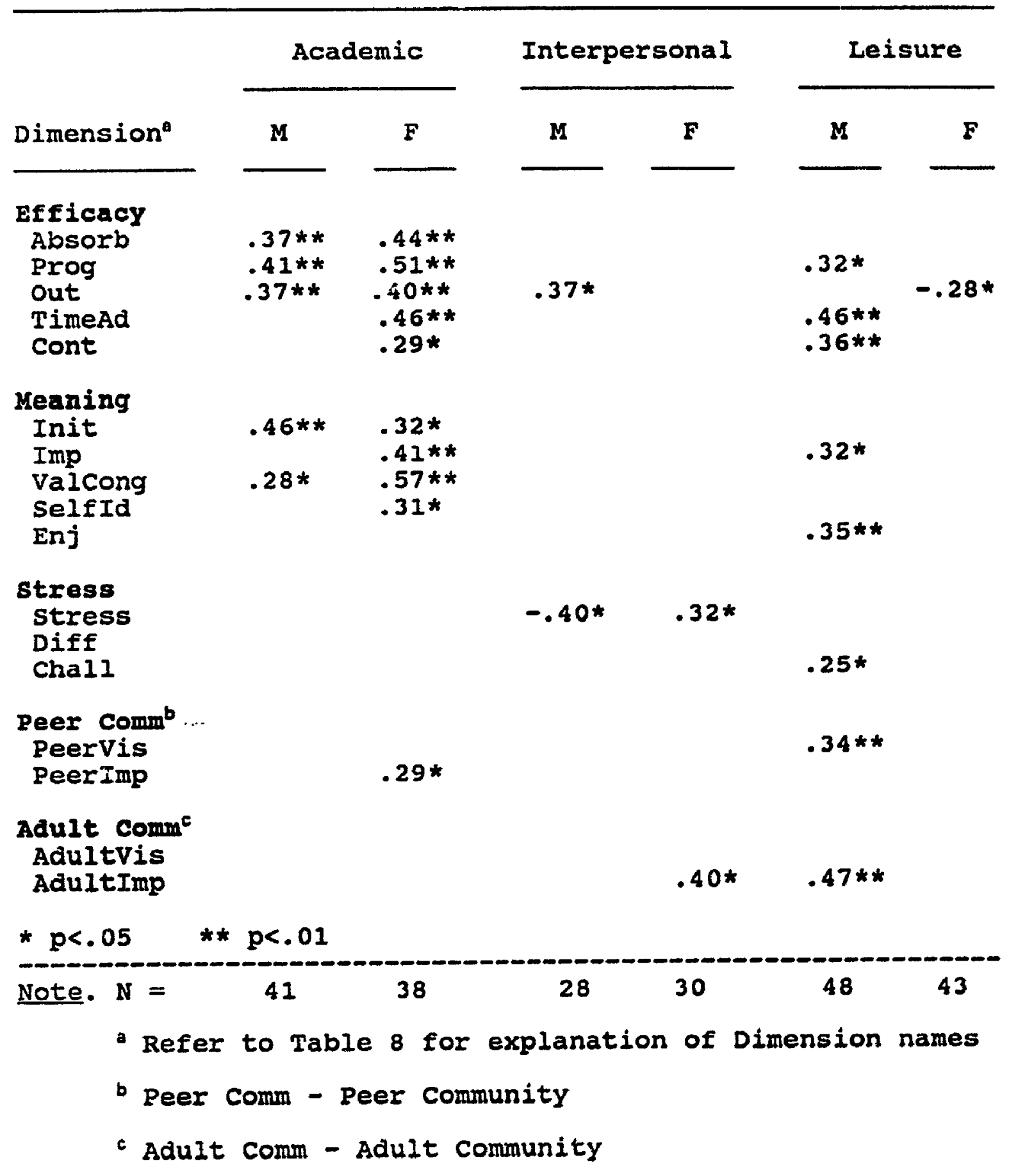


Female Interpersonal results. Male Life Satisfaction for example is significantly correlated with outcome whereas female Life Satisfaction is most strongly related to adult importance. Further, although the stress dimension is significantly related to both male and female Life Satisfaction, the direction of these relationships is different. The relationship between female Interpersonal stress and Iife satisfaction is particularly intriguing as this finding indicates that an increase in Interpersonal stress is associated with increased female Life-Satisfaction. Gender differences are also evident within the Leisure project category. In this dowain the number of significant correlations between the project dimensions and Life Satisfaction is substantially larger for males than females. Further, male Life satisfaction can be seen to be significantly related to at least one of the dimensions associated with each of the project factors. Within the Adult and Peer Community factors for example, adult importance and peer visibility respectively are seen to be related positively to male Life satisfaction. It is interesting to note as well that challenge, one of the Strens dimensions, is also related positively to male Life Satisfaction. Finally, it can be seen that the single significant correlate of female Life Satisfaction is outcome. The valence of this correlation indicates that an expectation of success in Leisure projects is associated 
with lower female Life Satisfaction.

Taken together, the results displayed in Table 11 point to category and gender differences in the relationship between early adolescent activity and Life Satisfaction. Academic project evaluations, for example, are more consistently related to female than male Life satisfaction wheras Leisure project evaluations are more strongly related to male than female Life Satisfaction. Somewhat surprisingly, Interpersonal project evaluations show relatively little relationship to either male or female Life satisfaction.

Table 12 provides a summary of the correlations relating Distress to dimension ratings within the Academic, Interpersonal, and Leisure project categories. Here again the results can be seen to vary across both gendur and project category. Within the Academic domain substantially fewer significant correlations are found in the male results than in the female results. Moreover, although academic project evaluations associated with Efficacy and Meaning emerge as significant correlates of Distress for both males and females, the patterns of significant correlations in the male and female resulis are somewhat different. The Efficacy dimensions of absorption and time adequacy for example are related to Distress for females but not for males. Gender differences are also evident in the relationships between Distress and the dimensions encompassed by the Meaning 
Table 12

Significant Pearson Product Moment Correlations Between

Dimension Ratings and Distress by project Category

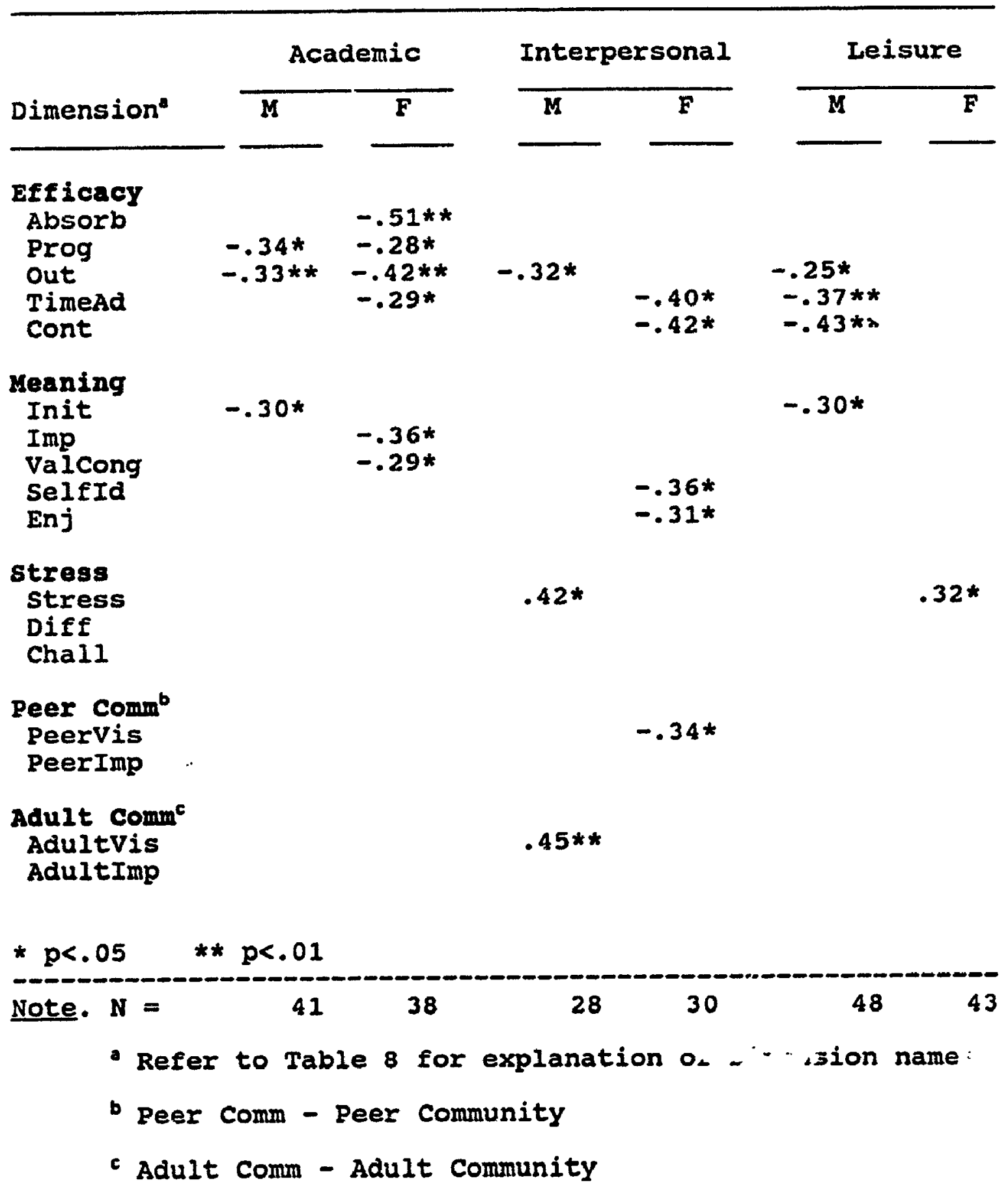


factor. Specifically, academic project initiation is associated (negatively) with male but net female Distress while importance and value congruency dimension ratings of academic projects are negatively related to Distress for females but not for males.

The Interpersonal category results also highlight gender differences in the relationship between project evaluations and early adolescent Distress. An overview of these findings reveals that there is little overlap in the male and female results. The stress dimension for example is related to male though not female Distress. Two Meaning dimensions - self identity and enjoyment - are significantly correlated (negatively) with Distress for females wheras none of the Meaning dimensions are related significantly to male Distress. Within the Efficacy dimensions, interpersonal project evaluations of control and time adequacy are associated (negatively) with female Distress wheras male Distress is related (negatively) to outcome evaluations. Finally, interesting gender differences can be seen within the Peer and Adult Community dimensions. specifically, peer visibility is seen to be negatively related to Distress for females while adult visibility is positively related to Distress for males.

within the Leisure domain a substantially larger number of significant correlatior:s are found in the male results than in the female results. The single significant correlate 
of female Distress is the stress dimension. Male Distress on the other hand is seen to be related (negatively) to three of the Efficacy dimension evaluations (ie. outcome, time adequacy, and control) and to the Meaning dimension, initiation.

In sum, the patterns of intercorrelations revealed in Table 12 suggest that there are category differences in the relationship between early adolescent activity and wellbeing. As was found with Life Satisfaction, the project dimension correlates of Distress also appear to vary as a function of gender.

\section{Summary of the Results}

The results indicate that there are gender differences in the types of activities engaged in by young adolescents, as well as categorical differences in the manner in which evaluations or these activities are related to early adolescent well-being. Although the findings vary across both gender and project category, several recurring themes emerge.

Mirst, Leisure and Academic projects appear to be especially salient to early adolescents. These two types of projects were listed by the greatest percentages of males and females involved in the study and were also most highly represented in the project listings of these two groups. 
Second, the dimensions which make up the Efficacy and Meaning factors are the best overall project-system predictors of early adolescent well-being as well as the most consistent predictors of well-being across the Academic, Interpersonal, and Leisure project categories.

Third, there are gender differences in the extent to which the Personal Project dimension evaluations of academic, interpersonal, and Leisure activities are related to early adolescent well-being. Academic project ratings show the most pervasive IInkage with female well-being and Leisure project ratings show the most pervasive Iinkage with male well-being.

Finally, the dimension correlates of early adolescent well-being vary simultaneously across activity domain and gender.

These findings, as well as others noted in the body of the results section, will be taken up in the discussion that follows. 


\section{Discussion}

What are early adolescents up to? How do they evaluate their activities in terms of such fa tors as efficacy, meaning, stress and community? Finally, how do these evaluations relate to the early adolescent's overall sense of well-being? The findings of this study suggest some answers to these questions.

The results indicate that early adolescent activity is largely focused on academic, interpersonal and leisure concerns, although the actual projects within these broad activity domains is somewhat dependent on gender. Gender effects are also evident in the relationship between subjective well-being and the adolescents' evaluations of their activities. Considered most generally, well-being in early adolescenca is most strongly related to a sense of Efficacy and Meaning in one's activities. Surprisingly, Adult and Peer Community do not show as strong a relationship with well-being as might be expected. This finding may reflect methodological shortcomings in failing to distinguish between the positive and the negative aspects of Community and their relationships with early adolescent well-being. To understand the nature of adolescent activity and the complexity of the relationship between early adolescent activity and well-being, each of these issues will be discussed in turn. 
The Personal Projects of Early Adolescents

\section{Proiect Content}

The findings that $61 \%$ of the total number of projects listed sonsisted of leisure (34\%), academic (15\%), and interpersonal (128) projects, and that the majority of early adolescents sampled listed projects in each of these activity domains is in accord with findings noted in other PPA research with similar aged cohorts (e.g. Franke, 1992; Little, 1987b). Franke (1992), for example, reported that leisuise (30\%), academic (17\%), and interpersonal (14\%) activities made up $61 \%$ of the total number of projects listed by a sample of 71 grade-eight students. The findings of the present study are also comparable to those found in pager studies detailing the amount of time spent on various activities.(e.g., Czikszentmihalyi \& Larson, 1977; Czikszentmihalyi, Larson, Prescott, 1977; Larson * Richards, 1989) Larson and Richards (1989), for example, found that a sample of 201 grade seven and eight students reported spending $65 \%$ of their waking hours pursuing leisure activities (31z), doing schoolwork (228), and socializing (128).

The strong similarities in the patterns of findings reviewed above suggest that Person i Projects are a reliable and valid measure of the content of early adolescent activity. Further, the results of this study indicate that 
leisure activity is a predominant concern of early adolescents.

PPA studies involving older adolescents report that academic, interpersonal, and leisure activities continue to be amongst the most frequently listed projects across the adolescent years (Benton, 1987; Franke, 1992; Lecci, 1991). The relative predominance of these three types of activities appears to change however as the transition is made from early to late adolescence. A longditudinal study investigating changes in the Personal Projects of students going from eighth to ninth grade, for example, reported a 138 drop in the percentage of leisure projects listed (Franke, 1992). The same study reported a 38 increase in the percentage of academic projects and a 58 increase in interpersonal projects over the same time period. University undergraduates have also been shown to list a greater percentage of interpersonal projects $(20 \%)$ and considerably fewer leisure projects (198) than early adolescents (Benton, 1987). Larsen and Richards (1989) similarily report that there is a decline in the percentage of time spent in leisure activity and a corresponding increase in interpersonal focus over the adolescent years.

A comparison of the results of the present study with those reviewed above highlights the distinctive nature of early adolescent activity. Specifically, when compared to older adolescents, early adolescents are seen to be sonewhat 
more preoccupied with leisure activities and relatively uninvolved in interpersonal projects. From this perspective, the Personal Projects of early adolescents may be seen to reflect the various 'life tasks' (Cantor, 1990; Cantor, Norem, Niedenthal, Langston, Brower, 1987; Zirkel \& Cantor, 1990) of this developmental period.

Project content and Gender. The finding that there are no major project category differences in the project listings of boys and girls indicates that the life tasks associated with early adolescent development are similar for these two groups. Gender differences noted in project content across the various sub-categories however, suggest that boys and girls pursue these tasks via different routes. Findings identifying gender differences in project content within two of the project categories investigated in this study provide support for this observation.

Within the Interpersonal project category, a greater proportion of males than females listed Intimate profects. This rinding appears to be at odds with tindings from a number of studies indicating that early adolescent females are more interested and involved in intimate peer relationships than are males (see Berndt, 1982). An examination of the project listings and the reasons given for engagement in another project category - that of Appearance - helps to resolve this apparent contradiction. 
The rationales given for Appearance projects such as "lose weight" and "get rid of my acne" indicate that these activities are often motivated by a desire "to be more attractive, so that boys [or girls] will like me". In contrast, the majority of Intimate projects listed are aimed directly at such issues as "finding a girlfriend for boyfriend] " or "going on dateg". The greater incidence of male Intimate project listings, therefore, may not represent a greater concern with intimacy on their part. Rather, the results may point to gender differences in the manner in which intimacy interests are expressed.

In order to examins the validity of this interpretation of the results, all of the Appearance projects listed were recoded as Interpersonal-Intimate projects. Chi-Square analysis performed on this recoded data revealed that there is no difference in the percentages of males and females who listed 'Intimate + Appearance' projects $[X 2(1, N=74)=$ $0.00, p=1.00 \mathrm{~J}$. This finding helps to confirm the notion that there are gender differences in the manner in which early adolescent intimacy interests are expressed. More specifically, it appears that girls of this age pursue their intimacy interests in a less direct fashion than do boys. Buhrmoster \& Fuhrman (1987) have similarily suggested that differtnces in boys and girls friendships reflect differences in style rather than substance.

Gender differences in profect contant were algo noted 
within the Leisure project category. The finding that a greater proportion of males listed Media-Based projects and that a larger proportion of females listed Hobby/Interest projects appears to reflect gender differences in companionship and supervision. The Media-Based projects consist largely of such activities as "going to see (the movie] 'White Men Can't Jump' ", "playing games at the arcade", and "watching MusicTelevision." These types of activities are most often pursued alone or in the company of friends, without adult supervision (Larson et ai., 1989). Hobby/Interest projects such as "drawing und painting" may also be done alone or with friends, but activities such as "doing well in Pathfinders" and "making it into Chamber Choir" often entail adult accompaniement and supervision. A number of studies have documented a proclivity on the part of parents to grant a greater degree of independence to their adolescent sons than daughters (e.g., Block, 1973; Papini \& Sebby,1988; Simmons and Blyth, 1987! - Gender differences in leisure activities noted in the present study may be related to this phenomenon.

Taken together, the findinge related to gender differences in project content suggest that early adolescent girls are somewhat more restrained than boys in their pursuit of interpersonal and leisure goals. An examination of the differences in the leisure pursuits of this sample of boys and girls indicate that this restraint may derive, at 
least in part, from environmental pressures or constraints.

\section{Dimensionality and Domains of Personal Project Systems}

Although there are gender differences in project content, gender is not a distinguishing variable with respect to the project evaluations. Early adolescent boys and girls describe their project-systems, as well as their academic, interpersonal, and leisure projects, similarly in terms of the Persorial Project dimensions.

\section{Project Factors}

The factor structure of the dimension ratings provides a conceptually coherent and practical framework for discussing the results related to the project evaluations. similar factors emerge in both project-system and categorical analyses and the factors themselves are readily interpretable. The factors of Efficacy, Meaning, Stress, Peer Community, and Adult Community also bear a strong resemblance to those identified in other PPA research (Little, 1988, 1989, 1993). While it is sometimes advantageous to amalgamate the variables that make up a factor into a single measure or score, at other times such an effort can dilute a potentially rich data set. For the purposes of this discussion, the dimension rating factor structure vill be used simply as an organizational device, 
and the data will be considered at the dimension level so as to capture the information specific to each of these dimensions. The advantage of this approach is perhaps best illustrated by a consideration of the dimension ratings that make up the factor of Meaning.

\section{Project Factor Dimension Evaluations}

project Meaning: Personal and social. An interesting pattorn is found within the Meaning dimension evaluations of initiation, importance, ralue congruency, self identity and enjoyment. An examination of these evaluations within the academic and leisure domains reveals that Leisure projects are rated highest on the dimensions of initiation and enjoyment, whereas Academic projects are rated highest in importarice. It appears that different and at timos competing dimensions may serve as a basis for evaluating the meaning of one's activities in early adolescance.

To understand the pattern of these results, it may be helpful to conceptualize meaning as being composed of two separate elements - personal meaning and cocial meaning - as Iittle (1988) has done in previous research. The degree of initiation and enjoyment associated with an activity may be understood to represent its personal meaning. That is, projects which we initiate and enjoy are activities that we feel are personally meaningtul. Leisure projects for 
example are personally meaningful for early adolescents in that they are relatively freely chosen and enjoyable. In contrast, the degree to which an activity is judged to be important may be more of a reflection of its perceived societal significance than of its personal meaning. The developmental literature, for example, stresses the importance of social relationships in early adolescence. Working out social relationships is thought to be a key developmental task at this age (Simmons \& Blyth, 1987). It is somewhat surprising therefore to find that Interpersonal projects are rated lower than Acsdemic projects in importance. This finding may be understood by conceptualizing the importance dimensiun as a measure of social meaning. In this sense, the importance attributed to Academic activities is seen to derive from environmental and cultural values. Academic tasks are important because they are deemed to be so by others.

The finding that Interpersonal projects are rated higher than Academic projects in personal meaning (i.e., initiation and enjoyment) are more in line with everyday observations of early adolescents and may explain early adolescente' prediliction to engage in social activities, often at the expense of more "important" academic pursuits. These results indicate that, at least in the eyes of early adolescents, there is some discrepancy in the degrees of social and personal meaning which are attached to these two 
types of activities.

Taken together, the results related to the Heaning dimension evaluations underscore the salience of the importance dimension, and of the initiation and enjoyment dimensions as thr respective markers of social, and personal meaning. They also suggest that participation in interpersonal and leisure activities at thi- age is related more to evaluations of personal than social meaning, and that involvement in academic activity is more highly related to estimates of social than personal meaning. Reports that conflict between parents and their early adolescont children often centre around these three types of activity (e.g., Smetana, 1989) are likely due to these alfferences in perspective.

Project strese. The stress factor, composed of the dimensions of stress, difflculty, and challenge, reflects the perceived amount of demand that is entailed in a project or set of projects. A similar factor has repeatedly emerged in PRA research with samples of diverse age, background, and gendor (Little, 1988) . Previous PPA research has shown that dimension ratings of stress vary with the type of activity being evaluated (Little, 1987b; Mavis, 1981). For this group, Academic projects are rated highest on the stress dimension and Laisure projects are rated lowest. Interpersonal projects sit clearly in the mid-range 
of these dimension evaluations. Similar findings have been noted in research with older adolescents ( Lecci, 1951; Little, 1987t), although the contrast between the Interpersonal and Leisure project stress ratings of this early adolescent group is somewhat more pronounced than that found with older adolescents. Due to methodological Inconsistencies, it is not possible to determine if the Interpersonal project stress ratings of these two groups of adolescents are significantly different. Relative to their respective sets of leisure activities however, it appears that early adolescents find interpersonal activities more stressful than do older adolescents.

The pattern of the dimension ratings of difficulty is similar to that of the stress ratinge (i.e.. highest for Academic projects, lowest for Leisure projects). The pattern of challenge ratings however is somewhat different. While Loisure projects aro signiflcantly less challenging than Academic projects, Interpersonkil projects are not. Interpersonal projects are rated similarily to Academic profecte on the challenge dimension. This finding reinforces the notion that interpersonal activities are more stressful for younger adolescents than for older adolescents - or at least they regard isterpersonal pursuits as relatively challenging.

The Inding that Interpersonal projects differ from Acadomic projecte in ratings of stress and difficulty, but 
not in ratings of challenge, suggests that the challenge dimension is measuring a somewhat different aspect of the Stress factor than the dimensions of stress and difticulty. Kobasa (1979), in an investigation into the relationship between stressful life events and health in adults has drawn a similax distinction between the concepts of stress and challenge. Apparently, this distinction is also made by early adolescents. The relevence of this distinction will be discussed further when the relationships between the stress dimension evaluations of Leisure projects and early adolescent well-being are examined.

Profect Efficacy. The ratings of the dimensions associated with the Efficacy factor - absorption, progress, outcome, time adequacy, and control - reflect the degree to which individuals feel that they are capable of and focusad on dealing with a project. It is reasonable to assume that these feelings are related to the perceived difflculty of a project, the enjoyment associated with it, and to whether or not one chooses to engage in a specific project. It is not surprising to find, therefore, that Leisure projects (projects rated lowest in difficulty and highest in enjoyment and initiation) are rated highly on all of the Efficacy dimensions.

Several major longditudinal studies have reported that there is a significant decrease in feelings of academic 
efficacy during the early adolescent years (Eccles, Midgley, \& Adler, 1984; Harter, 1981; Simm Jns Blyth, 1987). Given these findings, and this study's lindings that Academic projects are rated highest on the dimension of difficulty and lowest in initiation and enjoyment, it would be expected that this type of activity would be associated with low feelings of efficacy. Contrary to expectations, however,Academic projects are rated similrily to Leisure projects on the Efficacy dimensions. Apparently, for this group, the intermediate school years are not accompanied by excessive feelings of disinterest, discouragement, or helplessness with respect to academic pursuits. Eccles and her collegues (Eccles Midgley, 1989; Eccles et al., 1984; Feldlaufer, Eccles ( Midgley, 1988) have argued that variables such as school size, classroo:n structure, and teachers' expectations can influence early adolescents' achievement-related beliefs. The finding that this study's students reported feeling relatively efficacious with respect to academic pursuits, in spite of perceptions that Academic projects, as compared to Leisure projects, were relatively difficult, unenjoyable, and were felt to be less self-initiated is likely related to characteristics of their school, classrooms, and teachers. The students involved in this study attended a relatively small school (185 students). Although i either classroom nor teacher characteristics were assessed in this study, 
converging evidence from a number of sources indicates that the size of a school's student body is related to both classroom structure and climate as well as teachers and student attitudes (Carnegie Council on Adolescent Development [CCAD], 1989; Feldlaufer et al., 1988; North Carolina State Department of Public Instruction [NCSDPI], 1990; Simmons, Carlton-Ford, \& Blyth, 1987).

As a group these young people feel least efficacious with regards to their interpersonal activities. This is not surprising given the disruption of old (Felner, Ginter, \& Primavera, 1982) and emergence of new peer social networks (Hartup, 1983), an increasing interest in dating (Dornbusch et al., 1981; Gargiulo, Brooks-Gunn, Attle, \& Warren, 1987) and intimacy (Berndt, 1982), transformed relationships with parents (Collins, 1990; HiLI, 1988; Steinberg, 1987, 1988) and teachers (Midgley et al., 1:988; Feldlaufer et al., 1988) and the associated challenges that come to the fore during this transitional period.

\section{Proiect community: Peers and Adults. The community} dimensions cluster into separate adult and peer components. The Adult and Peor Community factors reflect the extent to which individuals perceive that these two groups are aware of and think that their projects are important. The finding that these early adolescents make a distinction between their adult and peer communities is in accord with theory 
and research (Coleman, 1961) indicating that there exists a peer culture for adolescents that is somewhat distinct from that of the adult commurity.

The Iiterature (e.g., Csikszentmihalyi Larson, 1984 ; Larson Richards, 1989), and everyday observations of early adolescents, indicate that individuals spend more of their time with peers than with adults during this developmental period. It is interesting to find therefore, that these young people reel that their activities are more visible and important to adults than to peers. A possible explanation for these finaings may lie in the maks up of the early adolescent's peer and adult communities.

The content of the project Iistings within the interpersonal domsin indicates that the early adolescent peer community is made up of a mixed group of best and close friends, "just friends", classmates, and more distant school aquaintances. In contrast, the Interpersonal profect listings focused on adults are primarily parent oziented. Less than two percent of the adolescents listed projects in the interpersonal domain that involved significant adults other than their parents. From this perspective, aimension ratings associated with the Peer community can be seel to encompass elements that are not contained in those associated with the Adult Community. More specifically, the Peer Community evaluations may be based on perceptiors of a collective paer community that includes a set of less 
intimate others, whereas the Adult Community evaluations appear to be based primarily on perceived views of parents. This potential confound in the Peer Community evaluations will be considered further when the relationship between the Community dimension evaluations and well-being is discussed.

The findings related to dimension ratings of peer and adult importance within the domains of academic, interpersonal, and leisure activities reinforce Coleman's (1961) view that the values of the adolescent peer culture may, at times, be at odds with those of the adult community. This group of adolescents, for example, reports that their peers feel that their Leisure projects are more important than do the adults in their community. Their Academic projects on the other hand are perceived to be more important to adults than peers.

Earlier in this discussion, it was hypothesized that the dimensions of initiation and enjoyment could be thought of as measures of personal meaning, and that the importance dimension could be thought of as a measure of social meaning. Working within the frawework of this hypothesis, it is interesting to compare the pattern of this group's Academic and Leisure project ratings of importance, initiation, and enjoyment to their ratings of percelved adult and peer importance. The pattern of the adult importance ratings, for esrimple, is similar to that of self- 
rated importance. Academic projacts are rated higher than Leisure projects on both of these "importance" dimensions. The pattern of the adult importance ratings contrasts with those of initiation and enjoyment however. Academic projects are rated lower than Leisure projects on these two "personal meaning" dimensions. Finally, the findings related to the peer importance ratings in the Academic and Leisure domains indicate that early adolescents feel that their paers do not make any distinction as to the importance of their Academic and Leisure projects.

The similarities and differences in the patterns of findings reviewed above suggest that perceptions of social meaning are more closely aligned with perceived adult than peer values. Further, these findings suggest that estimates of personal meaning are relatively unaligned with peer values. Coleman (1961) emphasized the predominance of a monolithic peer culture and its powerful influence on adolescent thinking an behaviour. The results of this study call these observations into question and are more in accord with studies highlighting the salience of parents in childron's lives thr sughout the adolescent years (Greenberg, Slegel, Leitch, 1983; Offer, 1969; Rosenberg, 1979; Smith, 1976)."11 
Factor Dimension Profiles of Leisure, Academic and Interpersonal Project Evaluations

Having reviewed the project dimension ratings, it is. now possible to paint a fairly comprehensive picture of early adolescent activity as seen by the early adolescent. Leisure projects, activities listed by the greatest number of individuals involved in this study, are descr'bed as high in personal meaning (i.e., initiation and enjoyment) and low in sockal meaning (i.e., importance). They are felt to be relatively unstressful, and early adolescents report that they feel capable of and are focused on dealing with this type of activity. As is the case with all of their activities, early adolescents feel that significa:s adults in their environment are more aware of their Leisure projects than are their peers. In contrast however, they feel that their Leisure projects are more important to their peers than to adults.

Academic projects, activities rated highest in social meaning and lowest in personal meaning, are described by this study's sample as being relatively stressful and difficult. These early adolescents report however, that they feel as capable and focused in dealing with their Acedemic projects as they are with their Leisure projects. Of the three types of activities investigated, early adolescents feel that adults in their lives perceive Acalemic projects 
as being most important. They also report that Academic projects are amongst the types of activities that adults and peers in their community are most aware.

This study's early adolescent group describes their Interpersonal projects as neither particularly socially meaningful, nor espectally personally meaningtul. They feel that they are less in control of their Interpersonal projects than their Academic and Leisure projects. They also feel there is less likelihood that they will be successfull in their interpersonal pursuits than in their academic or leisure pursuits. Interpersonal activities are considered to be more difficult and stressful than leisure activities, but less so than academic activities. This group reports, however, that Interpersonal projects are as challenging as Academic projects. With regards to others views of these activities, Interpersonal projects are described as being less visible and important to both adults and peers than are Academic or Leisure projects. Finally, these early adolescents report that adults feel that their Interpersonal projects are more important than do their peers, although these two groups are described as being equally aware of these activities. 


\section{Personal Projects and Welt-Being}

In these final sections of the discussion, the relationship between early adolescents' evaluations of their activities and their overall sense of well-being is examined. Generally speaking, the dimensions associated with the Meaning and Efficacy factors show the most substantial and pervasive linkage to early adolescent wellbeing. Both the number and patterns of significant correlations between well-being and the dimension ratings within the Academic, Interpersonal, and Lelsure project categories vary somewhat however. There are also gender differences in the relationship between these category dimension ratings and early adolescent well-being.

An examination of the project-system and categoryspe-Lfic correlational analyees relating well-being to the dimension ratings reveals that the Distress correlations are, in the main, a weak mirror image of the Life Satisfaction results. For the sake of clarity therefore, these sections of the discussion will concentrate on the relationship between the project evaluations and the life Satisfaction component of well-being. Where intriguing and potentially important findings emerge in the Distress results, these findings will be drawn upon to provide a fuller understanding of the manner in which early adolescent activity is related to well-being. 
Project-System Dimension Evaluations ard Well-Being

Project-System Meaning and Well-Being. For both males and females, all of the Meaning dimensions are significantly related to both male and female Life Satisfaction. While signjiricant correlations between these dimensions and Life Satisfaction have been reported in PPA studies with older adolescents and adults, the magnitude of these correlations have generally been considerably lower (see wilson, 1990). The substantial associations of the dimensions of initiation and importance with Iife satisfaction are especially notable in this respect. Wilson (1990) has speculated that the generally low correlations found between these two Meaning dimensions and Iife Satisfaction is due to a screening out, at the PPA elicitation stage, of projects which have little meaning or importance for an individual. Projects that have little meaning are not listed.

The discrepancy between the early adolescent and older groups with respect to tre importance and initiation correlations may be related to the issue of autonomy. Early adolescents, as compared to older groups, are less free to chcose which activities they will pursue. School attendance, for example, is mandated by law for early adolescents. Thus academic projects may be perceived to be socially meaningful (1.e., important) although they are not perisonally meaningful 'i.e., self initiated). Conversely, Leisure 
projects may be self initiated (i.e., personally meaningful) although they are not thought to be deemed by others as important (i.e., socially meaningful). From the early adolescents' perspectives, the personal and social meaning associated with the various activities in which they are engaged varies greatly. Their set of projects is 1088 integrated along the dimensions of importance and initiation than chose of older populations. The slgnificant correlations between these dimensions and Life satisfaction found in this study may reflect early adolescents' vulnerability to inheriting at least some projects that are felt to be soci'ily, but not personally, meaningeul.

An examination of the findings relating Dietress to the dimension evaluations associated with Meaning points to gender differences in the relationship between these variables. Project initiation is significantly related (negatively) to male, though not female Distress. The magnitude of this correlation is larger than those reported in studies with older samples (Howe, 1986; Little, 1988). The significant correlation between initiation and male Life Satisfaction found in this study is Iikely related to the issue of identity development. Expanding on Erikson's (1968) ideas, Marcla (1987) has proposed that adolescents go through repeated cycles of exploration and committment as they seek to develop and refine their sense of self. Within this framework, project initiation may be seen to be a 
measure of exploration reflecting the degree to which individuals are choosing to experiment with various roles and activities. The results of this study suggest that a sense of exploration is more relevent to male than female well-being in early adolescence.

Profect-Sygtem Stregs and Well-Being. This study's finding that project system stress, as reflected in the dimension ratings of stress, difficulty, and challenge is not significantly associated with Life satisfaction differs from findings involving older adolescents and adults (Little, 1988, 1989). Although the effect size in these stucies has shown considerable variation across sample age groups, the stress dimension has been pa:ticularly robust in its relationship (negative) to Life Satisfaction (Wilson, 1990). Differences in these results to those noted in the present study may be attributable to an increased need for stimulation in early adolescence provoked by physical, cognitive, or environmental change. Findings repor'ing an increase in riak taking behaviours involving minor delinquencies (Achenbach Edelbrock,1981; Loeber. 1982), sexual activity (Coles Stokes, 1985; Zelnik Shaw, 1983), and experimentation with drugs and alcohol (Achenbach and Edelbrock, 1981; Loeber, 1982) during the early adolescent years combined with teenagers frequent reports of being "bored" suggest that at least some degree of stress may be 
satisfying for this uge group.

The finding that stress dimension ratings are significantly related to early adolescent Distress is consistent with results obtained with older aged samples (Briscoe, 1992; Collette, 1985; Howe, 1986; Mikelson, 1984). stress has also been related to such variables as oubstance abuse (Newcomb \& Bentler, 1989), depression (Daniels \& Moos, 1990; Tolor Kurphy, 1985), and suicide (Blumenthal Kupfer, 1988; Neiger * Hopkins, 1988) in adolescence.

Taken together, the findinge relating early adolescent well-being to the stress dimension evaluations present an interesting contrast. While the stress associated with an individual's activities may be distressing, it does not appear to be associated with lowered life satisfaction. This issue will be revisited when the relationship between wellbeing and the category-specific project dimension evaluations are discussed.

Project-System Efficacy and fell-Being. All of the projectsystem efficacy dimension ratings are significantly related to either male or female Life satisfaction. The results indicate that, for males and females alike, progress is the best single predictor of early adolescent Iife Satisfaction. This variaole has been shown to be amongst the strongest predictors of we11-being in the bulk of PPA research (Little, 1988). Substantial relationships between similar 
variables and well-being have also been noted in studies utilizing other mothodologies with children, adolescent.i, and adults (Bandura, 1986). A sense of efficacy appears to be as relevent to early adolescent well-being as it is to other age groups.

An examination of the findings relating the projectsystem evaluations to Distress highlights gender differences that are also found in the Life Satisfaction results. The dimensions of outcome art control are significantly correlated with both of these well-being measures for males, but not for females. These findings suggest that a sense of control, and the anticipated outcome of ones activities, is more relevent to male than female well-being. Possible explanations for these two findings will be discussed in turn.

The control dimension closely resembles Rotter's (1966) locus of control. An internal locus of control has been associated with higher levels of life satisfaction and lower levels of depression in studies involving early adolescent boys and girls (Ortman, 1988; siegel and Griffin, 1984). Sevoral PRA studies involving older adolescents have similarily reported that there is a positive relationship between project-system control and we11-being (Benton, 1987; Briscoe, 2992; Lece1, 1991; Palys (Little, 1983). It is not surprising therefore that project-system control is related positively to the well-being of this study's male sample. It 
is unexpected however that this same dimension is not related to the well-being of their female cohort.

Differences between the present and other study findings relating early adolescent's control orientation to well-being may be due to differences in their respecti je methodologies. Whereas ortman (1988) and Siegai and Griffin (1984) based their analyses on a set of prescribed situations and/or realms of activity, the present study based its analysis on a set of perscnally generated items. It may be that methodologies that assume a communality of male and female experience obscure gender differences in the nanner in which con'rol is related to early adolescent welljeing.

The above noted discrepancy betweer, the present and other PPA study findings suggest that project-system control is less related to female well-being in early adolescence than it is in late adolescence. Literature from a variety of sources related to identity, and in particular to sex-role identity development, provides a context for exploring the source of this difference.

It is generally acknowledged that one of the $m 2$, or tasks of adolescence is the development of a coherent sense of identity that includes an awareness of and comfort with one's biological sex (e.g. Erikson, 1950, 1968; Havighurst, 1953). The sex component of a developing individual's identity may be especially salient in early adolexzence as 


$$
\frac{2}{\text { 醀 }}
$$


pubertal changes accentuate the physical differences between boys and girls. These changes are accompanied by changes in relationships with peers and adults that reflect an increased expectation of confcrmance to "appropriate" sextyped behaviour (Block, 1973, 1984; Stoddart Turiel, 1985). Cognitive advances (Piaget, 197/2) and changes in social cognition (Hill \& Palmquist, 1978) make differences between stereotypic male and female roles even more apparent to early adolescents.

Recent studies are consistent in reporting that psychological and behavioural differences between boys and girls intensify as the transition is made from late childhood to early adolescence (Galambos, Almeida, Petersen, 1990; Hill Lynch, 1983; Simmons and Blyth, 1987). There is evidence as well that indicates that young adolescents attach greater importance than younger children to sex-role conformity (Stoddart \& Turiel, 1985), and that sexist attitudes are more common among young adolescents than among older adolescents (Benson \& Vincent, 1980). Considered together these findings suggest that early adolescents are more likely than other age groups to incorporate culturally defined definitions of masculinity and feminity into their sex-role identities.

In an examination of the sources, nature, and consequences of gender differences in self-schamata, Markus Ind Oyserman (1989) suggest that individuals' self- 
definitions are laxgely influenced by their ongoing social experiences. They describe women as having a primarily communal or "connectednes;" self-schema and men as having a primarily egocentric or "separateness" self-schema. They argue that these cognitive schemata influence perceptual processes and thought in specific and systematic ways. Womens' connectedness schemata make them particularly sensitive and responsive to information that involves others. In contrast, mens' separateness $\div$.enata make them particularly sensitive and responsive to information that addresses issues of autonony.

Markus and Oyserman (1989) use this framework to review a variety of findings related to gender differences in cognitive, affective, and social functioning. In doing so they indicate that, rather than gender per se, it is genderrelated socialization experiences such as level of education and work experience that structure self-schemata. They propose that "it is the way men and women are socialized and the way they take meaning from this socialization that contributes to differences in how they make the self/nonselif distinction" (p. 119).

Project-system control, the degree to which ones' projects are felt to be under self versus others control, can be seen to be based on a premise of separateness. To the extent that an individual values such a distinction, he or she may be raid to be exercising a separateness self-schema. 
From this perspective, the present study's finding that project-system control is related to male but not to female well-being indicates that early adolescent boys are more sensitive and responsive than similar age girls to issues of autonomy.

Two complementary explanations are offered for the findings indicating that there are age differences in the extent to which gender is implicated in the relationship between project-system control and well-being. First, the samples used to investigate this relationship in late adolescence may not be representative of tha late-adolescent population. These samples were drawn from a pool of university undergraduates. The socialization experiences of these males and females would likely have been more similar than those of the wider late-adolescent population. There is some evidence indicating that the relationship between (an internal) locus of control and academic achievement is stronger in university students than in other populations (Findley \& cooper, 1983). The finding that project-system control is related to the well-being of both male and female older adolescents may reflect a shared orientation of uriversity students to a separateness self-schema - an orientation thet may not be as common to early adolescent boys and girls.

The second explanation draws on a body of 11 terature that emphasizes the ongoing nature of identity development 
(e.g. Marcia, 1966, 1987; Block, 1973, 1984). Block (1973, 1984) has been particularly articulate in outlining a sequence of sex-role stages that originates in early childhood and continues into the adult years. She felt that the "conformity stage" is especially critical in the acquisition of a sex-role definition, and provided evidence indicating that, as a result of the interaction of a number of biological, social, and cognitive influences, the developmental paths of boys and girls diverge dramatically at this stage. A heightened awareness of, and pressures to conform to stereotypic sex-roles lead girls to suppress their individualistic tendencies and to incorporate more communal attributes into their sex-role identities. The same factors lead boys to supress their communal tendencies and to incorporate more individualistic attributes into their identities.

Although ages were not attached to Block's (1973, 1984) stages, evidence contained in her work suggests that most early adolescents would be at the conformity stage of sexrole development. Gender differences in the relationship between project-system control and well-being noted in the present study's resuits are consistent with Block's (1973, 1984) work indicating that early adolescent boys' sex-role identities include a greater sense of agency and control than do girls'.

In contrast to more traditional theories (e.g., Freud, 
1965/1961a, 1905/1961b), Block (1973, 1984) saw sex-itole development as extending beyond an awareness of conventionally defined male and female attributes and the identification of oneself as being either masculine or feminine (Sedney, 1987). The stages following that of conformity include a more moderated and less stereotypic conception of sex-role identity that allows individuals to integrate attributes traditionally defined as masculine as well as those considered feminine within the self. Block'g (1973) highest, or most integrated level of sex-role development is referred to as "androgenous" - a terr that emphasizes its nonparochial nature.

Block (1973) cautioned against equating personal adjustment with sex-role stage. She suggested instead that sex-role developmental status more accurately reflects attempts to comprehend and deal with issues of parsonal significance. Thus while an awareness of, and conformity to stereotypic sex-roles may be adaptive in early adolescence, a more androgynous conception and endorsement of sex-role identity might be more advantageous in other circumstances. A sex-role identity that includes some degree of separateness, or locus of control orientation for example, might facilitate academic achievement. Differences between the present and other PPA study findinge indicating that project-system control is related to fomale well-being in late, but not early adolescence may reflect difforences in 
the sex-role statuses of the groups studied. In sum, the results of this study highlight the relevance of biological and cognitive growth, as well as self and others' expectations, in the relationship between project-system control and early adolescent well-being.

Findings indicating that there are differences in the relationship between project-system evaluations of outcome and male and female well-being mày reflect gender differences in the desirability of anticipated "future selves". Marcus and her collegues (Marcus Nurius, 1986; Marcus \& Ruvalo, 1989) have pointed out that peoples' self concepts include conceptions of anticipated, hoped for, and dreaded future selves. An individual's pool of possible selves derives from his or her immediate experiences as well as from models, images, and symbols in the environment. The nature of these possible selves can include such descriptors as academic or occupational possibilities, life style possibilities, and possibilities related to interactions with others. Possible selves not only function as incentives for future behaviour, but also provide an evaluative context for ones current self-view.

Individuals' conceptions of their future selves have been shown to be related to both positive and negative affect (Marcus \& Nurius, 1986). Visions of probable future selves heve been particularly strong in this respect, consistently providing additional and often greater 
explanatory power than that provided by present self conceptions. Considered from this perspective, gender differences in the relationship between outcome evaluations and well-being may be seen to reflect parallel differences in the desirability of anticipated future selves. It may be that an anticipation of success in at least some of early adolescent girls' activities is more of a threat than a boost to their well-being. In this sense, gender differences in these results do not reflect differences in the salience of the outcome dinension. They suggest instead, that content differences in the activities of early adolescent girls and boys have implications for their sense of well-being. The location and nature of these differences, as well as their relevence to early adolescent well-being, will be discussed further when the relationship between Leisure frofect evaluations and well-being are examined.

Project-System Community and Well-Being. Separate adult and peer community dimension ratings have not previously been used in PPA research. A direct comparison of the results of this study with those involving other age groups is therefore not possibla. Stuailes using more generaliz d measures of community (1.e., cthers' vlew of importance, visibility to others), however, have reported significant correlations with these measures and the well-baing of older adolescents and adults (Briscoe, 1992; Carver, 1988; 
Little, 1988). This study's finding that a greater sense of community, as reflected in ratings of peer and adult importance, is associated with increased Life Satisfaction is in accord with these findings.

The results indicate that the dimension of peer importance is related to girls', but not to boys' life satisfaction in early adolescence. Similax gender differences in the degree to which peers' views are related to early adolescent well-being have been reported in studies utilizing other methodologies (e.g., Kurdek, 1987). These findings are consistent with Marcus and Oyserman's (1989) contention that females are more sensitive and responsive than males to information that involves others. They are also in accord with Block's (1973, 1984) and others' (Simmons \& blyth, 1987; Stoddart \& Turiel, 1985) work indicating that an awareness of and conformity to stereotypic sex-roles is particularly compelling in early adolescence. Considered together, these observations highlight the influence that early adolescent girls' focus on peere' views may have on their sense of well-being. The present study's findings that Distress is not related to the early adolescents' Peer and Adult Community dimension evaluations contrasts with findings reported in PPA studies involving older aged samples (Briscoe, 1992; Collette, 1985; Little, 1988). These latter studies report that variables reflecting distress (e.g., stress, 
depression) are negatively related to others views of importance and/or visibility to others. Discrepancies noted in these two sets of findings may be due to differences in the natures of the study groups' interactions with their respective communities.

Interactions with the peers and adults may involve a greater degree of stress for young adolescents than is the case with older age groups. Rapid change in cognitive, biological, and social development in early adolescence may be implicated in this difference. The emergence of formal operational thought (Inhelder Piaget, 1958) invites potentially threatening comparisons with peers (Barenboim, 1981). This same phenomenon provokes arguments with parents as early adolescents are struck with seeming inconsistencies in their parents beliefs and behaviours (Smetana, 1988). Physical development interacts with peer pressure encouraging participation in new activities such as dating (Dornbusch et al., 1981; Gargiulo tt al., 1987) - activities that the young adolescent may not yet have the eocial skil1s, or desire, to deal with. Advances in physical maturity also lead to conflict in adolescent-parent interactions (Collins, 1990; Hill, 1988; steinberg, 1987, 1938). Finally, teachers expectations of, and attitudes towards, intermediate school students are less favourable than towards students in 10wer grades (Feldlaufor at al., 1988 ; Nottelman, 1987). 
Social Hindrance, a measure reflecting the presence of negative and potentially hurtful interactions or relationships with respect to one's projects, has been shown to be inversely related to the well-being of university undergraduates (Ruehlman Wolchik, 1988). Early adolescents may be especially vulnerable to these negative aspects of community. Rapid changes in cognitive, physical, and social development may at times raise feelings of distress. Young adolescents do not have as much freedom as older persons to avoid situations or persons that provoke these reactions. They have less choice in selecting their teachers, and in deciding whether or not they will interact with their parents.

Early adolescents may also be more captive than older persons to the negative aspects of the peer community. While they may be less limited in choosing and deciding how much they will interact with friends than with adults, they have less choice in the degree to which they are exposed to the larger peer school-community. Early adolescents are particularly sensitive to this "imaginary audience" (Elkind, 1974). Thus while the relationship between early adolescent well-being and Iriendship may be similar to that of other age groups, being "rejected" or "neglected" (see Parker Acher, 1987) by peers may impact more negatively on well being in early adolescence than at other stages of development. Further evidence that early adolescent 
Community evaluations may include a negative aspect, as well as a positive aspect, will be presented in the discussion of the results relating the category-specific dimension ratings to well-being.

In sum, chis study's findings relating project-system evaluations to early adolescent well-being are perhaps best appreciated by contrasting them with findings from studies involving older populations. Whereas feelings of efficacy are related to the well-being of both of these groups, the relationships between evaluations reflecting the meaning, community, and stress associated with early adolescent activity and well-being are somewhat different from those of older groups. A brief review of these differences serves to highlight the distinctiveness of the early adolescent situation.

Differences in the relationships between well-being and dimension evaluations reflecting social meaning (1.e importance) and community, for example, point to the relative vulnerability of early adolescents; they are less free than older persons to choose the activities that they will pursue and persons with whom they w1ll interact. Differences in the relationship between personal meaning (i.e., initiation) and well-being complement this perspective in accentuating the salience of issues of autonomy in eariy adolescence. Differences in the relationship between well-being and stress evaluations (i.e. 
difficulty, stress, and challenge) suggest that while too much stress may prove overwhelming and lead to feelings of distress in early adolescence, a certain degree of stress may in fact be relatively satisfying at this age. In contrast to older groups, therefore, the nature of the relationship between stress and well-being in early adolescence appears to be less consistent than it is for older persons.

One final set of differences in the findings of this study and those involving older populations is worthy of nots. In a review and synthesis of PPA research on Life Satisfaction, Wilson (1990) concludes "Based on the metaanalytic results of almost the full body of PPA literature it can be said with some certainity that gender differences in the dimensions which contribute to life satisfaction are virtually non-existent" (p. 86). Gender differences in the relationship between the project-system dimension evaluations (i.e., control, outcome, peer importance) and early adolescent life satisfaction found in this study auggeat that wileon's (1990) conclusion may have been premature. Her analysis was based on studies that included relatively few early adolescents and thus may not adequately represent this population's reality. The results of this study indicate that gender plays a role in the relationship between everyday activity and life satisfaction in early adolescence that is not found in studies involving older age 
groups.

Explanations offered for differences noted in this study's project-system results to those involving older samples have largely centered around the distinctive nature of early adolescence. A finer grained examination of, and possible explanations for, these age and gender differences is provided in the discussion of the relatienship between early adolescent well-being and academic, interpersonal, and leisure activities that follows.

Category-Specific Project Dimension Evaluations and hel1Being

Category as we:11 as gender differences are noted in the findings relating early adolescent well-being to dimension evaluations within the Academic, Interpersonal, and Leisure project domains. The results indicate that, at least in terms of the dimensions assessed, Academic project evaluations are more related to female than male well-being, Leisure profect evaluations are related to male well-being, but are virtuaily unrelated to female sell-being, and that Interpersonal project evaluations are relatively unrelated to both male and female well-being. The relationship between these three types of activities and early adolescent wellbeing will be discussed separately and in turn. 
Academic Projects and Well-Being. The number of significant correlations found in the results relating Academic project evaluations to Life satisfaction indicates that academic activity is closely linked to early adolescent well-being. This is not surprising given that school attendance is sompulsory at this age and a significant proportion of the day is opent either in class or doing homework. studies utllizing other met_udclogies have also identified school related activities as a major source of concern fviolato \& Holden, 1987), stress (Greene, 1988; McGuire \& Mitic, 1987), and role strain (Babo, Gilchrist, Elmer, snow, \& Schinke, 1986) for early adolescents.

within the Academic domain, dimension ratings associated with Efficacy and Meaning best predict wellbeing. Academic self-efficacy has consistently been shown to be related to early adolescent well-being (Ehrenberg, cox, \& Koopman, 1991; Harter, 1988; Simmons \& Blyth, 1987). Relatively little research has been conducted, however, investigating the relationship between well-being and tile meaning associated with academic activities. The resultc of this etudy anggest that efforts to investigate the relationship between early adolescents' well-being and their sense of personal and social meaning with respect to academic pursuits would be fruitful.

The numbers of significant correlations found in the female versus male results suggest that academic activity 
is more relevent to female than male well-jeing. Findings contained in this study indicate that evaluations of academic activities on the dimensions of time adequacy, importance, and peer importance are related to female wellbeing, but not to male well-being. A number of studies have similarily reported that early adolescent girls show a greater sensitivity to school issues than do boys of the same age (Bobo et al., 1986; Greene, 1988; McGuire \& Mitic, 1987; Violato Holden, 1987). The results of this study indicate that individual differences in girls responsiveness to school concerns may be related to such issues as the amount of time spent on academic projects, the perceived social meaning of this type of activity, and the extent to which peers feel that academic pursuits are important.

Leisure Projects and Well-Being. Research into the relationship between leisure activity and well-being in adolescence is relatively sparse. Much of it has been c... ried out with older adolescents, and has attempted to link activities such as drinking and drug use activity to negative outcomes such as depression (e.g., Newcomb a Bentler, 1989) and suicide (E.g., Fowler, Rich, \&oung, 1986). As a result, it is difficult to compare this study's Leisure findings to those of earlier studies.

A recent study has investigated the relationship between early adolescent activity and well-belng from a 
different, and perhaps more productive, perspective (Kanner, Feldman, Weinberger, \& Ford, 1987) . This study included a focus on the "uplifts" as well as the "hassles" in early adolescents lives, and their relationship to both positive and negative measures of well-being . Uplifts were defined as events which, when they happened, made individuals "feel good". The results indicate that leisure activities are rated as being amongst the most potent of uplifts in early adolescence. The present study's early adolescent group similarily describes their Leisure projects as relatively enjoyable. The results also indicate that, for both boys and girls, frequency of reported uplifts is related (positively) to perceived self-worth and perceived social competence and (negatively) to depression and distress. Further, stepwise regression analyses revealed that for most of the outcome measures, uplifts added significantly, and sometimes quite substantially, to the variance accounted for by hassles.

It is from this latter perspective that the Leisure results of this study will be discussed. The potential benefits, as opposed to the costs of leisure time activity will be emphasized, and the processes by which well-being may be enhanced, versus diminished will be explored.

The numbers of significant correlations found in the male versus female Leisure results indicate that leisure activity is more closely and consistently linked to boys" than girls' well-being in early adolescence. These results 
also indicate that there is no overlap in the dimensions that are significantly related to the well-being of these two groups. The male and female results will therefore be discussed separately anis in turn.

The results relating dimension evaluations of Leisure projects to male well-being are similar to those found in the male project-system results. Feelings of efficacy with respect to leisure activities as well as perceptions that these activities are personally (i.e., enjoyment) and socially (i.e., importance) meaningful are associated with enhanced Life satisfaction. The finding that the dimension of time adequacy is one of the strongest Leisure correlates of both Life Satisfaction (positively) and Distress (negatively) is in accord with findings reported by Kanner and his associates (Kanner et al., 1987).

The finding that, within the Leisure domain, the dimension of adult importance is the single best predictor of male Iife Satisfaction is intriguing. Project-system estimates of adult importance are only weakly related to male Life Satisfaction and ratings of this same dimension within the Academic and Interpersonal domains are not significantly related to male Life satisfaction. It may be that adults in the male adolescents' community are more willing and capable of providing active psychological and/or material support to their leisure activities than to other types of activity. This interpretation is tempered somewhat 
however by the earlier reported finding that, at least in the eyes of early adolescents, adults consider their ieisure pursuits to be relatively unimportant. An alternative explanation may be that the extent to which adults allow early adolescent boys to independently engage in various lelsure activities reflects a recognition that leisure activities, while not as important as Interpersonal or Academic projects to future well-being, provide some relief from the everyday hassles involved in this transitional period. The finding that Leisure project control is related to both male Life Satisfaction (positively) and Distress (negatively) adds some weight to this latter interpretation: The finding that the dimension of peer visibility in the Leisure domain is positively related to male life Satisfaction is also intriguing given that none of the other Peer Community dimension ratings - neither within the Academic, Interpersonal, and Leisure project categories nor across the project-system - are significantly related to male well-being. The significance of this finding is best considered in the context of the meaning of leisure activities to early adolescenis. This study's group of adolescents describe their Leisure projects as being more personally meaningful (i.e., initiation and enjoyment) than their Academic and Interpersonal projects. It may be argued, therefore, that a recognition by peers that one is involved in leisure activities that are personally meaningful, as 
opposed to those that are are perceived by peers as being important, leads to increased life satisfaction. While neither causality nor the direction of chis relationship can be assumed, such an interpretation highlights the refreshing possibility that adolescents are at times capable of acting without regard to peer pressure. Such a view is consiatent with findings from research into peer and family influence on adolescent thinking and behaviour which report that a significant number of adolescents "abandoned the provided response categories and spontaneously added [comments such as] 'myself' and 'personal opinion' to emphasize Independent choice" (Sebald, 1986, p. 11).

The finding that increased challenge in leisure activities is associated with enhanced Life Satiefaction for boys serves to clarify the nature of the distinction made between the dimensions of stress and challenge by this early adolescent group in describing their Academic, Interpersonal, and Leisure projects. In the first of a series of articles investigating the relationship between stressful life events and health in adults, Kobasa (1979) suggests that the way in which an individual evaluates a stressful life event with which he or she is confronted has implications for their well being. Hore speciflcally, one of her hypotheses states that "Among persons under stress, those who view change as a challenge will remain healthier than those who view it as a threat" (Kobasa, 1979, p. 4). 
She and her colleagues later went on to define challenge as " the belief that change rather than stability is normal in life and that the anticipation of changes are interesting incentives to growth rather than threats to security" (Kobasa, Maddi, \& Kahn ,1982, p. 169).

The dimension evaluations provided by this study's group indicates that leisure activities are not perseived as particularly stressful by early adolescents. Nevertheless, Kobasa's work may have relevence to this study's findings. The positive relationship between challenge evaluations of Leisure projects and male Life Satisfaction may reflect satisfaction found through exploration and growth in leisure pursults. This issue will be revisited ono tinal time following a short discussion of the female Leisure results. In contrast to the male Leisure results where at least one dimension associated with each factor is related to Life Satisfaction, the single significant dimension correlate of femsle Life Satisfaction is that of outcome. Interestingly, the valence of this correlation indicates that an increased expectation of success in Leisure projects is associated with decreased Life satisfaction. The explanation for this counter intuitive finding may lie in the implication that success in this type of activity has for females "possible" future selves. As discussed earlier, early adoleccent girls Leisure activities appear to be somewhat more restricted than those of boys. While the boys and girls involved in 
this study describe their Leisure projects similarily in terms of such limensions as absorption and enfoyment, the results do not provide any indication of whether or not these two groups would be equally pleased to continue such activities in the future. It is possible that while girls are presently content to engage in some leisure-time activities that are monitored and supervised by adults, an anticipation of success in these activities may raise expectations that future leisure activities and life style will be constrained by others. This future self may be evaluated as less than desirable and may provoke immediate feelings of dissatisfaction.

The finding that increased atress in leisure activities is related positively to female Distress is more in line with common sense predictions. The contrast between this finding and the positive relationship between Life Satisfaction and challenge in the male Leisure results discussed above is also of interest here. considered together, these two findings suggest that whereas leisure activities have the potential for providing satisfaction for boys, girls leisure activities are more closely Iinked to distress. This gender difference is likely due to content differences in the boys and girls Leisure projects.

Differences in this study's findinge indicating that leisure activities are capable of providing an "uplift" to early adolescent boys', but not to girls' sense of well- 
being, and those reported by Kanner and his colleagues (Kanner et al., 1987) indicating that leisure activities could be a source of uplift for both boys and girls are likely due to methodological differences. These latter results were based on a common set of items presented to boys and girls alike whereas the present study's findings were based on a set of self generated personal projects. Before leaving the Leisure results, it is worth noting the contrast in the valence of the relationship between female well-being and the stress dimension (negative) and that of male well-being and the challenge dimension (positive). This contrast suggests that the stress entailed in early adolescent activity may best be conceived of as being on a continuum ranging from well-being enhancing developmental challenge, to more demanding situations than can overwhelm coping resources. In Kobasa's (1982) terms, developmental demands may function as "incentives to growth" or as "threats to security". The strength of the relationship between adult importance and male Life Satisfaction in the Leisure domain $(x=.47, p<.01)$, along with the equally strong correlation in this domain between challenge and adult importance $(r=.40, p<.001)$, highlight the contribution "approprlate" adult support can make toward assuring that the demands of the early adolescent transition ore experienced as challenges, as opposed to threats. ${ }^{12}$ 
Intecpersoiji irojects and Well-Being. Theory and research complement anecdotal evidence in suggesting that relationships with others are particularly meaningrul in early adolescence. Developmental theory (e.g., Erikson, 1968; Havighurst, 1953) is well supported by empirical findings indicating that relationships with parents and peers are a source of major concern for this age group (Bibby Posterski, 1985; Compas, Davis, Forsythe, Wagner, 1987; McGuire Mitic, 1987; Violato Holden, 1988). Evidence from a number of sources further indicates that interpersonal activity is related to early adolescent wellbeing (Daniels \& Moos, 1990; Greenberg, Slegel, Laitch, 1982; Kanner et al., 1987). Finally, the early adolescents involved in this study describe their interpersonal activities as being more stressful and difficult than leisure activities, feel less in control of their interpersonal projects than their academic projects and leisure projects, and do not expect to be as successful in their interpersonal pursuits as in their academic and leisure pursuits. Given this evidence, it would be expected that the dimension evaluations of Interpersonal projects would be strongly linked to this sample's well-being. As compared to the Academic and Leisure project category results however, relatively few of the Interpersonal profect evaluations are related to Life satisfaction.

A possible explanation for this finding resides in the 
content of the Interpersonal projects used to invertigate this relationship. The Interpersonal projects used in these analyses contain a broad range of activities focused on a mixed group of parents, friends, siblings and peers. The relationship between well-being and dimension evaluations may be different with respect to these different groups. Enjoyment felt in peer interactions for example may be more (or less) satisfying than enjoyment felt in interactions with parents. Sinilarily, a feeling that one has spent adequate time with parents may ke less satisfying (or distressing) than a feeling that one has spent enough time with peers. Due to sample size restrictions, analyses of the Interpersonal project data was not performed at the subcategory level. The relatively weak pattern of association between well-being and evaluations of interpersonal activity noted in this scudy may reflect this restriction. It should be noted $3 s$ well that this potential cenfound may not only attentuate, but may also provide a distorted view of the relationship between early adolescent Interpersonal projects and well-being.

Despite this shortcoming, several thought provoking findings emerge in the Interpersonal results. First, the counterintuitive finding indicating that increased stress in interpersonal activity is associated with enhanced life satisfaction for young adolescent girls is intriguing. It may be that the relationship is spurious and that both girls 
life satisfaction and their sense of well-being are related to a third variable not identified in this study. Alternatively, it may be that stress engendered by conflict with others is ultimately satisfying for girls in that it signals, or results in a breaking away from existing or traditional expectations. Conversely, girls who feel a positive sense of well-being may be more inclined to act in a manner that challenges others' views of what is "appropriate" female behaviour, and to live with the stress that this challenge engenders. Brown and Gilligan (1992) provide evidence that suggests that the relationship between early adolescent girls well-being ond stress in interpersonal activity is more direct, than spurious.

In an interview-based longitudinal study investigating Semale psychological development, Brown and Gilligan (1992) noticed that girls "voices" change as they make the transition from childhood into adolescence. The younger girls spoke "freely of feeling angry, of fighting or open conflict in relationships, and [took] difference and disagreement for granted in daily life" (Brown \& Gilligar 1992, p. 4). With advancing age and physicas maturity, these same girls became less articulate and spoke in more abstract terms when questioned about conflict in relationships.

Brown and Gilligan (1992) provide evidence indicating that this change in voice reflects adolescent remales' perceptions that they are expected to measure up to socially 
defined notions of femininity - notions that emphasize participation and harmony in relationship. They also provide evidence indicating that these perceptions encourage early adolescent girls to become "female impersonators" (Heilbrun, 1988). Rather than assert their true feelings and risk dissonance and rejection, they mask their feelings and act In accord with others' expectations and beliefs with respect to relationship. Although this strategy minimizes the risk of rejection by others, inconsistencies between what these girls-becoming-women experience and how they act can induce feelings of alienation and stress.

Given a sympathetic audience, many of early adolescents interviewed by Brown and Gilligan (1992) were able to express dissatisfaction with a strategy that involves a devaluation of self. The interview-narratives of these adolescents articulate their struggle to choose, or at least compromise between rejection of self and rejection by others. The present study's finding that increased stress in interpersonal activity is associated with enhanced life satisfaction suggests that early adolescent girls who opt to endure at least some degree of open conflict or stress in relationshipe experience a greater sense of well-being than those who internalize their feelings. 13

Given the previously mentioned confound, it is difficult to tease out or confirm the nature of the relationship between early adolescent girls' Iife 
satisfaction and stress in interpersonal pursuits. This intriguing finding nevertheless raises some interesting questicns which deserve attention in future research.

The findings that, in the Interpersonal domain, control is the highest single dimension correlate (negative) of female Distress and that this same variable is not significantly related to male Distress cast further light on the nature of the gender differences in early adolescent's self schemata. These differences become particularly clear when these findings are compared to those noted in the project-system results - findings which indicate that a sense of control over a broad range of activities is related to boys, but not to girls well-being. In this context, the relevance of interpersonal or social organizational control to early adolescent girls well-being stands out. This perspective complements Brown and Gilligan's (1992) work in highlighting the unique and special situation of early adolescent girls. It should be noted as well that these findings are consistent with Miller's (1986) view that women's greater interest and investment in interpersonal activity emanates from a need to survive in a male dominated society.

Finally, the finding that the dimension of adult visibility is related positively to male Distress raises questions about the nature of the relationship between the adult community and early adolescent we1l-being. While 
causality cannot be assumed, it may be that this finding indicates that adults monitor the interpersonal activities of boys who are distressed. An alternative explanation may lie in Rook's (1984) suggestion that well-being may be negatively affected by an invasion of privacy. In a somewhat different vein, Elkind (1981) has suggested that parents and teachers may be 'hurrying' children along the road to distress as they seek to live out or rationalize their lives through these children. These latter perspectives highlight the potentially disruptive influence that the adult community may have on early adolescent well-being.

Given that all of the other significant correlations in the male and fenale project-system and category results are positively related to well-being, it is tempting to regard adult interest and concern as being a supportive factor in early adolescent davelopment. Such a view does not appear to totally reflect reality however. It seems rather that the relationship between the adult community and early adolescent well-being is more complex, and that the adult community may impact negatively as well as positively on early adolescent well-being. This effect may be particularly evident in activity domains that early adolescents consider to be areas of "personal jurisdiction" (Smetana, 1988).

overall, the category results complement the projectsystem results by providing further insights into the manner 
in which project evaluations are related to well-being in early adolescence. The category results also complement the project-system results by highlighting gender differences in the types of activities that are most relevent to early adolescent well-being. Taken together these results indicate that the relationsip between early adolescent activity and well-being is best understood when the variables of gender and project-category content are taken into consideration. 
Conclusion and Recommendations

One of the major goals of this study was to investigate the utility and value of using Personal Projects Analysis with young adolescents. The results show that this methodology can be profitably used with this population. The vast majority of the young adolescents involved in the study completed the PPA package in less than one hour with no guidance other than that provided in the writted protocol. The profects listed appear to be representative of the activities of early adolescents as measured by other methodologies. Projects such as "build a solar-powered go cart" illustrate that the concept of a personal project is within the grasp of this age group. Projects such as "help my mom clean so we can sell the house in one year, and the reasons given for engaging in them - "to get away from John" - show that PPA is capable of getting at the content of significant events in the lives of early adolescents, as well as the everyday stresses, hassles, and uplifts. These projects also highlight the 'face validity' of the personalized units of analysis that are used in PPA. Together, they provide an intimate picture of the early adolescent experience.

The project evaluations add to this picture and provide valuable information about the early adolescent experience. These descriptions allowed the relationship 
between 17 dimension evaluations of various types of activities and well-being to be investigated. In the majority of cases, the direction of the relationships with well-being and the project evaluations are consistent with theoretical and common sense predictions. It should be noted that while the magnitude of these zero-order correlations are not particularly high, many of them approach or exceed the '.30 barrier' frequently noted by authors in the field of personality reseurch (e.g., Jackson Paunonen, 1980). It should also be mentioned that exploratory analyses performed on this study's data have generated relatively powerful multiple regression equations. ${ }^{14}$ In sum PPA is a useful and valuable tool that can be used to investigate a wide variety of affective, cognitive and behavioural issues related to early adolescent functioning.

While the majority of this study's correlational findings were in the expected direction, a number of findings contained in the results suggest that modifications to the PPA package might provide further insights into the relationship between early adolescent activity and wellbeing. It might be revealing for example to divide the Community dimensions into more distinct components. The Peer community dimensions could be broken down into best friends, friends, and classmates in order to separately assess the salience and impact of these diverse groups. Similarily, the Adult Community dimensions could focus separately on 
parents and teachers. In addition, distinguishing between peer and adult 'support' and 'hindrance' might provide an even more powerful framework within which to explore the dynamics of the early adolescent community.

Depending on the research objective, modifications to the elicitation protocol might also prove enlightening. This study's examination of the relationship between Interpersonal project evaluations and well-being was limited by a paucity of data. The Leisure results also raised some interesting questions that could have been more thoroughly explored with a larger data set. It might be useful therefore to prime for a specific type of project when it is anticlpated that there will be insufficient $N$ to aliow for detailed analyses of activity area of particular interest.

The results of this study suggest that the use of open columns is not beyond the capacity of young adolescents.This study's use of a "why?" column allowed the categorization system to be more precise than it would otherwise have been. It also provided valuable information that facilitared posthoc inquiry into the nuances of early adolescent activity. It might be interesting to add a 'how?' column in order to confirm and/or expand on the notion that there are gender differences in the manner in which early adolescents pursue a common set of lifis tasks. The modularity of PPA methodology allows such modifications and additions to be made in order to answer specteic research questions. 
It would be premature to make extensive and sweeping recommendations based on the results of this single exploratory study. The results however are consistent with a body of literature that reports that the early adolescent years are a period of significant distress for many individuals (e.g. Simmons \& Blyth, 1987). Several studies have further reported that feelings of distress frequently increase in early adolescence (Siddique D'Arcy, 1984; Ehrenberg, Cox, \& Raymond, 1990; Rutter, 1986) and that these feelings can have dramatic short and long term consequences (Rutter, Izard, \& Read, 1986). Perhape as a consequence, the early adolescent years, once described as "the forgotten years" (Lipsitz, 1977) are now more often described in such terms as "the quick-silver years" (Bonson, Williams, Johnson, 1987)) and "the last best chance" (NCSDPI, 1990). Times of change and crisis are often the most opportune times for intervention - possible "turning points" (CCAD, 1989). It would be unfortunate therefore if the major implications of this study were overlooked.

In a thought provoking article, sommer (1973) suggests that studies aimed at documenting peoples' perceptions about the quality of their lives may be equally if not more valuable than those which attempt to link these perceptions to more distal criteria. The results of this study indicate that an examination of the content of early adolescents' personal projects, and their evaluations of the meaning, 
stress, efficacy, and community associated with these activities provides a fairly comprehensive p:cture of the early adolescent experience. This picture - a picture drawn from the early adolescent perspective - is comparable to, but different than those depicted by other methodologies and persons. The results are also quite clear in showing that academic and interpersonal activities are relatively difficult and can be stressful for early adolescents, and that leisure activities are not only enjoyable, but also have the potential to moderate the daily demands of the early adolescent transition. Finally, gender differences in project content, and in the relationship between project evaluations and well-being indicate that there are subtle and meaningful differences in the experiences and perspectives of early adolescent boys and girls. Future studies should capitalize on the modular approach inherent in Parsonal Project methodology in order to further focus on and address these realities. 
Footnotes

1. A McQuitty Linkage Analysis involves identifying the correlation of the greatest absolute magnitude in each column of a full correlation matrix. The overall highest correlation is taken as the central pair of the first cluster. All other Identified high correlations which fall within the rows of the central pair are then linked to the variable in whose row it is found. These variables are removed from the matrix and the process is repeated until all variables have been used.

2. The use of multivariate techniques and unequal group sizes within or between categories necessitated a careful examination of the data with respect to its appropriatenese for analysis. The statistical Package for the social Sciences - Version 5.0 was used in the following, and all subsequent, analyses.

Prior to analysis eight cases with missing values in one or more of the project or well-being variables were deleted. Univariate outliers were Identified within each group as those individuals having a standardized score are any variable larger than the recommended maxtmum of \pm 3 (Tabachnik Fidell, 1983). Individuals within each group with a Mahalanobis D-squared distance large enough to be significant at the .001 level of signiflcance were 
identified as multivariate outliers. A total of seven cases identifled as univariate or multivariate outliers were deleted leaving 94 cases for analysis. Appendix $J$ provides data on the deleted cases.

Normality, linearity, and homoscedasticity assumptions were assessed within each group for the project and well-being variables. An examination of the skew and kurtosis standard scores and the shape of the histogram for the variables, combined with an inspection of scatterplots of all pairs of variables used in the analysis, led to the decision not to transform any of the scores.

Box's y test was performed to assess the homogeneity of the variance-covariance matrices of the identified groups and of the major activity categories investigated. The test of equality of the group variance-covariance matrices did not reach significance $(2<.001)$. The test of equality of the category variance-covariance matrices was significant however (p>.001). In these analyses Pillais Trace criterion instead of wilkes Lambda was used to evaluate multivariate significance (Olson, 1979).

Finally, in order to minimize problems of multicollinerity and singularity due to the low $\mathrm{N}$ to variable ratio, stepwise regression analysis was used in which a tolerance test was performed before each variable was entered. 
3. It should be noted that although analyses examining gender differences in well-being scores were not significant (p>.05), the multivariate test of significance of the nine well-being measures included in the present otudy, as well as that of the Iife Satisfaction and Distress composites approached significance $(\mathrm{g}<.10)$. The means and standard deviations of the male and female scores on the nine wellbeing measures included in the present study are presented in Appendix $\mathrm{K}$. These figures are accompanied by the results of a series of ANOVAs investigating the significance of gender differences in these scores.

A review of Appendix $K$ reveals that three of these univariate tests are significant, and that in all three of these cases the results point to greater male, than fomale, well-being. Of particular interest is the finding that the female CESD-C score is higher then that of the males'. This finding is consistent with a body of literature indicating that early adolescent and older females are more distresend (i.e. depressed) than their male cohorts (Angold, 1988; Canadian Psychiatric Association, 1993; Siddique a Drcy, 1984; Nolan-Hoeksema, 1990), as well as with literature ouggesting that differences between older males and fomales we11-being originate in early adolescence (Aligood-Herten Lewinson, 1990; Nolen-Hoeksema, 1990; Fotersen, Sarigian1, Kennedy, 1991; Rutter, 1986). 
4. The PSS scores were weighted to account for scale differences in the two Distress measures. This was accomplished by dividing each individual's PSs score by 56 and then multiplying it by 60 . As a result, each Individual's Distress composite score is made up equally of their respective PSS and CES-DC component scores.

5. The decision to proceed with Life Satisfaction and Distress composite scores was guided as well by a principal components (varimax rotation) analysis of the well-being measur scores. A two factor solution emerged in this analysis that wis similar to but not as coherent as that provided by the linkage analysis.

6. Modifications to Lecci's (1991) schema included the creation of new broad categories (e.g APPEARANCE), the disaggregation of subcategories into smaller units (e.g. ACADEMIC-Short Term and ACADEMIC-Long Term), and the inclusion of examples thought to be relevent to early adolescent concerne (e.g. get rid of my acne). Instructions to coders as to the appropriate use of the information provided in response to the 'Why?' question were also insluded, along with default guidelines that were to be used when there was insufficient information available to allow for a definitive classification of projects that could be classified into more than one category or subcategory. 
7. Chi-Square analysis requires that fewer than twenty percent of the cells have an expected frequency of less than five and that no cell has an expected frequency of less than one. In order to meet these requirements, some of the subcategories within three of the broad categories were combined for these analyses. Specifically, within the Interpersonal project category, the other significant Adults subcategory was combined with that of Community Supportive; within the Intrapersonal project category, the Coping/Adjustment subcategory was combined with that of Meta; and within the Leisure project category, the Drinkink/Drugs subcategory was combined with that of Food and the Phone/Letter Writing subcategory was combined with that of Getting out/Away.

8. Previous PPA research studies have sometimes focused on the percentages of the total number of projects liated within various activity domains as opposed to the percentages of individuals who listed projects within activity domains. In order to facilitate comparison with these studies, Appendix N displays the percent ages of the total number of projects listed within each of the broad categories. Separate male and female as well as the combined group percentages are presented. 
9. Appendix $P$ presents the combined male and female project-system, male project-system, and female projectsystem dimension rating intercorrelations, as well as the combined male and female Academic, Interpersonal, and Leisure profect rating intercorrelations from which the linkage analyses presentæd in Appendix 0 were derived.

10. Females rated adult importance within the Leisure project category $(Y=5.50)$ more highly than did males $(Y=$ 4.15), $E(1,89)=6.21,2=.015$.

11. Sebald (1986) provides evidence indicating that adolescents' orientations towards adults and peers fluctuated substantially over the years 1963 through 1982. Colemans (1961) findings therefore may not be in conflict with the results of the present and other studies (e.g., Greenberg, siegel, Leitch, 1983) investigating the influence of the the adult and peer communities on adolescent functioning. Sebald attributes fluctuations in the relative influence of these two groups to larger sociocultural changes on North American society over the $1960^{\prime} \mathrm{s}, 70^{\prime} \mathrm{s}$, and $80^{\prime} \mathrm{s}$. Sebald's analysis 1..ghlights the importance of recognizing the role that larger ecosystems (e.g., exo-system and macro-systemj play in the relationship between children's development and their more immediate communities (see Brofenbrenner, 1977; Little Ryan, 1979; 
see Tietjen, 1989).

12. While much of the research examining the correlates of such leisure-time activities as drug or alcohol use and sexual experimentation stresses the negative impact (e.g., addiction and teenage pregnancy that such behaviours may have on adolescent development(see Mccord, 1990; M11lstein \& Litt, 1990), another body of 1iterature (e.g., Marcia,1987; Mitchel1, 1992) suggests that some degree of sexual and substance experimentation in adolescence is associated with healthy identity achievement - Together, these perspectives suggest that, while risk taking behaviour may prove to be pathogenic, it cannot be assumed to be pathological. Such a view of the relationship between risk taking behaviour and well-being, as it pertains to early adolescents, should bo complemented by the works of Elkind (1967, 1974) and Baumrind (1968, 1978, 1987).

Elkind (1974) has pointed out that an increasing capacity and proclivity to conceptualize and reason about ones own and others' thoughts in early adolescence results in an overdifferentiation of feelings and perception of the self as epecial and unique. Elkind (1974) refere to this phenomenon as "personal fable, a story which he [the adolescent] tells himself and which is not truen(p. 93) . An early adolescent's personal fable may include wuch concept: as "I will never get addicted", "Pregnancy will never happen 
to me", and "I couldn't get AIDS. Engagement in potentially harmful behaviours by early adolescents whose functioning is guided by such illusions of invulnerability is likely more hazardous than it would be for older adsiescents who have a more realistic conception of their uniqueness.

Baumrind (1987) counsels that appropriate child-rearing practicea can provide a framework within which early adolescent.. healthy search for identity through potentially harmful experimentation may lead to enhanced well-being. She describes "authoritative" parents as those who are open to negotieting standards and limits with, as opposed to merely imposing their values on, their children. Authoritative parents are more likely to use reason and example than "authoritarian-restrictive" or "punitive" measures when dealing with their children. In contrast to authoritarian or punitive parenting styles which may incite open or more covert rebellion, authoritative parenting minimizes the threatening aspects of identity-experimentation by capitalizing on early adolescents' new found ability and sporadic enthusiasm for discussion and dispute. By being open and receptive to dialogue, authoritative parents are in a position to provide support that maximizes the possibility that their children's early adolescent experiences will be dovelopmentally challenging without proving to be overly stressful. 
13. It is interesting to note that while early adolescent girls who mask or deny their feelings may present an "appearance" of well-being, those who experience open conflict with others might in fact be more psychologically vital. Kuch of the literature aimed at understanding and enhancing adolescent well-being highlights gender di:ferences in the way in which adolescents express distress. This literature suggests that females are prone to internalize feelings of distress wheras males are more prone to externalize expressions of distress. It is ironic to think that efforts aimed at enhancing adolescent well-being may inadvertently be making it more difficult for girls to deal with the early adolescent transition. Literature suggesting that females who internalize feelings of distress are more "normal" than those who externalize their feelings may be perpetuating an unacceptable status-quo. The results of the present study indicating that stress in relationships is related positively to early adolescent girls life satisfaction suggest that what is normal, average, or expected behaviour does not necessarily lead to enhanced well-being.

14. Appendix $Q$ provides a summary, broken down by gender, of the results of a series of analyses regressing life Satisfaction and Distress on the project-system and category-specific dimension evaluations. For the most part, 
these finciings reinforce those noted in the correlational analyses. An overview for example reveals that early adolescent well-being is best predicted when the variables of gender and project-category are taken into consideration. The regression analyses also highlight gender differences in the degree to which academic, leisure, and interpersonal activities are related to early-adolescent well-being. Academic project evaluations account for a greater proportion of variance in female than male Life satisfaction and Distress wheras Leisure project evaluations account for a greater proportion of male than female Life Satisfaction and Distress. Interestingly, although Interpersonal profect evaluations predict relatively little of either male or female Life Satisfaction, four dimensions explain a highly significant ( $2<.0001) 58 \%$ of of the variance in male Distress. While this finding contrasts with those noted in the corresponding correlational results, the valence of the Beta weights in the regression equation reinforces the notion that the adult community may impact negatively, as well as positively, on early adolescent well-being. 
References

Achenbach, T.M., Edelbrock, C.S. (1981). Behavioral problems and competencies reported by parents of normal and disturbed children aged four through sixteen. Yonographs of the Society for Research in Child Development, 46, (1, Serial No, 188). Allgood-Merten, B., Lewinsohn, P.K., Hops, H. (1990). Sex differences and adolescent depression. Journal of Abnormal Psychology, 44(1), 55-63.

Angold, A. (1988). Childhood and adolescent depression: 1. Epidemiological and aetiological aspects. British Journal of Psychiatry, 152, 601-617.

Baltes, P.B., Reese, H.W., \& Lipsitt, L.P. (1980). Lifespan developmental psychology. Annual Reytew of Psychology, 31, 65-110.

Bandura, A. (1986). Social foundations of thought and action: A social cognitive theory, Englewood Cliffs, NJ: Prentice Hall.

Bareriboim, C. (1981). The development of person perception in childhood and adolescent: From behaviorsl comparisons to psychological comparisons. Child Development, 52, 129-144. Baumrind, D. (1968). Authoritarian versus authoritative parental control. Adolegeence, 3 (2), 255-272. 
Baumrind, D. (1978). Parental disciplinary patterns and social competence in children. Youth and society, $9(3)$, $239-276$.

Baumrind, D. (1987). A developmental perspective on adolescent risk taking in contemporary America. In C. E. Irwin, Jr. (Ed.). Adolescent social behaviour and health: New directions for child development, no. 37 (pp.93-125) . San Francisco: Jossey-Bass.

Benson, P.I., Vincent, S.M. (1980). Development and valication of the Sexist Attitudes Toward Fomen Scale (SATws) - Psychology of Momen Quarterly, 5, 276-291.

Benson, P.L., Williams, D.I., \& Johnson, A.L. (1987). The onicksilver years: The hopes and fears of early adoleseence. San Francieco: Harper and Row. Benton, N. (1987). An investigation of the catecorization of personal projects. Unpublished bachelor's thesis, Carleton University, ottawa.

Berndt, T.J. (1982). The features and effects of friendship In early adolescence. Child Development, 53, 14471460.

Bibby, R.W., Posterski, D.C. (1985). The emerging onneration: A' inside 10ok at canada's teenacers. Toronto: Irwin.

Block, J.H. (1973) . Conceptions of sex role. Some crosscultural and longitudinal perspectives. American Peychologtat, 28, 512-526. 
Block, J.H. (1984). Sex role ldentity and ego development. San Francisco: Jossey-Bass Publishers.

Blumenthal, S.J., \& Kupfer, D.J. (1988). Overview of early detection and treatment strategies for suicidal behavior in young people. Journal of Youth and Adolescence, 17(1), 1-23.

Bobo, J.K., Gilchrist, L.D., Elmer, J.F., Snow, W.H., \& Schinke, S.P. (1986). Hassles, role stralr and peer relations in young adolescents. Journal of Early Adolescence, $5(4), 339-352$.

Briscoe, S.R. (1992) - Rersonal profects and pacental influence. Unpublished honour's thesis, Carleton University, ottawa.

Brofenbrenner, U. (1977). Toward an experimental ecology of human development. American Pexchelegift, 32, 513-531.

Brown, L.M. (1991). Telling a girl's life: selfauthorization as a form of resistance. Fomen f Therapy. $11(3 / 4), 71-86$

Brown, I.M., Giligan, C. (1992). Keeting at the crossroads: The osychology of women and the dovelopment of girle. Cambridge, Mass: Harvard University Press.

Buhrmester, D. \& Furman, W. (1987). The development of companionship and int1.acy. Child Development, 58, 1101-1113. 
Canadian Psychiatric Association. (1993) - Canadian youth mertal health and illness survey: Facts and figures. Ottawa, Ontario: Canadian Psychiatric Association. Cantor, N. (1990) . From thought to be behavior: "Having" and "doing" in the study of personality and cognition. American Psychologigt, 45, 735-750.

Cantor, N., Kihlstrom, J.F. (1987) Personality and social intelligence. Englewood Cliffs, NJ: Prenctice-Hall. Cantor, N., Norem, J.K., Niedenthal, P.M., Langston, C.A., \& Brower, A.M. (1987) . Life tasks, self-concept ideals, and cognitive strategies in a transition. Journal of Pergonality and Social Psychology, 53(6) , 1178-1191.

Carnegie Council on Adolescent Development. (1989). Turning pointe: Preparing american youth for the 21 st century. Washington, D.C.: Carnegie Corporation.

Carver, L. (1988) - Personal protects system rating scale: The prediction of enotional we11-being. Unpublished honour's thesis, Carleton University, ottawa.

Chamberlain, K. (1988) On the structure of subjective wellbaing. Social Indicators Research, 20, 581-604. Chatterfee, J. (1981). Personal profect correlateg of life sat lsfaction in Bangladesh and canada: A social ecologtcal analysis. Unpublished manuscript, social Ecology Laboratory, Carleton University, ottawa. 
Cohen, J. (1960). A coefficient of agreement for nominal scales. Educational and Psychological Keasurenent, 20, $37-46$.

Cohen, S., Kamarck, T., \& Mermelsteln, R. (1983). A global measure of perceived stress. Iournal of Health and Social Behaviour, 24, 385-396.

Coleman, J.S. (1961) . The adolescent society. New York: Free Press.

Coles, R., stokes, G. (1985). Sex and the american teenager. New York: Harper Colophon Books.

Collette, D. (1985) - Personal projects analysis: An index of individual differences moderating the effects of life stress. Unpublished honour's thesis, carleton University, ottaria.

Collins, W.A. (1988). Research on the transition to adolescence: Continuity in the study of deviopmental processes. In M. Gunnar *.A. Collins (Eds.), Development during the transition to adolesences (pp. 1-15). Hillsdale, HJ: Erlbaum.

Collins, W.A. (1990). Parent-child relationships in the transition to adolescence: Continuity and change in interaction, affect, and cognition. In R. Montemayor, G.R. Adams, and T.P. Gullotta (Eds.), From childhood to adolescence (pp. 85-106). Newbury Park, Cal1fornia: SAGE Publications. 
Compas, B.E., Davis, G.E., Forsythe, C.J., Wagner, B.M. (1987). Assessment of major and daily stressful events during adolescence: The adolescent perceived events scale. Journal of consulting and clinical Paychology, $55(4), 534-541$.

Crockett, L., Losoff, M., \& Petersen, A.c. (1984). Perceptions of the peer group and friendship in early adolescence. Journal of Farly Adolescence, $4,155-181$. Csikszentmilhalyi, M., Larson, R., \& Prescott, s. (1977). The ecology of adolescent activity and experience. Iournal of Youth and Adoleseence, 6(3), 281-294. Daniels, D. Moos, R.H. (1990) . Assessing Iife stressors and soctal resources among adolescents: application to depressed youth. Journal of Adolescent Research, $5(3)$, $268-289$.

Devins, G.M., \& Orme, C.M. (1985) - Center for epidemiologic etudies depression scale. In D.J. Keyser R.C. Swoetland (Eds.), Test critiques: Vole?. Kansas city, Mo: Test Corporation of America. Doereler, I.A., Felner, R.D., Rawlinson, R.T., Raley, P., \& Evans, E. (1988). Depression in children and adolescents: $A$ comparative analysis of the utility and construct validity of two assesement measures. Journal of consulting and clinical peychology, 56(5), 769-772. 
Dornbusch, S.K., Merrill, J., Gross, R.T., Martin, J.A., Jennings, D., Rosenberg, A., \& Duke, P. (1981). Comparison of biological and social influences upon one set of behaviors. Child Development, 52, 179-185.

Dornbusch, S.M., Carlsmith, J.M., Gross, R.T., Martin, J.A., Jennings, D., Rosenberg, A., Duke, P. (1981). Sexual development, age, and dating: A comparison of biological and social influences upon one set of behaviors. Child Development, 52, 179-185.

Duckett, E., Raffaelli, M., Richards, M.H. (1989). "Taking care": Maintaining the self and the home in early adolescence. Journal of Youth and Adolesennce, 18. 549-565.

Eceles, J.S., \& Midgley, C. (1989). Stage/environment Iit: Developmentally appropriate classrooms for early adolescents. In R.E. Ames C. Ames (Eds.), Berearch on motivation in education (Vol. 3, pp. 139-186). New York: Academic Press.

Eccles, J.S., Midgley, C. (1990). Changes in academic motivation and self-perception during early adolescence. In R. Montemayor, G.R. Adams, T.P. Gullota (Eds.) From childhood to adolesences: A transitional peiciod? (pp. 134-155). Newbury Park, California: Sage. 
Eccles, J., Midgely, C., \& Adler, T. (1984). Grade-related changes in the school environment: effects on achievement motivation. In J.G. Nicholls (Ed.), Advances in kotivation and Achievement. Vol. 3, (283331). JAI Press Inc., Greenwich, Conn. Ehrenberg, M.F., Cox, D.N., K Koopman, R.F. (1990). The prevalence of depression in high school students. Adelescence, 25(100), 905-912.

Ehrenberg, H.F., Cox, D.N., Koopman, R.F. (1991). The relationship between self-efficacy and depression in adolescents. Adelescence, 26(102), 361-374. Elkind, ग. (1957). The hurried child: Growing up too fast 'coo poon. Reading, Mass.: Addison -Wesley. Elkind, D. (1967). Egocentrism in adolescence. Child Development, 38, 1025-1034.

Elkind, D. (1979). Imaginary audience behavior in children and adolescents. Developmental Psychology, 15, 38-44. Grikzon, E. (1968). Identity: Youth and crisis, New York: Norton.

Faulotich, M.E., Carey, K.P., Ruggiero, L., Enyart, P., \& Gresham, F. (1986). Assessment of depression in Childhood and adolescence: An evaluation of the Centre for Epldemiological studies Depression scale for Childron (DES-DC) . American Journal of Paychiatry, $143(8), 1024-1027$ 
Feldaufer, H., Midgley, C., Eccles, J.S. (1988). Student, teacher, and observer perceptions of the classroom ervironment before and after the transition to funior high school. Journal of Farly Adolescence, 8(2), 133156.

Felner, R.D., Ginter, M., \& Primavera, J. (1982). Primary prevention during school transitions: social aupport and environmental structure. Americen Journal of Community Psychelegy, 10, 277-290.

Findley, J.J.. Cooper, H.M. (1983). Locus of control and academic achievement: A literature review. Journal of Rersonality and social Psycholocy, 44(2), 419-427.

Fleiss, Joseph L. (1981).Balanced incomplete block designs for inter-rater reliability studies. Applied Psychological Yeasurement, $5(1), 105-112$.

Franke, T.M. (1992) - current 1ife tapke and rocial problem solving: The transition from middle wahool to hioh school. Unpublished doctoral dissertation, University of wisconsin-Madison.

Freud, S. (1961a). Some psychical consequences of the anatomical distinction between the sexes. In $J$. Strachay, Ed. and Trans. (1961). The ntandard edition of the complete paychological rorks of stomund prand (Vol. 7) (pp. 243-260) . London: Hogarth Prese. (original work published 1905 ). 
Freud, s. (1961b). Three essays on the theory of sexuality. In J. Strachey, Ed. and Trans. (1961). The standard edition of the complete psychological works of sigmund Ereud (Vol. 7) (pp.125-231). London: Hogarth Press. (original work published 1905).

Galambos, N.C., Almeida, D.M., Petersen, A.C. (1990). Masculinity, femininity, and sex role attitudes in early adolescence: Exploring gender intensification. Child Development.

Gargiulo, J., Brooks-Gunn, J., Attie, I., Warren, M.P. (1987). Girla' dating behavior as a function of social context and maturation. Deveiopmental peycholocy. $23(5), 730-737$.

Garrison, C.Z., Addy, C.L., Jackson, K.L., KcKeown, R.E., \& Wa1ler, J.L. (1991). The CES-D as a screen for depression and other psychiatric disorders in adolescents. Journal of the drarican Academy for Child and Adologent Peychiatry, 30(4), 636-641. Garrison, C.Z., Schoenbach, V.J., Kaplan, B.H. (1985). Depregsive eymptome in adolescence. In A. Dean (Ed.), Dopression in multidisciplinary perspective (pp. 6082). Now York: Brunner/Mazel.

George, I.K. (1981) . Subjective well-belng: conceptual and mathodological issues. Annual Review of Gerentolocy and Feriatrice, 2, 345-382. 
Greenberg, M.T., Siegel, J.M., Leitch, C.J. (1983). The nature and importarce of attachment relationships to parents and peers during adolescence. Journal of Youth and Adolescence, $12(5), 373-386$.

Greene, A.L. (1988). Early adolescents' perceptions of stress. Journal of Early Adolescence, 8(4), 391-403. Hamburg, D.A., \& Takanishi, R. (1989). Preparing for 11fe: The critical transition of adolescence. American Psychologist, 44, 825-836.

Harding, S.D. (1982). Psychological well-being in Great Britain: An evaluation of the Bradburn Affect Scale. Personality and Individual Differences, 3, 167-175. Harter, s. (1981). A new self-report scale of intrinsic versus extrinsic orientation in the classroom: Motivational and informational components. Developmental Peycholocy, 17(3), 300-312. Harter, S. (1988). The self-perception proflle for adolescents. Unpublished manuscript. University of Denver.

Harter, s. (1989). Causes, correlates, and the functional role of global self-worth: A life-span perspective. In J. Kolligan \& R. Sternberg (Eds.), Rerception: of competence and incompetance acrose the lite non (pp. 67-98). New Haven, CT: Yale University Press. 
Hartup, พ.พ. (1983). Peer interaction and the behavioral development of the individual shild. In w. Damon (Ed.) Social and personality development: Essays on the growth of the child, pp. 220-233, New York: Norton. Havighurst, R.J. (1953). Human development and education. New York: Longmans Green. Headey, B., Holmstrom, E., \& Wearing, A. (1985). Models of well-being and ill-being. Social Indicators Research, 17. 211-234.

Heilbrun, C.G. (1988). Writing a women's life. NewYork: W.W. Norton.

Hill, J.P. (1988). Adapting to menarche: Familial control and conflict. In M.M. Gunnar (Ed.), 21st Minnesota symposium on child psychology (pp. 43-47). Hillside, NJ: Erlbaum.

Hill, J.P., Lynch, M.E. (1983). The intensification of gender-related role expectations during early sdolescence. In J. Brooks-Gunn and A.C. Petersen (Eds.), Girls at puberty (pp. 201-228). New York: Plenum.

Hill, J.P., Palmquist, w. (1978). Social cognition and sonial relations in early adolescence. International Journal of Behavioral Development. 1, 1-36. Holmes, T.H. Rahe, R.H. (1967). The social readjustment rating scale. Psychosomatic Kedicine 11, 213-218. 
Howe, N. (1986). Depressive affect and personal projects: The role of "Special Projects", Unpublisined honour's thesis, Carleton University, Ottawa.

Huston, A.C., Alvarez, M. (1990). The socialization context of gender-role development in early adolescence. In R. Montemayor, G.R. Adams, and T.P. Gulotta (Eds.), From childhood to adolescence: A transitional period? Newbury Park, CA: Sage.

Inheldex, B., \& Piaget, J. (1958). The growth of legical thinking from childhood to adolescence. New York: Basic Books.

Jackson, D.N., \& Paunonen, S.V. (1980) - Personality structure and assessmeint. Annual Review of Rsychology, 31, 503-551.

Kanner, A.D., Feldman, S.S., Weinberger, D.A., Ford, M.E. (1987). Uplifts, hassles, and adaptational outcomes in early adolescents. Journal of Farly Adolescence, $Z(4)$, 371-394.

Kirshnit, C.E., Ham, M., Richards, M.H. (1989). The sporting life: Athle: c activities during early adolescence. Journal of Youth and Adelescence, 28, 601-615.

Klinger, E. (1977). Keaning and veid: Inner experience and the incentives in people's liveg. Minneapolis: University of Minnes: $:$.. Press. 
Kobasa, S.C. (1979). Stressful life events, personality, and health: an inguiry into hardiness. Journal of Personality and social Psychology, 37(1), 1-11.

Kobasa, S.C., Maddi, S.R., \& Kahn, S. (1982). Hardiness and health: A prospective study. Journal of Personality and Socist Psychology, 42(1), 168-177.

Kurder, L.A. (1987). Gender differences in the psychological symptomatology and coping strategies of young adolescents. Journal of Farly Adolescenve, I(4), 395410.

Largon, I., Kubey, R., \& Colletti, J. (1989) . Changing channels: Early adolescent media choices and shifting investments in family and friends. Journal of Youth and Adolescence, 18, 583-599.

Larson, R. Richards, M.H. (1989). The changing life space of early adolescence. Journal of Youth and Adolescence, $18(6), 501-509$

Lacci, L. (1991). Personality, personal projects, and adaptation to university. Unpublished master's thesis, Carleton University, Ottawa.

Lipsitz, J. (1977). Growing up forgotten: A review of research and programs concerning young adolescents. Lexington, Mass.: D.C. Heath.

Little, B.R. (1983). Personal projects: A rationale and method for investigation. Environment and Behaviour, $15(3), 273-309$ 
Little, B.R. (1987a). Personality and the environment. In D. Stokols \& I. Altman (Eds..). Handbook of environmental psychology. New York: Wiley. Little, B.R. (1987b) - Personal projects and fuzzy selves: Aspects of self-identity in adolescence. In T. Honess \& K. Yardley (Eds.), Self and identity: Perspectives across the life span. London: Routledge Kegon Paul. Little, B.R. (1987c). Personal projects analysis: A new methodology for counselling psychology. Natcom, 13, 591-614.

Little, B.R. (1988) - Personal projects research: Yethod. theory and research. Final Report to Social Sciences and Humanities Research Council of Canada, Ottawa, Canada.

Little, B.R. (1989). Personal projects analysis: Trivial pursuits, magnificent obsessions, and the search for coherence. In D. Buss \& N. Contor (Eds.), Personality psychology: Recent trends and emerging airections (pp. 15-31). New York: Springer-Verlag.

Little, B.R. (1993). Personal projects and the distributed self: aspects of a conative psychology. In $J$. Suls (Ed.) , Psychological Perapectives on the self: yol.4, (pp. 157-186). Hillsdale, NJ: Lawrence ErIbaum Associates. 
Little, B.R., \& Ryan, T.J. (1979). A social ecological model of development. In K. Ishwaren (Ed.), Childhood and adolescence in Canada (pp. 273-301). Toronto: McGraw-Hill Ryerson.

Loaber, R. (1982). Child behavior: A review. Child Development, 53, 1431-1446. Marcia, J.E. (1966). Development and validation of egoidentity status. Journal of Personality and Social Paychology, 3, 551-558.

Marcia, J.E. (1987). The identity status approach to the study of ego identity development. In $T$. Honness \& $K$. Yardley (Eds.), Self and identity: Perspectives across the Lifespan. London: Routledge and Kegan Paul. Markus, H., Nurius, P. (1986). Possible selves. American Psychologist, 41(9), 954-969.

Markus, H., Oyserman, D. (1989). Gender and thought: The role of the self-concept. In $X$. Crawtord and $X$. Gentry (Eds.), Gender and thought: Psychological perspectives, (pp. 100-127). New York: Springer Verlag.

Markus, H., Ruvolo, A. (1989). Possible selves: Personalized representations of goals. In Pervin, L.A. (Bd.). Goal concepes in personality and social paychology, (211-242). Hillsdale, NJ: Lawrence ErIbaum Associates. 
Mavis, B. (1981). Rersonal projects and indicators of change in men at mid-life. Unpublished master's thesis, Carleton University, Ottawa.

Mccord, J. (1990). Problem behaviours. In S.S. Feldman E G.R. Elliot. (Eds.). At the threshold: The developing adolescent (pp. 414-430). Cambridge, Massachusetts: Harvard University Press. McGuire, D.P., \& Mitic, w. (1987). Perceived stress in adolescents: What normal teenagers worry about. Canada's Yental Health, June, 2-5.

Mcquitty, L. (1967). A mutual development of some typological theories and pattern-analytic methods. Journal of Educationel and Pevehological verancement, 27. 21-46.

Michalos, A.C. (1985). Multiple Discrepancies Theory (MDT) . Social Indicators Research, 16, 347-414.

Midgley, C., Feldlaufer, H., Eccles, J.S. (1988). The transition to funior high school: Beliefs of pre- and posttransition teachers. Journal of Youth and dololescence, 27(6), 543-562.

Millstein, S.G., Litt, I.F. (1990). In S.S. Feldman \& G.R. Elliot. (Eds.). At the threshold: The developing adolescent (pp. 414-430). Cambridge, Massachusetts: Harvard University Press. 
Mikelson, W.P. (1984). Personal projects systems and health status. Unpublished master's thesis, Carleton University, Ottawa.

Mitchell, J.J. (1992). Adolescent struggle for selfhood and identity. Calgary: Detselig Enterprises.

Neiger, B.L., \& Hopkins, R.W. (1988). Adolescent suicide: Character traits of high-risic teenagers. Adolescence, $23(90), 469-475$.

Newcomb, K.D., Bentler, P.M. (1989). Substance use and abuse among children and teenagers. American Paycholegiet, 44(2), 242-248.

Nolen-Hoeksema, S. (1990). Sex differences in depression. Stanford, CA: Stanford University Press. North Carolina State Dept. of Public Instruction. (1990). Last best chance: Yiddile grades task force report. Raleigh, N.C.

Nottelmann, E.D. (1987). Competence and self-esteem during transition from childhood to adolescence. Developmental Peychology, 23(3), 441-450.

offer, D. (1985). A portrait of normal adolescents. Amretcen Bducator, $2(2), 34-37$. offor, D. (1969). The peychological world of the teenager, New York: Basic Books.

Oke, L. (1985). A personal projects analysis of depresgion. Unpublished honour's thesis, Carleton University, Ottawa. 
Ortman, P.E. (1988). Adolescents' perceptions of and feelings about control and responsibility in their lives. Adolescence, $23(92)$, Winter 1988, 913-924. Palys, T.S. (1979) - Personal protect systems and perceived life satisfaction. Unpublished doctoral dissertation, Carleton University, ottawa.

Palys, T.S., Little, B.R. (1983). Perceived life satisfaction and the organization of personal project systems. Journal of Personality and social Prycholocy. $44(6), 1221-1230$

Papini, D., E Sebby, R. (1988). Varlations in conflictual family issues by adolescent pubertal status, gender, and family member. Journal of Parly Adolescence, 8, 115.

Parker, J.G., Asher, S.R. (1987). Peer relat1ons and later personal adjustment: Are low accepted chlidren at risk? Peychological Bulletin, 102, 357-389.

Petersen, A.C. (1988) - Adolescent development. Annual Revilew of Psychology, 39, 583-607.

Petersen, A.C., Earigiani, P.A., E Kennedy, R.E. (1991). Adolescent depression: Why more girls? Iournal of Youth and Adolescence, $20(2), 247-271$.

Piaget, J. (1972). Intellectual evolution from adolescence to adulthood. Human Development, 15, 1-12. 
Radloff, I.S. (1977). The CES-D scale: A self-report depression scale for research in the general population. Applied Psychelogical Measurement, 385-401. Raffaell1, M. Duckett, E. (1989). "We were just talking - .": Conversations in early adolescence. Journal of Youth and Adolescence, 18, 567-582.

Richards, M.H.. Larson, R. (1989). The life space and soclalizations of the self: Sex differences in the young adolescent. Journal of Youth and Farly Adolegeence, 18, 617-626.

Roberts, R.E. (1990). Assessment of depression in adolescents using the centre for epidemiologic studies depression scale. Iournal of consulting and clinical Peycholocy, 2(2), 122-128. Roberts, R.E., Lewinsohn, B.K., \& Seeley, J.R. (1991). screening for adolescent depression: A comparison of depression scales. Journal of American Academy for Child and Adolescent Paychiatry, 30(1), 58-66. Rook, K.S. (1984) . The negative side of social interaction: Impact on psychological well-being. Journal of Perronality and Social Peychology, 46, 1097-1108. Rosonberg, H. (1979) . Conceiving the self. New York: Basic. Rotter, J.s. (1966) . Generalized expectancies for internal versus external control of reinforcement. Psychological Yonographe, 80(1). Thole No. 609. 
Ruehlman, L.S., Wolchik, S.A. (1988). Personal goals and interpersonal support and hindrance as ractors in psychological distress and well-being. Journal of Personality and Social Psychology, 55(2), 293-301. Rutter, M. (1986). The developmental psychopathology of depression: Issues and perspectives. In K. Rutter, C. Izard, \&. Read (Eds.), Depression in young people: Developmental and clinical perspectives (pp. 3-30). New York: Guilford.

Rutter, M., Izard, C.E., Read, P.B. (1986). Depression in young people: Developmental and clinical perspectives. New York: Guilford Press.

Sebald, H. (1986). Adolescents' shifting orientation toward parents and peers: A curvilinear trend over recent decades. Journal of Marriage and the Family, 48, 5-13. Sedney, M.A. (1987). Development of androgyny: Parental influences. Psychology of Women Suarterly, 11, 311-326. Siddique, C.M., \& D'Arcy, C. (1984). Adoleszence, strese, and psychological well-being. Journal of Youth and Adolescence, 13(6), 459-473.

Siegel, L.J., Griffin, N.J. (1984). Correlates of depressive symptoms in adolescents. Journal of Youth and Adolescence, $13(6), 475-487$.

Simmons, R.A., Blyth, D.A. (1987). Moving into adolecence: The impact of pubertal change and rchool context. New York: Aldine de Gruyter. 
Simmons, R.G., Carlton-Ford, S.L., Blyth, D.A. (1987).

Predicting how a child will cope with the transition to junior high school. In R.M. Lerner T.T. Foch (Eds.), Biological-psycosocial interactions in early Adolescence (pp. 325-375). Hillsdale, N.J.: Lawrence ExIbaum Associates.

Smetana, J.G. (1988) . Adolescents' and parents' conceptions or parental authority. Child Development, 59, 321-335. Smotana, J.G. (1989) - Adolescents' and parents' reasoning about actual family conflict. Child pevelopment, 60, 1052-1067.

Smith, T.E. (1976). Push versus pull: Intrt.-family versus peer-group variables as poseible determinants of adolescent orientations toward parents. Youth $f$ society, 8, 5-26.

Sommer, R. (1973) . Evaluation, yes; research, maybe. Repregentative Regearch in social peychology, 4,127 133.

steinberg, L. (1987). Impact of puberty on family relations: Befects of pubertal status and pubertal timing. Developmental Psychology, 23(3), 451-460.

steinberg, I. (1988). Reciprocal relation between parentchild distance and pubertal maturation. Developmental Peycholocy, 24(1), 122-128. 
stoddart, T., Turiel, E. (1985) - Children's concepts of cross-gender activities. Child Development, 56, 12411252

Tabachnick, B.G., Fidell, L.S. (1989). Using multivariate statistics. New York: Harper and Row.

Tietjen, A.M. (1989). The ecology of children's social support networks. In D. Belle (Ed.), Chlldren's social networks and social supports (pp.1-69). New York: Wiley. Tolor, A., Murphy, V.K. (1985). Stress and depression in high school students. Psychological Reports, 57, 535541.

Violato, C., Holden, W.B. (1988). A confirmatory factor analysis of a four-factor model of adolescent concerns. Journal of Youth and Adolescence, 17(1), 101-113. Watson, D., Tallegen, A. (1985). Toward a consensual structure of mood. Esychological Bulletin, 98, 219-23. Weissman, H.K., Orvaschel, H., Padian, W. (1980). Children's symptom and social functioning self-report scales: Comparison of mother's and children's reports. The Journal of Nervous and Kental Diesere, 168(12), 736-740.

Wilson, D. (1990). Rersonal project dimensions and perceived iffe satisfaction: a quant itative ountheste. Unpublished master's thesis, Carleton University. ottawa. 
Yard, G.F. (1980) . Persoral project system variables as predictors of job satisfaction and pertormance effectiveness in members of the Royal Canadian younted police. Unpublished master's thesis, Carleton University, ottawa.

Youniss, J., Smollar, J. (1985). Adolescent relations with mothers, fathers, and friends. Chicago: University of Chicago Press.

zelnik, M., Shah, F.K. (1983). First intercourse among young americans. Family planning Perspectiveg, 15(2), $64-70$.

zirkel, S., Cantor, N. (1990). Personal construal of life tasks: Those who struggle for independence. Journal of Rersonality and social Psychology, 58(1), 172-185. 
151

Appendix A

Personal Projects Analysis Package: Elicitation Listing and Rating Matrix 


\section{PERSONAL PROJECTS ANALYSIS}

We are interested in studying the kinds of activities and concerns that people have at different stages of their life. We call these personal projects. All of us have a number of personal projects at any given time that we think about, plan for, carry out, and sometimes (though not alway's) complete.

Here are some examples of projects:

Completing my English essay.

Trying to help Gary get along better with others.

Overcoming fear of meeting new people.

Getting mure outdoor exercise.

Trying to finish the book Allan gave me.

Taking a trip to Ottawa.

Cutting the grass.

Finding a pait-time job.

Redecorating my bedroom.

Trying to clarify my religious beliefs.

Losing ten pounds.

Making a birthday present for my friend.

We are also very interested in finding out how people feel about these personal projects, how enjoyable they are, and so on. We would appreciate it if you could begin by just writing down in the next ten minutes as many personal projects as you can that you are engaged in cr thinking about at the present time-remember these are not necessarily formal projects, or important ones-we would prefer you to give us more of the everyday kinds of activity or concerns that characterize your life at present. 


\section{List of Projects}

Please go ahead and write down as many as you can in ten minutes. 
Now copy the projects in as brief a form as possible on PAGE 5. Just make your description long enough to keep each project clearly in mind. As you can see, there is space for 10 projects. If your initial list contains more than 10 . select the 10 that you are most likely to engage in over the next month or so. If you wrote down fewer than 10, see if you can think of several more, or break down some of thos: you listed into several projects. It is important for everyone to try to fill in 16 . projects.

In columns 1 to 17 please rate each one of your projects using any number from 0 to 10 on the following dimensions. Remem, ar that numbers between 0 and 10 can also be used.

1. Importance: how important each project is to you at the present time (use 10 if the project is very important to you and 0 if it is not at all important to you).

2. Enjoyment: how you enjoy working on each project (use 10 if you enjoy it a great deal and 0 if you do not enjoy it at all).

3. Difficulty: how difficult you find it to carry out each project (use 10 for a project that you find very difficult to carry out and 0 for one that you do not find difficult at all).

4. Visibility: how visible each project is to the relevant people who are close to you, that is how aware are they that you are engaged in this project (use 10 for a project which is very visible to those around you and 0 for a project which is not at all visible to those around you).

5. Control: how much you feel you are in control of each project (use 10 for a project over which you feel in complete control and 0 for a project over which you feel you have no control at all).

6. Initiation: how much you feel responsible for having initiated each project (use 10 if you feel fully responsible for having initiated a project and 0 if you feel you have taken no part whatsoever in initiating a project).

7. Stress: how stressful it is for you to carry out each project (use 10 if a project is very stressful to carry out and 0 if a project is very relaxing to carny out).

8. Time how much you feel that the amount of time you spend adequacy: working on each project is adequate (use 10 if you feel that the amount of time spent on a project is perfectly adequate and 0 if you feel, for one reason or another, that the amount of time you spend working on a project is not at all adequate).

9. Outcome: what you anticipate the outcome of each project to be (use 10 if you think that a project will be extremely successful and 0 if you thin's that a project will turn out to be a total failure).

10. Self-identity: how typical of you each project is (use 10 if a project is very typical of you and 0 if it is not at all typical of you). 
11. Others' view: how important each project is seen to be by relevant people who are close to you (use 10 if a project is seen by others as very important and 0 it it is seen as not important at all).

12. Value to what extent is each project consistent with the values congruency: which guide your life (use 10 if a project is totally consistent with your values and 0 if a project is tolally at odds with them).

13. Positive

how much you feel that each project helps the others. impact:

Don't worry whether it hinders or not, we'll get to that on the next dimension (use 10 to indicate that a project greatly increases your chances of working on other projects and 0 to indicate that a project has no positive effect).

14. Negative impact:

how much you feel that each project hinders other projects (use 10 to indicate that a project seriously hinders your chances of working on other projects and 0 to indicate that it does not have any negative effect).

15. Progress: how successful you have been in a project so far (use 10 to indicate that you have been very successful and 0 to indicate that you have had no success at all).

16. Challenge: to what extent each project is demanding and chalienging to you (use 10 if a project is most challenging and 0 if it is not challenging at all).

17. Absorption: to what extent you become engrossed or deeply involved in a project (use 10 if you generally get absorbed in an activity and 0 if you tend to be uninvolved when doing it).

In column 18, please write down the names of the other people involved in each project with you. You may use only first names, but include the initial of the last name to differentiate people who share the same first name. If there is no one else involved in a project with you, leave the corresponding space blank.

In column 19, please indicate the setting in which you would most likely or most typically carry out each project. Some projects may not be taking place in any particular setting, in which case you would leave the corresponding space blank. 


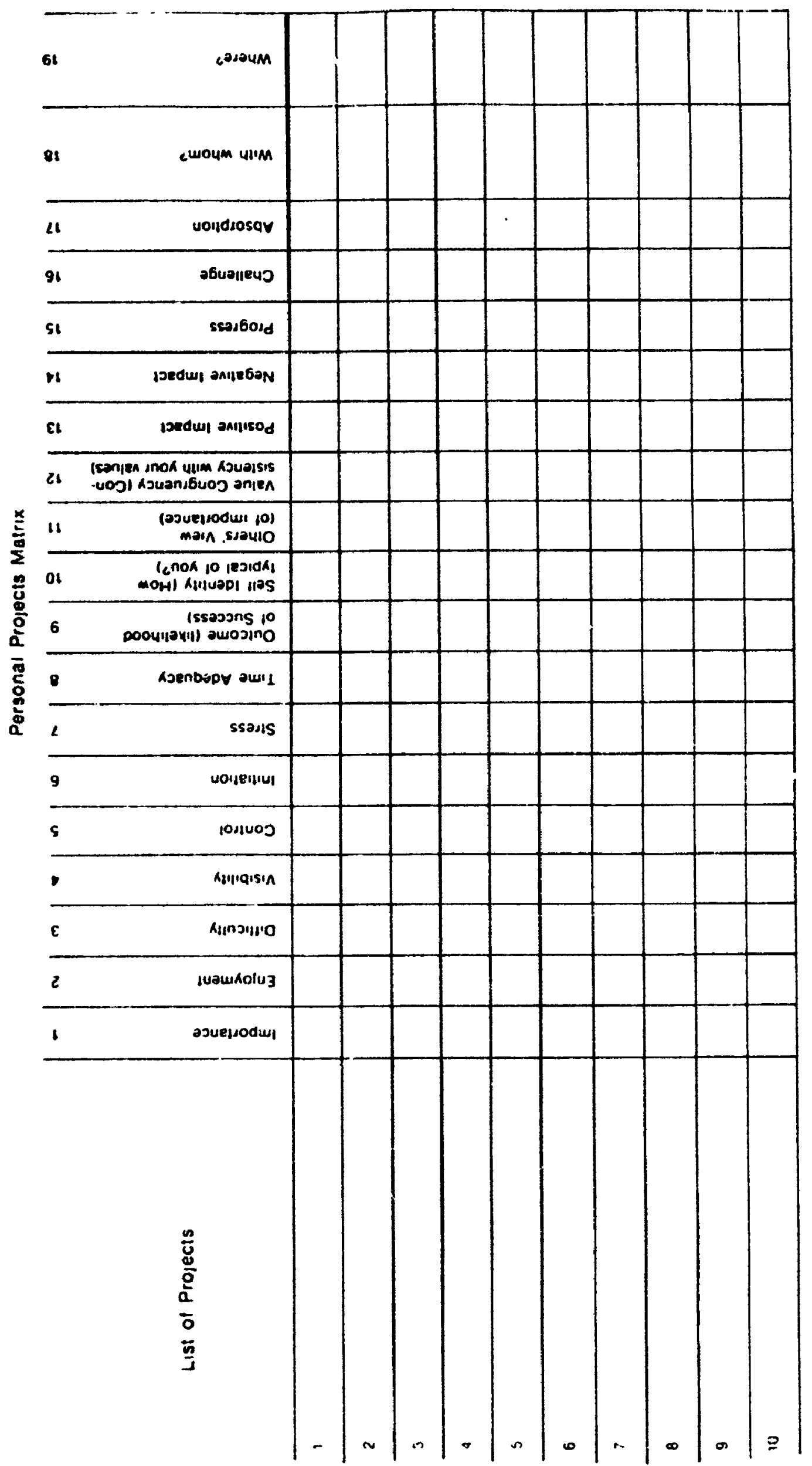




\section{Appendix B}

Study Information Letter and Parental Consent Form 


\section{Carleton University}

Dear Parent:

We are interested in leaming more about the everyday activities and feelings of early adolescents. To this end we have designed a survey that we will be asking approximately 200 grade 7 and grade 8 students to complete.

Our goal is to gain a clearer appreciation of the early adolescent perspective so that we may be better able to help during these difficult transitional years.

This study has been approved by the Advisory Research Committee of the Ottawa Board of Education and the principal of your child's schoul has given permission for his or her school to be involved.

The survey will be conducted in the classroom and will take approximately 60 minutes to complete. Scheduling will be at the convenience of the teacher to minimize interference with daily routine.

Participants names will not be connected to the survey responses and the information collected will be used solely for research purposes.

If you consent, we will ask your child if he or she would like to participate. It should be made clear that your consent does not obligate your child in any way. If he or she does not want to participate, his or her wishes will be respected. Should any participant wish to withdraw at any point after agreeing to participate, he or she may do so without penalty.

Attached is a Parent Consent Form. We have also provided a list of the names and telephone numbers of individuals who will respond to any questions or concerns that you may have (now or in the future) about the methods or content of this survey. consent.

If you are willing to have your child participate in this survey, please complete and sign the attached

Thank you for your consideration.

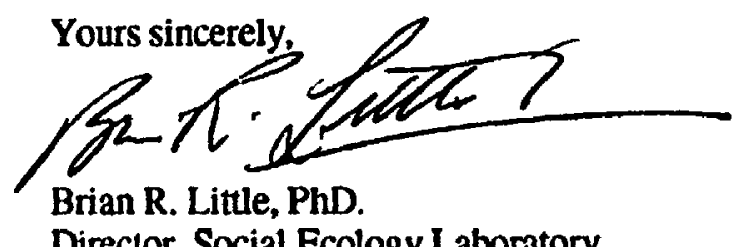

Director, Social Ecology Laboratory

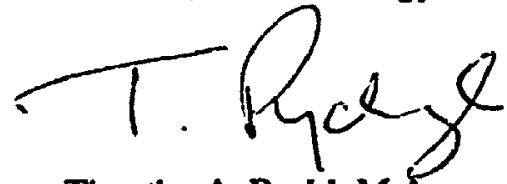

Timothy A. Pychl, M.A.

Division Leader

Summit Alternative School

Ottawa Board of Education

PhD. Candidate

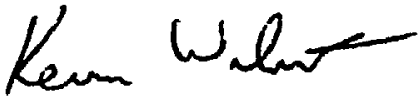

Kevin P. Wilmut

M.A. Cand:date 


\section{Names and Phone Numbers \\ Everyday Activities and Feelings Survey}

Information: If you would like any further information about this exercisc or its findings, please contact:

Kevin Wilmut or

Dr. Brian R. Little

Department of Psychology

Deparment of Psychology

Carleton University

Carleton University

788-2600 Ext. 2697

788-2600 Ext. 2697

Concerns: If you have any concems about the methods or questions used in this exercise, please contact:
Dr. W. Jones
or
Dr. C. Herdman
Chair
Chriti, Ethics Committee
Department of Psychology
De.partment of Psychology
Carleton University
Cirleton University
788-2600 Ext. 2668
788-2600 Ext. 2684

\section{PLEASE RETURN THIS FORM TO YOUR CHILD'S TEACHER AS SOON AS POSSIBLE}

I have read the above request for my child to participate in a survey about early adolescent activities and feelings.

I give permission for my child to participate

I do not give permission for my child to participate

Student's name:

(please print)

Name of parent or guardian:

(please print)

Date:

Signature:

Relationship to child: 
160

Appendix C

Solicitation Poster

(Note: Actual size was 8 1/2" by 11", colour varied.) 


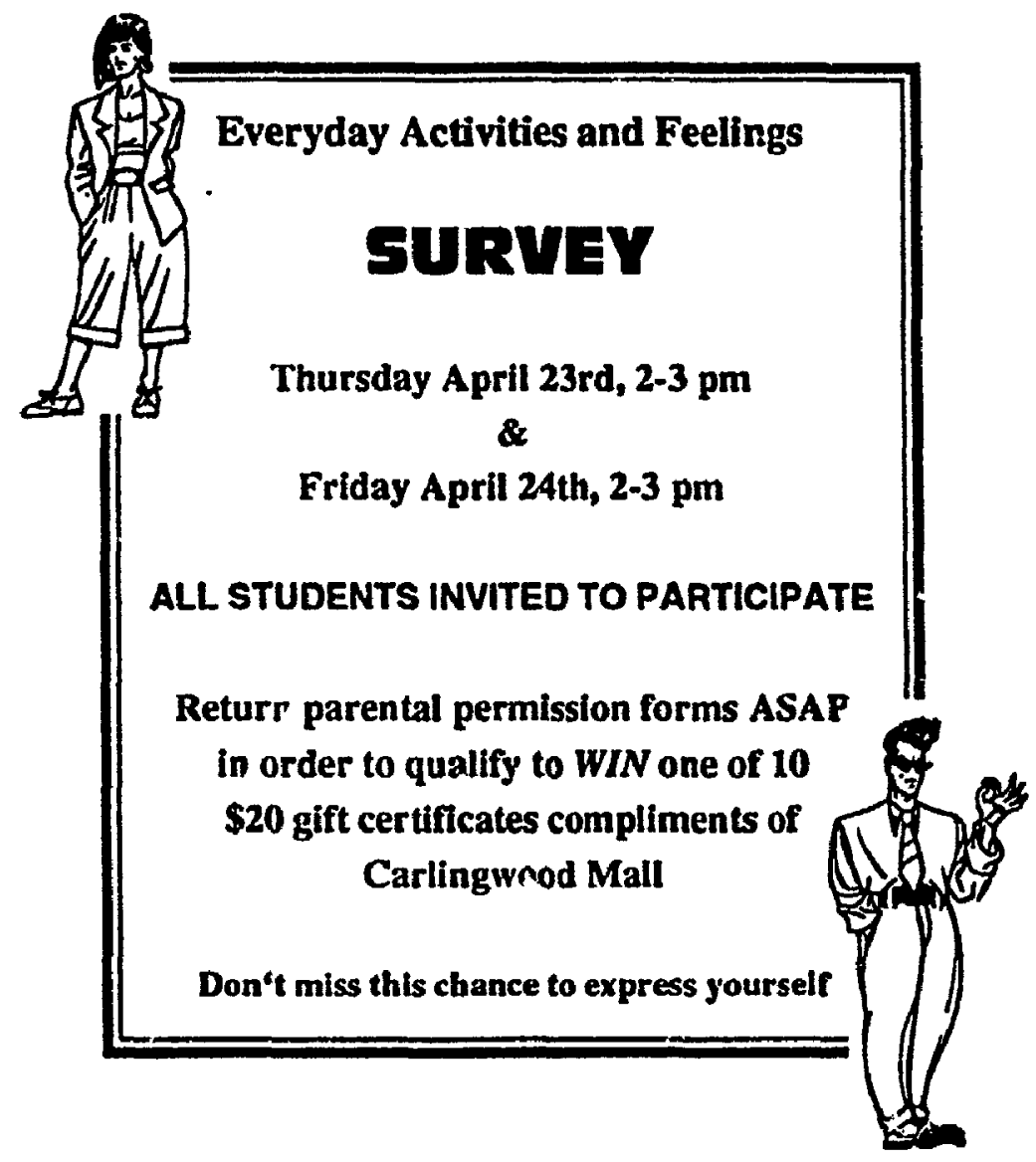


Appendix D

student Information and consent Forms 
This booklet contains a number of questionnaires that are intended to provide information about the everyday activities and feelings of adolescents. Should you agree to participate in this survey, you will be asked to answer a series of questions. The survey will be ccnaucted in the school and will take approximately 1 hour to complete.

It should be made clear from the beginning that this is not a test - there are no right or wrong answers. Although the instructions vary for each questionnaire, all are straight forward. However, if for any reason you feel that you do not wish to answer any question, you may skip over it. As well, you are free to stop participating at any time and for any reason.

On the following page you will find an Informed Consent $:$ rm that summarizes your rights and the researchers' obligations with regard to this survey. Please note that all material gathered is confidential and will be used for research purposes only. The Informed Consent Form will be separated from the questionnaires before the data are analyzed.

If you decide to participate, you may be interested in knowing about the findings, or you may have concerns about the methods or questions used in the survey. The following page therefore also provides a list of individuals who will respond to your questions or concerns. You are encouraged to remove his list from the booklet for future reference.

At this point we would like you to consider whether or not you wish to participate in this survey. If you do wish to participate, please complete and sign the Informed Consent Form on the following page. If you do not wish to participate, please remain seated until everyone has made a decision. 


\section{INFORMED CONSENT}

Title of Survey: $\quad$ Everyday Activities and Feeings

Principle Researciter: Dr. Brian R. Little

Carleton University

Department of Psychology

Name of Participant:

$$
\text { (please print) }
$$

I understand that this survey will involve filling out questionnaires.

I understand that my participation is voluntary and that I may stop participating at any time.

I understand that I may skip over any question that I do not wish to answer.

I understand that all information gathered will be kept strictly confidential.

Signature of Participant:

$$
\text { (please sign) }
$$

Signature of Investigator

Datc:

\section{Names and Phone Numbers \\ Everyday Activities and Feelings}

Infonmation: If you would like any further information about this survey or its findings, please contact:

Dr Brian R. Litule

Deparment of Psychology, Carleton University

788-2600 Ext. 2697

Concerns: If you have ariy concens about the methods or questions used in this survey, please contact:

Dr. W. Jones, Cizair

Department of Psycioblogy, Carleton University

788-26(K) Ext. 2648

or

Dr. C. Herdman, Chair

Ethics Committec, Carleton University

788-2600) lExt. 2689) 
Appendix E

Centre for Epicemiologic Studies Depression Scale fo: Children 


\section{Questionnaire \#3}

Below is a list of the ways you might have felt or behaved. Please indicate how of ten yor have felt this way during the past woek by rating each item on the following scale.

Rarely or None of the Time (Less than 1 Day) $=0$

Some or a Little of the Time (1 - 2 Days) $=1$

Occasionally or a Moderate Amount of time $(3-4$ rays $)=2$

Most or All of the Time (5 - 7 Days)

$=3$

During the past weak:

- 1. I was bothered by things that isually don't bother me.

2. I did not $f \epsilon a l$ like eating. I wasn't very hungry.

- 3. I wasn't able to feel happy, even when my family or friends tried to help me feel hetter.

4. I felt that I was just as good as other kids.

- 5. I felt like I couldn't pay attention to what I was doing this week.

6. I feit down and unhappy this week.

7. I felt like I was too tired to do things this past week.

8. I felt like something good was going to happen.

9. I felt like things I did before didn"t work out right.

10. I felt scared this week.

11. I didn't sleep as well as I usually sleep this week.

12. I was happy this week.

13. I was more quiet than usual this week.

14. I felt lonely, like I didn't have any friends.

15. I felt like kids I knew were not friendly or that they didn't want to be with me.

16. I had a good time this week.

17. I felt like orying this week.

18. I felt sad.

19. I felt people didn"t like me this week.

20. It was hard to get started doing things this wsak. 
Appendix $\mathbf{F}$

Perceived Stress Scale 


\section{Questionnaire \#4}

The questions in this scale ask you about your feelings and thoughts during the iast month. In each case, you will be asked to indlcate row eten you felt or thought a certain way. Although some of the questions are similar, there are differences between them and you should treat each one as a separate question. The best approach is to answer each question fairly quickly. That is, dont try to count up the number of times that you felt a particular way, but rather indicat:e the alternative that seems like a reasonable estimace.

For each guestion choose from the following alternatives:

During the past wonth:

$$
\begin{aligned}
& 0=\text { never } \\
& 1=\text { almost never } \\
& 2=\text { sometimes } \\
& 3=\text { fairly often } \\
& 4=\text { very often }
\end{aligned}
$$

1. How often have you been upset because of something that happened unexpectedly?

2. How often have you felt that you were unable to conicrol the important things in your life?

3. How often have you felt nervous and stressed?

4. How often have you dealt successfully with irritating ilfe hassles?

5. How often have you felt that you were effectively coping with important charges that were occurring in your life?

6. How often have you felt confident about your

ability to handie your personal problems?
How often have you felt that things ere going your way?

8. How often have you found that you could not cope with all the things that you had to do?

9. How often have you been able to control irritations in your life?

10. How often have you felt that you were ou top of things?

11. How often have you been angered because of things that happened that were outside of your control?

12. How often have you found yourself thinking about things that you have to accomplish?

13. How often have you been able to control the way you spend your time?

14. How often have you felt difficulties were piling up so high that you could not overcome them? 
Appendix $\mathbf{G}$

General and Domain Specific Satisfaction Scales 
Questionnaire \#2

1. In general, how satisfied or disatisfied are you with your l1fe as whole as it is right now?

Circle the number on the scale below that comes closest to how you feel.

$$
\begin{array}{lllllllllll}
0 & 1 & 2 & 3 & 4 & 5 & 6 & 7 & 8 & 9 & 10
\end{array}
$$

Completely

Diesetiefied
Noutral completely cetisfiod

2. In geieral, how satisfied or disatisfied are you with your acadomic life as it is right now?

circle the number on the scale below that comes closest to how you feel.

$$
\begin{array}{lllllllllll}
0 & 1 & 2 & 3 & 4 & 5 & 6 & 7 & 8 & 9 & 10
\end{array}
$$

Completely

Disietiseied
Neutral completely entisfied

3. In general, how satisfied or disatified are you with your noelal life as it is right now?

Circle tre number on the scale below that comes closest to how you feei.

$$
\begin{array}{lllllllllll}
0 & 2 & 2 & 3 & 4 & 5 & 6 & 7 & 8 & 9 & 10
\end{array}
$$

Completely Diecetiefied
Neutra1 coupletely satisfied

4. In general, how satisfied or disatisfied are you with your hone 11 ife as it is right now? circle the number on the scale below that comes closest to how you feel.

$\begin{array}{lllllllllll}0 & 1 & 2 & 3 & 4 & 5 & 6 & 7 & 8 & 9 & 10\end{array}$

Completely Diseatiegied 
(Appendix G, i.e. Questionnaire 2, continued below) Questionnaire \#2 (continued)

5. In general, how satisfied or disatisfled are you with your emotionel ate as it is right now?

circle the number on the scale below that comes closest to how you feel.

$$
\begin{array}{lllllllllll}
0 & 1 & 2 & 3 & 4 & 5 & 6 & 7 & 8 & 9 & 10
\end{array}
$$

Completely

Dlasetiofjed

Noutral

Coupletely

satieliod

6. In general, how satisfied or disatisfied are you with your recreational life as it is right now?

circle the number on the scale below that comes closest to how you feel.

$$
\begin{array}{lllllllllll}
0 & 1 & 2 & 3 & 4 & 5 & 6 & 7 & 8 & 9 & 10
\end{array}
$$

conplote1y

Diseatiefied
Noutral

\section{Conplotely} satioried

7. In general, how satisfied or disatisfied are you with your physical health as it is right now? circle the number on the scale below that comes closest to how you feel.

$$
\begin{array}{lllllllllll}
0 & 1 & 2 & 3 & 4 & 5 & 6 & 7 & 8 & 9 & 10
\end{array}
$$


Appendix $\mathrm{H}$

study Booklet 

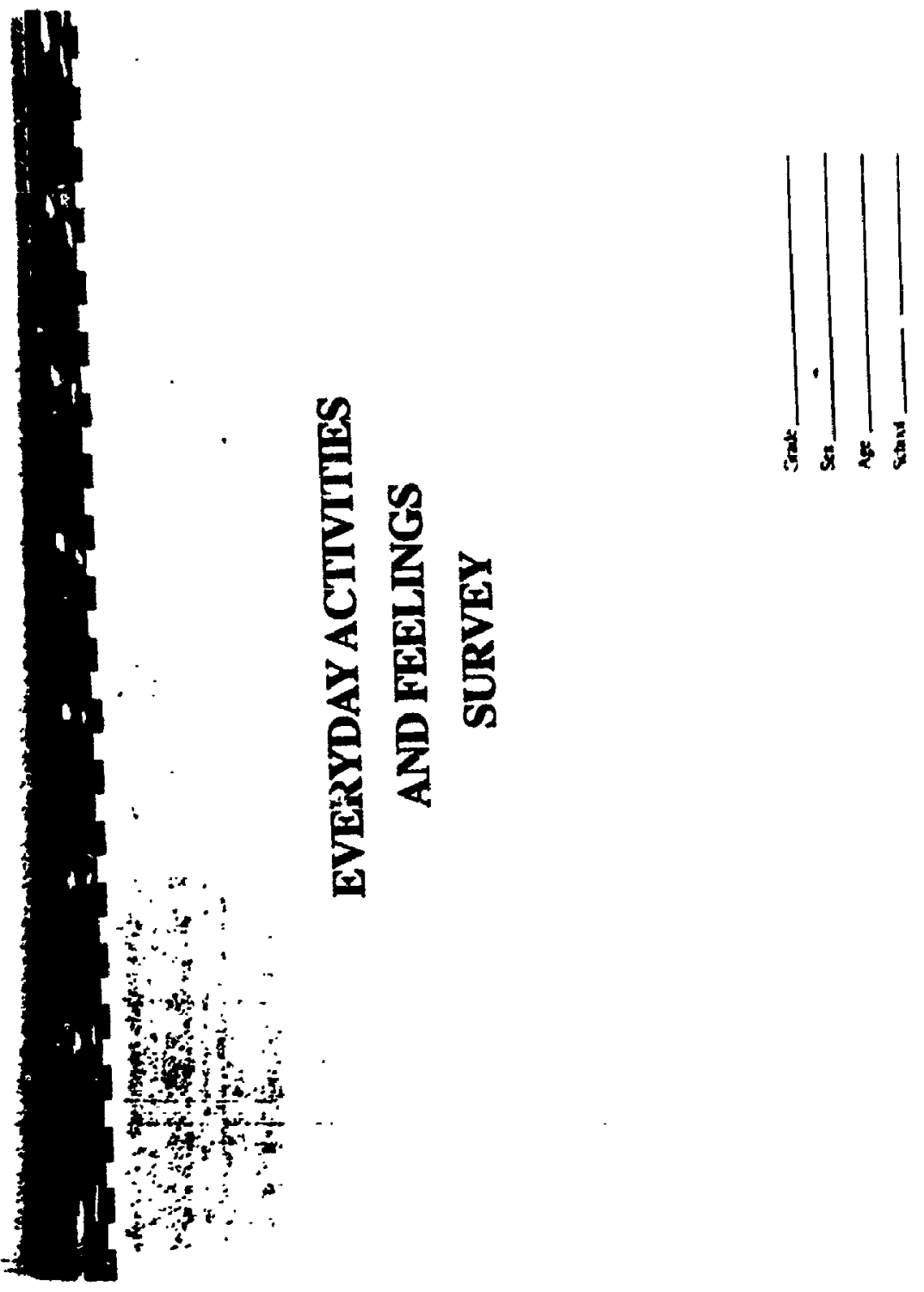


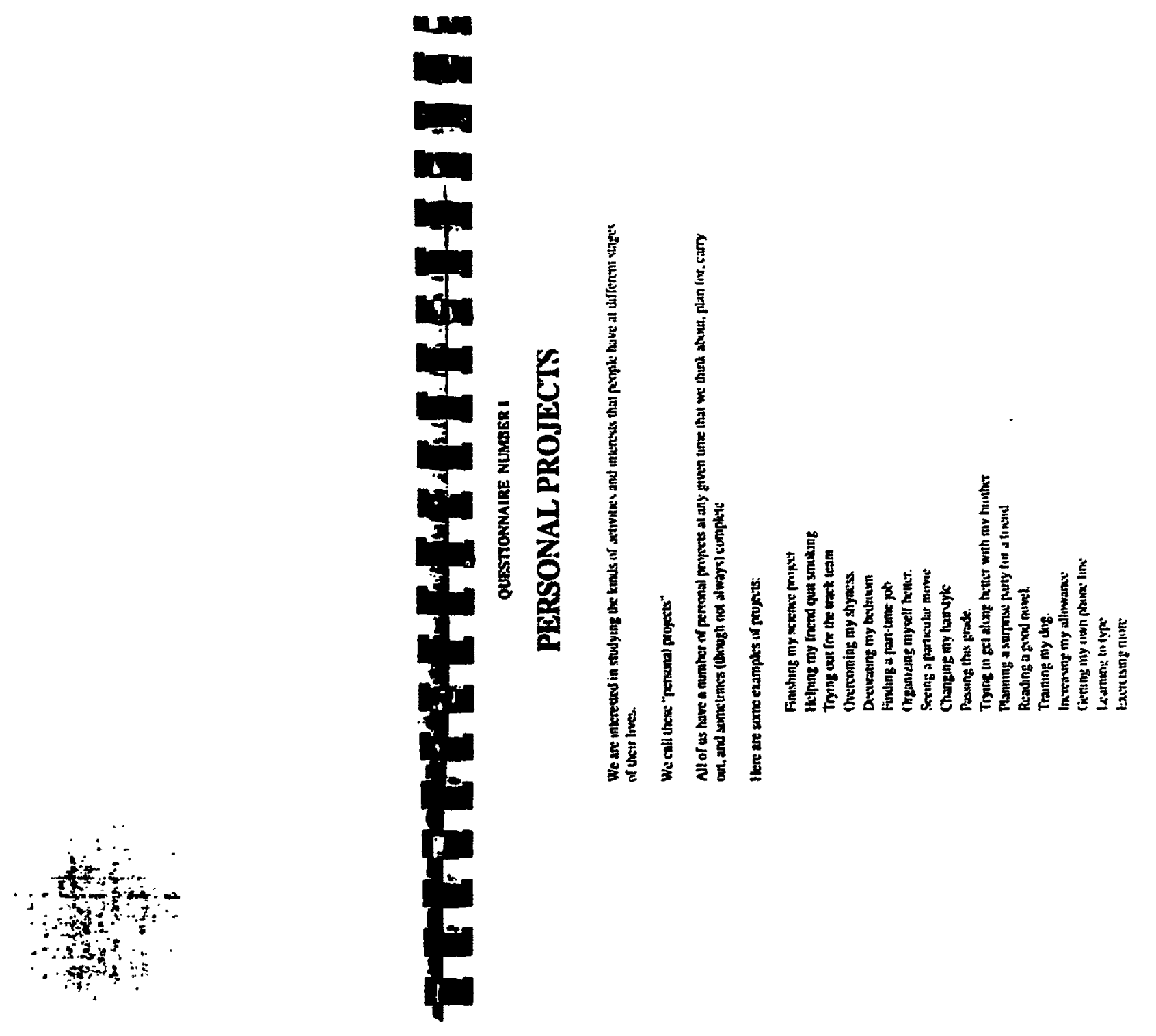




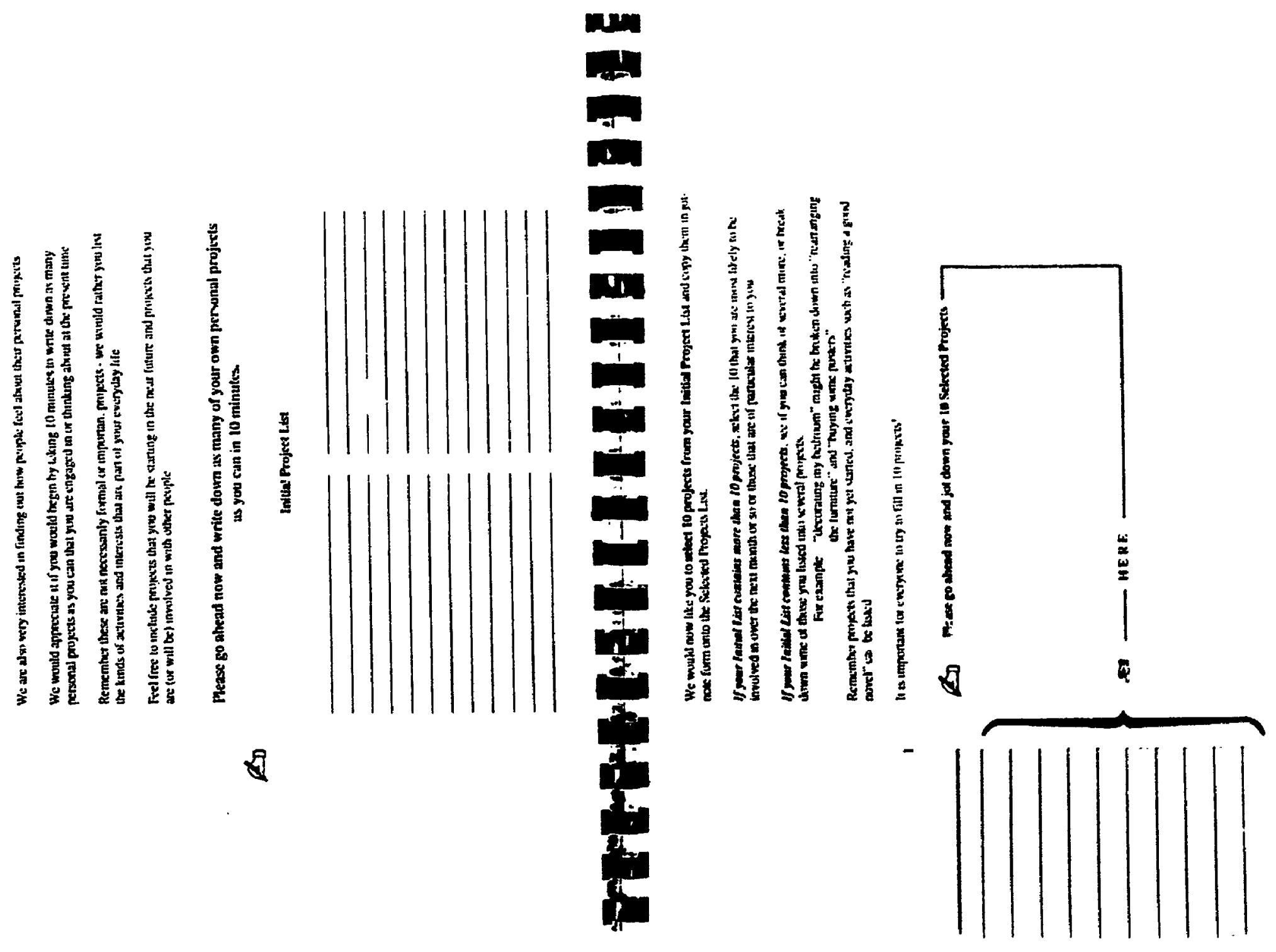




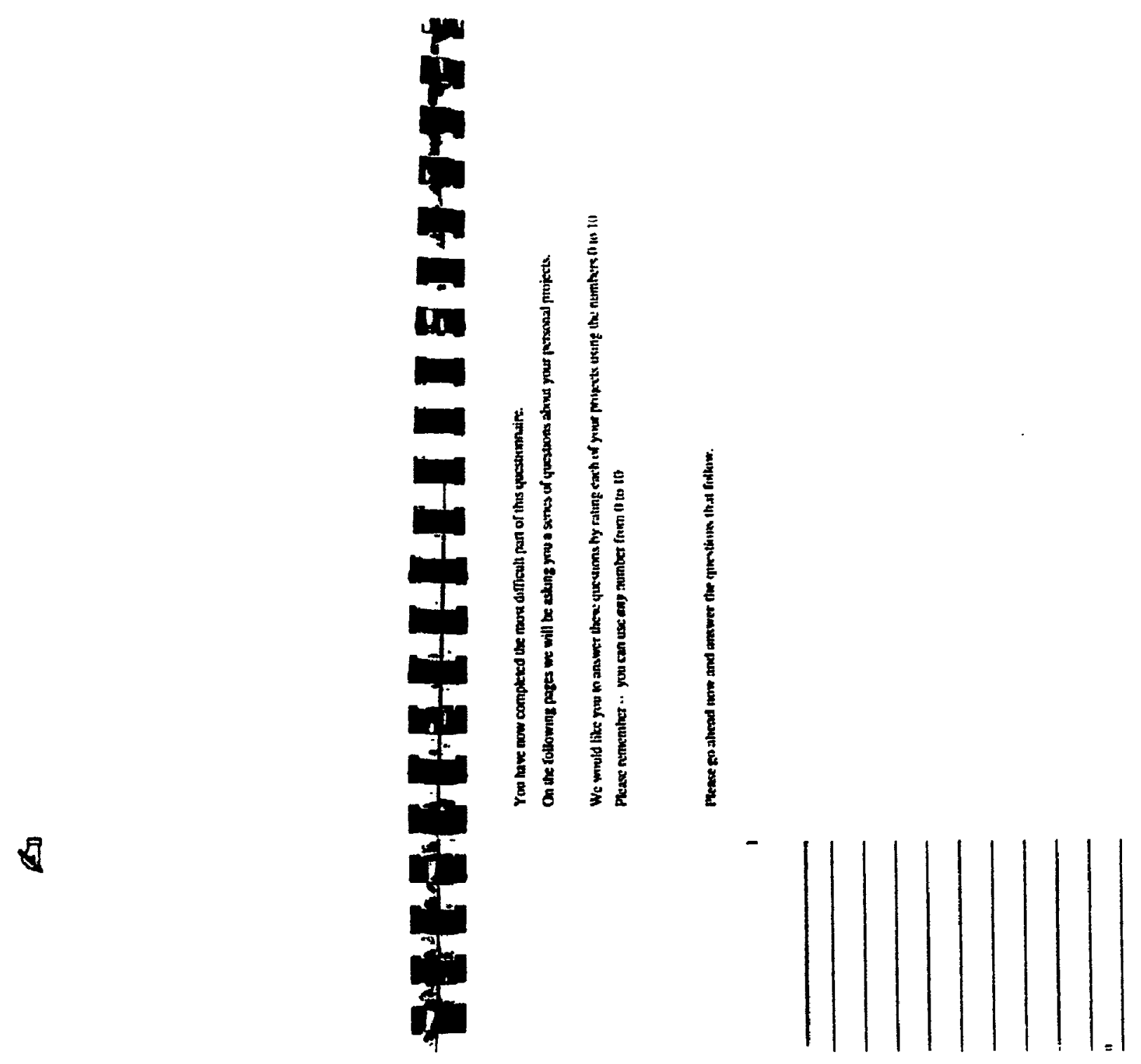




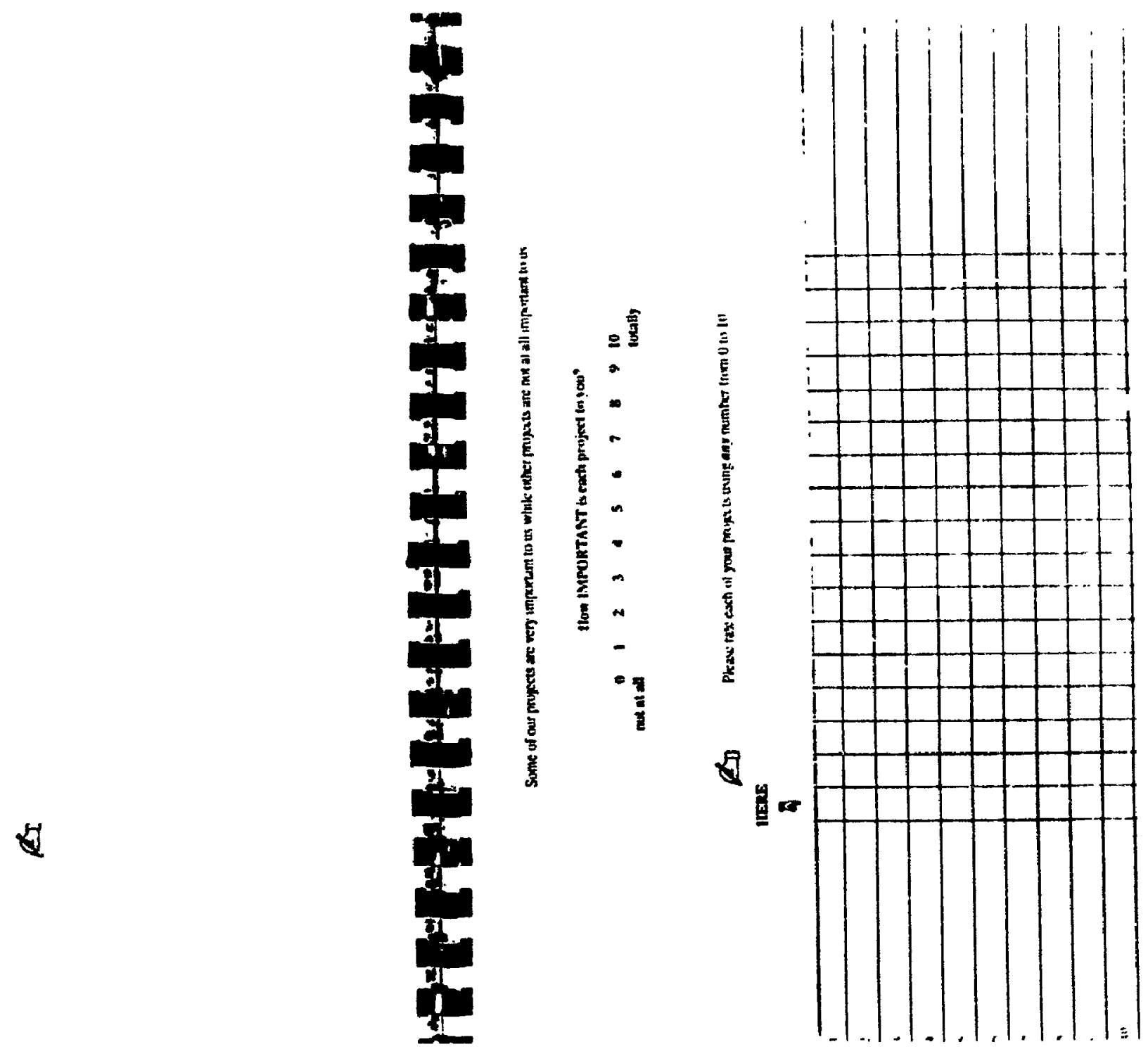




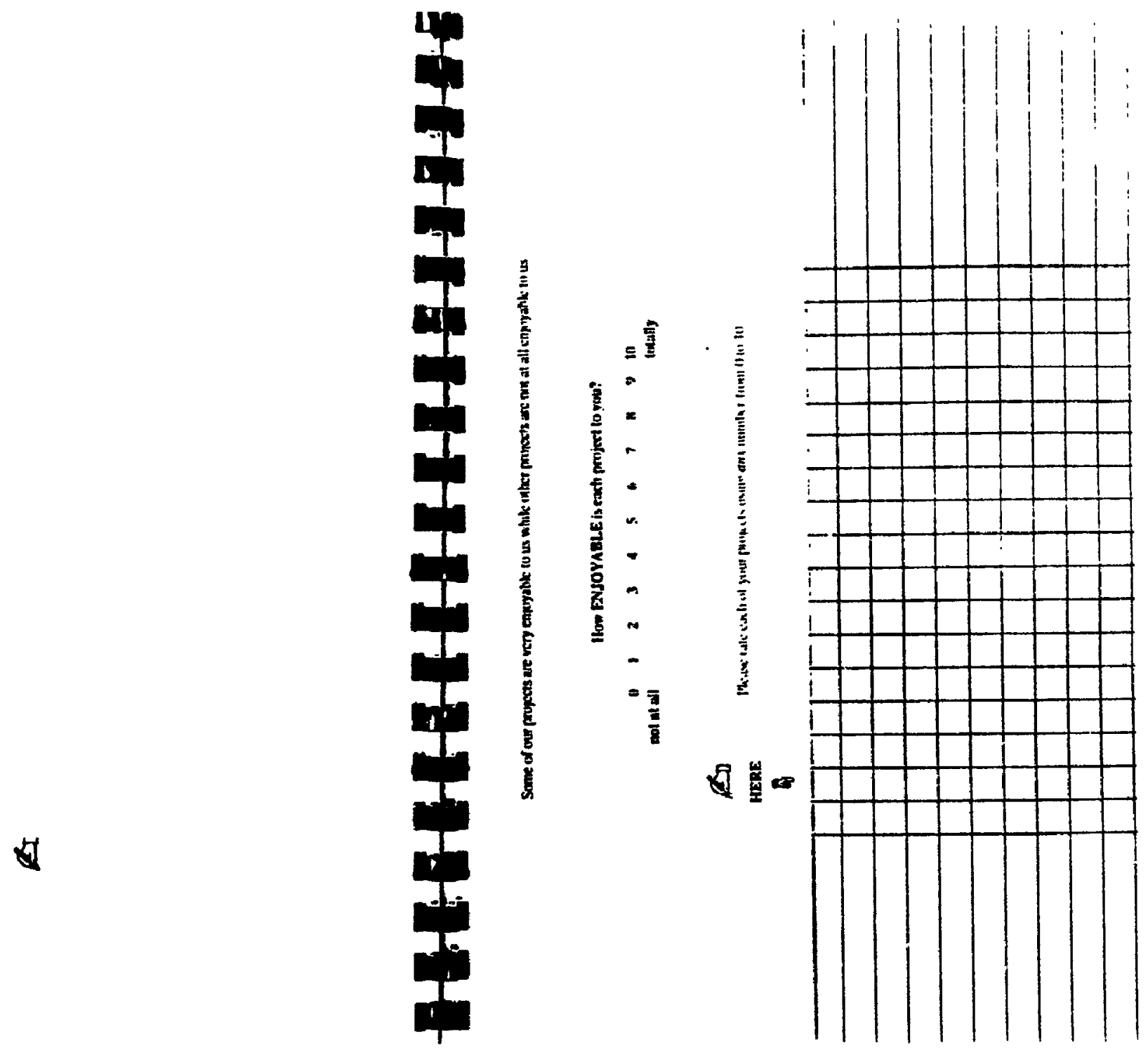




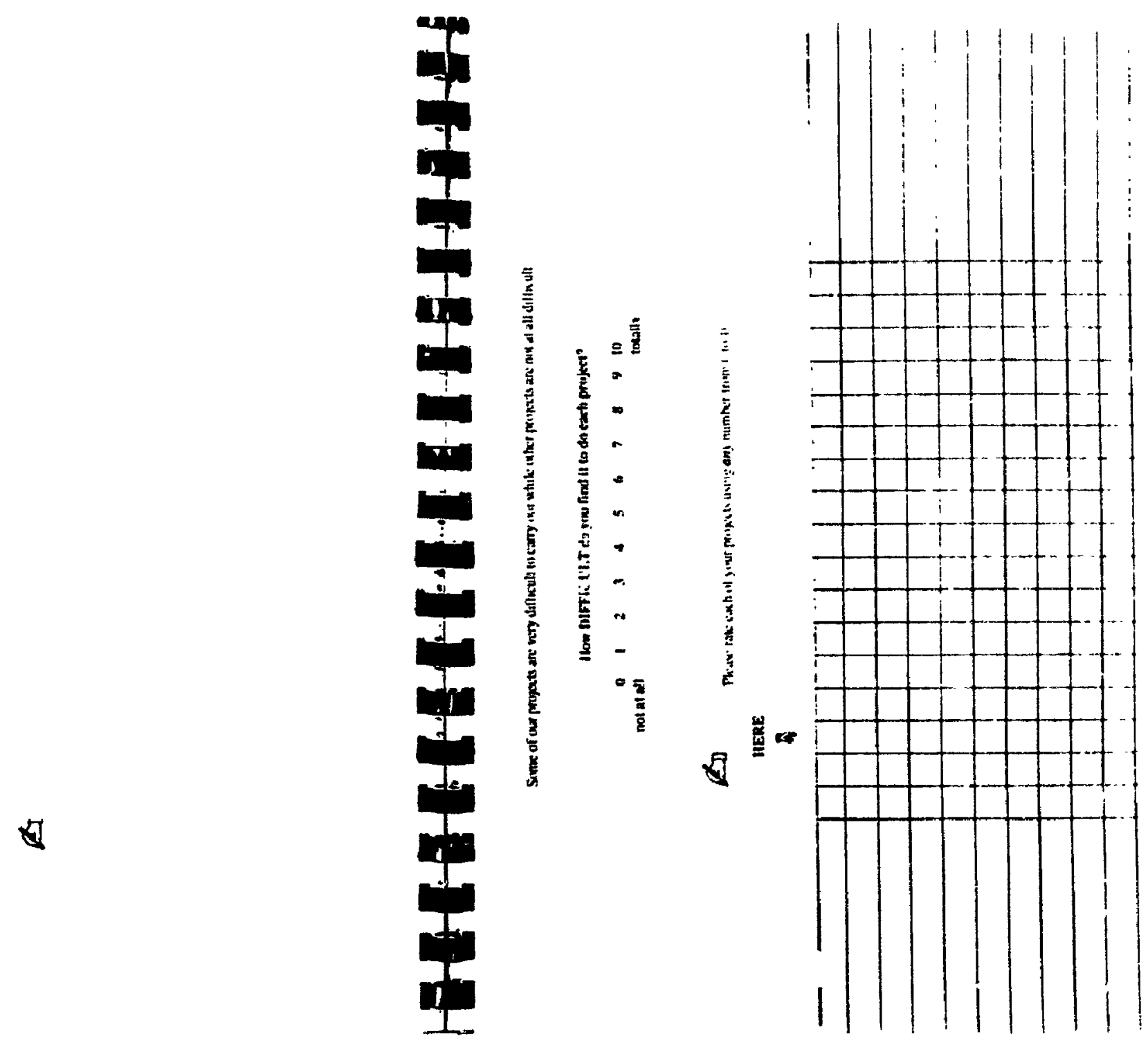



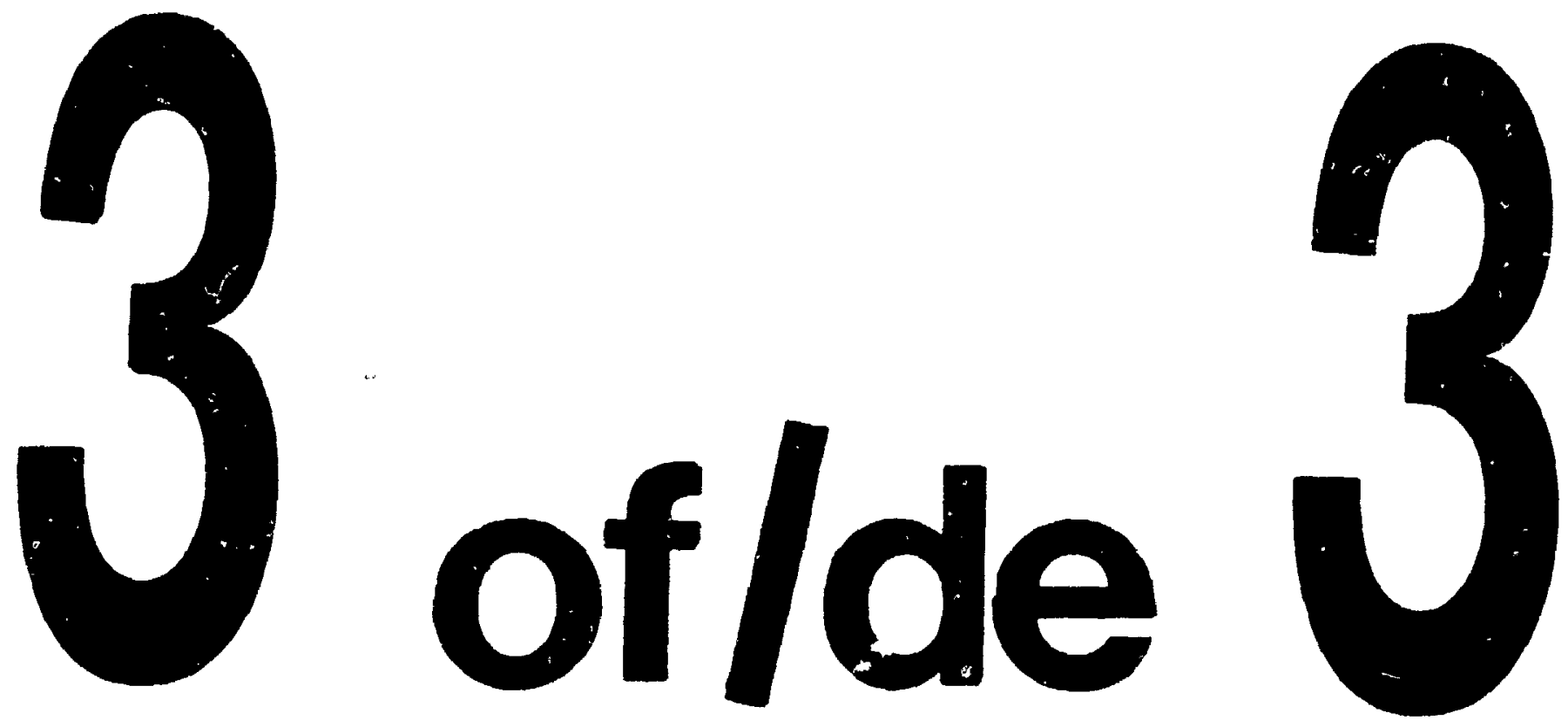

PM-1 31/2" $\times 4 "$ PHOTOGRAPHIC, MICROCOPY TARGET NBS 1010a ANSI/ISO \#2 EOUIVALENT

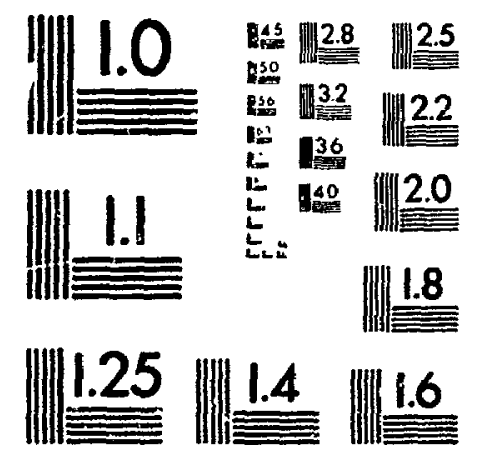

PRECISIONSM RESOLUTION TARGETS 


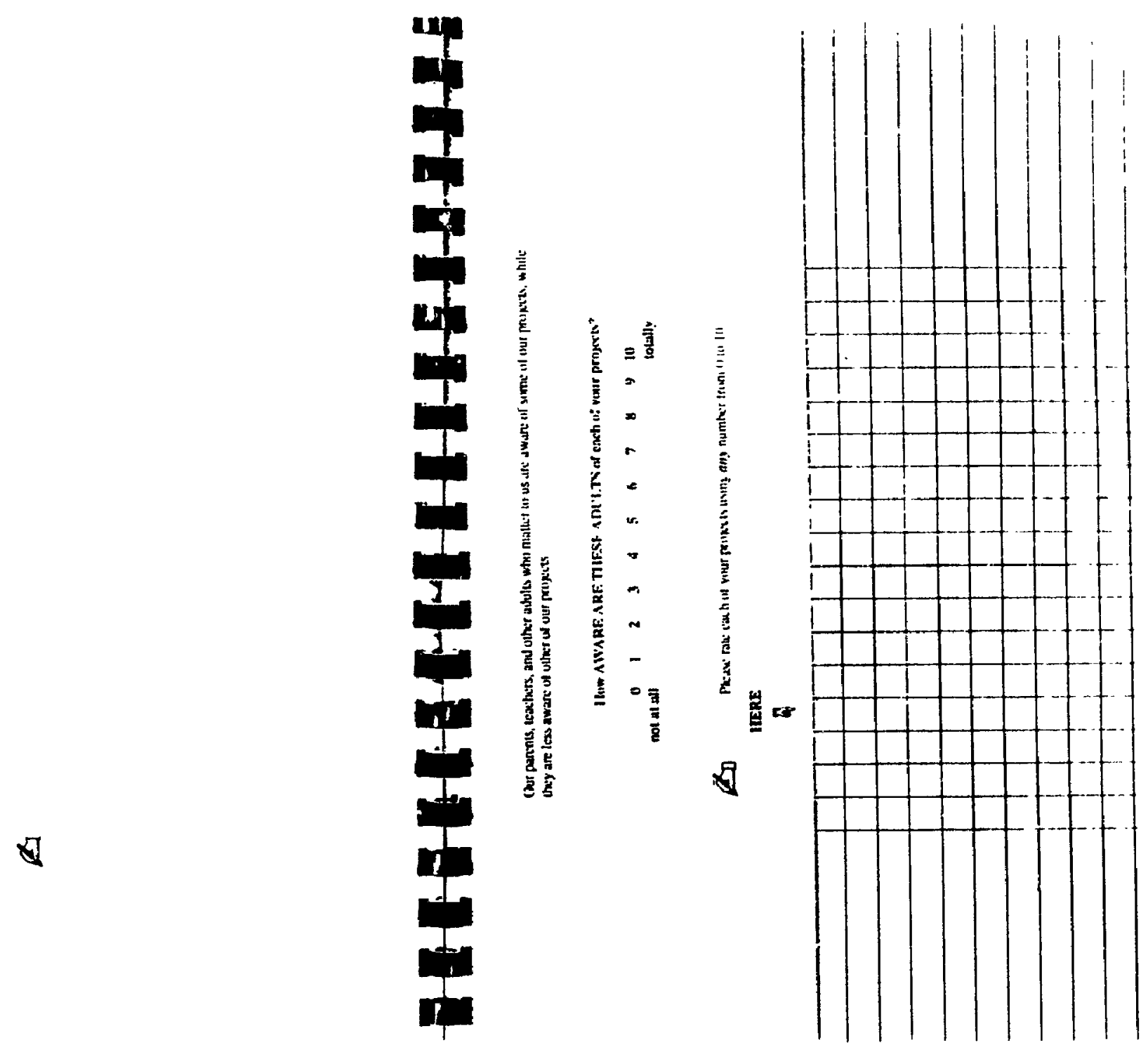




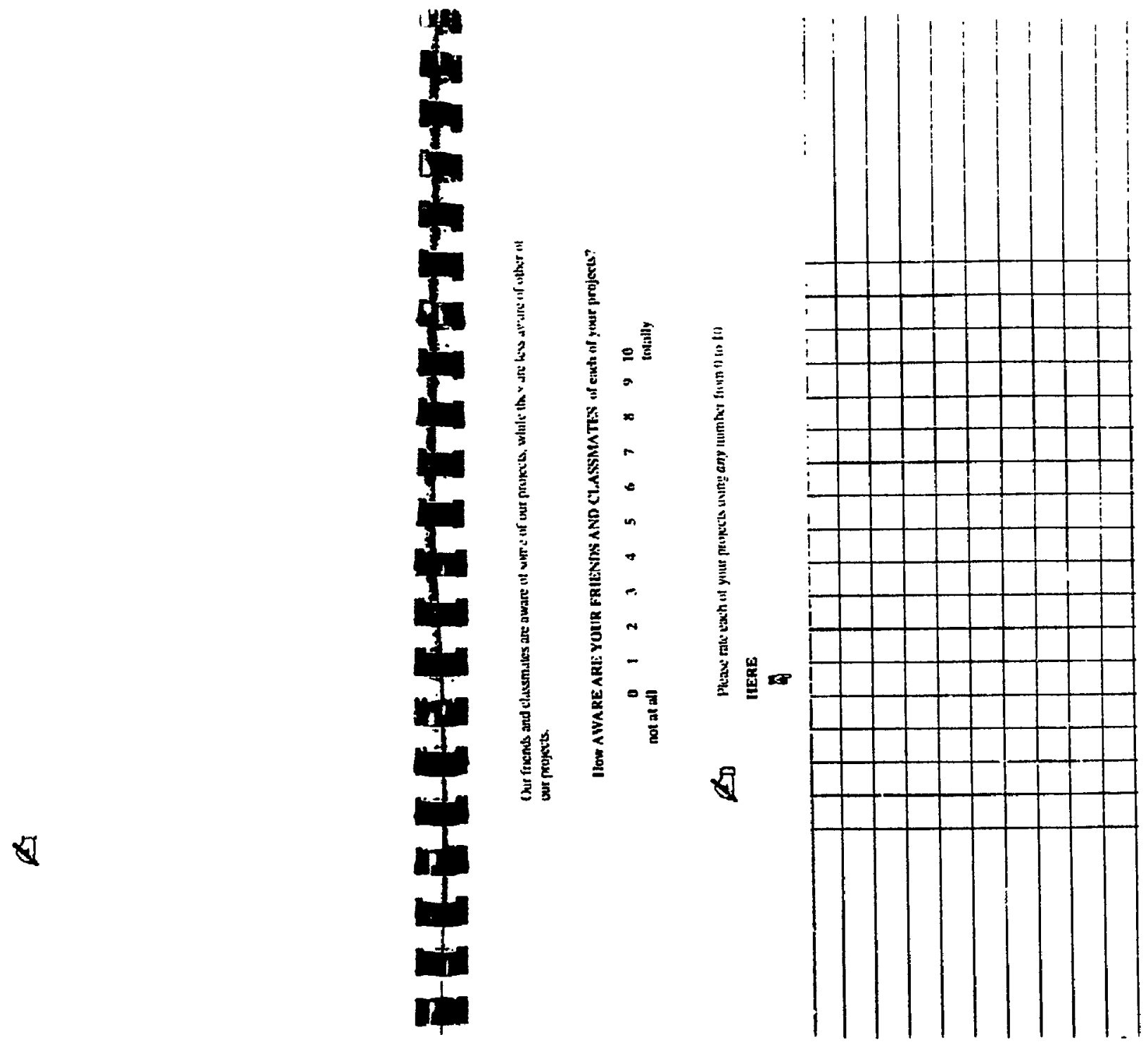




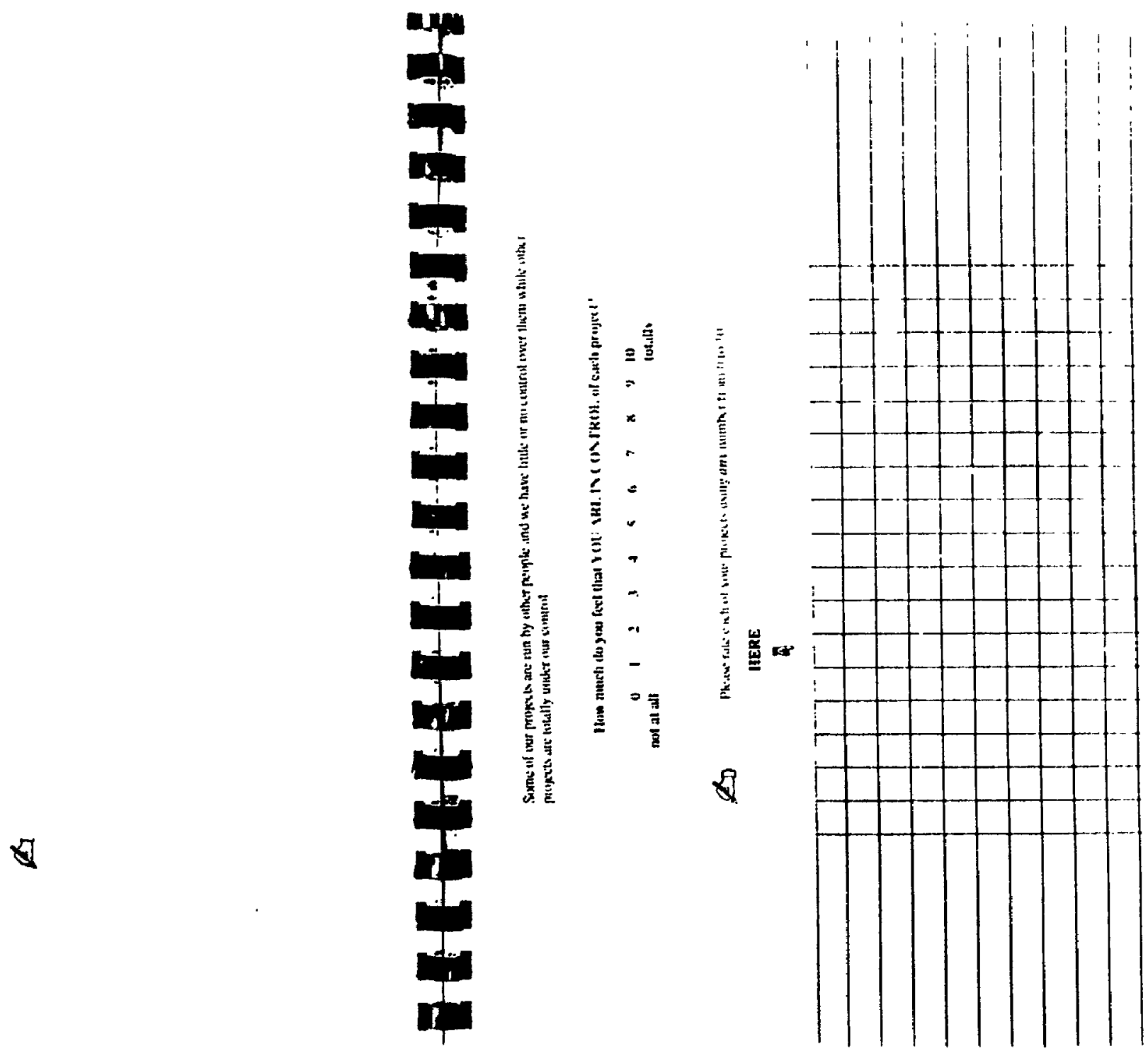




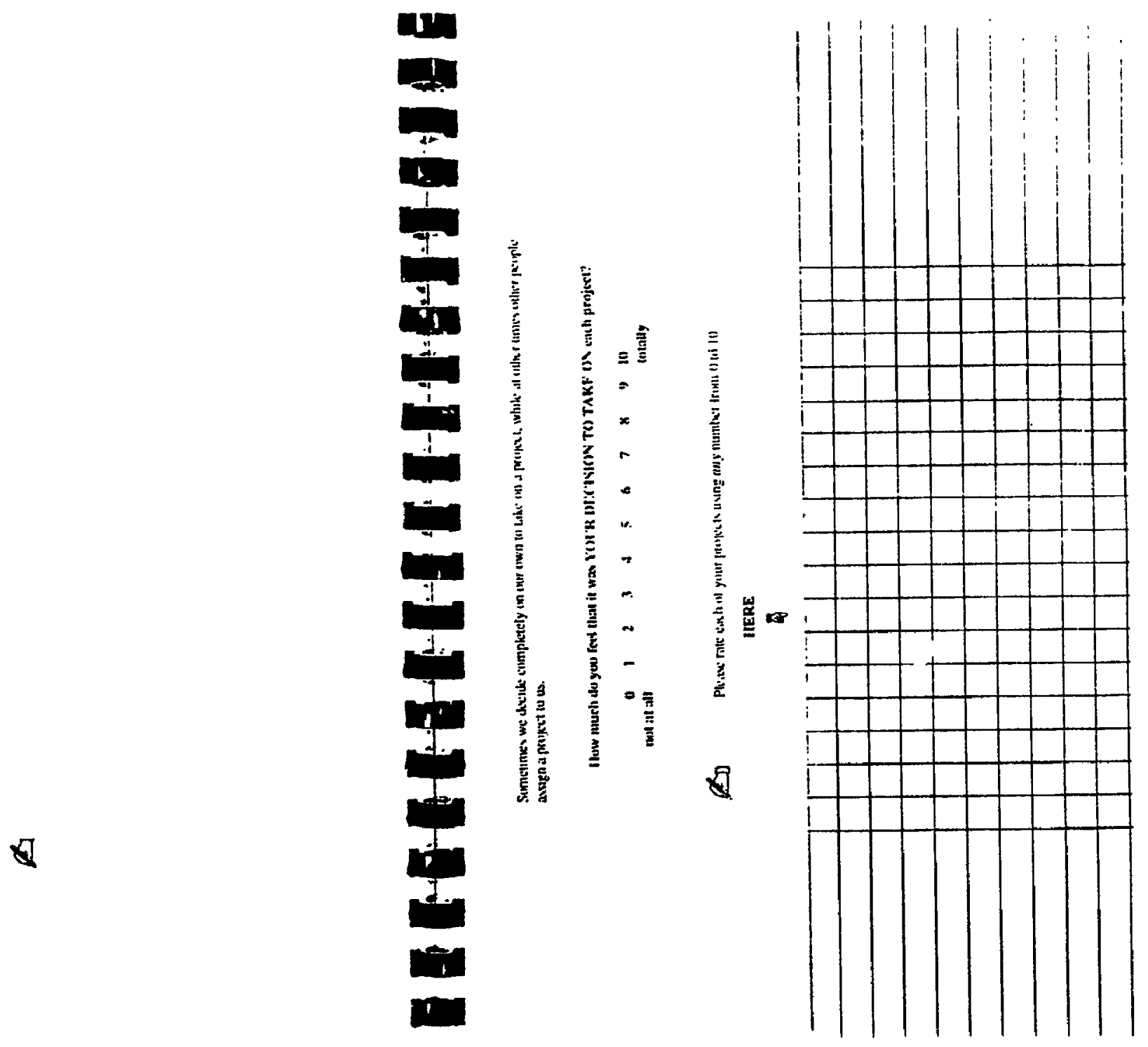




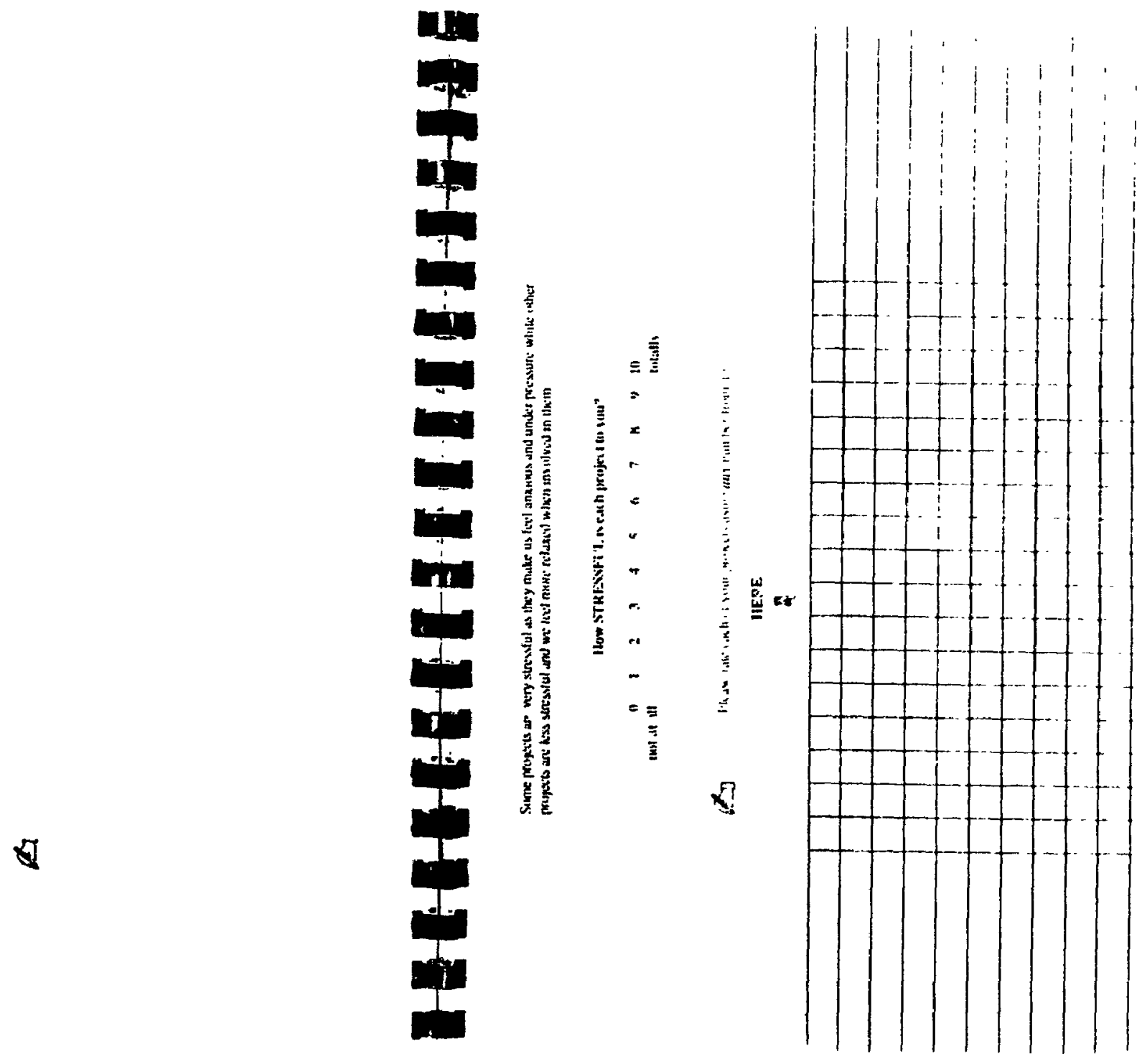




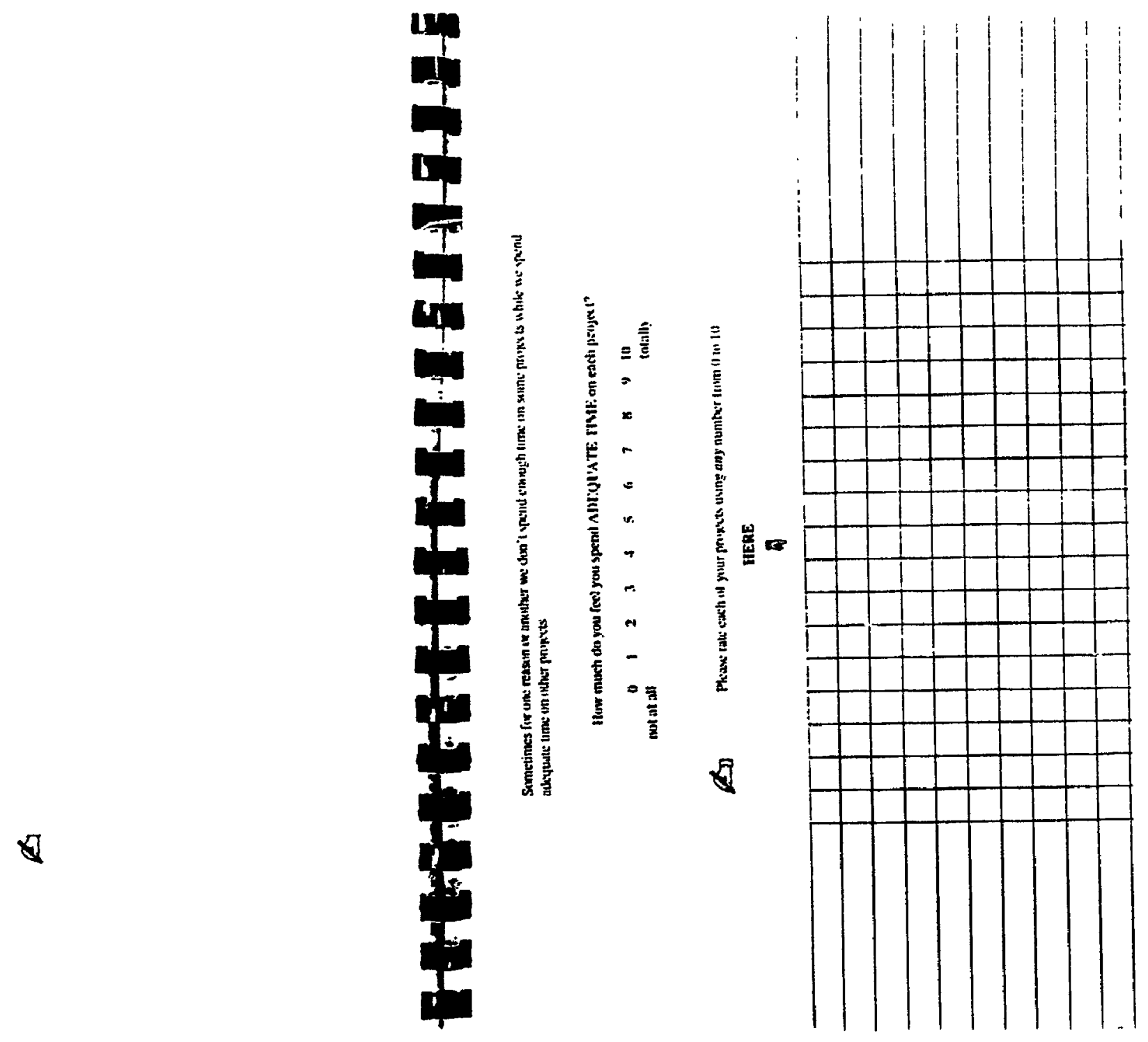




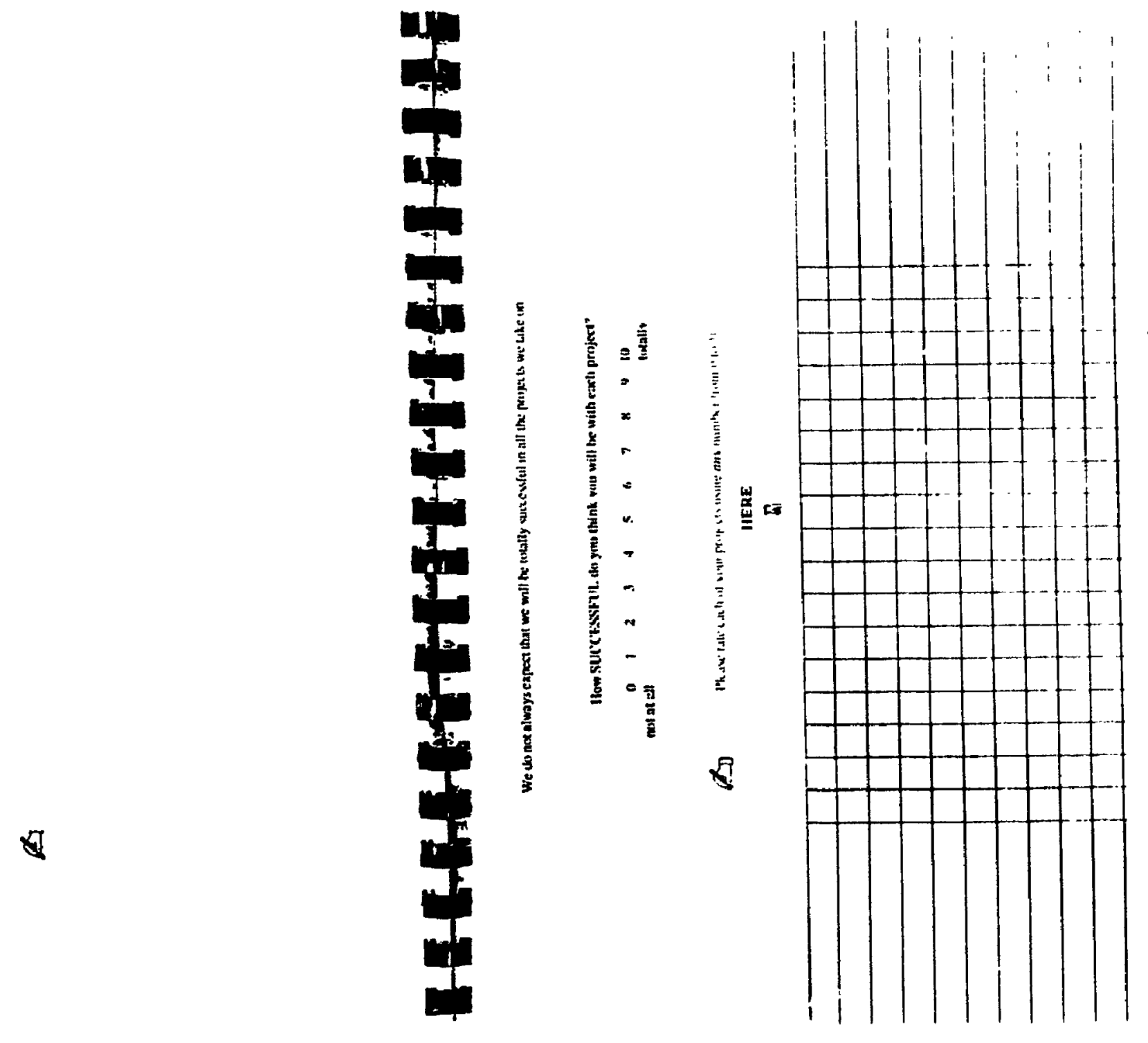




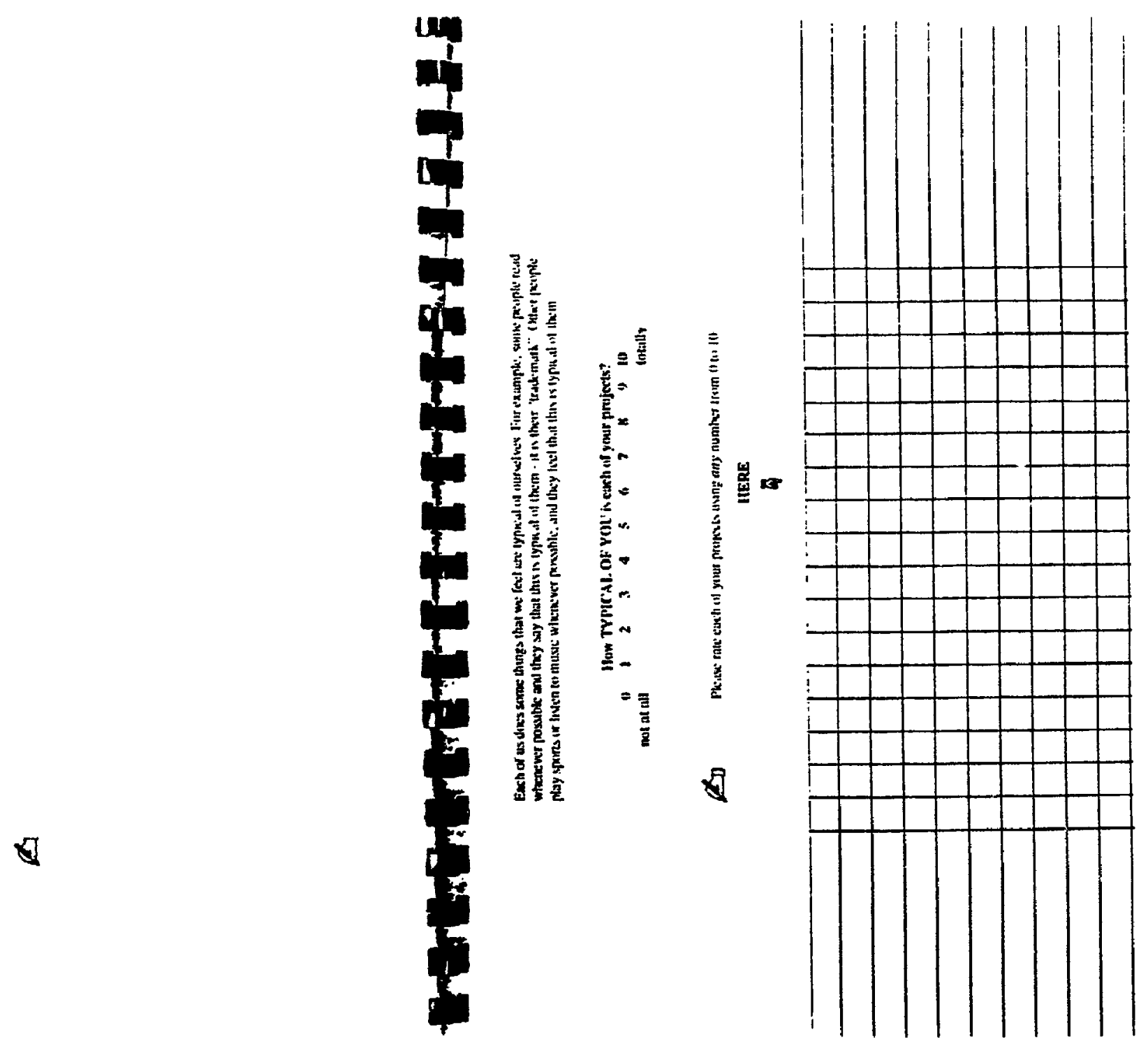




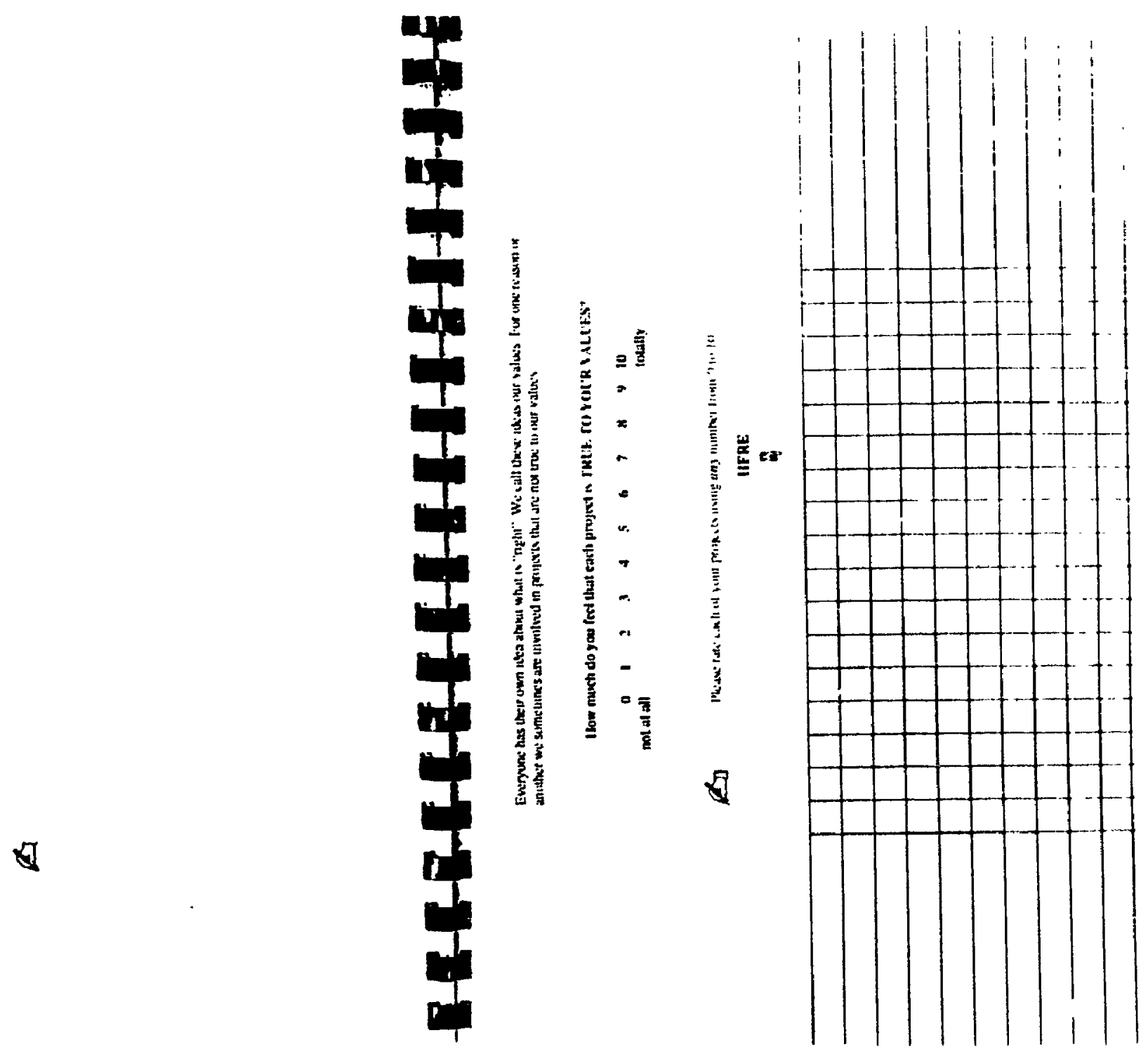




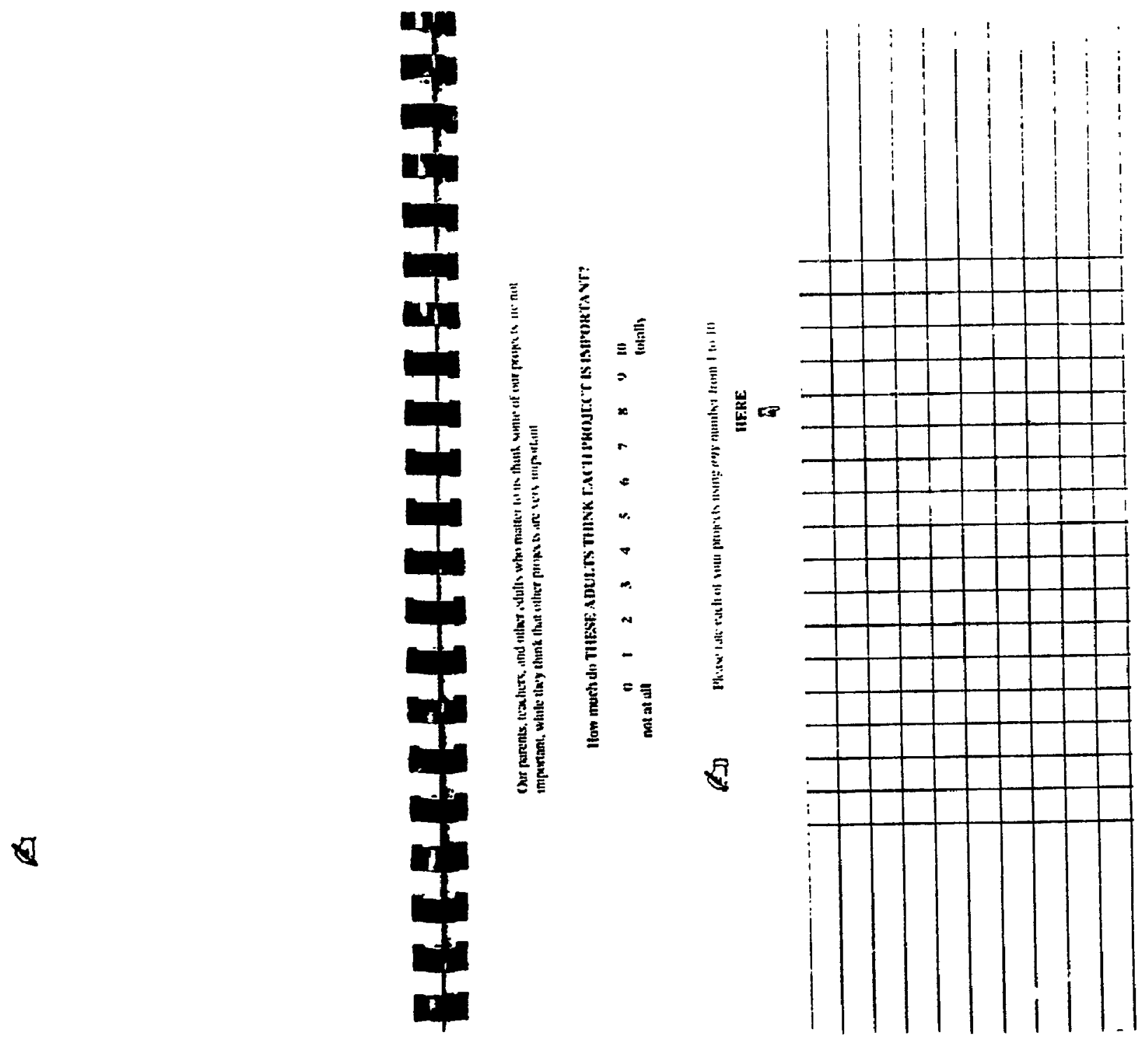




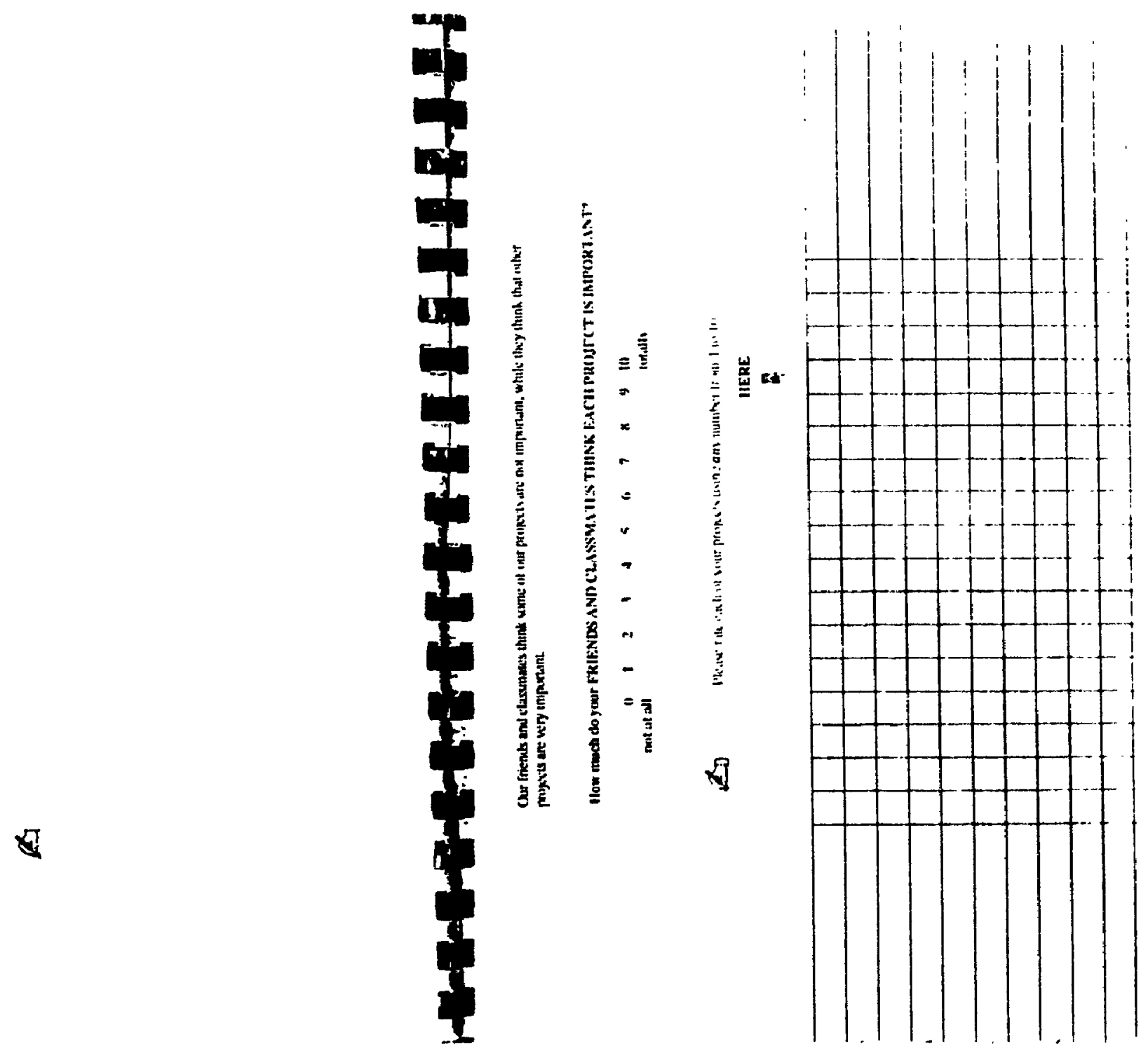




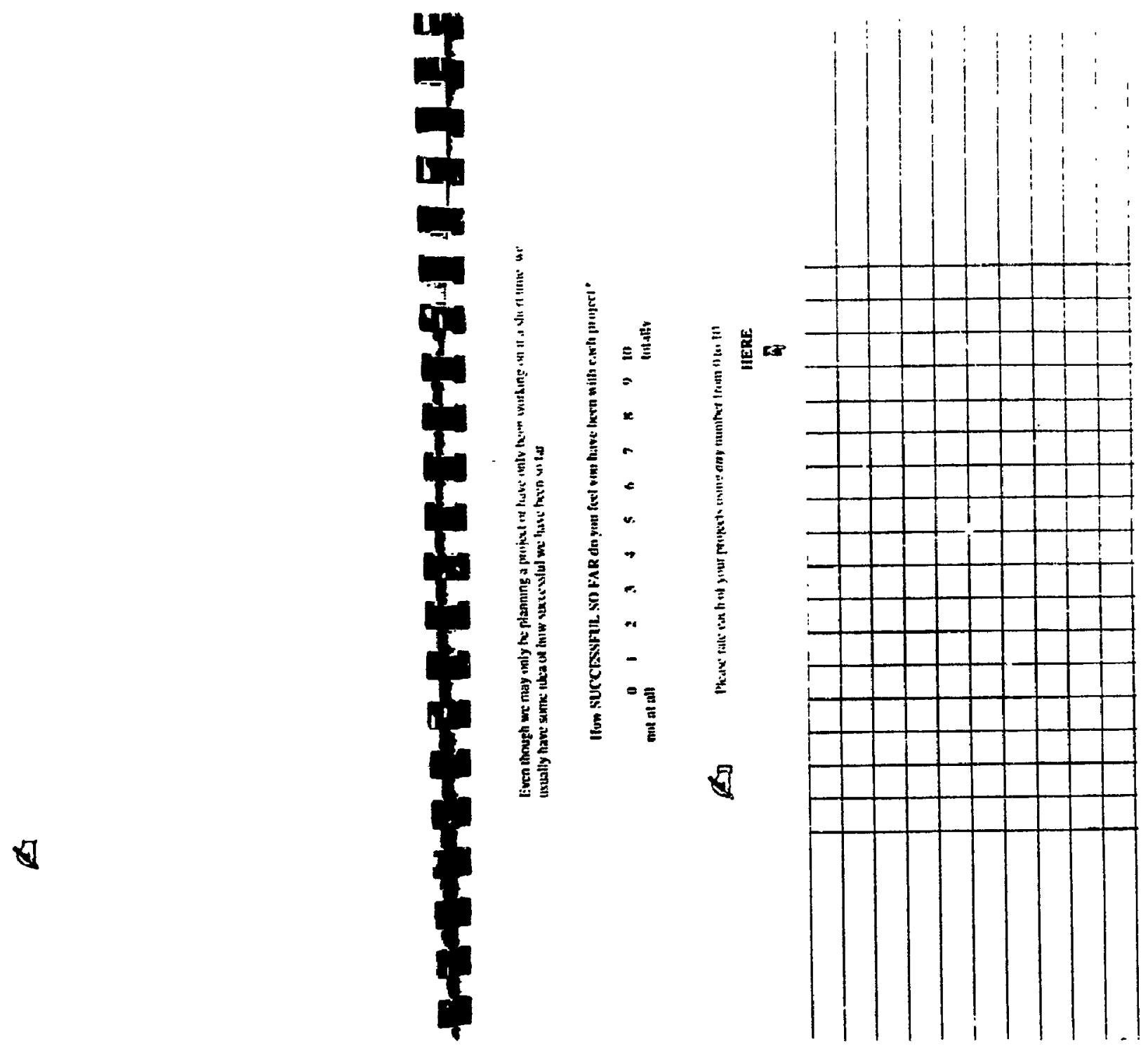




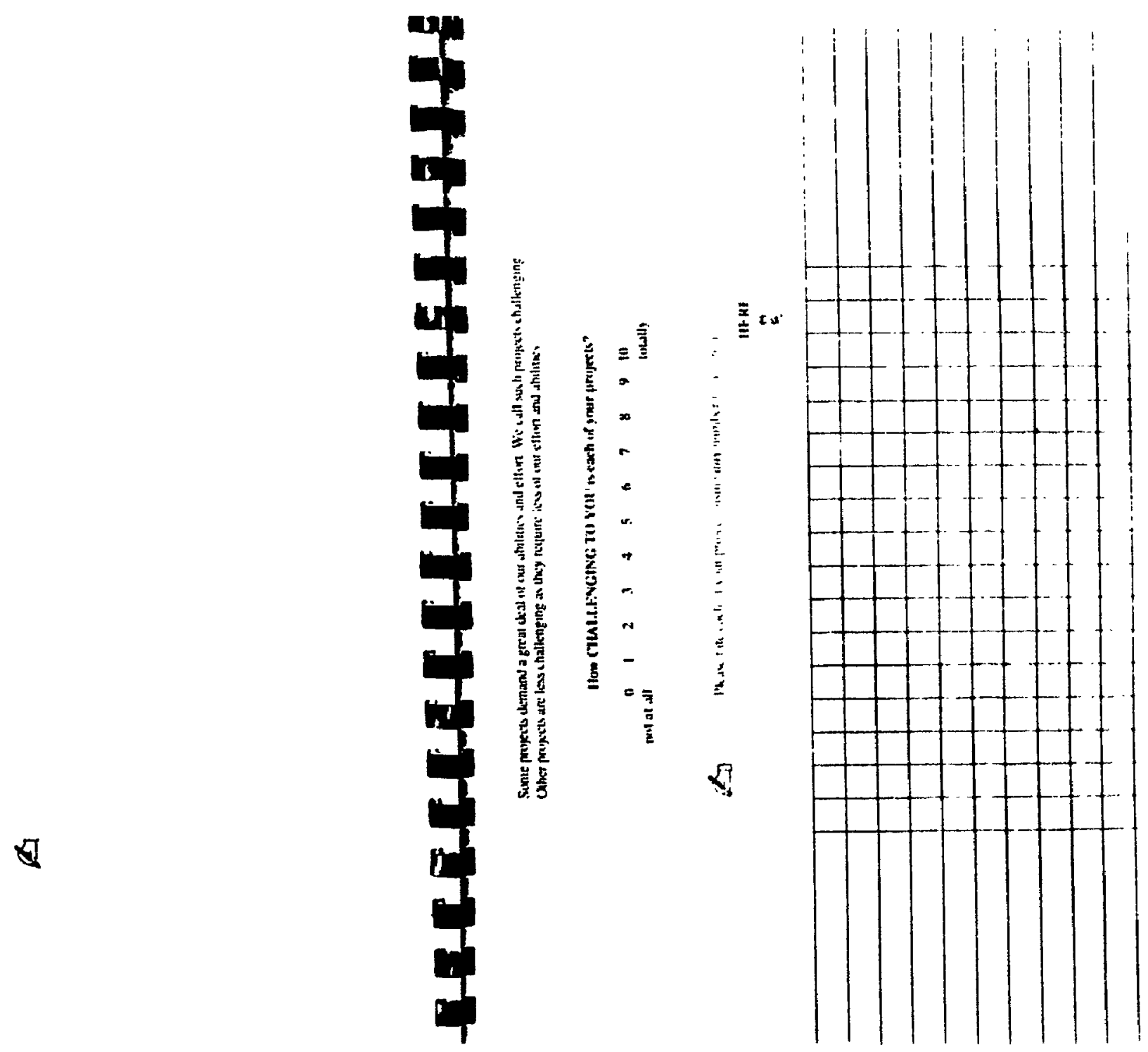




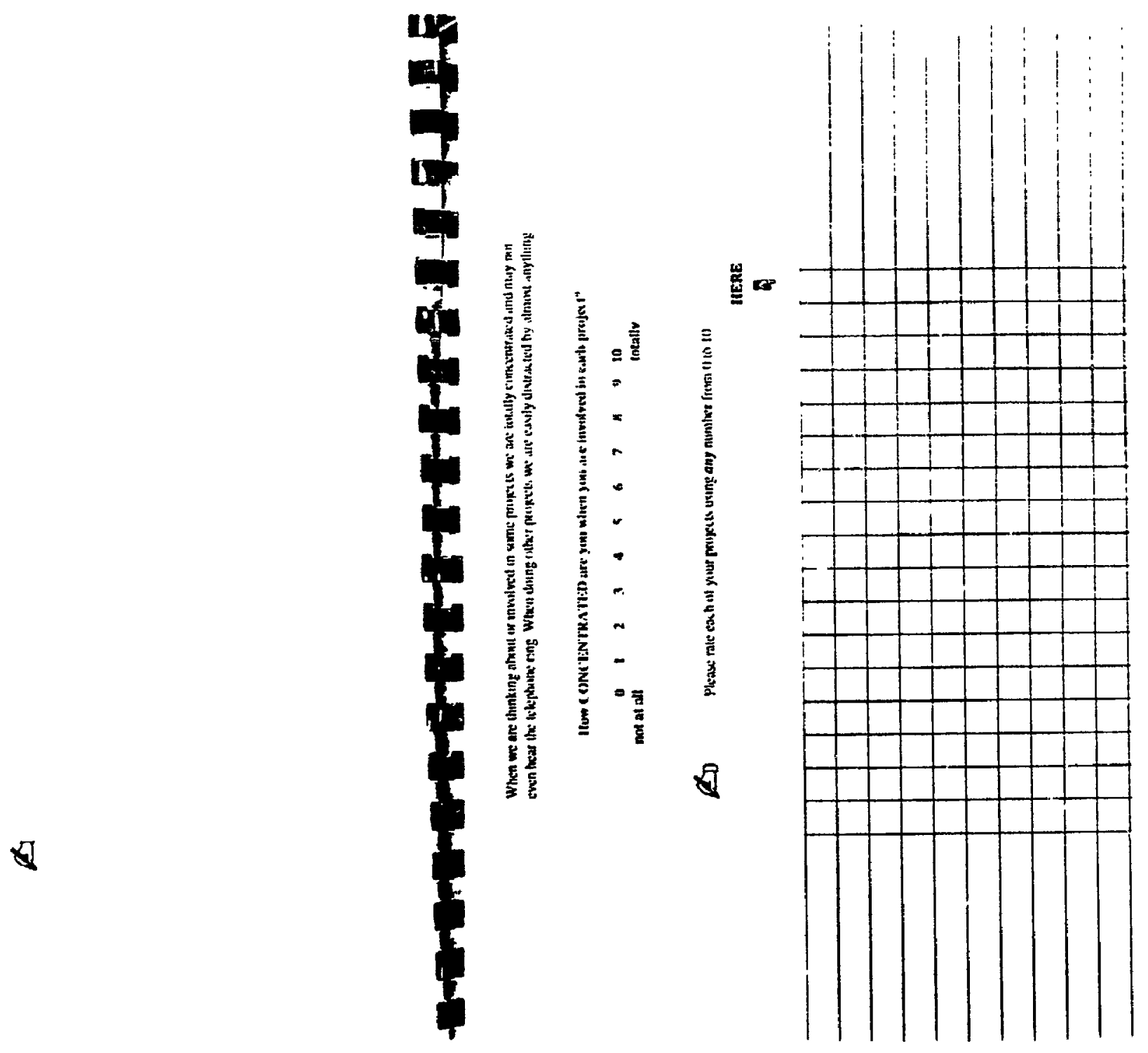




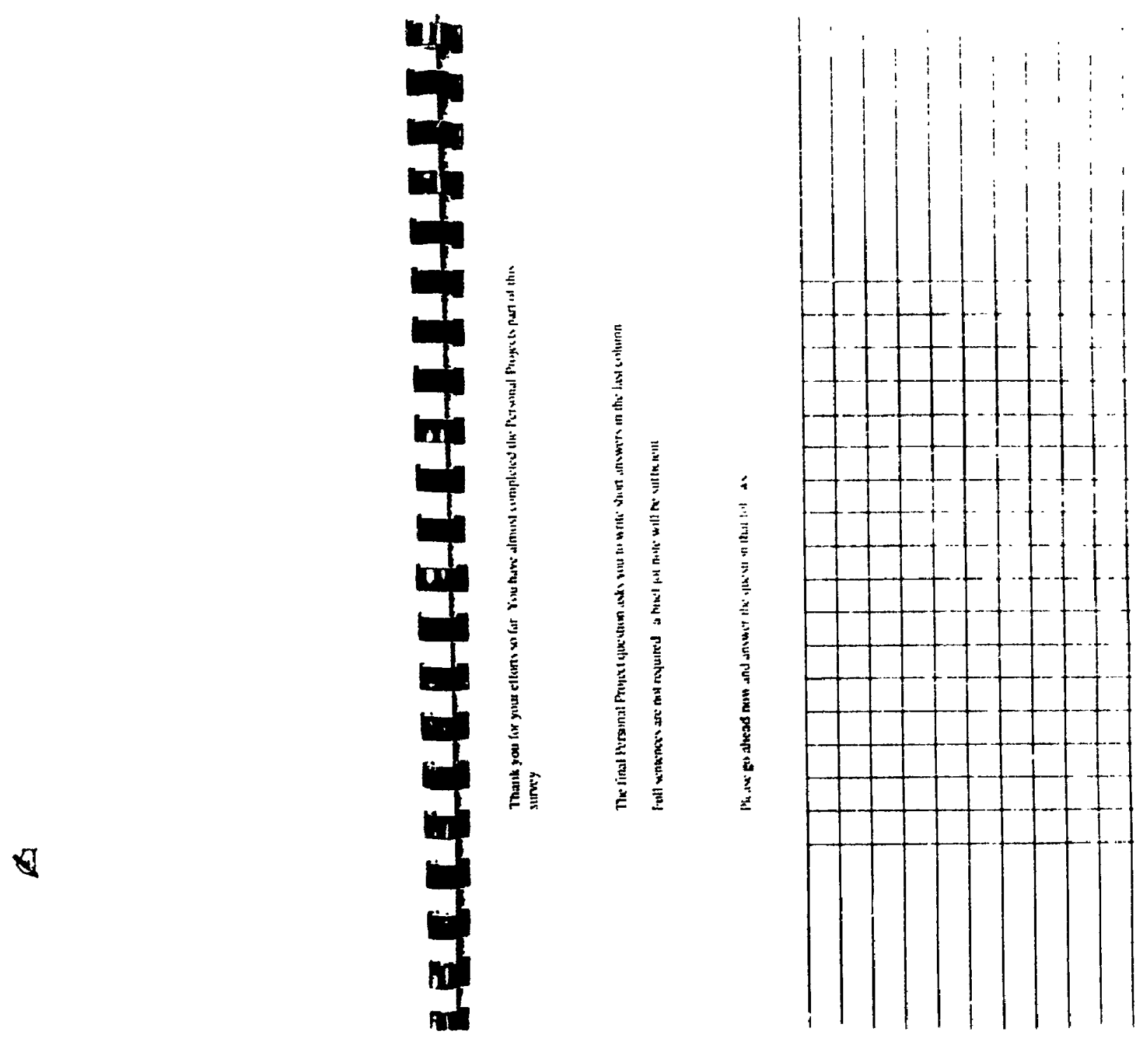




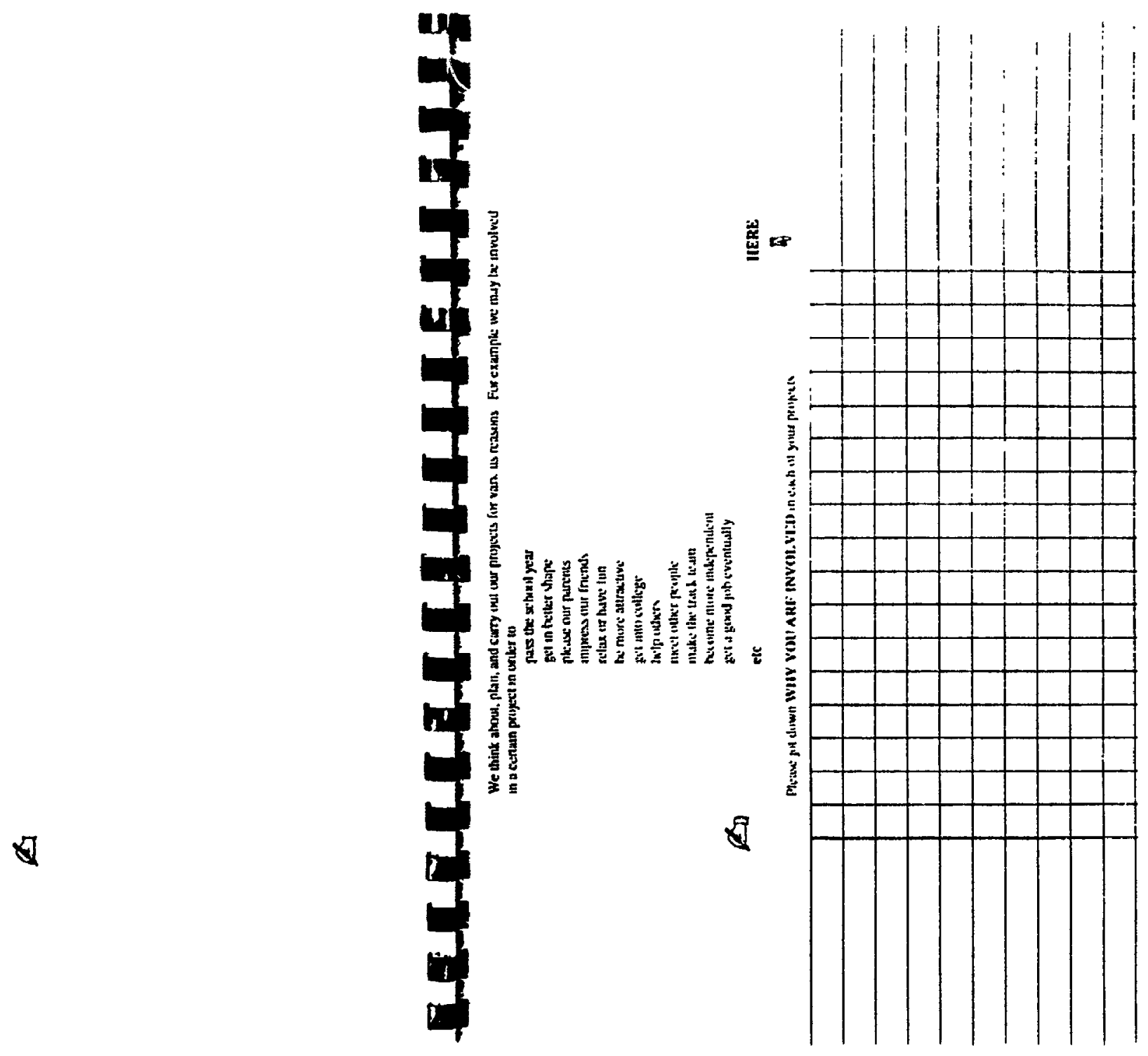




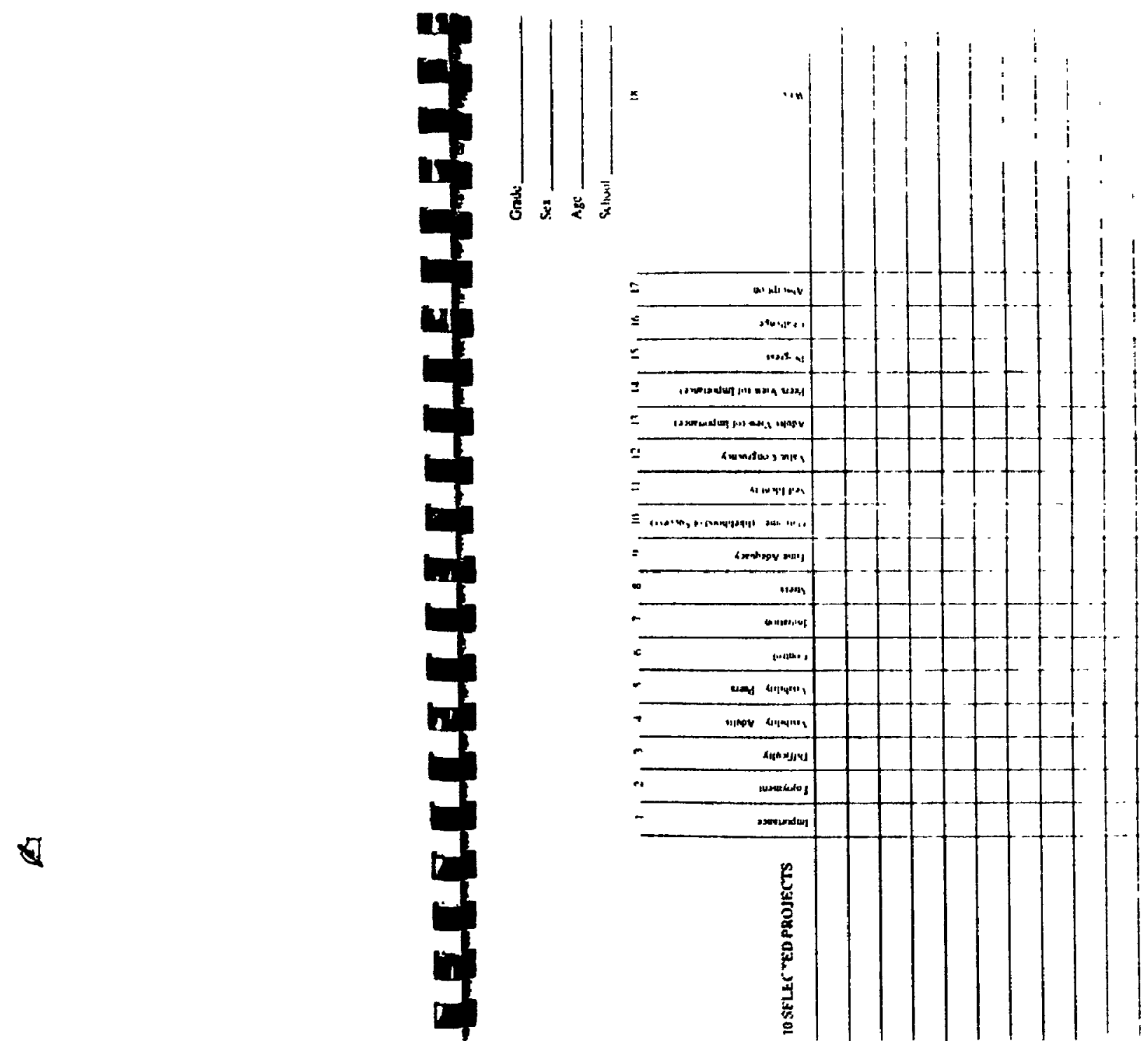




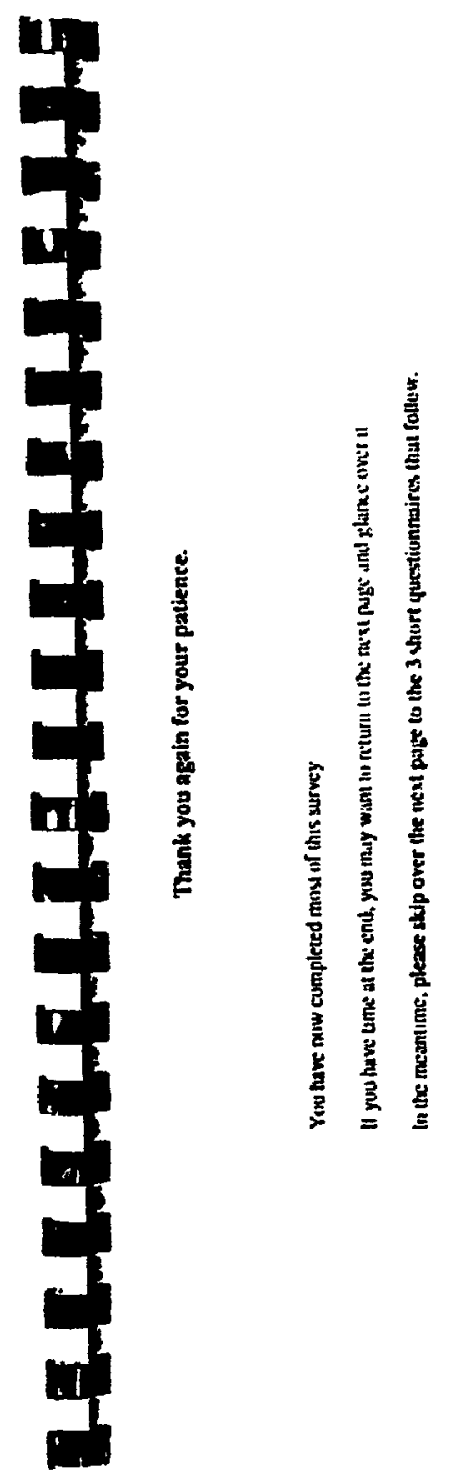




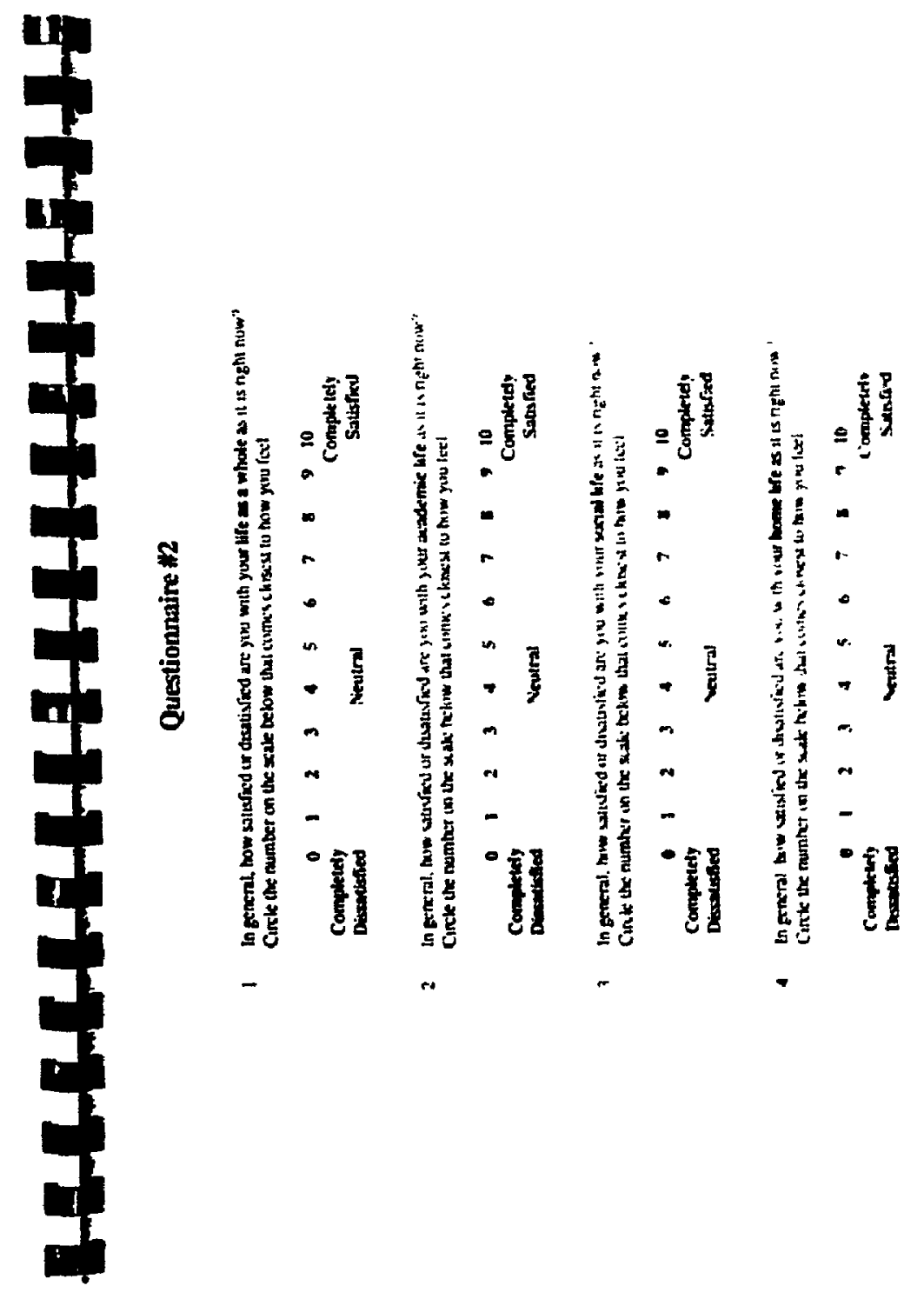




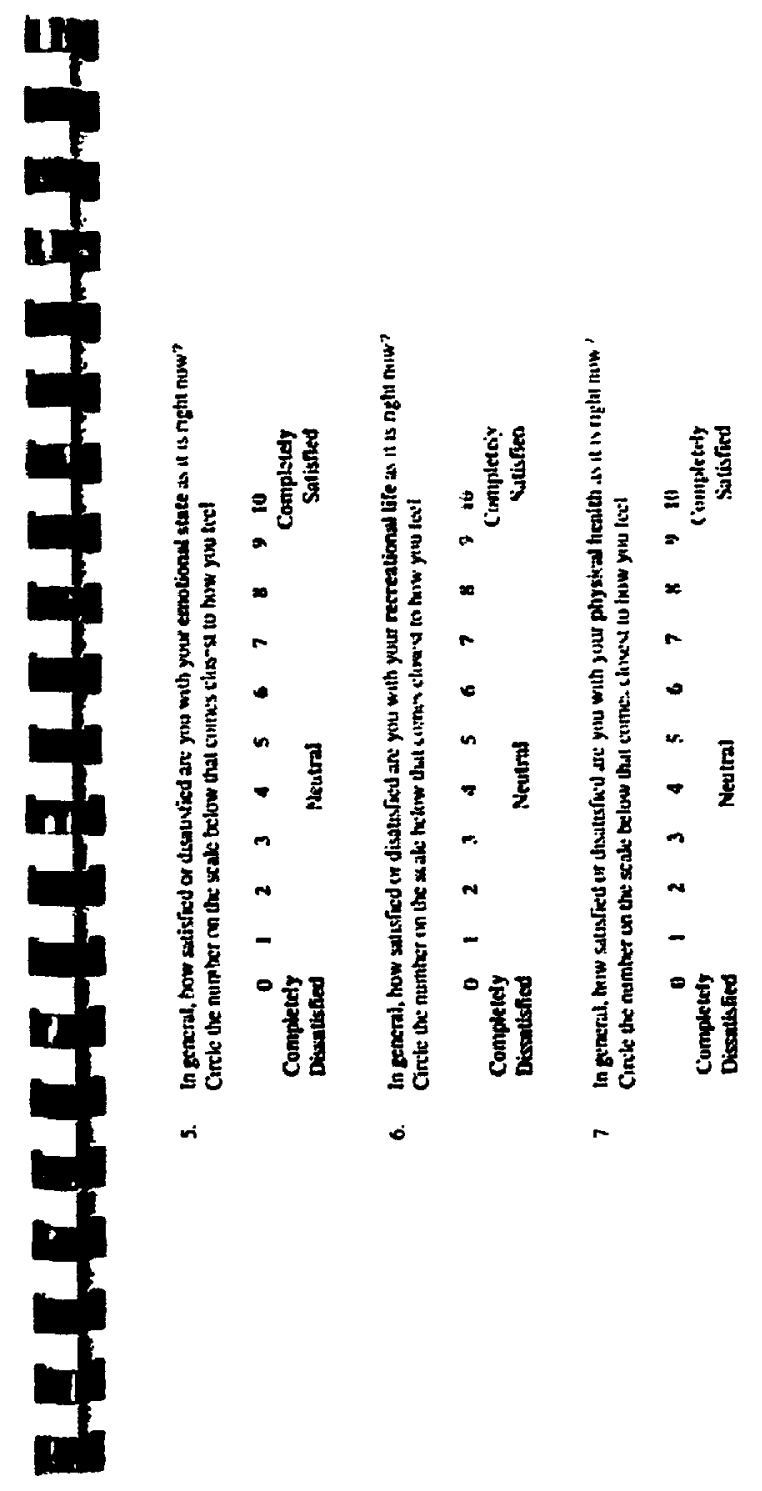




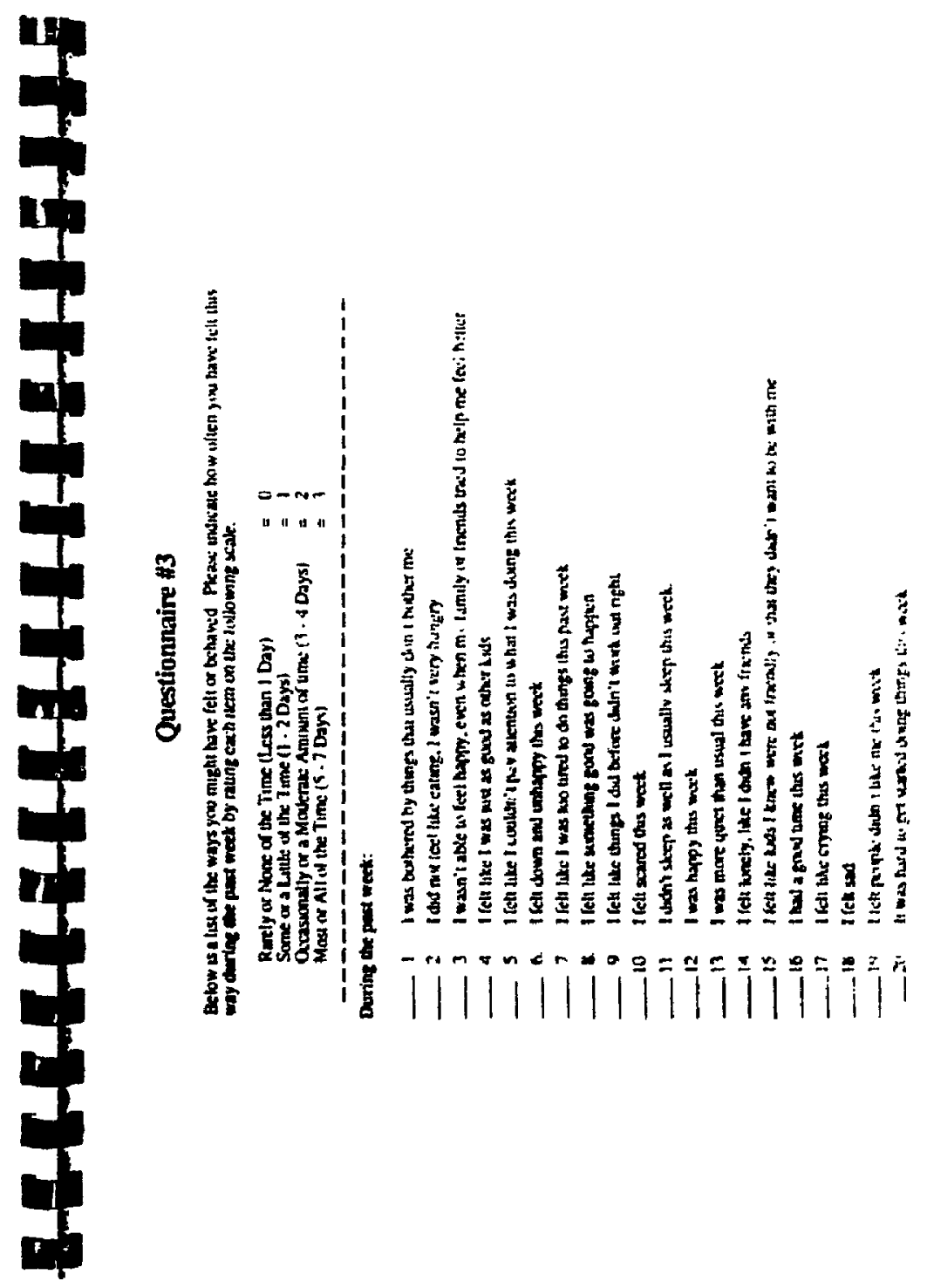




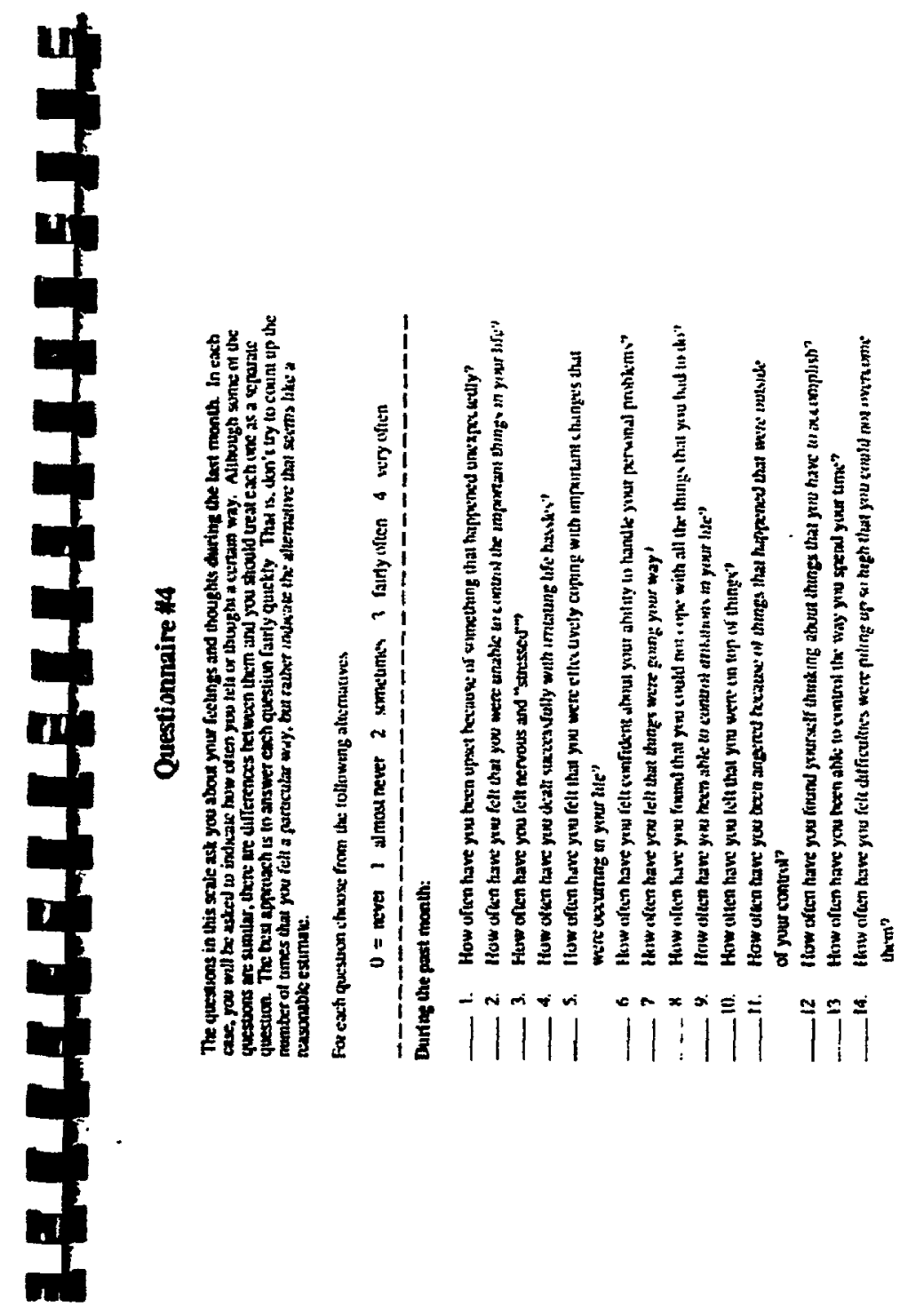




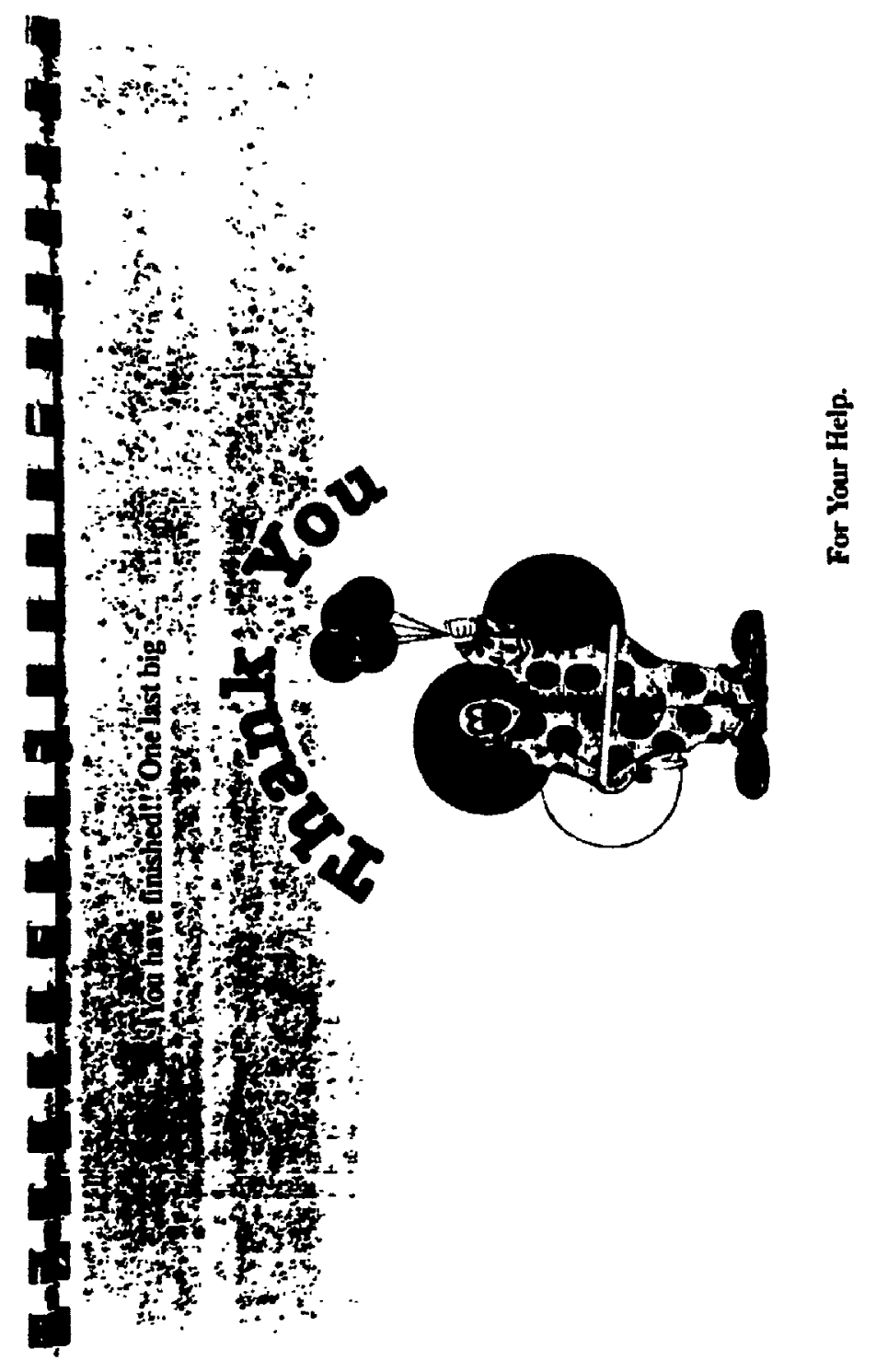


Oarleton University

Text complete; leaf 203 omitted in numbering. 
204

Appendix I

Personal Project Dimension Questions With Definitions and

Question Regarding Rationale for Project Engagement 
Some of our projects are very important to us while other projects are not at all important to us.

How IMPORTANT is each project to you?

$\begin{array}{lllllllllll}0 & 1 & 2 & 3 & 4 & 5 & 6 & 7 & 8 & 9 & 10\end{array}$

not at all totally

Please $r^{-t}$ ? each of your projects using any number from 0 to 10

Some of our projects are very enjoyable to us while other rrojects are not at all enjoyable to us.

How ENJOYABLE is each project to you?

$\begin{array}{lllllllllll}0 & 1 & 2 & 3 & 4 & 5 & 6 & 7 & 8 & 9 & 10\end{array}$

not at all

totally

Please rate each of your projects using any number from 0 to 10

Some of our projects are very difficult to carry out while other proects are not at all difficult.

How DIFEICULT do you find it to do each project?

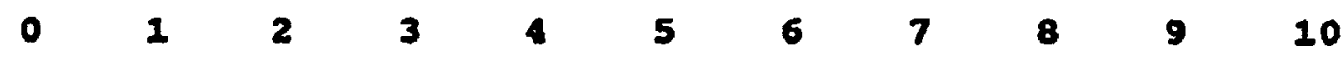

not at a11

totally

Please rate each of your projects using any number from 0 to 10 
our parents, teachers, and other adults who matter to us aro aware of some of our projects, while they are less aware of other of our projects.

HOW ATARE ARE THESE ADULTS of each of your projects?

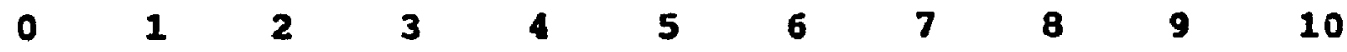

not at all

totally

Please rate each of your projects using any number from 0 to 10

Our friends and classmates are aware of some of our projects, while they are less at are of other of our projects.

HOW AWARE ARE YOUR FRIENDS AND CLASSMATES Of each of YOUT projects?

$\begin{array}{lllllllllll}0 & 1 & 2 & 3 & 4 & 5 & 6 & 7 & 8 & 9 & 10\end{array}$

not at all

$\operatorname{tota11y}$

Please rate each of your projects using any number from 0 to 10

Some of our projects are run by oiner people and we have 1 ittle or no control over them while other projects are totally under our control.

How much do you feel that YOU ARE IN CONTROL of each project?

$\begin{array}{lllllllllll}0 & 1 & 2 & 3 & 4 & 5 & 6 & 7 & 8 & 9 & 10\end{array}$

not at all

$\operatorname{tota11y}$

Please rate each of your projects using any number from 0 to 10 
Sometimes we decide completely on our own to take on a project, while at other times other people assign a project to us.

How much do you feel that it was youR DECISION TO TARE ON each project?

$\begin{array}{lllllllllll}0 & 1 & 2 & 3 & 4 & 5 & 6 & 7 & 8 & 9 & 10\end{array}$

not at all $\operatorname{tota11y}$

Please rate each of your projects using any number from 0 to 10

Some projects are very stressful as they make us feel anxious and under pressure while other projects are less stressful and we feel more relaxed when involved in them.

How STRESSEUI, is each project to you?

$\begin{array}{lllllllllll}0 & 1 & 2 & 3 & 4 & 5 & 6 & 7 & 8 & 9 & 10\end{array}$

not at a11 totally

Please rate each of your projects using any number from 1 to 10

Sometimes for one reason or another we dont spend enough time on some projects while we spend adequate time on other projects.

How much do you feel you spend ADEQUATE TIME ex each project?

$\begin{array}{lllllllllll}0 & 1 & 2 & 3 & 4 & 5 & 6 & 7 & 8 & 9 & 10\end{array}$

not at all

totally

Please rate each of your projects using any number from 0 to 10 
We do not always expect that we will be totally successful in all the projects we take on.

How successful do you think you will be with each profect?

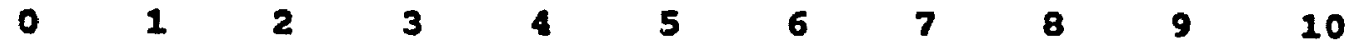

not at a11

totally

Please rate each of your projects using any number from 0 to 10

Each of us does some things that we feel are typical of ourselves. For example, some people read whenever possible and they say that this is typical of them - it is their trademark. Other people play sports or listen to music whenever possible, and they feel that this is typical of them.

\section{HOW TYPICAL OF YOU is each of your projects?}

$\begin{array}{lllllllllll}0 & 1 & 2 & 3 & 4 & 5 & 6 & 7 & 8 & 9 & 10\end{array}$

not at all

totally

Please rate each of your projects using any number from 0 to 10

Everyone has their own idea about what is

right. We call these ideas our values. For one reason or another we sometimes are involved in projects that are not true to our values.

how much do you feel that each project is TRUE TO YOUR VALUES?

$\begin{array}{lllllllllll}0 & 1 & 2 & 3 & 4 & 5 & 6 & 7 & 8 & 9 & 10\end{array}$

not at a 11

total1y

Please rate each of your projects using any number from 0 to 10 
our parents, teachers, and other adults who matter to us think some of our projects are not important, while they think that other projects are very important.

HOW much dO THESE ADULTS THINR EACH PROJECT I8 IMPORTANT?

$\begin{array}{lllllllllll}0 & 1 & 2 & 3 & 4 & 5 & 6 & 7 & 8 & 9 & 10\end{array}$

not at all

tota11y

please rate each of your projects using any number from 1 to 10

our friends and classmates think some of our projects are not important, while they think that other projects are very important.

HOW much do your FRIENDS AND CLASSMATES IINR EACH PROJECT IS IMPORTANT?

$\begin{array}{lllllllllll}0 & 1 & 2 & 3 & 4 & 5 & 6 & 7 & 8 & 9 & 10\end{array}$

not at all

totally

Please rate each of your projects usirg any number from 1 to 10

Even though we may only be planning a project or have only been working on it a short time, we usually have some idea of how successful we have been so far.

How successfur so FAR do you feel you have been with each project?

$\begin{array}{lllllllllll}0 & 1 & 2 & 3 & 4 & 5 & 6 & 7 & 8 & 9 & 10\end{array}$

not at a 11

$\operatorname{tota11y}$

Please rate each of your projects using any number from 0 to 10 
Some projects demand a great deal of our abilities and effort. We call such projects challenging. Other projects are less challenging as they require less of our effort and abilities.

How ChaLlengING TO YOU is each of your projects?

$\begin{array}{lllllllllll}0 & 1 & 2 & 3 & 4 & 5 & 6 & 7 & 8 & 9 & 10\end{array}$

not at a.11

totaliy

Please rate each of your projects using any number from 0 to 10

When we are thinking about or involved in some projects we are totally concentrated and may not even hear the telephone $r$ ing. When doing other projects we are easily distracted by almost anything.

How CONCENTRATED are you when you are involved in each project?

$\begin{array}{lllllllllll}0 & 1 & 2 & 3 & 4 & 5 & 6 & 7 & 8 & 9 & 10\end{array}$

not at al1

tuta11y

Please rate each of your projects using any number from 0 to 10 
Appendix $\mathrm{J}$

Data on Deleted Cases 
Deleted Cases

Missing Data on Project Variables - Grade 7 Males = 3

- Grade 7 Females $=1$

- Grade 8 Males $=2$

- Grade 8 Females $=0$

Missing Data on Well-Being Variables - Grade 7 Males $=1$

- Grade 7 Females $=3$

- Grade 8 Males $=2$

- Grade 8 Females $=2$

Univariate outliers

- Grade 7 Males $=3$

- Grade 7 Females $=1$

- Grade 8 Males $=0$

- Grade 8 Females $=0$

Univariate and Multivariate Outliers - Grade 7 Males = 1

- Grade 7 Females $=0$

- Grade 8 Males $=1$

- Grade 8 Eemales $=1$ 
Appendix $\mathrm{K}$

Gender Differences in Well-Being Scores 
Table Appendix $\mathrm{K}-1$

Gender Differences in Well-Being scores ${ }^{a}$

\begin{tabular}{|c|c|c|c|c|c|c|}
\hline \multirow[b]{3}{*}{ Variable } & \multicolumn{2}{|c|}{ Male } & \multicolumn{2}{|c|}{ Female } & F value & $\mathbf{p}$ \\
\hline & Mean & SD & Mean & SD & & \\
\hline & & & & & & \\
\hline Gen sat & 7.54 & 2.04 & 7.04 & 1.81 & 1.560 & .22 \\
\hline AcadSat & 6.71 & 1.98 & 7.46 & 1.75 & 3.765 & .05 \\
\hline socsat & 6.96 & 2.45 & 6.33 & 2.43 & 1.576 & .21 \\
\hline Homesat & 7.85 & 1.83 & 6.91 & 2.47 & 4.434 & .04 \\
\hline Emotsat & 7.23 & 2.42 & 6.63 & 2.26 & 1.533 & .22 \\
\hline Recsat & 8.31 & 1.89 & 7.26 & 2.11 & 6.474 & .01 \\
\hline CES-DC & 13.79 & 7.92 & 17.93 & 20.53 & 4.675 & .03 \\
\hline PSS & 21.90 & 7.01 & 24.50 & 7.77 & 2.916 & .09 \\
\hline
\end{tabular}

Note.

Male $N=48 \quad$ Female $N=46$

a refer to Table 2 for explanation of variable names. 


\section{Appendix L}

Personal Project Categorization System First Used in Early Adolescent Study

wilmut, K. 1993 


\section{Categories of Early Adolescent Personal Projects}

Personal Projects can be sorted into content categories by considering the general types of activities involved in the elicited projects. A categorization scheme facilitates the examination of common themes between or across individuals or groups. For example, are leisure activities more related to male than female well-being, or are projects dealing with academic pursuits felt to be more stressful than interpersonal activities.

Although categorization is an attempt to partition activities into specialized domains, some overlap of categories may exist with certain projects. For example, the project "go to the movies with Jean" contains elements of both leisure and interpersonal activity. In such cases classification should be based on the primary focus of the activity as literally expressed. The above example therefore would be classified as a Leisure project. The same rationale would assign the project "ask Jean to go to the movies with me" to the Interpersonal project category. project classification should be based primarily on the content of the project as listed in the initial elicitation. The reason given for engagement in an activity may prove helpful in clarifying such issues as the time frame or relationship of individuals involved in a project. This information however should not be used to reassign a project from one category to another. For example, the reason "to be with my friends" should not be used to reassign the leisure activity of "go to the movies" to the Interpersonal project category. Similarily, the reason "because I would like to get to know Jean better" should not be used to reassign the Leisure project "go to the movies with Jean" to the Interpersonal category. While it may be argued that such (for example) leisure activities often involve interpersonal concerns, in this study we are interested in examining of everyday activities of individuals as initialiy expressed in the project listings.

This perspective does not preclude the possibility that a specific project, or any number of projects, may in fact be in the service of more molar goals, or that a single project may serve to integrate or organize a number of more molecular interests. Nor does it ignore the possibility that there may be individual differences in the level of molarity at which projects are expressed. Rather it chooses to focus on the level of everyday activity a's conceived of and expressed by the individual, recognizing that an individual's Personal Projects may encompass and rellect the individual's conceptions of these possibilities. Projoet claselfication therveore should be baged prinnily on the project os listad in the initial elieltation and the renson given for engagoment in an activity should be used nolely for the purpose of clarification. 
Finally, some projects may appear to fit into more than one category. For example, the project "finish reading my book" may be a Leisure project or an Academic project. similarily, the project "lose weight" may be a

Hedith/Fitness project or an Appearance project. Often the reason given for engagement in the project will provide clarification. For example, the reason "for fun" indicates that "Inish reading my book" is a leisure project. At other times the rationale may provide little clarification. For example, the reason "because I want to" does not provide information that would allow for a definitive classification of the "lose weight" project. Default categorization

guidelines are provided for use in these latter cases. That is, in the absence of sufficient or contradictory information, such projects are consistently assigned to a pre-determined category.

The following presents a list of the broad project categories and their respective subcategories along with definitions, examples, default guidlines, and notes expanding on the above. Coders are encouraged to read and faulij-ize themselves with the complete classification schems before commencing categorization.

\section{ACADGEIC}

Thir category includes school activities that are related to classwork, homework, and academic achievement. The subcategories are:

1 Bhort-The (projects that are being or will be pursued up to and including the completion of Junior High school, e.g. finish my french story, passing this year, get out of junior high). Dofaul' - In the absence of contradictory information, reading profects should be coded as ACADEMIC projects e.g. "read my book" accompanied by the reason "to finish it" or unaccompanied by a reason.

2. rong-The (projects that are anticipated to be pursued upon completion of Junior High school, e.g. go to high school, get into a good university). Dofunit - In the absence of contradictory information, ACADEMIC projects should be coded as short-Term, e.g. "do well in school" accompanied by the reason "I want to".

Norn - This category does not include extracurricular activities (LEISURE) or reading for pleasure (LEISURE).

BOrs - A consideration of the reason given for engagement in 
a project may be helpful in establishing whether a given activity is indeed related to academic pursuits (e.g. "finish reading my novel" - "for school" versus "for fun") or to establish its time frame (e.g. "study harder" - to pass this grade" versus "to get into a good university"). The reason provided however should not be used to reassign an academic activity to another project category. For example. "pass this grade" should be coded as an ACADEMIC project even though the reason given may be "to please my parents", "to be with my friends", or "to get a good job".

\section{2. vOcaTIONAI}

This category includes activities related to occupation. The subcategories are:

1. Bhort-Texm (projects involving actual work tasks and activities concerned with finding employment in the near future, e.g. doing my paper route, baby-sitting, looking for a summer job).

2 rong-rert (projects involving longer term (1.e. beyond the junior high school years) occupational concerns and aspirations, e.g. get a job when I graduate, become a lawyer, make it into the NHL). Default - In the abscence contradictory information, VOCATIONAL projects should be coded as short-Term, e.g. "get a good job" accompanied by the reason "I want to".

NOHE - A consideration of the reason given for engagement in in a project may be helpful in establishing its time frame (e.g. "get a good job" - "to buy clothes that I like" versus "to be rich"). The reason given however should not be used to reassign a vocational activity to another project category. For example, "get a part time job" should be coded as a VOCATIONAL project even though the reason given may be "to buy a basketbali net" or "for college".

\section{IIMERPGR8ORNI}

This category includes activities dealing with others on a personal level. The subcategories are:

1. Pnrent (projects in which parents are the primary focus either individually or within the family context, e.g. get along better with mom, convince ny parents to let me buy my own clothes, spend more time with my family). 
the primary focus, e.g. be nicer to my sister, teach my brother to ride a bike).

3 Iflende (projects in which (more than one) friends, peers, or classmates are the primary focus, e.g. help my friends quit smoking, spend more time with my Eriends).

I Intimnte pear (projects in which a single peer, friend, or classmate, or a desire for intimacy involving another of the same or other sex is the primary focus, e.g. buy a tape for Jean's birthday, get a certain guy's attention, go on a date).

s other Bfonfelcant Adulta (projects in which an adult or adults other than parents are the primary focus, e.g. visit my grandmother, not be so rude to teachers).

L comuntty gupportive (projects in which groups of people other than siblings, peers, parents or other significant adults are the primary focus, e.g. volunteer work).

27 Mte (projects in which relationships with unspecified people in general are the primary focus, e.g. become more popular, being everyone's friend).

\section{INTRNPERBOIN}

This category includes activities dealing with outlook and attitudes relating to the self. The subcategories are:

if splritunl/chuee (projects relating to the clarification or expression of religious beliefs, values, or environmental concerns, e.g. get along with God, be true to myself, helping the environment).

e sne-rmprovenent (projects that are related to psychological, as opposed to physical, change, e.g. overcome my shyness, be more relaxed, control my temper better).

23 Mte (projects that are intended to establish or maintain an overall sense of order in an individual's collective activities, e.g. being more organized).

s. Inteve nithdrawal (projects that are aimed at reducing the amount of time or money invested in free time activity, e.g. watch less $T V$, stop spending money on useless stuff). 
S Coplng/adiustment (projects related to dealing with or adapting to significant life events, e.g. try to forget about my aunt's death).

\section{LEIBURE}

This category includes recreational activities that are done alone or with others. The subcategories are:

1 Media Entertainment (projects (except those that are print based) that involve watching, listening to, or interacting with audio, visual, or live mediums that are pursued primarily for entertainment, e.g. see more movies, listen to music, go to the theatre, play video games).

2 Pleneure Readir (projects that involve reading of printed material primarily for enjoyment, e.g. read MAD magazine, read the new stephen $k i n g$ novel, $f$ inish my book tonight - accompanied by the reason "for fun") . Default - In the abscence of contradictory information, reading activities should be coded as ACADEMIC projects. For example, "read my book tonight" accompanied by the reason "to finish it" or unaccompanied by a reason shoui 1 be coded as an ACADEMIC project.

.3 Plensure shopping (projects that involve looking at merchandise in stores and store windows primarily for pleasure as opposed to shopping for required items, e.g. going shopping to see what's new, shopping accompanied by the reason "for fun"; .

Default - In the abscence of contradictory information, shopping activities should be coded as ADMINISTRATIVE projects. For example, "shopping" accompanied by the reason "my bicycle is too small for me" or unaccompanied by a reason should be coded as an ADMINISTRATIVE project.

4. 8port (projects involving physical activity that are pursued primarily for entertainment and are not specifically identified as being motivated by health, fitness, or appearance concerns, e.g. learn to skateboard, playing volleyball, go biking, exercise accompanied by the reason "for fun", not exercise accompanied by the reason "to get in shape (HEALTH/FITWESS) nor by the reason "to look better" (APPEARANCE)) .

Defoult - In the abscence of contradictory ingormation, activities involving sports should be coded as IEISUREsport projects. However, if the reason accompanying a 
sports activity specifically indicates that it is being pursued primarily for health, fitness, or appearance concerns, the activity should be coded accordingly. For example, "go jogging every day" accompanied by the reason "to get in shape" should be coded as a HEALTH/FITNESS project while the same project accompanied by the reason"so that I will look better" should be coded as an APPEARANCE project.

5 Hobbylinterest (projects other than those that are sport related that involve the acquisition or exercise of knowledge or skills primarily for pleasure, as opposed to for academic or vocational, reasons, e.g. orgam'ing my hockey cards, learn to play guilar, set up a $\because$ rrarium, learn more about computers accom $:$ ied by the reason "for fun"). Default - In the abscence of contradictory information, projects involving learning about or engaging in activities that may or may not be school or job related should be coded as LEISURE projects. For example. "learn to speak French" should be coded as a LEISUREHobby/Interest project unless the reason accompanying such a project indicates utherwise, e.g. "I have to" or "to pass this year". These latter reasons suggest that such a project is not primarily a recreational activity and it should be considered to be related to academic or vocational interests.

6 Pood (projects that are focused primarily on the consumption, as opposed to the preparation, of food, e.g. get a pizza after school, eating junk food).

7 pet (projects involving pets that are pursued primarily for enjoyment, as opposed to for practical, reasons, e.g. playing with my cat, walking my dog accompanied by the reason "for fun").

Default - In the absence of contradictory information, activities involving pets should be coded as LEISUREpet Projects. For example, "walk my dog" should be coded as a LEISURE project unless the reason accompanying such a project indicates otherwise, e.g. "I have to" or "to please my parents". These latter reasons indicate that such a project is not primarily a recreational activity and it ghould be considered to be an administrative activity.

s prinking/Druge (projects involving the recreational use of non-prescription drugs or alcohol, e.g. drink some beer on the weekend, get high, not quit smoking (HEALTH/FITNESS)).

e Pertie/Danceg (projects focused primarily on the 
planning of or participation in organized social gatherings that involve a group of friends or peers, e.g. go to the dance on friday, have a sleepover, pian a surprise party for Jean).

.10 Getting out/Away (projects that involve vacations and travel to or stays at local or more distant destinations primarily for the purpose of pleasure, e.g. go to Paris, getting out more with my friends, hanging out at the mall).

-11 Phone/Letter Nriting (projects focused primarily on initiating or maintaining contact with others via the telephone or through written communication, e.g. write to my pen pal, talking on the phone).

NOTE - Most extracurricular recreational activities should be coded as LEISURE projects, e.g. make the school soccer team, join the school choir.

NOrE - A consideration of the reason given for engagement in a project may be helpful in establishing whether or not a given activity is primarily a LEISURE project, e.g. "Einish my book" or "learn about computers" - "for fun" versus "because I have to". The reason provided however should not be used to reassign a leisure activity to another project category. For example, the project "go to the movies" should be coded as a LEISURE project even though the reason given may be "to be with my friends".

\section{ADKINIBTRATIVE}

This category includes mundane activities related to meeting basic needs or acquiring or maintaining possessions anc the immediate living environment. The subcategories are:

1 yoney Related (projects that involve getting or saving money for a specified reason or generaliy, without specific mention of a job, e.g. get a clothing allowance, save up for a new bicycle, earn money to buy a horse, not get a part-time job so that I can buy a horse (VOCATIONAL -short Term)).

2. Mnintennen (projects, other than those focused on material acquisitions (see below), that primarily involve the meeting of basic needs or the maintenance or the enhancement of ones' immediate living environment, e.g. chores, redecorate my room, get to school on time, get a bus pass, organjize my room, not be more organized (INTRAPERSONAL-Meta), learn to cook accompanied by the reason "to be more independent", not 
learn to cook better - accompanied by the reason "I like to cook (LEISURE-Hobby/Interest)).

3 clothing rcouisitione (projects that primarily involve shopping for or purchasing clothing without specific mention that the activity is being pursued for the sake of appearance, e.g. get new shoes, shop for a grad dress, shopping -accompanied by the reason "for clothes", not shopping - accompanied by the reason "for fun" (LEISURE- Pleasure Shopping) nor accompanied by the reason "to look better" (APPEARANCE- Clothing)) . Default - In the absence of contradictory information, activities involving the acquisition of clothing should be coded as ADMINISTRATIVE-Clothing Acquisition projects, e.g. "get Nikeairs" - unaccompanied by a reason.

A Other Rcquisitions (projects that primarily involve shopping for or purchasing items other than clothing, e.g. get a new bike, get my own phone, shopping accompanied by the reason "for stuff").

5 Pet (projects that involve pets that are pursued primarily for practical, as opposed to enjoyment, reasons, e.g. training my cat, walk my dog accompanied by the reason "I have to" or accompanied by the reason "to please my parents", not walk my dog accompanied by the reason "for fun" (LEISURE-Pet)). Default - In the absence of contradictory information, activities involving pets should be coded as LEISUREpet projects, e.g. walk my dog - unaccompanied by a reason.

NOT: - A consideration of the reason given for engagement in a project may be helpful in establishing whether or not a given activity is primarily an ADMINISTRATIVE project, e.g. "buy clothes" - "I need them" versus "to look nice". The reason provided however should not be used to reassign an administrative activity to another project category. For example, the project "buy a basketball net" should be coded as an ADHINISTRATIVE project even though the reason given may be "to be a better basketball player" or "to get in better shape".

\section{APPENRNMCE}

This category includes activities that are related to personal appearance. The subcategories are:

1 Body (projects, other than those related to basic needs, that deal primarily with the maintenance or 
enhancement of ones physical self without specific mention that the activity is being pursued for health or fitness reasons, e.g. get a hair cut, lose weight, get rid of my acne, exercise - accompanied by the reason "to look better" , not exercise - accompanied by the reason "to get in shape" (HEALTH/FITNESS)). Default - In the absence of contradictory information, activities that focus on the maintenance or enhancement of ones body should be coded as APPEARANCE-Body projects, e.g. "lose weight" unaccompanied by a reason. However, if the reason accompanying such an activity specifically indicates that it is being motivated primarily by health or fitness concerns, the activity should be coded accordingly. For example, "lose weight" accompanied by the reason "to get in shape" should be coded as a HEALTH/FITNESS project.

.2 clothing (projects, other than those related to body appearance, that are specifically aimed at improving or making one feel better about his or her appearance, e.g. buy new clothes - accompanied by the reason "to look better" go shopping for clothes - accompanied by the reason "to look good").

Default - In the absence of contradictory information, activities involving the acquisition of clothing should be coded as ADMINISTRATIVE-Clothing Acquisition projects, e.g. "buy Nikeairs" unaccompanied by a reason.

Nors - A consideration of the reason given for engagement in a project may be helpful in establishing whether or not a given activity is primarily an Appearance project, e.g. "exercise" - "to look better" versus "to get in shape". The reason provided however should not be used to reassign an appearance activity to another project category. For example, the project "get bigger muscles by lifting weights" should be coded as an APPEARANCE project even though the reason given may be "to get a girifriend".

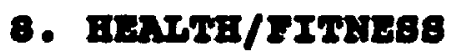

This category includes activities that are clearly and specifically stated as being primarily related to health and fitness concerns. The subcategories are:

s. Benith (projects that are specifically almed at maintaining or enhancing ones physical health status, e.g. quit smoking, not drink, get more sleep, swim accompanied by the reason "to overcome my asthma"). Default - In the absence of contradictory : formation, activities that may be considered to be related to both 
health and fitness concerns should be coded as Health projects, e.g. "quit smoking" - unaccompanied by a reason.

2. Pltnes (projects that are specifically aimed at maintaining or enhancing ones fitness level, e.g. keep fit, get in better shape, play basketball - accompanied by the reason "to get in better shape", not play basketball - accompanied by the reason "for fun" (LEISURE-Sport) nor accompanied by the reason "to lose weight" (APPEARANCE-Body)).

Default - In the absence of contradictory information, activities that may be considered to be related to both health and fitness concerns should be coded as Health projects, e.g. "quit smoking" - unaccompanied by a reason.

DERAULT - In the absence of contradictory information, activities involving sports should be coded as LEISURE-Sport projects, e.g. swin everyday - unaccompanied by a reason. 


\section{Appendix $\mathrm{M}$}

Personal Project Categorization System Lecci, L. 1991 


\section{Cotegories \\ of \\ Personal Projects}

Personal projects can be sorted into content categories ay considering the gereral tupes of activities involved in the eliciteit Frojerts. A categorization sheme iacilitates the examination of common themes across individuals. For example, are projecte dealing with actemit pursuits more streseful than boupational tosks or do leistre actrities anelionte the potentially negative eifects of streseful [rojects?

Althugh categoriation 's an attempt to fartition activities into sponolized domains or core elements, some overlop of categories may Eust with certain projects When categorizing projects, coders should be arore that many actinties are multioceted, eg. Sally's involvement in intrombal bakettal! may be manly for fun (LEISURE) but she knows that

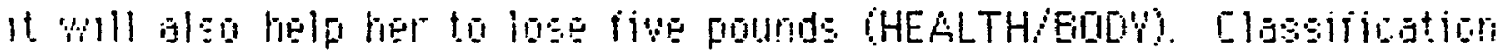

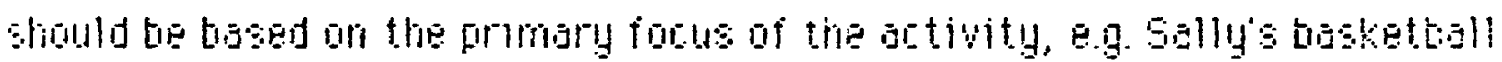
Ohand bie catenorized as a LEISURE activity.

\section{OTCIFATIOHAL/ALADEIIIL}

This cotegory includes actust wort or tasts on the job $6 \mathrm{eg}$. Cinch

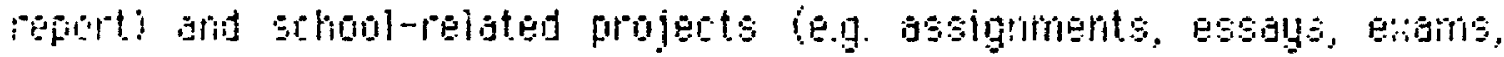
restings The sutiotegories are:

1. Arodemic projects

$\therefore$ Jot-related projects

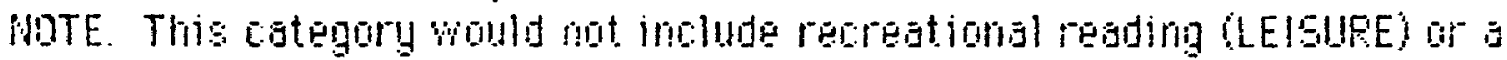
course on learning to play bridge (LEIGUEE).

\section{$\therefore$ HEALTH/BODO}

This categury includes activities reloting to apperance, health.

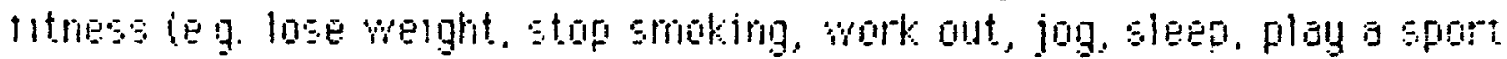
with a fitress goil blearly etated and hot for recreational purposes). HOTE This category would not inciude recreational sporting activities. ILEISUEE:

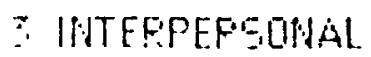

This cotegon mindes projects dealing with others an a peronal 
level. The sututegunes are:

1. Family ipojects imoluing parents, spouse grandparents etc as fous either individually or in a group, eq. visiting my grandmother. taking mity mun to do her grocery shoping?

2. Interpersonol intimate iprojects involving intimate others such as boyigirlirend or close inends eg. qetting aver lary. sesual activities not boy-watching (LEISURE) or girls (iiTEEFEPSONAL secondary).

3 Interpersonal secondiry assume interpersonal projects are secondary unles fiamily members of intimate friends are spectitud, frojects dealing with acquantonces such is olasmites. teachers, co-workers, etce, eg. getting along better with my toss. Entertioning. going out with the gorig not portying (LEISURE)

4. Communitu/supoortive projects forojects involving actwitiss reloted to groups of people other than family or friends, eq. soccer couch, voluntear work soute girl gudes, helping people)

5. lleta -projects (eg. getting my social life together).

\section{INTFAFEFGONALVYALUE CONCEFNS}

This cotegory includes projecte dealing with outlow and attitudes releting to the self. The subiategories are:

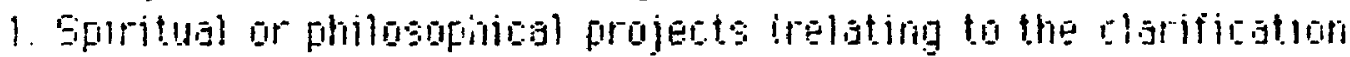
or expresion of religious bellets, philosophical questioning

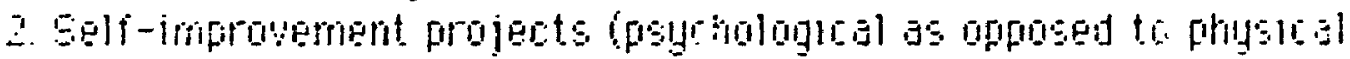
thanges

$\therefore$ lleta-brojects leg mantaining somo sense of order in my life.

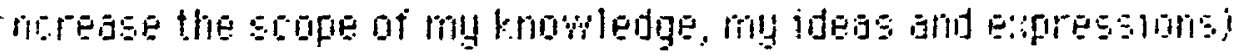

\section{LESGHE}

The category includes recrestiond actuities that are dome alone or with others. The subrategories are:

1. Entertaiment ieg. Telovision, lovies, ilusums, Theatre.

Fock or Classical Concerts

2. Farties/oances

CHobbies (eg. Stam Collectmg!

4. Consumar (eg plesoume onofoirig)

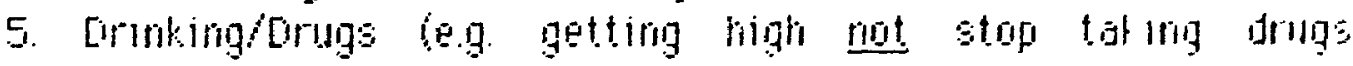
(HEALTH/EIOOH)

E. Flegsure reading and writing. letter-writing

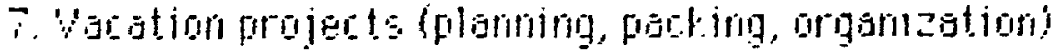

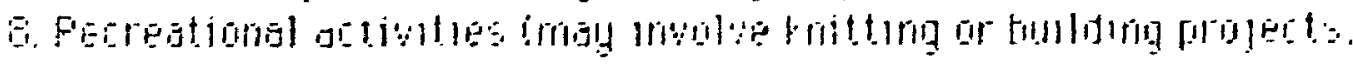

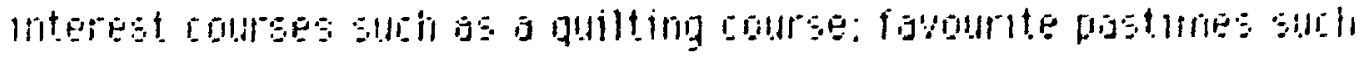




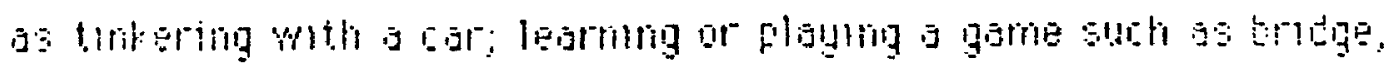
Ehess, Artoune?

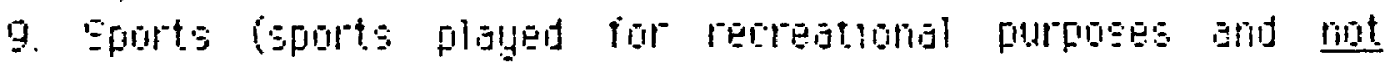

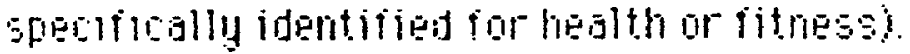

10. Enjoung your pet (eg. ploying with my cat not toking the dog for

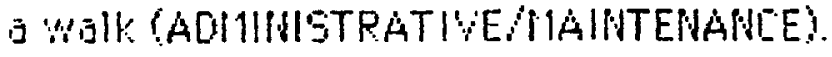

\section{ALHHWSTPATIVEMAIMTEMAHCE}

This cotegory inoludes projects relating to orquniation aria achunistration. The subiategories include:

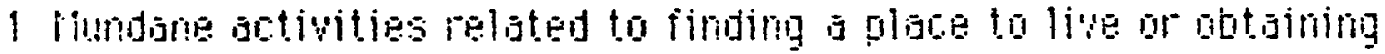
amploument fog. registering at the Employment Centre filiing out.

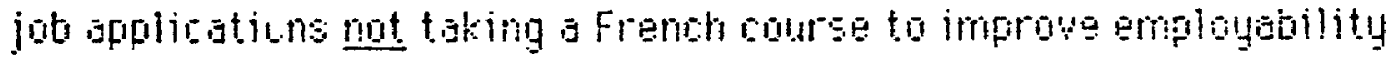
COILLUPATIOHAL ACALEIHICI

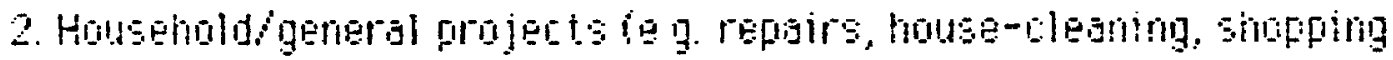
fur hecssities such as qroceries

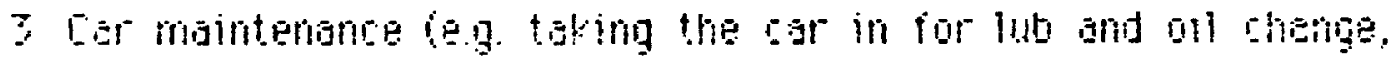

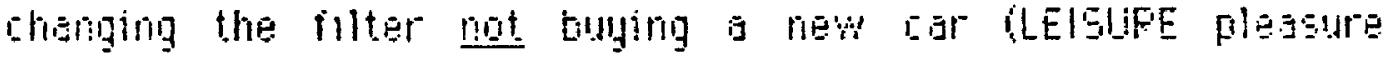
shoporigi:

4. Polping bills, shanging finshes, loans.

5 butting rapistered for a course ar program.

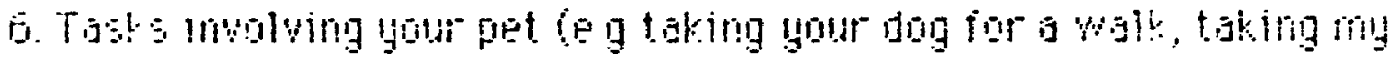
Fet th the uet for distemper shots not noving fun whth Spot ILElSIFE)

\section{T. DTHEP}

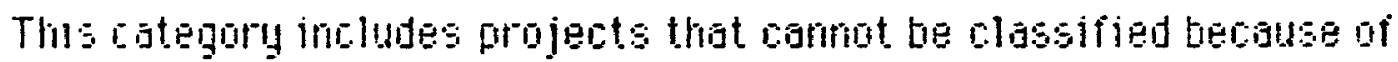
inalequte infomation. Biote using this category an attempt. should be made ta gain mare information in oraer ta correctly classify the projert. The project statement an the original elicitation list and the dimensian rating scores for this project risy be helpful sources. For esamale, if a project is listed only as "Mary", teference to the original elicitation ?st may show thist the propect was phrsed as "Wrejking up with liary" in which rase the projert. sould be correctly olassifies as INTERFERSOPAL intimate. With a projet listed as "Ehristmos shoppirin", an smbiguity for

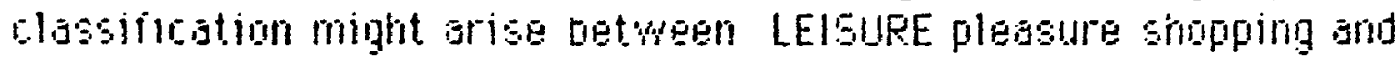

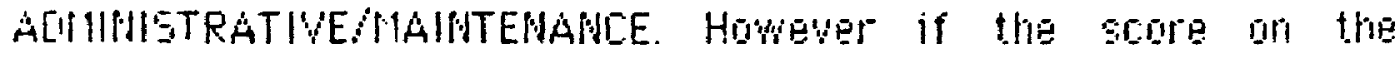
Enowhen columin for thot froject was high, the froject should we

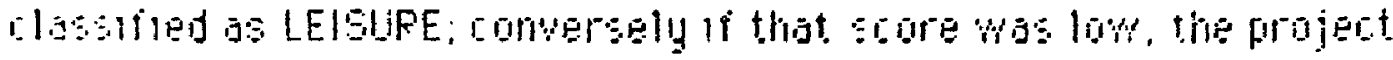

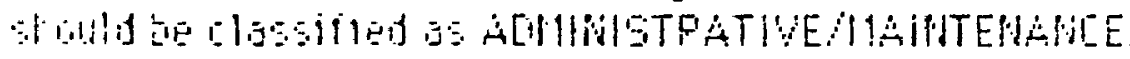


Appendix N

Percentages of the Total Number of Project Listed within the Broad Project Categories 
Table Appendix $\mathrm{N}-1$

Rercentages of the Total Number of Projects Listed in the Broad Project Categories

Project Category

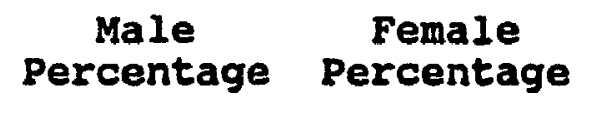

Combined Percentage

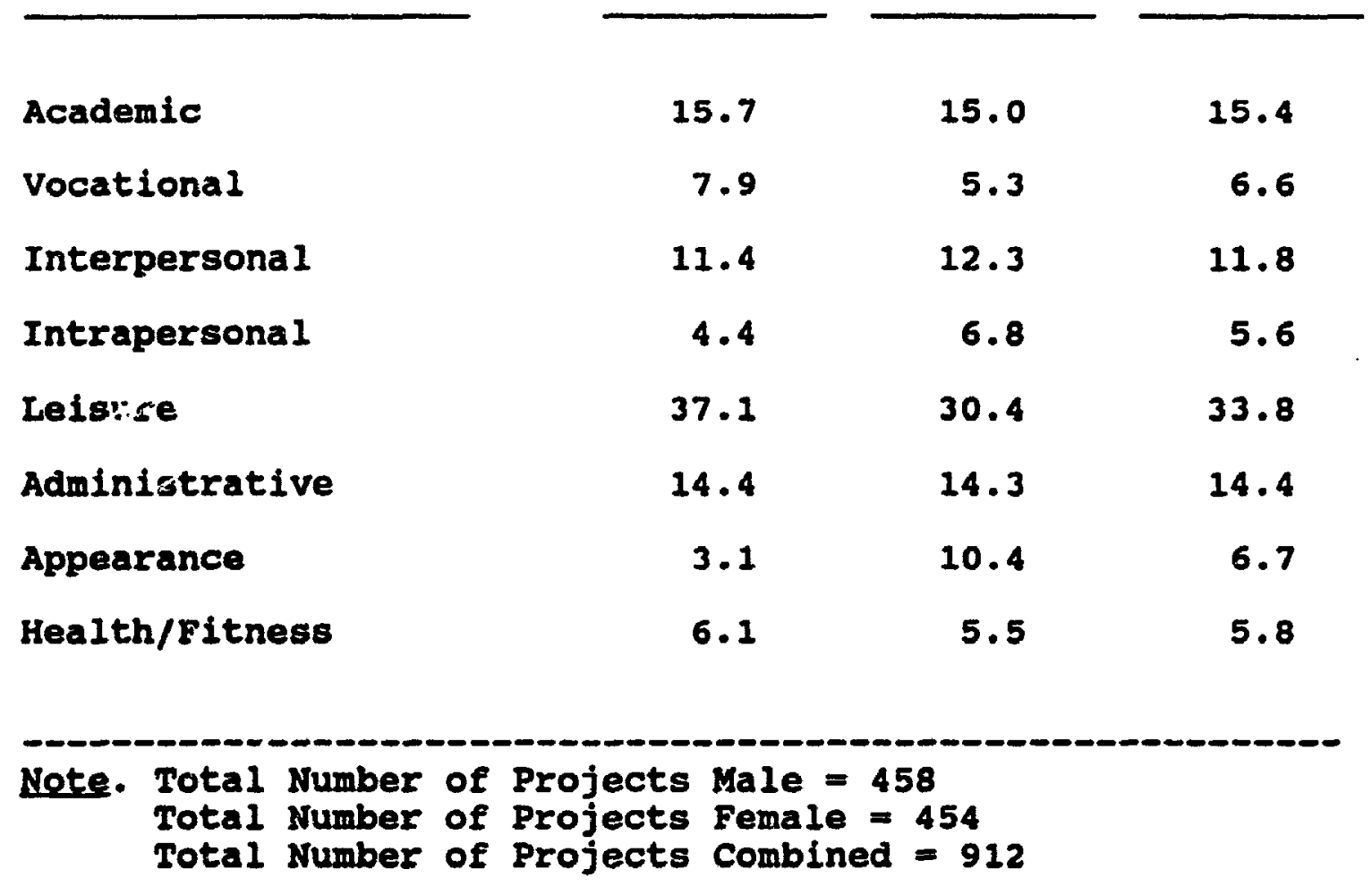


Appendix 0

McQuitty Linkage Analyses 
Figure Appendix 0-1

Ycouitty Linkage Analysis of Male Project-System Dimension Ratings:

cluster 1

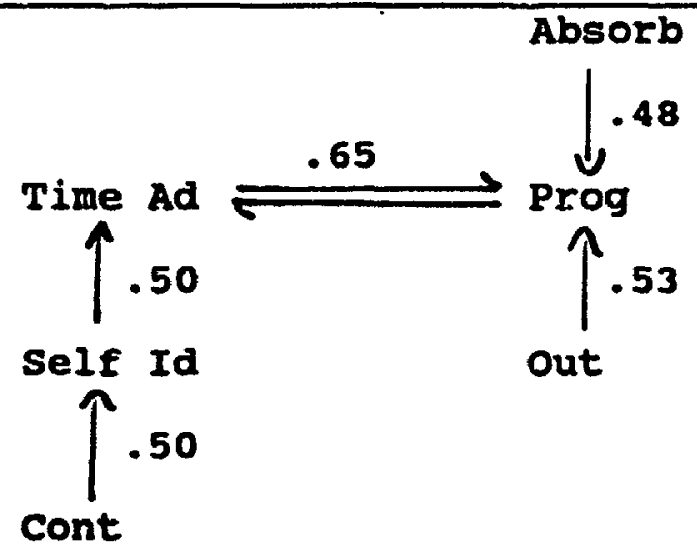

cluster?

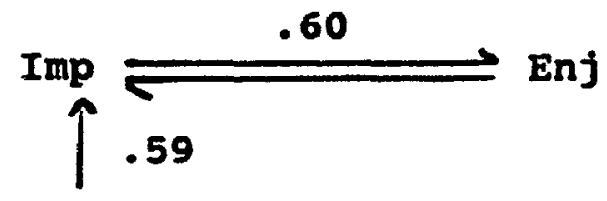

Val cong<smiles>CCC[AsH3]</smiles>

Cluster 3

Init

\section{cluster 3}

Peer Imp $\underset{.56}{\rightleftharpoons}$ Peer Vis

\section{Chall}

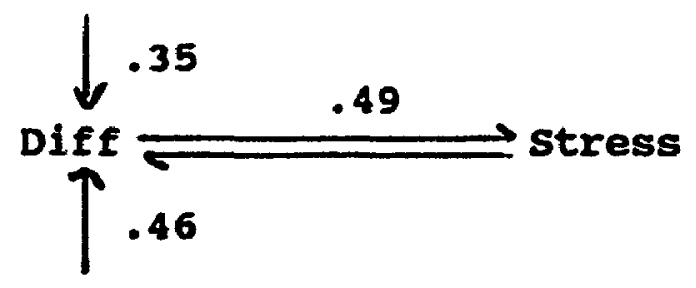

Cluster 4

Ad Vis

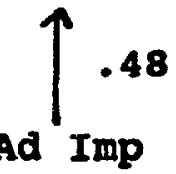

Note. $N=48$

- Refer to Table 8 for explanation of Project Dimension names. 
Figure Appendix 0-2

Mcouitty Linkage Analysis of Female Project-System Dimension Ratings

Cliuster 1

cluster 2

Cluster 3

Cluster 4
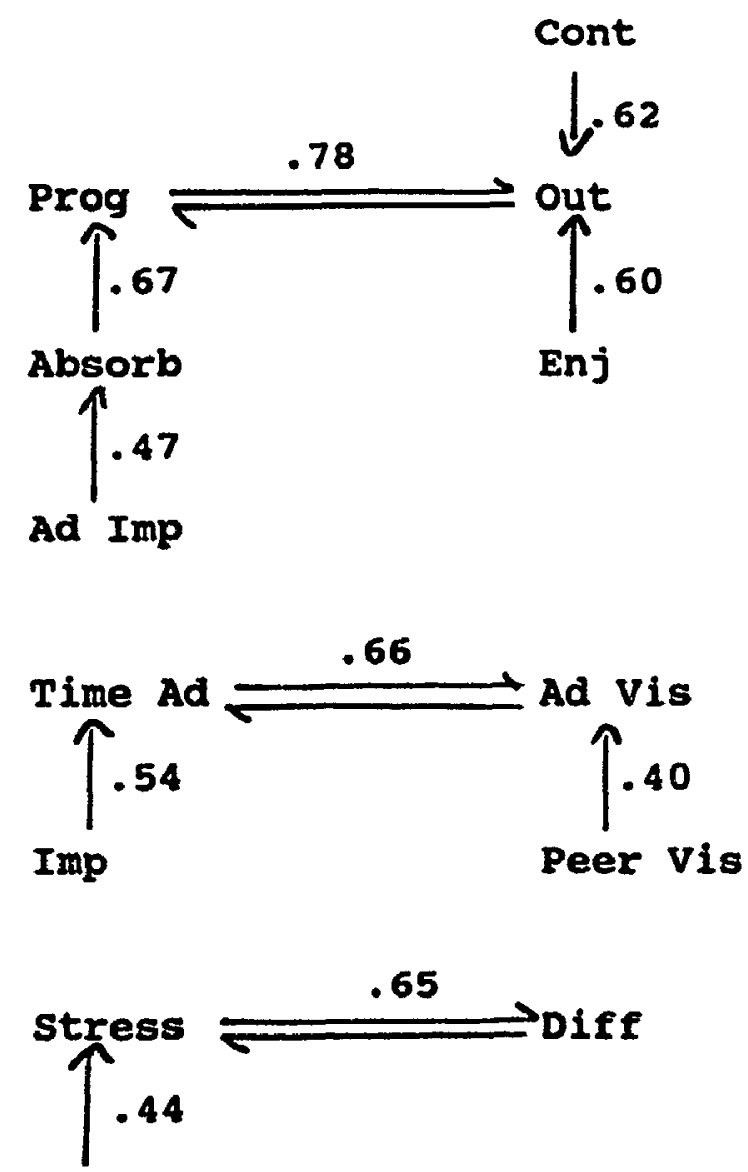

Chall

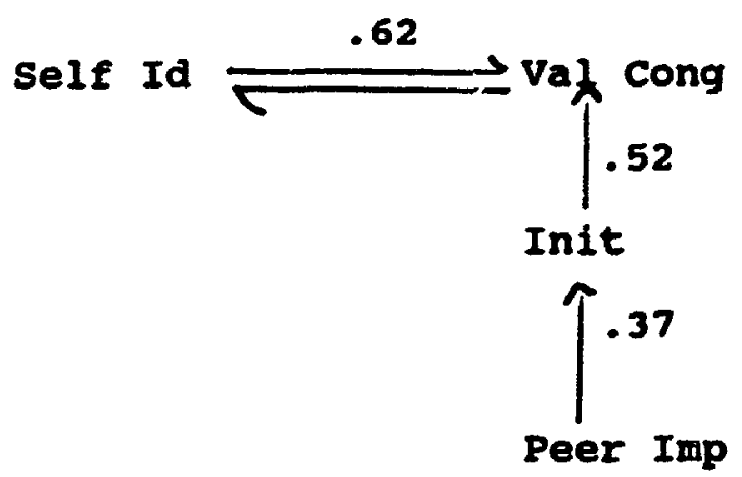

Note. $N=46$

- Refer to Table 8 for explanation of Project Dimension names. 
Figure Appendix 0-3

McQuitty Linkage Analys is of Acacemic Project Dimension Ratings

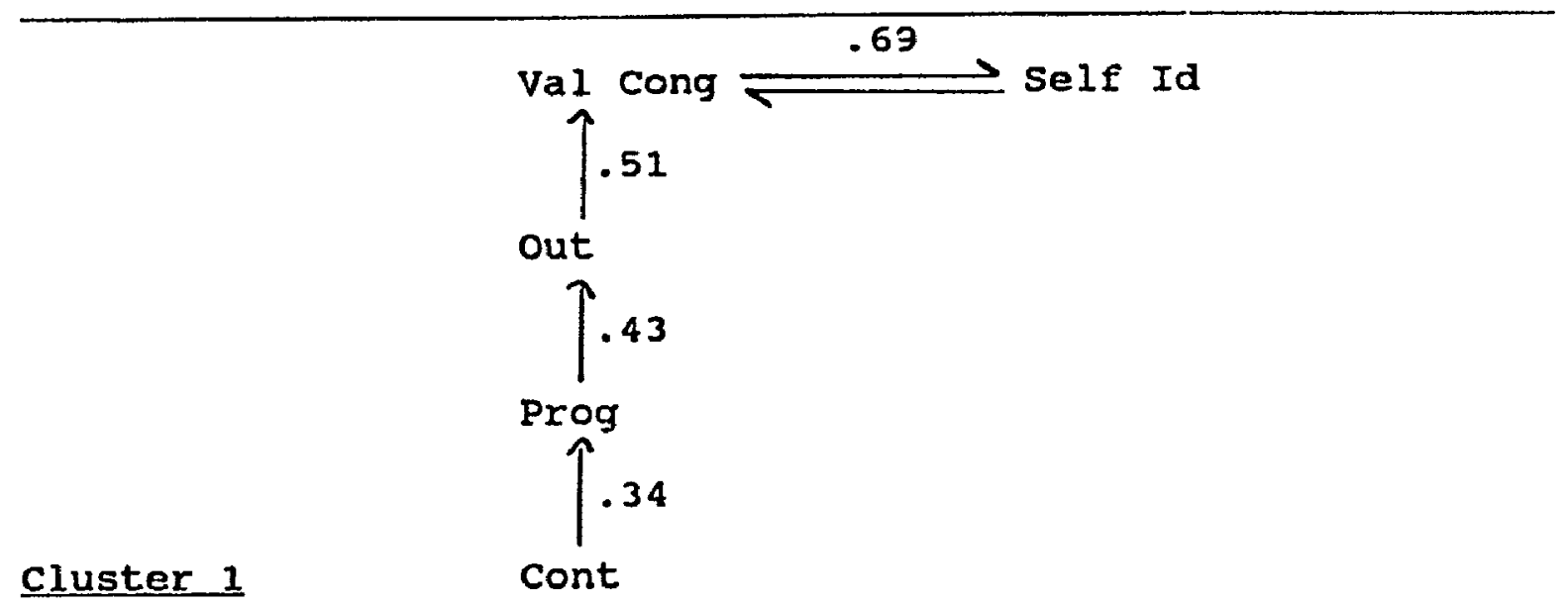

Cluster 2

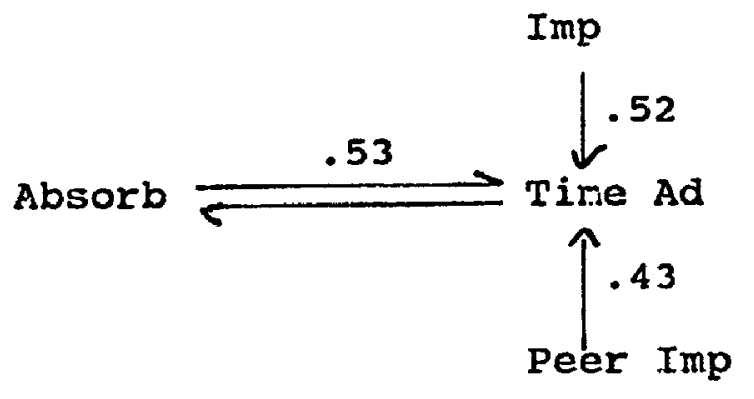

Cluster 3

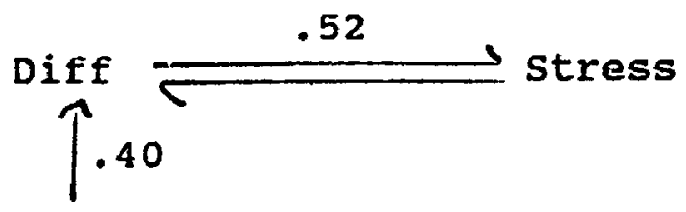

cluster 4

Chall
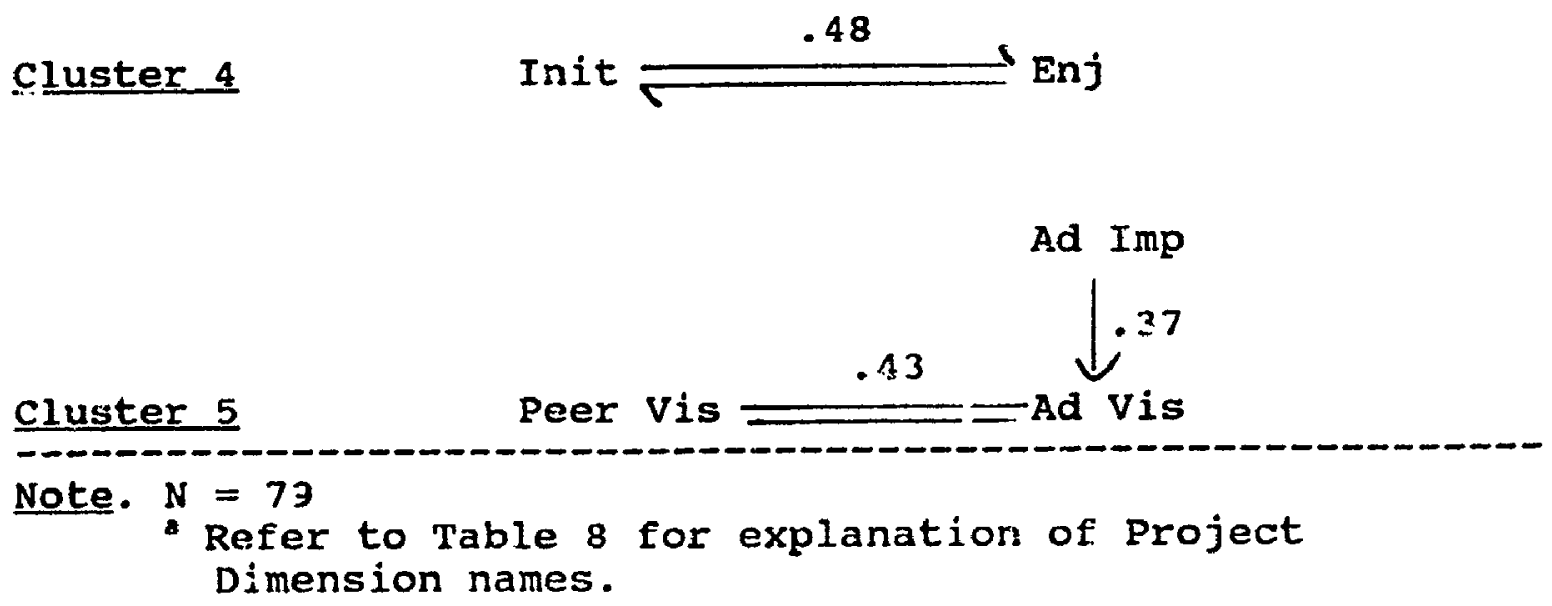
Figure Appendix 0-4

McQuitty Linkage Analysis of Interpersonal Dimension Ratings

Cluster 1

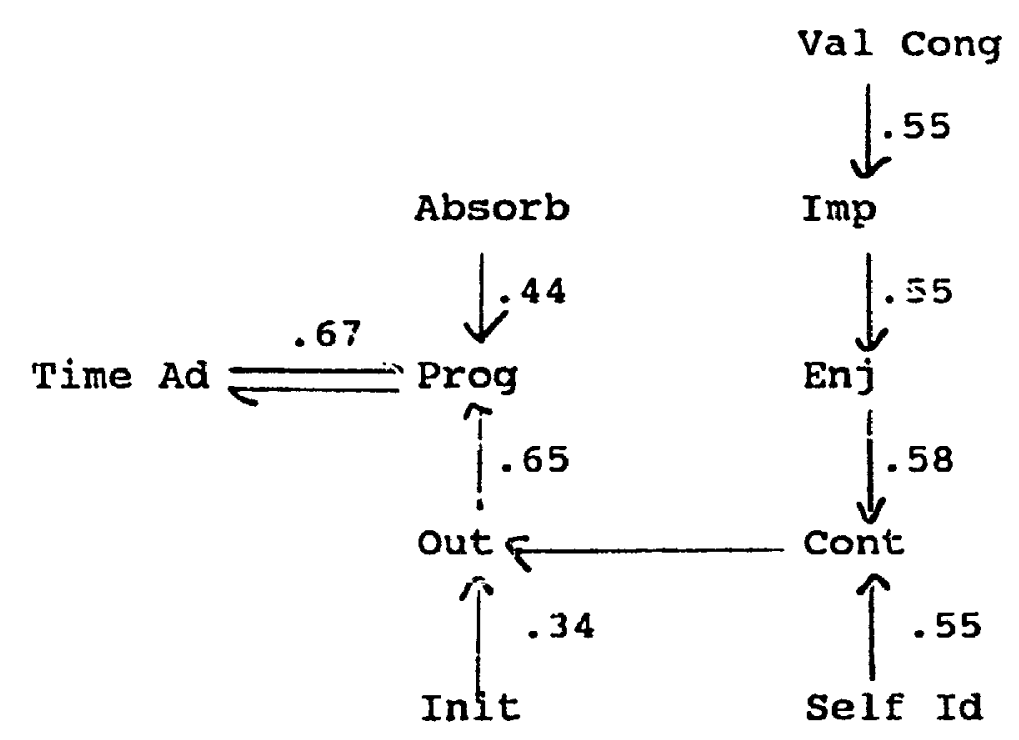

Cluster 2

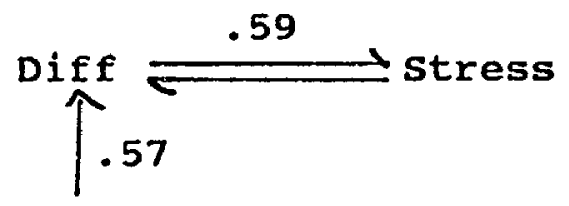

Cluster 3

Chall

Cluster 4

Ad Vis $\stackrel{.47}{\longleftarrow}$ Ad Imp

Peer vis $\stackrel{.47}{\rightleftharpoons}$ Peer Imp

Note. $N=58$

a Refer to Table 8 for explanation of Project Dimension names. 
Figure Appendix $0-5$

Mcouitty Linkage Analysis of Leisure Dimension Ratings

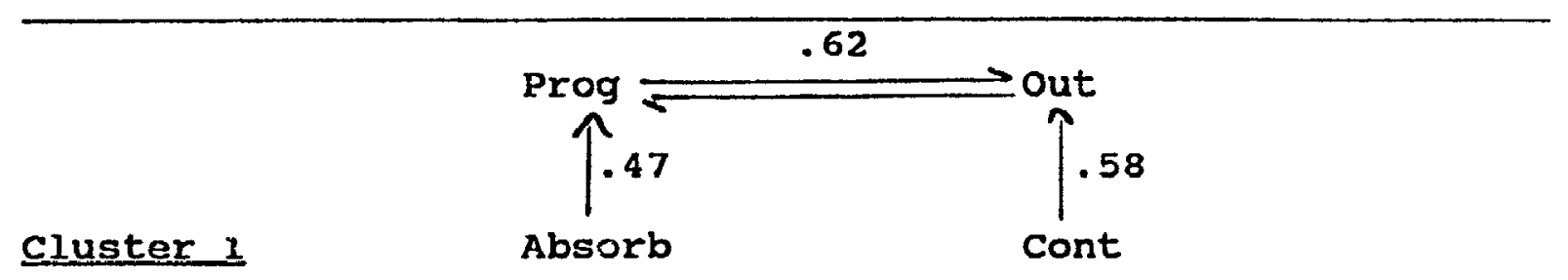

Cluster 2

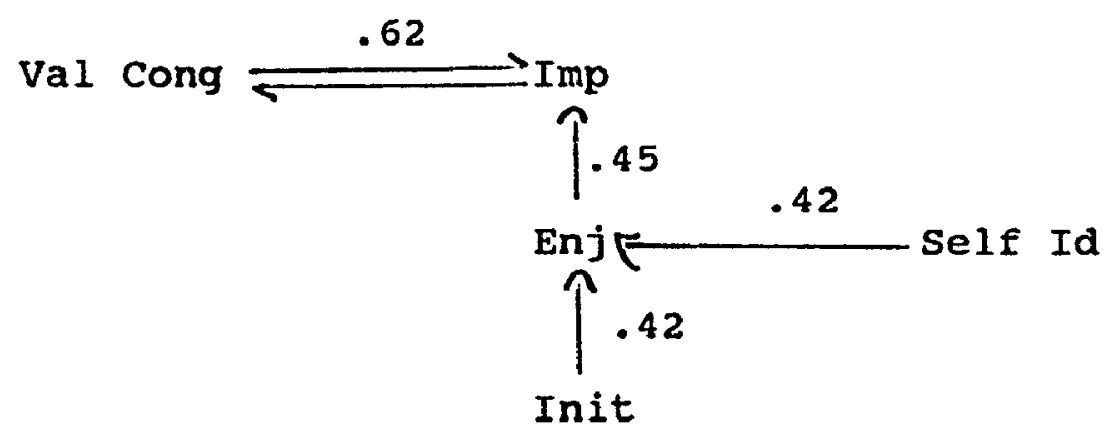

Cluster 3

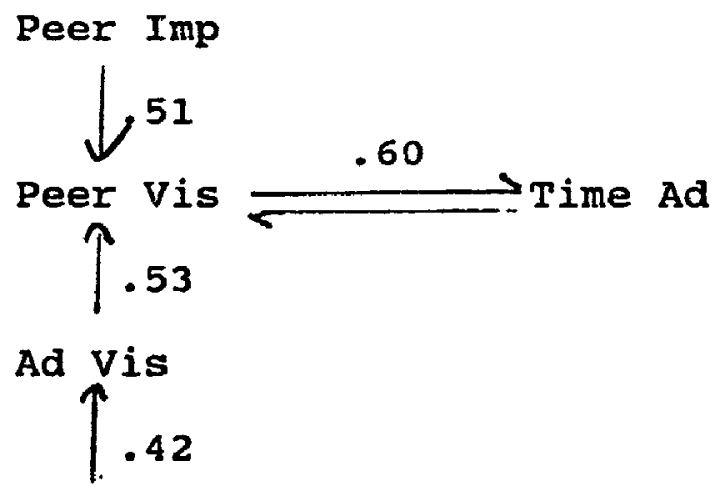

cluster 4

Ad Imp

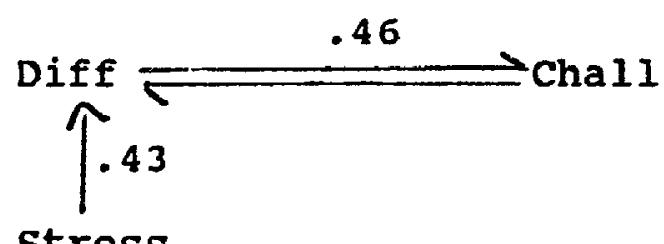

Note. $N=91$

- Refer to rable 8 for explanation of Project Dimension names. 


\section{Appendix P}

Project-System and Category Dimension Rating Intercorrelations 
Table Appendix $\mathbf{P}-1$

Combined Male and Female Project-system Dimension

Intercorrelations ${ }^{\circ}$

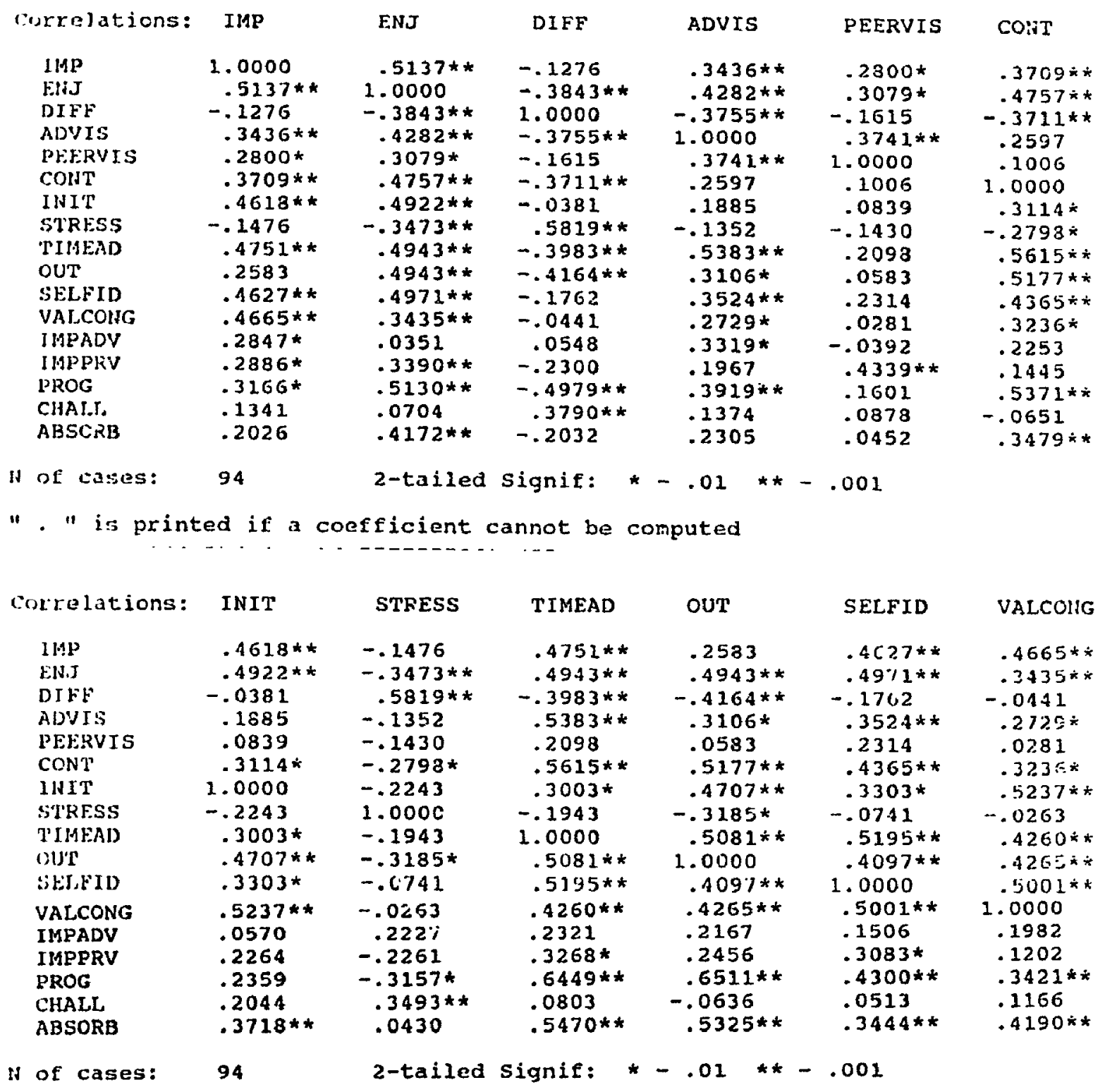

". "is printed if a coefficient cannot be computed 
Table Appendix P-1 Continued

Combined Male and Female Project-system Dimension Intercorrelations $^{a}$

\begin{tabular}{|c|c|c|c|c|c|}
\hline Correlations: & IMPADV & IMPPRV & PROG & CHALI & ABSORB \\
\hline INP & $.2847 \star$ & $.2886 *$ & $.3166 *$ & .1341 & .2026 \\
\hline ENS & .0351 & $.3390 * *$ & $.5130 * \star$ & .0704 &.$+172 * *$ \\
\hline$D I E F$ & .0543 & -.2300 & $-.4979 * k$ & $.3790 \star \star$ & -.2032 \\
\hline ADVIS & $.3319 *$ & .1967 & $.3919 * k$ & .1374 & .2305 \\
\hline PEFRVIS & -.0392 & $.4339 * *$ & .1601 & .0878 & .0452 \\
\hline CONT & .2253 & .1445 & $.5371 * *$ & -.0651 & $.3473 * k$ \\
\hline INIT & .0570 & .2264 & .2359 & .2044 & $.3 / 18 * *$ \\
\hline STRESS & .2227 & -.2261 & $-.3157 *$ & $.3493 * *$ & .0 .430 \\
\hline TIMEAD & .2521 & $.3268 *$ & $.6449 * *$ & .0803 & $.5470 * *$ \\
\hline OUT & .2167 & .2456 & $.6511 * \star$ & -.0636 & $.5325 \star \star$ \\
\hline SEIJFID & .1506 & $.3033 *$ & $.4300 * *$ & .0513 & $.3444 * *$ \\
\hline VAICO:IG & -1982 & .1202 & $.3421 * \star$ & .1166 & $.4190 * \star$ \\
\hline IMPADV & 1.0000 & .1539 & .2493 & .2278 & .1480 \\
\hline IMPIRV & .1589 & 1.0000 & $.2904 *$ & .0385 & .2150 \\
\hline PLOG & .2493 & $.2904 *$ & 1.0000 & -.0067 & $.5760 k *$ \\
\hline CHALL & .2278 & .0385 & -.0067 & 1.0000 & .1290 \\
\hline$A B S C R B$ & .1480 & .2150 & $.5760 * *$ & .1290 & 1.0000 \\
\hline$\|$ of cases: & 94 & 2-tailed & Signif: * & $=-.01 * k-$ & -.001 \\
\hline
\end{tabular}

Note. $\mathrm{N}=94$

a refer to Table 8 for explanation of Dimensions. 
Table Appendix $\mathrm{P}-2$

\section{Male Project-System Dimension Intercorrelations ${ }^{a}$}

\begin{tabular}{|c|c|c|c|c|c|c|}
\hline Corrolations: & I MP & E:HJ & DIFF & ADVIS & PEERVIS & Cont \\
\hline $\begin{array}{l}\text { IMP } \\
\text { FIII }\end{array}$ & $\begin{array}{l}1.0000 \\
.6005 * \star\end{array}$ & $\begin{array}{l}.6005 * k \\
1.0000\end{array}$ & $\begin{array}{l}-.1710 \\
-.3249\end{array}$ & $\begin{array}{l}.2451 \\
.2854\end{array}$ & $\begin{array}{l}.3295 \\
.4739 \star k\end{array}$ & $\begin{array}{l}.3495 \\
.4339 * *\end{array}$ \\
\hline DI IFF & -.1710 & -.3249 & 1.0000 & $-.4615 * k$ & $-.3741 *$ & -.2641 \\
\hline ADVIS & .2451 & .2854 & $-.4615 * *$ & 1.0000 & .3525 & .1255 \\
\hline PEERUIS & .3235 & $.4739 * *$ & $-.3742 *$ & .3525 & 1.0000 & .1355 \\
\hline cols & .3495 & $.4839 * *$ & -.2641 & .1255 & .1355 & 1.0000 \\
\hline $1 \mathrm{NIT}$ & $.4572 *$ & $.4711 * *$ & .0881 & .2072 & .1379 & .3339 \\
\hline STRES' & -.1998 & -.3527 & $.4918 * *$ & -.1864 & -.3290 & -.3220 \\
\hline TIMEAL & $.4098 *$ & $.4677 * *$ & $-.402 .1 *$ & $.4153 *$ & .1781 & $.5333 * *$ \\
\hline ou'r & .3051 & $.3836 *$ & -.312 & .2130 & .0363 & $.4039 x$ \\
\hline \$EI.FID & $.4323^{*}$ & $.4734 * \star$ & -.1214 & .1961 & .2242 & $.4957 * *$ \\
\hline VAICOHG & $.5850 * \star$ & .2363 & -.0266 & .1405 & .0963 & .3203 \\
\hline JMPADY & .2667 & .0202 & .0381 & $.4477 *$ & -.0744 & .0915 \\
\hline JALPKV & .3560 & $.4045 *$ & -.3628 & .2371 & $.5551 * *$ & .1349 \\
\hline Proc & .3608 & $.4534 *$ & $-.4406 *$ & .3297 & .2434 & $.4643 * *$ \\
\hline C:1HA.1 J, & .2042 & .1751 & .3532 & .1338 & .2024 & -.0276 \\
\hline$A B \operatorname{SONB}$ & .1067 & $.3844 *$ & -.2003 & .0322 & .0582 & .3166 \\
\hline "I of cases: & 48 & $2-t a i l e d$ & signif: & -.01 & .001 & \\
\hline
\end{tabular}

". "is printed if a coefficient cannot be computed

\begin{tabular}{|c|c|c|c|c|c|c|}
\hline cisrolations: & INIV & SILESS & TIMEAD & oUT & SEIFID & UALCO::C \\
\hline $\operatorname{IMP}$ & $.4572 *$ & -.1998 & $.4098 *$ & .3051 & $.4328 *$ & $.5350 * *$ \\
\hline$F: 1 . J$ & $.4711 * *$ & -.3527 & $.4677 * \star$ & $.3336 *$ & $.4734 * *$ & .2863 \\
\hline $\mathrm{D} \perp \mathrm{Fr}$ & .0881 & $.4913 * *$ & $-.4024 *$ & -.3127 & -.1214 & -.0206 \\
\hline ABV $1: 3$ & .2072 & -.1864 & $.4153 \dot{x}$ & .2130 & .1961 & .1405 \\
\hline PERRVIS & .1379 & -.3290 & .1781 & .0363 & .2242 & .0963 \\
\hline co:di & .3339 & -.3220 & $.5333 * *$ & $.4039 *$ & $.4957 \hbar \star$ & .3203 \\
\hline IIII'j & 1.0000 & -.1326 & .1749 & $.4192 *$ & $.3915 *$ & $.5262 * *$ \\
\hline STkESS & -.1326 & 1.0000 & -.1946 & -.3024 & -.0360 & -.1132 \\
\hline ('IMFAD & .1749 & -.1946 & 1.0000 & $.4405^{*}$ & $.4997 * \star$ & .1402 \\
\hline OUT & $.4192 *$ & -.3024 & $.4 .405 *$ & 1.0000 & $.4151 *$ & $.3797 *$ \\
\hline :HAHID & $.3915 *$ & -.0360 & $.4997 * *$ & $.4151 *$ & 1.0000 & $.3726 \div$ \\
\hline VALCONG & $.5262 * *$ & -.1132 & .1402 & $.3797 *$ & $.3726 *$ & 1.0000 \\
\hline IMPADV & .0908 & .1842 & .2192 & .2289 & .1871 & .1847 \\
\hline IMPPRV & .1089 & -.2308 & .3918 * & .2095 & $.4207 *$ & .0640 \\
\hline PROG & .0982 & -.3649 & $.6519 * *$ & $.5250 * *$ & .3542 & .1203 \\
\hline CHALL & .3324 & .2669 & .1009 & .0798 & .0917 & .0862 \\
\hline ABSORB & .3457 & -.0024 & $.4226 *$ & $.4662 \star *$ & .3728 t & .1804 \\
\hline$N$ of cases: & 48 & 2 -tailed & signif: & $-.01 * *$ & -.001 & \\
\hline
\end{tabular}

". " is printed if a coefficient cannot be computed

(Table continues) 
Table Appendix P-2 Continued

Male Project-System Dimension Intercorrelations ${ }^{a}$

\begin{tabular}{|c|c|c|c|c|c|c|}
\hline Correlations: & IMPADV & IIHPPRV & PROG & CHALIJ & & ABSORB \\
\hline $\operatorname{lnP}$ & .2667 & .3560 & .3608 & .2042 & & .1067 \\
\hline EIIJ & $.020 ?$ & $.4045 \star$ & $.4534 *$ & .1751 & & $.3844 *$ \\
\hline DIFF & .0381 & -.3628 & $-.4406 *$ & .3532 & & -.2008 \\
\hline ADVIS & $.4477 *$ & .2371 & .3297 & .1388 & & .0322 \\
\hline PEERVIS & -.0744 & $.5551 * *$ & .2434 & .2024 & & .0582 \\
\hline Cont & .0915 & .1349 & $.4643 * *$ & -.0276 & & .3166 \\
\hline INIT & .0908 & .1089 & .0982 & .3324 & & .3457 \\
\hline STRESS & .1842 & -.2308 & -.3649 & .2669 & & -.002. \\
\hline TIMEAD & .2192 & $.3918 *$ & $.6519 * *$ & .1009 & &. $.226 k$ \\
\hline OUT & .2289 & .2095 & $.5250 * *$ & .0798 & & $.4662 \star \star$ \\
\hline SEIFID & .1871 & $.4207 *$ & .3542 & $.091^{7}$ & & $.3728 *$ \\
\hline VALCO::G & .1847 & .0640 & .1203 & .0862 & & .1804 \\
\hline IMPADV & 1.0000 & .1658 & .2507 & .2128 & & $\rightarrow .0068$ \\
\hline IMPPEV & .1653 & 1.0000 & .3638 & .1555 & & .187 .3 \\
\hline PIROG & .2507 & .3638 & 1.0000 & .1529 & & $.4762 k k$ \\
\hline CHAII & .2123 & .1555 & .1529 & 1.0000 & & .1279 \\
\hline$A B S O R B$ & -.0068 & .1873 & $.4762 * \hbar$ & .1279 & & 1.0000 \\
\hline :f of cases: & 48 & 2-tailed & signif: & $\star-.01$ & $* *-$ & .001 \\
\hline
\end{tabular}

Note. $N=48$

a refer to Table 8 for explanation of Dimensions. 
Table Appendix $\mathrm{P}-3$

Female Project-system Dimension Intercorrelations ${ }^{a}$

\begin{tabular}{|c|c|c|c|c|c|c|}
\hline Correlations: & $I: 42$ & E!S.T & DIFF & ADVIS & PEERVIS & CONT \\
\hline$I M P$ & 1.0000 & $.4521 *$ & -.1009 & $.4360 *$ & .2327 & $.4059 *$ \\
\hline$F: 11 \mathrm{~J}$ & $.4521 \star$ & 1.0000 & $-.4280 *$ & $.5737 * \pi$ & .1621 & $.4545 *$ \\
\hline$D I F F$ & -.1009 & $-.4280 *$ & 1.0000 & -.3076 & .0050 & $-.4543 *$ \\
\hline ADVIS & $.4360 *$ & $.5737 * \star$ & -.3076 & 1.0000 & $.4005 *$ & $.3976 *$ \\
\hline PEFRVI:3 & .2327 & .1621 & .0050 & . $\operatorname{sinn} 5 *$ & 1.0000 & .0856 \\
\hline cont & $.4059 \star$ & $.4545 k$ & $-.4543 *$ & $.3976 *$ & .0856 & 1.0000 \\
\hline INIT & $.4989 * \star$ & $.5022 * \star$ & -.1331 & .1687 & .0502 & .2580 \\
\hline STRESS & -.1028 & -.3 .121 & $.6473 * *$ & -.0890 & .0193 & -.2403 \\
\hline TIMEAD & $.5431 *$ * & .5056 ** & $-.3880 *$ & $.6554 * *$ & .2642 & $.5749 * *$ \\
\hline OUT & $.23: 3$ & $.5979 * \star$ & $-.5099 * *$ & $.4259 *$ & .1133 & $.6225 * *$ \\
\hline SFILFID & $.48: 3 \star \star \star$ & $.5348 k *$ & -.2283 & $.5131 * *$ & .2344 & $.3944 *$ \\
\hline VALCONG & $.4064 \star$ & .3747 & -.0400 & $.3818 *$ & -.0048 & .3111 \\
\hline IMPADV & .3053 & .1009 & .0437 & .2154 & -.0325 & .4538 * \\
\hline IMPPRV & .2292 & .2669 & -.1125 & .1517 & .3079 & .1492 \\
\hline PROG & .2914 & $.5606 * *$ & $-.5450 * *$ & $.4591 *$ & .0949 & $.5972 * *$ \\
\hline CHALI, & .0576 & -.0096 & $.4026 *$ & .1430 & -.0638 & -.0711 \\
\hline$A B S$ SORB & .3272 & $.4312 *$ & -.1917 & $.4599 \star$ & .0700 & .3476 \\
\hline :N ot casers: & 46 & $2-t a i l e d$ & Signif: & -.01 & -.001 & \\
\hline
\end{tabular}

" " is printed if a coefficient cannot be computed

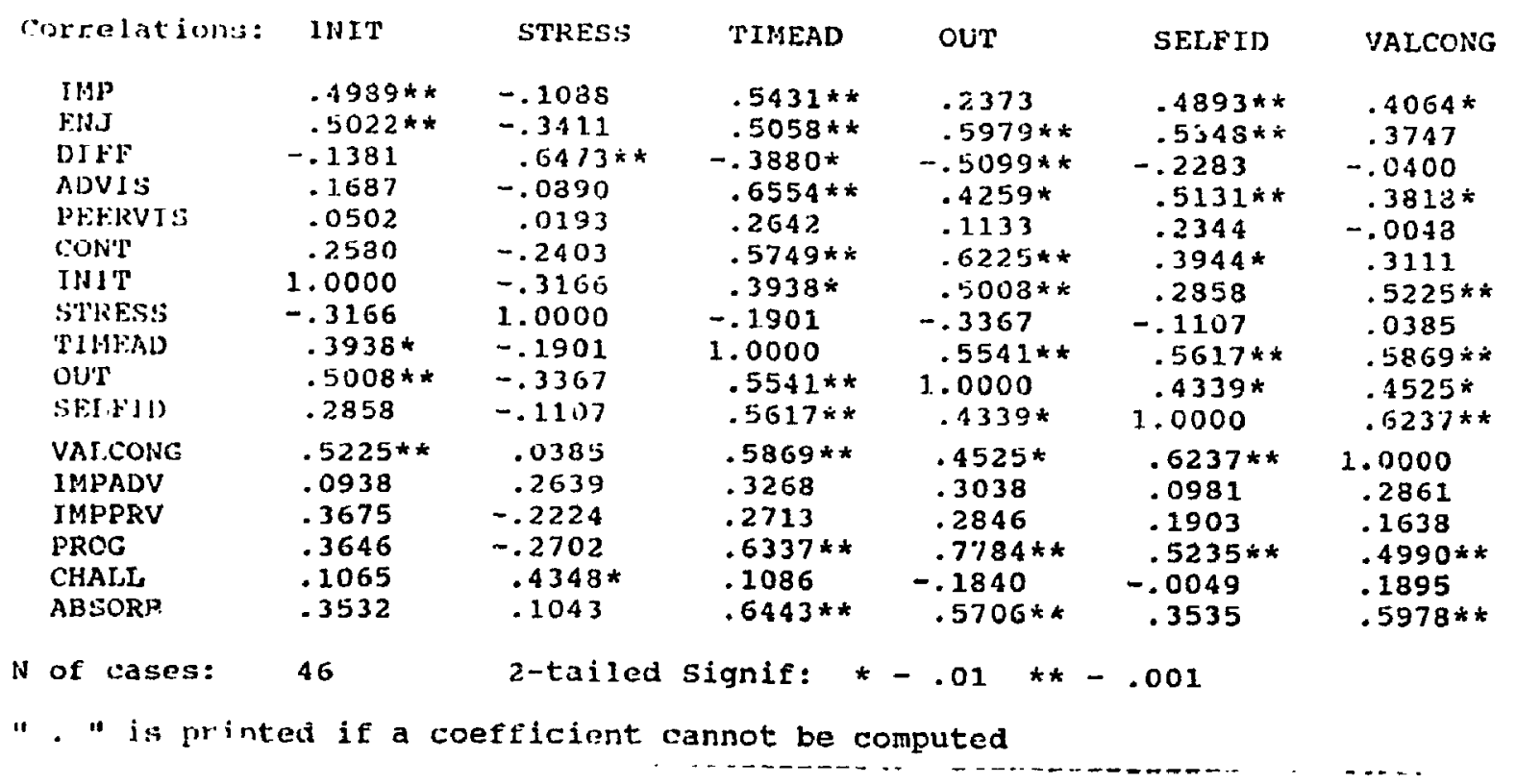

(Table continues) 
Table Appendix P-3 Continued

Female Project-system Dimension Intercorrelations ${ }^{\circ}$

\begin{tabular}{|c|c|c|c|c|c|}
\hline Correlations: & IMPADV & IMPPRV & PROG & CHALL & ABSOKB \\
\hline INP & .3058 & .2292 & .2914 & .0576 & .3272 \\
\hline ENJ & .1009 & .2669 & $.5606 * k$ & -.0096 & $.4312 *$ \\
\hline DIFE & .0487 & -.1125 & $-.5450 * \star$ & $.4026 *$ & -.1911 \\
\hline ADVIS & .2154 & .1517 & $.4591 *$ & .1430 & $.4599 *$ \\
\hline PEERVIS & -.0325 & .3079 & .0949 & -.0638 & .0700 \\
\hline Cort & $.4538 *$ & .1492 & $.5972 * *$ & -.0711 & $.34 / 6$ \\
\hline INIT & .0938 & .3675 & .3646 & .1065 & .3532 \\
\hline STRESS & .2639 & -.2224 & -.2702 & $.4348 *$ & .1043 \\
\hline TIMFAD & .3268 & .2713 & $.6337 * *$ & .1035 & $.0443 * *$ \\
\hline OUT & .3038 & .2846 & $.7784 * *$ & -.1840 & $.5706 * *$ \\
\hline SELFID & .0981 & .1903 & $.5235 * *$ & -.0049 & .3535 \\
\hline VALCONG & .2361 & .1638 & $.4990 * *$ & .1895 & $.5978 * *$ \\
\hline IMPADV & 1.0000 & .1733 & .3186 & .1944 & $.4738 * *$ \\
\hline IYPPRV & .1733 & 1.0000 & .2059 & -.0925 & .2 .142 \\
\hline PRCG & .3286 & .2059 & 1.0000 & -.1505 & $.6705 * *$ \\
\hline CHALL & .194. & -.0925 & -.1505 & 1.0000 & .2181 \\
\hline ABSORB & $.4738 * *$ & .2442 & $.6705 *$ * & .2181 & 1.0000 \\
\hline : of cases: & 46 & 2-tailed & Signif: & -.01 & -.001 \\
\hline
\end{tabular}

Note. $N=46$

a refer to Table 8 for explanation of Dimensions. 
Table Appendix $\mathrm{P}-4$

Combined Male and Female Academic Project Dimension Intercorrelations ${ }^{\circ}$

\begin{tabular}{|c|c|c|c|c|c|c|}
\hline Correlations: & IMP & EIJU & DIFE & ADVIS & PEERVIS & CONT \\
\hline IMP & 1.0000 & $.4095 * *$ & .1333 & .2622 & $.4067 * \star$ & .1237 \\
\hline EllJ & $.4095 * *$ & 1.0000 & $-.3615 \star$ & .1644 & .0437 & .1743 \\
\hline DIFE & .1333 & $-.3615 *$ & 1.0000 & .0608 & .2692 & -.0765 \\
\hline ADVIS & .2622 & .1644 & .0603 & 1.0000 & $.4254 * \dot{x}$ & -.0563 \\
\hline PEERVIS & $.4067 * *$ & .0437 & .2692 & $.4254 * *$ & 1.0000 & -.0715 \\
\hline CONT & .1237 & .1743 & -.0765 & -.0563 & -.0715 & 1.0000 \\
\hline INIT & $.3944 * *$ & $.4763 * *$ & -.0659 & -.0172 & -.0156 & .1084 \\
\hline STRFSS & .2108 & -.1426 & $.5218 k *$ & .0653 & .2150 & -.1235 \\
\hline TIRSFAD & $.5199 * *$ & .2860 & .1382 & $.3117 *$ & $.3521 *$ & -.0023 \\
\hline OUT & .1223 & $.3747 * *$ & -.0936 & .2639 & .0880 & .1351 \\
\hline SELFID & .2573 & $.4511 * *$ & -.1234 & .2745 & .2 .094 & .1777 \\
\hline VALCOLG & $.3014 *$ & $.4750 \star \star$ & -.0495 & .1748 & .0657 & -.0019 \\
\hline IMPADV & $.2987 *$ & .1450 & .2192 & $.3715 * *$ & $.3050 *$ & -.1376 \\
\hline IMPPRV & $.3889 \star *$ & .2405 & .2451 & .1039 & $.3588 *$ & .1392 \\
\hline PROG & $.3451 *$ & $.3396 *$ & -.0076 & $.3026 *$ & $.3043 *$ & $.3359 *$ \\
\hline CIHALL & .2614 & -.1155 & $.3954 * *$ & .1561 & .2435 & -.0321 \\
\hline ABSORB & $.4604 * \star$ & .2590 & .0709 & .1710 & .2040 & .0400 \\
\hline II OE CaES: : & 79 & 2 -tailed & Signif: & -.01 & .001 & \\
\hline
\end{tabular}

" " is printed if a coefficient cannot re conputed

\begin{tabular}{|c|c|c|c|c|c|c|}
\hline Correlaticn:;: & INIT & S'TRESS & TIMEAD & DUT & SELFID & VALCOIAG \\
\hline IMp & $.3944 * \star$ & .2103 & $.5199 * *$ & .1223 & .2573 & $.3014 *$ \\
\hline E:HJ & $.4763 * *$ & $-.142 \sqrt{3}$ & .2360 & $.3747 * *$ & $.4511 * *$ & $.4750 * *$ \\
\hline DIFF & -.0659 & $.5215 * *$ & .1382 & -.0936 & -.1284 & -.0495 \\
\hline AidV $]$; & -.0172 & .0653 & $.3117 *$ & .2639 & .2745 & .1743 \\
\hline PEFRVIS & -.0156 & .2150 & $.3521 *$ & .0880 & .2094 & .0657 \\
\hline Cont & .1084 & -.1285 & -.0023 & .1351 & .1777 & -.0019 \\
\hline 11112 & 1.0000 & -.0135 & .2525 & $.3526 *$ & .0763 & $.3234 \%$ \\
\hline sllktss & -.1135 & 1.0000 & .2413 & -.1253 & -.0922 & -.0105 \\
\hline TIMFAD & .2625 & .2116 & 1.0000 & .1318 & .2502 & $.3284 *$ \\
\hline olji & $.3526 *$ & -.1263 & .1318 & 1.0000 & $.3502 *$ & $.5092 * *$ \\
\hline SELFLO & .0763 & $\begin{array}{r}-.0922 \\
-.0105\end{array}$ & & $\begin{array}{l}.3502 * \\
.5092 * *\end{array}$ & $\begin{array}{l}3.0000 \\
.6881 * \dot{x}\end{array}$ & $\begin{array}{l}.6831 * * \\
1.0000\end{array}$ \\
\hline VALCONG & & $\begin{array}{r}-.0105 \\
.1280\end{array}$ & $\begin{array}{l}.3284 \div \\
.1273\end{array}$ & $\begin{array}{l}.2490^{n} \\
.1450\end{array}$ & $\begin{array}{l}.6881^{\star \star} \\
.2678\end{array}$ & $\begin{array}{r}1.0000 \\
.1688\end{array}$ \\
\hline $\begin{array}{l}\text { IMPADV } \\
\text { IMPPRV }\end{array}$ & $\begin{array}{r}-.0939 \\
.2521\end{array}$ & .1200 & $.4242 * *$ & .1632 & .2087 & $\begin{array}{l}.1700 \\
.1756\end{array}$ \\
\hline PROG & $.3138 *$ & -.1109 & $.3875 * *$ & $.4249 * *$ & $.3926 * *$ & $.3630 \%$ \\
\hline CHALL & .0380 & .2458 & .2579 & .0699 & -.0854 & -.0774 \\
\hline ABSORB & .2803 & .0270 & $.5267 * *$ & $.3421 *$ & .2849 & $.4393 * \star$ \\
\hline N of cases: & 79 & 2-tailed & signif: & -.01 & .001 & \\
\hline
\end{tabular}

" "I:s printed if a coefficient cannot be computed 
Table Appendix P-4 Continued

Combined Male and Female Academic Project Dimension

Intercorrelations ${ }^{a}$

\begin{tabular}{|c|c|c|c|c|c|}
\hline Correlations: & IMPADV & IMPPRV & PROG & CHALL & AB:5ORI3 \\
\hline IMP & $.2987 *$ & $.3889 * k$ & $.3451 *$ & .2614 & $.7604 k k$ \\
\hline ENJ & .1450 & .2405 & $.3396 *$ & -.1155 & .2590 \\
\hline DIFF & .2192 & .2481 & -.0076 & $.3964 * *$ & .0709 \\
\hline ADVIS & $.3715 * *$ & .1039 & $.3026 *$ & .1561 & .1146 \\
\hline PEERVIS & $.3050 *$ & $.3588 *$ & $.3048 *$ & .2435 & .2046 \\
\hline CONT & -.1376 & .1392 & $.3359 *$ & -.0821 & .0 .100 \\
\hline INIT & -.0939 & .2521 & $.3138 *$ & .0380 & .2803 \\
\hline $\begin{array}{l}\text { STRESS } \\
\text { TIMEAD }\end{array}$ & $\begin{array}{r}.1280 \\
.1273\end{array}$ & $\begin{array}{l}.2593 \\
.4242 * *\end{array}$ & $\begin{array}{r}-.1109 \\
.3875 * *\end{array}$ & $\begin{array}{l}.2458 \\
.2579\end{array}$ & .0270 \\
\hline OUT & .1450 & .2632 & $.4249 * \star$ & .0699 & $.3421 *$ \\
\hline SEI.EID & .2678 & .2087 & $.3926 * *$ & -.0854 & .28 .99 \\
\hline VALCOI:G & .1688 & .1756 & $.3630 *$ & -.0774 & $\ldots 393 *$ * \\
\hline I:MPAL' & 1.0000 & .2180 & .1234 & .1597 & .2652 \\
\hline I AIPPRV & .2180 & 1.0000 & $.2923 *$ & .1841 & $.3762 * k$ \\
\hline PROG & .1234 & $.2923 *$ & 1.0000 & .1290 & $.3693 * *$ \\
\hline CliALL & .1597 & .1841 & .1290 & 1.0000 & .1243 \\
\hline$A B \leq O R B$ & .2652 & $.3762 * *$ & $.3693 * *$ & .1443 & 1.0000 \\
\hline IJ of cases: & 73 & 2-tailed & signif: & -.01 & .001 \\
\hline
\end{tabular}

Note. $N=79$

a refer to Table 8 for explanation of Dimensions. 
Table Appendix $P-5$

Combined Male and Female Interpersonal Dimension

Intercorrelations ${ }^{a}$

\begin{tabular}{|c|c|c|c|c|c|c|}
\hline Correlations: & I MP & EHS & DIFF & ADVIS & PEERVIS & Cons \\
\hline $111 \mathrm{P}$ & 1.0000 & $.5545 * *$ & .1663 & .1368 & .1853 & $.4235 * *$ \\
\hline מAJ & $.5545 * *$ & 1.0000 & -.1153 & .1119 & $.4329 * *$ & $.5795 * \dot{x}$ \\
\hline DIFF & .2663 & -.1163 & 1.0000 & -.2264 & $-.3649 k$ & -.3065 \\
\hline ADVIS & .2863 & .1119 & -.2264 & 2.0000 & .2502 & .0480 \\
\hline IFEFVIS & .1353 & $.4323 * *$ & $-.3649 *$ & .2502 & 1.0000 & .2759 \\
\hline cols & $.4235 * *$ & $.5795 * *$ & -.3065 & .04 .40 & .2759 & 1.0000 \\
\hline $111 \mathrm{IT}$ & .2522 & .2857 & -.0071 & -.1771 & .1379 & .34238 \\
\hline SIIRE:SS & .0367 & $-.3707 *$ & $.5877 * *$ &. .1194 & $-.3529 *$ & -.2793 \\
\hline WIMtiad & .3232 & .2254 & -.1792 & .3263 & .3094 & $.4056 *$ \\
\hline ots & .2196 & $.3473 *$ & $-.4599 * *$ & .0002 & .1351 & $.5276 \approx *$ \\
\hline SEJ,F:D & .3256 & $.4871 * *$ & -.3276 & .2621 & $.4379 * *$ & $.549 * * *$ \\
\hline VALCOHG & $.5433 * *$ & $.5278 * *$ & .0710 & .2475 & .2435 &. $.1015 *$ \\
\hline IMPADV & .1901 & -.2267 & .1074 & $.4709 * \pi$ & -.1559 & $.0 \in 64$ \\
\hline IMPLRV & .1091 & $.3565 *$ & -.2402 & -.0693 & $.4679 \dot{x}$ & $.374: *$ \\
\hline HROG & .2449 & .2321 & $-.4156 \hbar$ & .2347 & .1756 & $.5600 \times *$ \\
\hline CHAIST & .2223 & -.0329 & $.5740 * *$ & .0719 & .0050 & .0420 \\
\hline AB:SOKB & .2367 & .1590 & -.0105 & .0717 & .0019 & $.27: 0$ \\
\hline :1 of cases: & 58 & 2-tailed & Signif: & -.01 & .001 & \\
\hline
\end{tabular}

" " is printed if a coefficient cannot be computed

\begin{tabular}{|c|c|c|c|c|c|c|}
\hline Corralations: & IHIT & STRESS & TIMEAD & our & SEI_LID & VALCC:B'; \\
\hline $\operatorname{IMP}$ & .2522 & .0367 & .3232 & .2196 & .3156 & $.5483 * \pi$ \\
\hline ENJ & .2857 & $-.3707 *$ & .2254 & $.3473 *$ & $.93 / 1 * *$ & $.5278 \times=$ \\
\hline DIFF & -.0071 & $.5877 * *$ & -.1792 & $-.4599 * t$ & -.3276 & .0110 \\
\hline ADVIS & -.1771 & -.1194 & .3269 & .0002 & .2621 & .2475 \\
\hline PFERVIS & .1979 & $-.3529 *$ & .3094 & .1351 & $.4379 * *$ & .2435 \\
\hline contr & $.3423 *$ & -.2798 & $.4056 *$ & $.6276 * *$ & $.5494 * *$ & $.4015 *$ \\
\hline $111 \mathrm{~T}$ & 1.0000 & -.0459 & .0350 & $.3430 *$ & .0498 & .2436 \\
\hline SIRFSS & -.0459 & 1.0000 & .0299 & -.3142 & -.2752 & .0330 \\
\hline 'INIMEAD & .0350 & .0299 & 1.0000 & .2330 & $.4365 *$ & $.4360 * *$ \\
\hline DUI & $.3430 *$ & -.3142 & .2880 & 1.0000 & $.5270 * *$ & .2239 \\
\hline SELFID & .0498 & -.2752 & $.4385 * *$ & $.5270 * \star$ & 1.0000 & $.5291 * *$ \\
\hline VALCONG & .2486 & .0880 & $.4360 * *$ & .2239 & $.5291 * *$ & 1.0000 \\
\hline IMPADV & -.3241 & .2731 & $.3632 *$ & .1081 & .0382 & .1379 \\
\hline IXPPRV & $.3383 *$ & -.2157 & .2656 & $.4571 * *$ & $.3713 *$ & .1782 \\
\hline PROG & .0044 & -.1621 & $.6688 * *$ & $.6527 * *$ & $.5448 * *$ & .3232 \\
\hline CHAJL & .2565 & $.3583 *$ & .1038 & -.1598 & -.1123 & .1473 \\
\hline ABSORB & .1104 & .1273 & $.3701 *$ & .1947 & .2764 & .1939 \\
\hline N of cases: & 58 & $2-t a i l c d$ & Signif: & 01 & .001 & \\
\hline
\end{tabular}

1. "is printed if a coefficient cannot be conputed 
Table Appendix P-5 Continued

Combined Male and Female Interpersonal Dimension

Intercorrelations $^{a}$

\begin{tabular}{|c|c|c|c|c|c|}
\hline Cortelations: & IMPADV & IUPPRV & PROG & CHALL. & AH:SORH \\
\hline $1: 9 \mathrm{P}$ & .1901 & .1091 & .2449 & .2223 & .2367 \\
\hline E:NJ & -.2267 & $.3565 *$ & .2321 & -.0329 & .1590 \\
\hline DIFF & .1074 & -.2402 & $-.4156 *$ & $.57 .40 * *$ & -.0105 \\
\hline SDVIS & $.4709 * *$ & -.0693 & .2347 & .0719 & $.072 \%$ \\
\hline EEERVIS & -.1558 & $.4679 * *$ & .1756 & .0050 & .0013 \\
\hline cont & .0661 & $.3708 *$ & $.5600 * *$ & .0420 & .2750 \\
\hline I:NIT & -.3241 & $.3383 *$ & .0044 & .2565 & .1104 \\
\hline SLRESS & .2731 & -.2157 & -.1621 & $.3583 *$ & .1213 \\
\hline TISEAD & $.3632 *$ & .2656 & $.0638 * *$ & $.103 a$ & $.3 / 01 *$ \\
\hline OUT & .1081 & $.4571 * *$ & $.6527 * *$ & -.1398 & .1947 \\
\hline SELFID & .0882 & $.3713 *$ & $.5748 * *$ & -.1123 & .276 .1 \\
\hline VALCONG & .1379 & .1732 & .3232 & .1473 & .1932 \\
\hline IMPADV & 1.0000 & -.0844 & $.4100 *$ & .1509 & .1303 \\
\hline IAFKV & -.0844 & 1.0000 & .2333 & -.0170 & .0251 \\
\hline ESCG & .4100 & .2839 & 1.0000 & -.1084 & $.1353 * \pi$ \\
\hline CHSAILL & .1509 & -.0770 & -.1084 & 1.0000 & .1116 \\
\hline A. $3 S O R B$ & .1303 & .0251 & $.4358 * *$ & .1416 & 1.0000 \\
\hline :J of cases: & 58 & 2 -tailed & Signif: * & $-.01 * \star$ & -.001 \\
\hline
\end{tabular}

Note. $N=58$

a refer to Table 8 for explanation of Dimensions. 
Table Appendix P-6

Combined Mals and Female Leisure Dimension

Intercorrelations ${ }^{a}$

\begin{tabular}{|c|c|c|c|c|c|c|}
\hline Gortalations: & IMP & EIIJ & DIFF & ADVIS & PEERVIS & CONT \\
\hline I!qP & 1.0000 & $.4460 k *$ & .0924 & $.3113 *$ & $.4115 \star x$ & $.2985 *$ \\
\hline HIS & $.4460 * \star$ & 1.0000 & -.156. & $.3128 *$ & $.3040 *$ & .2352 \\
\hline D J FF & .0924 & -.1569 & 1.0000 & -.1669 & -.0668 & -.1547 \\
\hline ADVIS & $.3113 *$ & $.31 \% 3 *$ & -.1669 & 1. 0000 & $.5322 * *$ & .0963 \\
\hline PEER'IS & $.4115 * *$ & $.3040 k$ & -.0668 & $.5322 * *$ & 1.0000 & .1953 \\
\hline COHT & $.2385 *$ & .2352 & -.1547 & .0963 & .1953 & 1.0000 \\
\hline IHIT & $.3375 *$ & $.4230 * *$ & -.0699 & .1868 & .2079 & .2207 \\
\hline SI'RES:3 & -.0023 & -.1016 & $.4270 * \star$ & .0624 & -.0317 & -.2035 \\
\hline TIMEAD & $.4650 * *$ & $.4034 * \star$ & -.26 .95 & $.4758 * \star$ & $.5981 \star *$ & $.4010 * *$ \\
\hline oljt & $.3048 *$ & .2569 & $-.3559 * k$ & .1745 & .2573 & $.5837 * \pi$ \\
\hline$S E I F I D$ & $.3584 k *$ & .4191 ** & -.0553 & .2180 & $.3154 *$ & $.4123 * \pi$ \\
\hline VALCOHN & $.6166 * *$ & .2358 & -.0011 & $.3557 * \pi$ & $.2923 *$ & .1453 \\
\hline$I M 1^{2} A D V$ & $.3447 * *$ & .0855 & .2532 & $.4223 * \star$ & .2176 & -.0206 \\
\hline $1 \mathrm{HPR}$ & .2548 & .0592 & .1277 & .2106 & $.5109 * x$ & .0440 \\
\hline PROG & $.3040 *$ & .2397 & $-.4015 * *$ & $.3528 * *$ & $.4130 \div \div$ & $.4293 * *$ \\
\hline CHAJ.I & .1905 & .1015 & $.9644 * *$ & .2196 & .1292 & -.1043 \\
\hline$A B \subseteq O R B$ & .2407 & .2085 & -.1515 & .2662 & .1910 & .1362 \\
\hline ol case:s: & 90 & $2-t a i l e d$ & Signit: & -.01 & .001 & \\
\hline
\end{tabular}

" " i:i printed if a coefficient cannot be computed

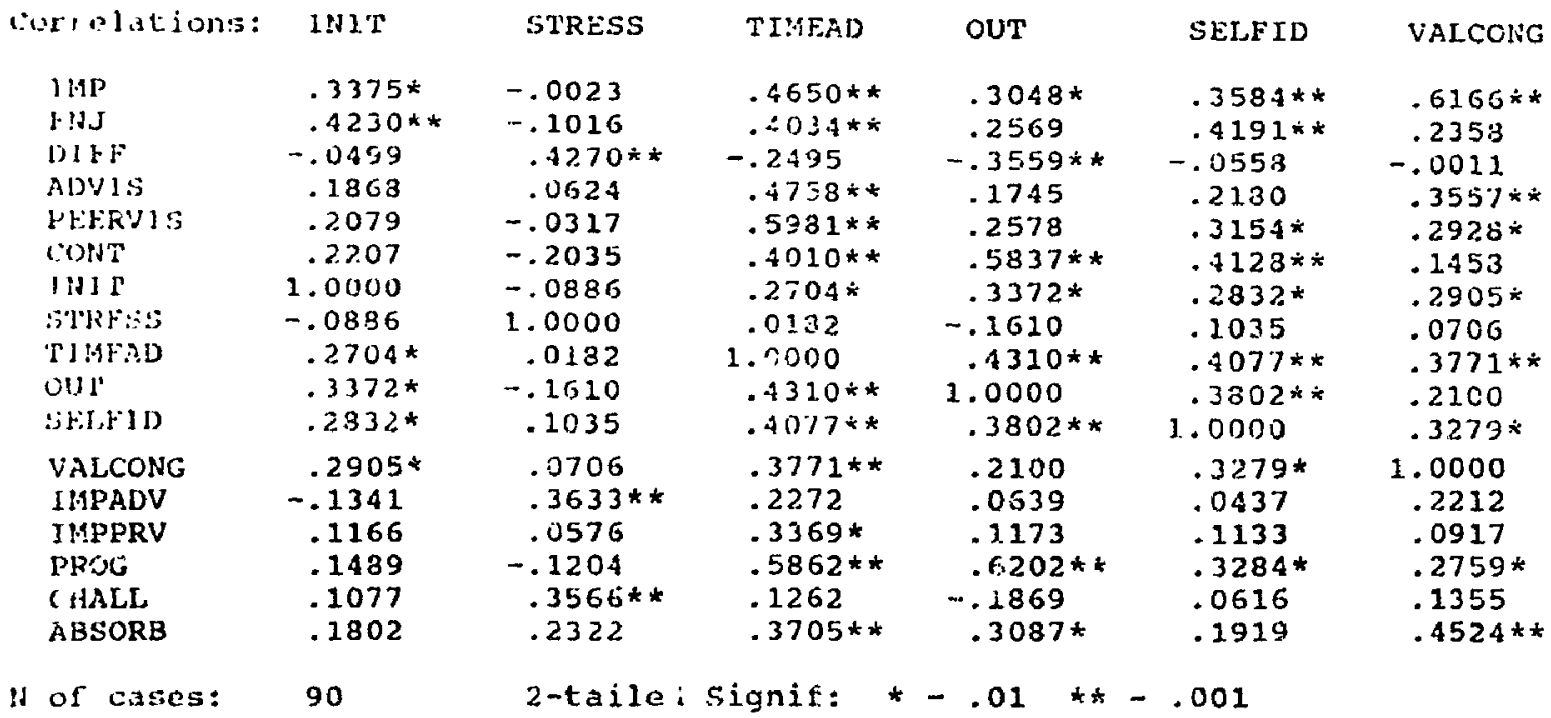

". " i:s printed if a coefficient cannot be conputed 
Table Appendix P-6 Continued

Combined raje and Female Leisure Dimension

Intercorreliations ${ }^{a}$

\begin{tabular}{|c|c|c|c|c|c|}
\hline Correlations: & IMPADV & IMPPKV & PROG & CHALL & ABSOK13 \\
\hline$M P$ & $.3447 * k$ & .2548 & $.3040 *$ & .1905 & .2407 \\
\hline E:SJ & .0855 & .0592 & .2397 & .1015 & .2085 \\
\hline DIFF & .2532 & .1277 & $-.7015 * *$ & $.4644 * *$ & -.1315 \\
\hline ADVIS & $.4223 * *$ & .2106 & $.3528 * \star$ & .2196 & .2662 \\
\hline PEERVIS & .2176 & $.5109 * *$ & $.4130 * *$ & .1292 & .1910 \\
\hline cont & -.0206 & .0440 & $.4293 *$ * & -.1043 & .1362 \\
\hline IIJIT & -.1341 & .1166 & .1489 & .1077 & .1802 \\
\hline STRESS & $.3633 * \star$ & .0576 & -.1204 & $.3566 * *$ & .2322 \\
\hline TI:AEAD & .2272 & $.3369 *$ & $.5862 * \star$ & .1262 & $.3705 * *$ \\
\hline Curi & .0639 & .1173 & $.6202 * *$ & -.1369 & $.3087 \star$ \\
\hline SEI.FID & .0437 & .1133 & $.3284 \star$ & .0616 & .1919 \\
\hline VALCONG & .2212 & .0917 & $.2759 *$ & .1355 & $.452 .4 * *$ \\
\hline IMPADV & 1.0000 & $.3205 *$ & .1393 & $.3967 * \star$ & .1711 \\
\hline I:APPEV & $.3205 \div$ & 1.0000 & $.2757 *$ & .1959 & .0445 \\
\hline FRCG & .1393 & $.2757 *$ & 1.0000 & -.0379 & $.4692 * k$ \\
\hline CHAIL & $.3967 \div \div$ & .1959 & -.0373 & 1.0000 & .1771 \\
\hline ABSORB & .1711 & .0445 & $.4692 * *$ & .1777 & 1.0000 \\
\hline IH of cases: & 90 & 2 -tailed & Siqnit: & -.01 & -.001 \\
\hline
\end{tabular}

Note. $\mathrm{N}=90$

a refer to Table 8 for explanation of Dimensions. 
Appendix $Q$

\section{Regression Analyses}


Table Appendix Q-1

Forward Stepwise Regression Analyses: Life Satisfaction on Male and Female Project-System Dimensions Ratings

Yale Project-8yatem

Einalstatistics

step Dimension Incr.Rsq. Adj.R sq. Beta sig.t

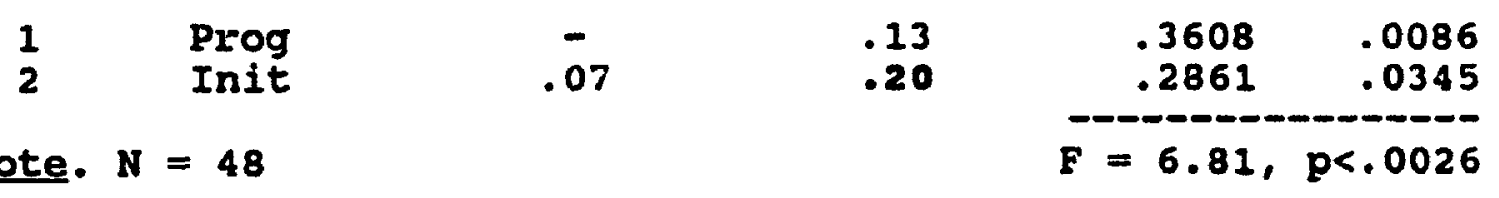

Pemale vroject-oystem

Einalstatistics

Step Dimension" Incr. $R$ sq. Adj. $R$ sq. Beta sig.t

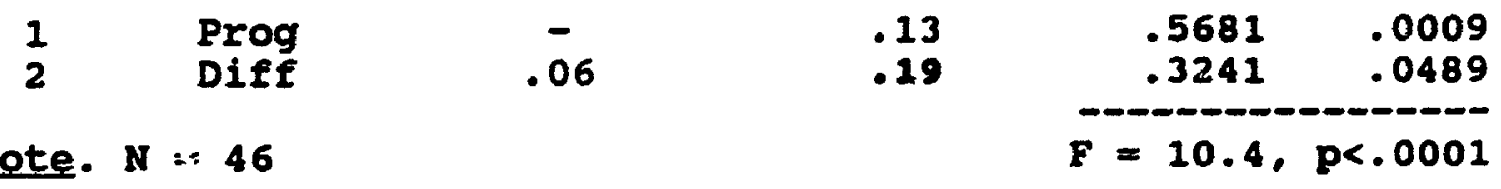

Refer to Table 8 for explanation of Dimensions. 
Table Appendix Q-2

Eorward Stepwise Regression Analysis : Distress on Male and Female Project-system Dimensions Ratings

unle Protect-Bystom

Einalstatistics

Step Dimension Incr. Rsq. Adj. R sq. Beta Siq.t out

.12

$-.3744 \quad .0087$

Note. $N=48$ $F=7.50, p<.0087$

\section{Innde profect-8yeten}

Finalstatistics

Step Dimension Incr. $R$ sq. Adj. $R$ sq. Beta sig.t

Note. $N=46$

\begin{tabular}{rr}
$-.3751, .0102$ \\
\hline$F=7.21, p<.0102$
\end{tabular}

- Refer to Table 8 for explanation of dimensions. 
Table Appendix $0-3$

Forward Stepwise Regression Analyses: Life Satisfaction on project Dimension Ratings by Category

\section{Acadomic category}

Einalstatistics

Step Dimension Incr. $R$ sq. Adi, $R$ sq. Beta sig.t Kale

1

2

Init

Absorb

.$\overline{07}$

Note. $N=41$

p<.0011

Pomale

1

2

Val cong
Prog

.07

Note. $N=38$
.19

$$
.4096 \quad .0050
$$$$
.3042 \quad .0330
$$$$
F=8.13 \text {, }
$$

\section{Intorpereonal category}

HeIe

1

Notes. $N=28$

Fome1e
Adult Imp

Note. $N=30$

1

Active

\section{.13}

.31
.38

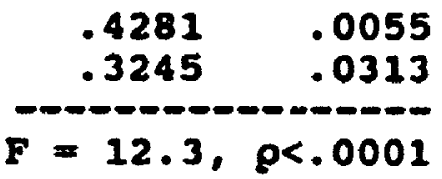

0055 0313

$-$

.13

\begin{tabular}{rr}
$.4042, .0268$ \\
\hline$=13.2, p<.0000$
\end{tabular}

\section{Ininure entegory}

y.10
1
Adult Imp
.12
.21
.33
Note. N $=48$

Fonale

Pin $=.050$, Limits reached: No variables entered. 
Table Appendix Q-4

Forward Stepwige Regression Analyses: Distress on Project Dimension Ratings by Category

Aonentio category

Einalstatistics

Step Dimension" Iner. $R$ sq. Adj, $R$ sq. Beta Sig.t

1210

1 Prog $\quad .09$

$$
F=5.05, p<.0304
$$

Note. $N=41$

ranale

$\begin{array}{llllrr}1 & \text { Absorb } & - & .24 & -.7517 & .0000 \\ 2 & \text { Self Id } & .09 & .33 & -.3379 & .0094 \\ 3 & \text { Out } & .13 & .46 & -.5232 & .0001 \\ 4 & \text { Enj } & .08 & .54 & -.4596 & .0022 \\ 5 & \text { Cont } & .09 & .63 & -.3068 & .0053 \\ & & & & F=13.3, \text { p<.0000 }\end{array}$

Interperenel category

Male

$\begin{array}{llll}1 & \text { Adult Vis } & - & .18 \\ 2 & \text { Out } & .15 & .33 \\ 3 & \text { Absorb } & .17 & .50 \\ 4 & \text { Adult Imp } & .08 & .58\end{array}$

Note. $N=28$
.18

50

58

$$
\begin{array}{rr}
.9023 & .0000 \\
-.5768 & .0002 \\
.4142 & .0046 \\
-.4011 & .0262 \\
\hline F=10.4, & p<.0001
\end{array}
$$

Jande

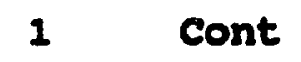

-

.15

$-.4191$

.0212

$F=5.97, p<.0212$

Note. $N=30$

(ce tinued below) 
Table Appendix Q-4 Continued

Forward stepwise Regression Analyses: Distress on Project Dimension Ratings by Category

\section{intrure category}

Einalstatistics

Step Dimension" Incr. $R$ sq. Ad. $R$ sq. Bets sig.t

in10

1

Cont

$-$

.16

$-.4253 \quad .0026$

Note. $N=48$

$F=10.2, p<.0026$

Iome10

1

stress

$-$

.08

\begin{tabular}{rr}
$.3188, .0396$ \\
\hline$=4.53, p<.0396$
\end{tabular}

- Refer to Table 8 for explanation of dimensions. 

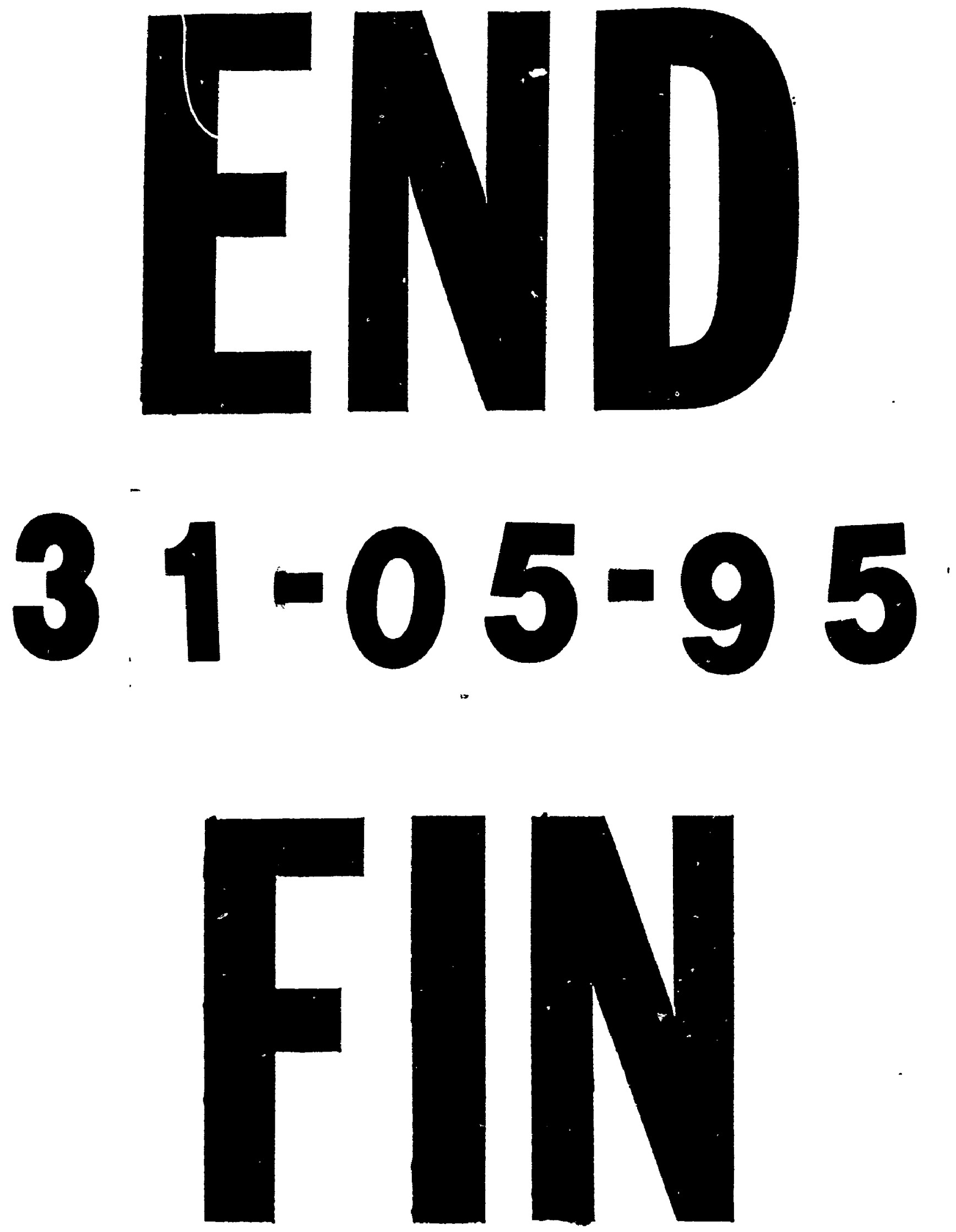